\title{
ANÁLISE EXPERIMENTAL DE BLOCOS SOBRE GRUPOS DE ESTACAS ESCAVADAS DE PEQUENO DIÂMETRO
}

IRAN SOUZA CARVALHO

\begin{abstract}
DISSERTAÇÃO APRESENTADA À ESCOLA DE ENGENHARIA DE SÃO CARLOS, DA UNIVERSIDADE DE SÃO PAULO, COMO PARTE DOS REQUISITOS PARA OBTENÇÃO DO TÍTULO DE MESTRE EM ENGENHARIA DE ESTRUTURAS.
\end{abstract}

ORIENTADOR: Prof. Dr. José Samuel Giongo

SÃO CARLOS - SP

DEZEMBRO - 1994 
" Quero trazer à memória

o que me pode dar esperança.

As misericórdias do Senhor

são a causa de não sermos

consumidos porque as suas

misericórdias não têm fim;

renovam-se cada manhã. Grande

é a tua fidelidade.

A minha porção é o Senhor,

diz a minha alma; portanto

esperarei nele.

Bom é o Senhor para os

que esperam por ele, para a alma que o busca."

Lm. 3: $21-25$ 


\section{AGRADECIMENTOS}

Ao Prof. Dr. José Samuel Giongo pela orientação, valiosos incentivos e cooperação para a elaboração deste trabalho.

À Coordenadoria de Aperfeiçoamento de Pessoal de Nível Superior - CAPES, pela bolsa de estudo concedida.

Ao Banco de Desenvolvimento do Estado do Epírito Santo - BANDES, por conceder financiamento a título de complementação da bolsa.

À Fundação de Amparo à Pesquisa do Estado de São Paulo - FAPESP, pelo apoio financeiro para viabilizar a montagem do Campo Experimental.

Ao Prof. Dr. José Carlos A. Cintra, pela constante colaboração e pela direção da equipe envolvida nesta pesquisa.

Ao Prof. Toshiaki Takeya, do Laboratório de Estruturas do SET, pelo auxílio imprescindível à preparação e execução das provas-de-carga, bem como pela supervisão na aquisição e interpretação dos dados experimentais.

À UNICAMP na pessoa do Prof. Dr. David de Carvalho pela instrumentação das Células de Carga de Concreto.

À colega Maria Elisa e ao colega Ronald Savoi de Senna Júnior, pela troca de informaçoes e pela participação na preparação e realização dos ensaios.

Aos técnicos do SET e do SGS, pela cooperação nos trabalhos de instrumentação e execução dos protótipos, assim como pelo apoio à preparação e realização dos ensaios.

À bibliotecária Maria Nadir e à secretária Rosi, pelas informações para a redação desta dissertação.

A Sílvia, pelo trabalho de desenho das figuras. 


\section{SUMÁRIO}

LISTA DE FIGURAS

LISTA DE TABELAS $\ldots \ldots \ldots \ldots \ldots \ldots \ldots \ldots$ ii

LISTA DE FOTOS ....................... iii

LISTA DE SÍMBOLOS $\ldots \ldots \ldots \ldots \ldots \ldots \ldots$ iv

RESUMO ............................. v

ABSTRACT $\ldots \ldots \ldots \ldots \ldots \ldots \ldots \ldots \ldots \ldots \ldots$ vi

1 - INTRODUÇÃO $\ldots \ldots \ldots \ldots \ldots \ldots \ldots \ldots \ldots$

1.1 - HISTÓRICO . . . . . . . . . . . . . . . . . . 2

1.2 - OBJETIVOS ......................... 2

1.3 - APRESENTAÇÃO $\ldots \ldots \ldots \ldots \ldots \ldots \ldots \ldots \ldots$

2 - ESTUDO TEÓRICO DOS BLOCOS …....... 5

2.1 - MÉTODO DAS BIELAS ................. 5

2.1.1 - PROCESSO SIMPLIFICADO $\ldots \ldots \ldots \ldots \ldots \ldots 7$

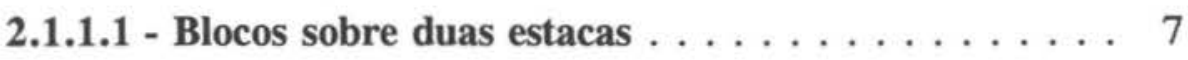

2.1.1.2 - Blocos sobre três estacas . . . . . . . . . 9

2.1.1.3 - Blocos sobre quatro estacas . . . . . . . . 11

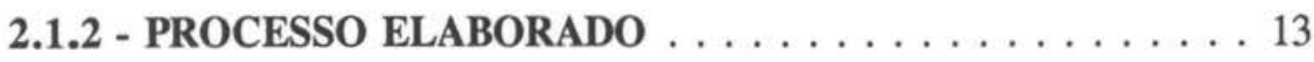

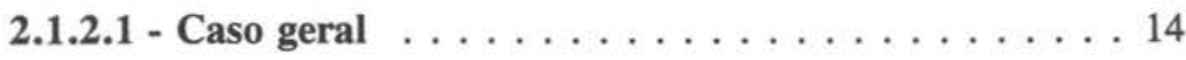

2.1.2.2 - Casos particulares . . . . . . . . . . . 24

2.1.3 - VERIFICAÇÃO DAS TENSÕES NAS BIELAS . . . . . . 27

2.1.4 - BLOCOS SOBRE GRUPAMENTOS DE ESTACAS COM

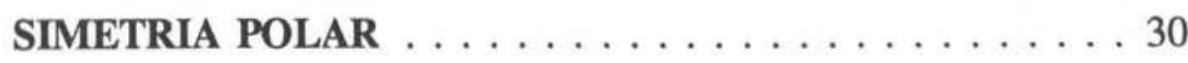


2.2.1 - DETERMINAÇÃO DA ÁREA DE ARMADURA INFERIOR 33 2.2.1.1 - Armaduras adicionais . . . . . . . . . . . 34

2.2.2 - VERIFICAÇÃO QUANTO AO ESFORÇO CORTANTE . . 36

2.2.3 - VERIFICAÇÃO DA ADERÊNCIA NA ARMADURA

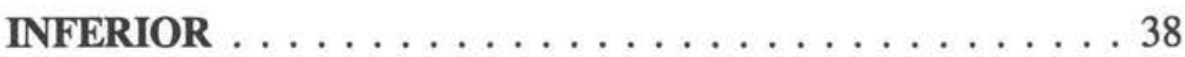

2.2.3.1 - Verificação da ancoragem por aderência na armadura

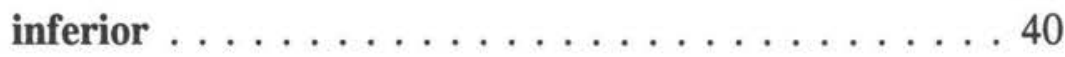

2.3 - BLOCO SOBRE UMA ESTACA $\ldots \ldots \ldots \ldots \ldots \ldots$

\section{3 - DIMENSIONAMENTO DOS PROTÓTIPOS . . . . 47}

3.1 - CONSIDERAÇÕES INICIAIS $\ldots \ldots \ldots \ldots \ldots \ldots 47$

3.2 - BLOCO SOBRE UMA ESTACA $\ldots \ldots \ldots \ldots \ldots \ldots 48$

3.3 - BLOCOS SOBRE GRUPOS DE ESTACAS . . . . . . . 52

3.3.1 - MÉTODO DE DIMENSIONAMENTO À FLEX̃̃o . . . . . 5 52

3.3.1.3 - Bloco sobre três estacas ( disposição triangular ) . . 66

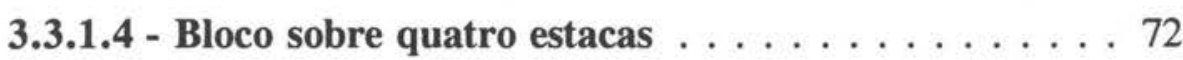

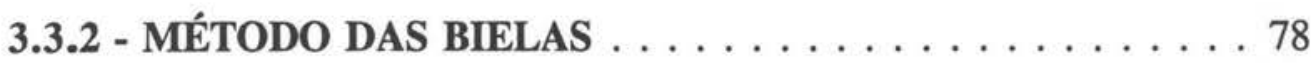

3.3.2.1 - Bloco sobre duas estacas $\ldots \ldots \ldots \ldots \ldots 78$

3.3.2.2 - Bloco sobre três estacas dispostas em linha . . . . 79

3.3.2.3 - Bloco sobre três estacas ( dispostas em triângulo ) . 80

3.4.2.4 - Bloco sobre quatro estacas . . . . . . . . . 82

4- DESCRIÇÃO DO CAMPO EXPERIMENTAL . . . 84

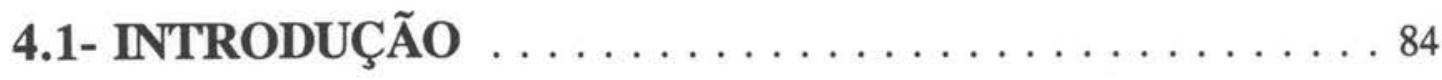

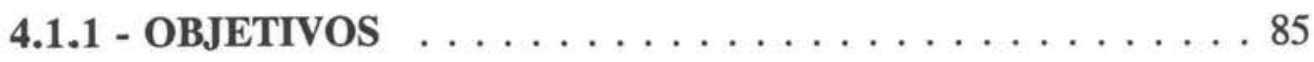

4.2- DESCRIÇÃO DO CAMPO EXPERIMENTAL . . . . . 85

4.2.1 - ESTACAS $\ldots \ldots \ldots \ldots \ldots \ldots \ldots \ldots \ldots \ldots \ldots$

4.2.1.1 - Estacas de reação (STRAUSS) $\ldots \ldots \ldots \ldots 86$

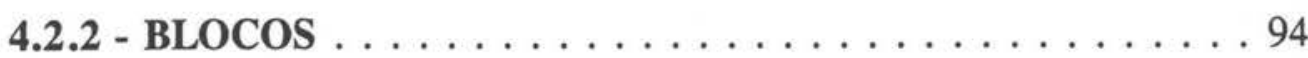


4.2.3 - ESTRUTURA PARA REALIZAÇÃo DAS PROVAS DE

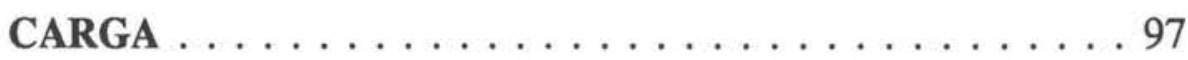

4.3 - MATERIAIS $\ldots \ldots \ldots \ldots \ldots \ldots \ldots \ldots$

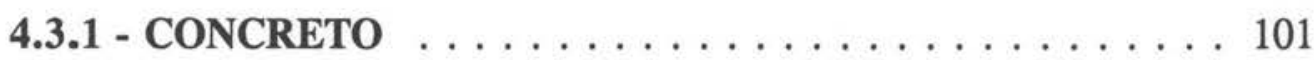

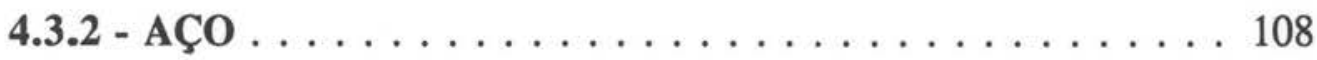

4.4 - INSTRUMENTAÇÃO DOS BLOCOS . . . . . . . . . . 109

4.4.1 - INSTRUMENTAÇÃO DAS ARMADURAS DOS BLOCOS 112

4.4.1.1 - Princípios fundamentais de extensometria . . . . 112

4.4.1.2 - Tipos de extensômetros elétricos de resistência . . 116

4.4.1.3 - Colagem dos extensômetros . . . . . . . . 117

4.4.1.4 - Medidas com extensômetros . . . . . . . . . 127

4.4.2 - CÉlulAS DE CARGA DE CONCRETO . . . . . . . . . 128

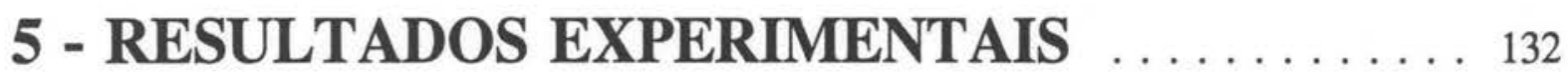

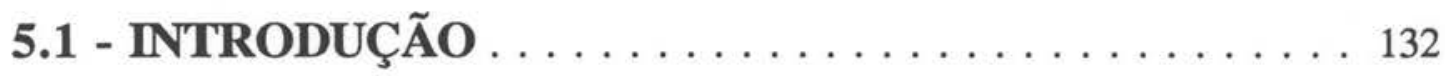

5.2 - RESUltados PARA O BLOCO SOBRE UMA

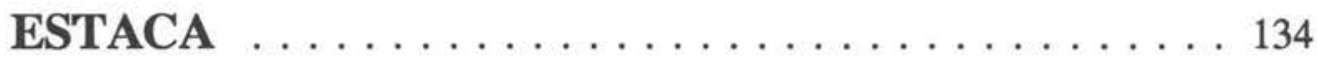

5.3 - RESULTADOS PARA OS BLOCOS SOBRE DUAS

ESTACAS $\ldots \ldots \ldots \ldots \ldots \ldots \ldots \ldots \ldots \ldots$

5.4 - RESULTADOS PARA O BLOCO SOBRE TRÊS ESTACAS

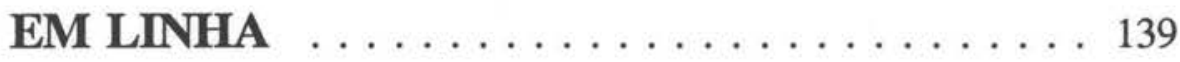

5.5 - RESULTADOS PARA O BLOCO TRIANGULAR . . . . 141

5.6 - RESULTADOS PARA O BLOCO SOBRE QUATRO

ESTACAS $\ldots \ldots \ldots \ldots \ldots \ldots \ldots \ldots \ldots \ldots \ldots$

5.7 - RESULTADOS PARA ESTACAS E SOLO - REAÇÕES 147

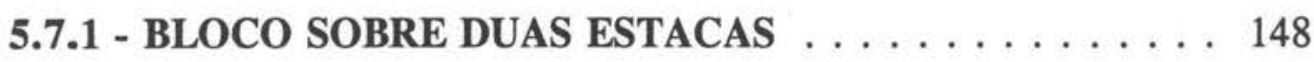

5.7.2 - BLOCO SOBRE TRÊS ESTACAS EM LINHA … . . 151

5.7.3 - BLOCO SOBRE TRÊS ESTACAS -TRIÂNGULO … . 152

5.7.4 - BLOCO SOBRE QUATRO ESTACAS . . . . . . . . 153 


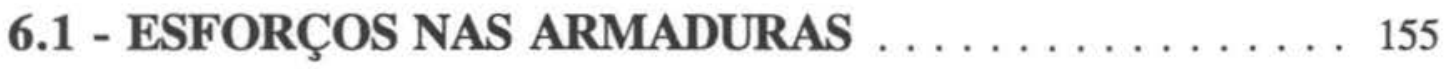

6.2 - CARGA TRANSMITIDA Às ESTACAS . . . . . . 156

6.3 - CONTRIBUIÇÃO DO SOLO . . . . . . . . . . . . . . 157

6.4 - CONTINUIDADE DA PESQUISA $\ldots \ldots \ldots \ldots \ldots 157$

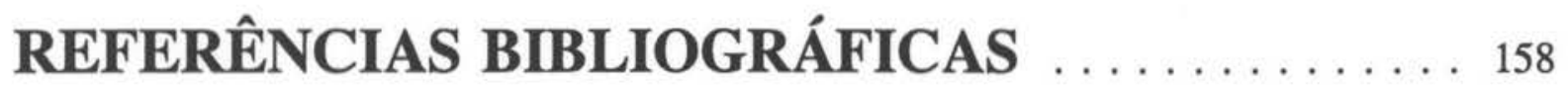

BIBLIOGRAFIA COMPLEMENTAR $\ldots \ldots \ldots \ldots 160$

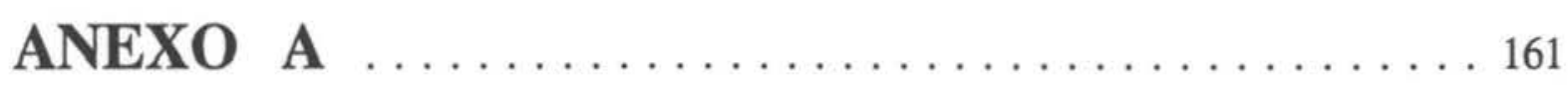

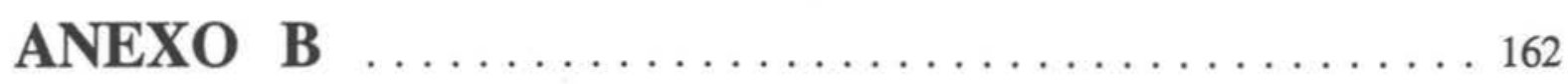

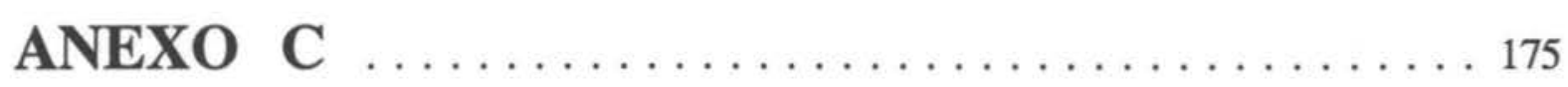

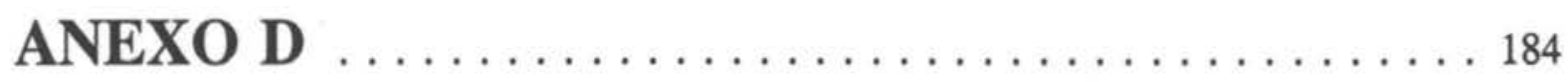




\section{LISTA DE FIGURAS}

Figura 2.1 - Sistema de forças para bloco sobre duas estacas. . . . . . . . 6

Figura 2.2 - Bloco sobre três estacas. . . . . . . . . . . . . . . 10

Figura 2.3 - Bloco sobre quatro estacas. . . . . . . . . . . . . . . 12

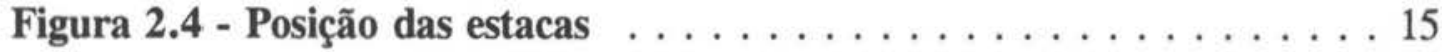

Figura 2.5 - Pilar retangular sob ação distribuída uniforme. . . . . . . . . 18

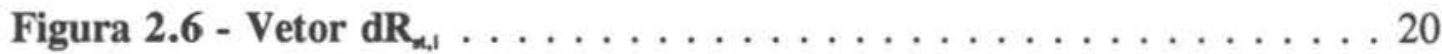

Figura 2.7 - Componentes de tração segundo os lados . . . . . . . . . . 21

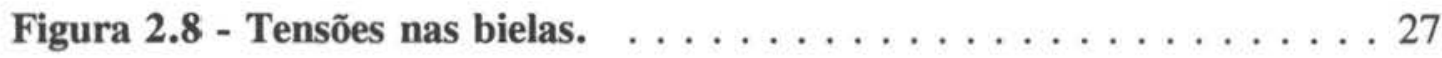

Figura 2.9 - Esforços para blocos com simetria polar . . . . . . . . . . . 30

Figura 2.10 - Seção de referência $S_{1} \ldots \ldots \ldots \ldots \ldots \ldots \ldots \ldots \ldots \ldots \ldots \ldots$

Figura 2.11 - Seção de Referência $S_{2} \ldots \ldots \ldots$. . . . . . . . 37

Figura 2.12 - Aderência da armadura inferior. . . . . . . . . . . 38

Figura 2.13 - Idealização bi-dimensional f . . . . . . . . . . . . 42

Figura 2.14 - Ruptura devido a esforços de tração. . . . . . . . . . . . . . 43

Figura 2.15 - Equilíbrio de um bloco parcialmente carregado. . . . . . . . 45

Figura 3.1 - Geometria do bloco sobre três estacas. . . . . . . . . . . . 61

Figura 3.2 - Bloco sobre três estacas ( triangular ) . . . . . . . . . 67

Figura 4.1 - Estrutura para reação - planta 100

Figura 4.2 - Estrutura para reação - cortes 100

Figura 4.3 - Interpretação geométrica do módulo de deformação. . . . . . 105

Figura 4.4 - Posição das CCC's . . . . . . . . . . . . . . . . . . . . 109

Figura 4.5 - Esquema da montagem das células de carga de concreto. . . 110

Figura 4.6 - Detalhe de um fio condutor . . . . . . . . . . . . . 113

Figura 4.7 - Extensômetro elétrico de resistência . . . . . . . . . . . . 117

Figura 4.8 - Esquema de construção das Células de Carga. . . . . . . . . . 128 


\section{LISTA DE TABELAS}

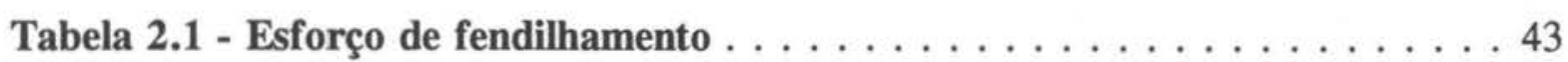

Tabela 4.1 - Resistência à compressão simples do concreto das estacas . . . . . 87

Tabela 4.2 - Resultados dos ensaios do concreto à compressão diametral . . . . . 102

Tabela 4.3 - Resultado dos ensaios do concreto à ompressão axial aos 28 dias . 103

Tabela 4.4 - Resultados de ensaios à compressão simples . . . . . . . . . . 107

Tabela 4.5 - Quantidade de aço empregado nos protótipos . . . . . . . . . 108

Tabela 5.1 - Constante de multiplicação das deformações $\ldots \ldots \ldots 133$

Tabela 5.2 - Bloco 1: Força de fendilhamento; $\mathbf{N}_{\mathrm{e}}=\mathbf{1 1 0 , 1} \mathbf{k N} ; \quad \mathbf{N}_{\mathrm{d}}=226 \mathbf{~ k N} \ldots 135$

Tabela 5.3 - Barra 1 (lateral); $\mathbf{N}_{\mathrm{e}}=\mathbf{3 2 3 , 4} \mathbf{~ k N} ; \mathbf{N}_{\mathrm{d}}=\mathbf{6 3 5} \mathbf{~ k N} \ldots \ldots \ldots 137$

Tabela 5.4 - Barra 2 (central); $\mathbf{N}_{\mathrm{e}}=\mathbf{3 2 3 , 4} \mathbf{~ k N} ; \mathbf{N}_{\mathrm{d}}=635 \mathbf{k N} \ldots \ldots \ldots \ldots 137$

Tabela 5.5 - Barra 3 (lateral); $\mathbf{N}_{\mathrm{e}}=\mathbf{3 2 3 , 4} \mathbf{k N} ; \mathbf{N}_{\mathrm{d}}=635 \mathrm{kN} \ldots \ldots \ldots 137$

Tabela 5.6 - Armaduras secundárias; $\mathbf{N}_{\mathrm{e}}=\mathbf{3 2 3 , 4} \mathbf{k N} ; \mathbf{N}_{\mathrm{d}}=\mathbf{6 3 5} \mathbf{~ k N} \ldots \ldots \ldots 138$

Tabela 5.7 - Bloco 3L: armaduras inferiores; $\mathbf{N}_{\mathrm{e}}=\mathbf{4 7 4 , 0} \mathbf{k N}$; $\mathbf{N}_{\mathrm{d}}=970 \mathrm{kN} \ldots \ldots 139$

Tabela 5.8 - Armaduras adicionais; $\mathbf{N}_{\mathrm{e}}=\mathbf{4 7 4 , 0} \mathbf{k N} ; \mathbf{N}_{\mathrm{d}}=970 \mathbf{k N} \ldots \ldots \ldots \ldots$

Tabela 5.9 - Bloco 3T: Armadura inferior; $N_{\mathrm{e}}=463,0 \mathrm{kN} ; \mathrm{N}_{\mathrm{d}}=1099 \mathrm{kN} \ldots \ldots 14$

Tabela 5.10 - Bloco 3T: Armaduras adicionais; $\mathrm{Ne}=\mathbf{4 6 3 , 0}$ kN; Nd=1099 kN . . 143

Tabela 5.11 - Armadura inferior: Lado oeste; $\mathbf{N}_{\mathrm{d}}=\mathbf{1 4 9 4} \mathbf{~ k N ~ \ldots . ~ . ~ . ~ . ~ . ~ . ~} 144$

Tabela 5.12 - Armadura inferior: Norte, Sul e Leste; $\mathbf{N}_{\mathrm{d}}=\mathbf{1 4 9 4} \mathbf{k N} \ldots \ldots . .145$

Tabela 5.13 - Armaduras adicionais: $\mathbf{N}_{\mathrm{e}}=\mathbf{5 9 2 , 3} \mathbf{~ k N} ; \mathbf{N}_{\mathrm{d}}=\mathbf{1 4 9 4} \mathbf{k N} \ldots \ldots \ldots 146$

Tabela 5.14 - Esforços (Método das Bielas) ․ . . . . . . . . . . . . 147

Tabela 5.15 - Reações no bloco $2 ; \mathbf{N}_{\mathrm{e}}=\mathbf{3 2 3 , 4} \mathbf{k N} \ldots \ldots \ldots \ldots \ldots$

Tabela 5.16 - Área líquida; $\mathbf{A}_{\mathrm{lq}} \ldots \ldots \ldots \ldots \ldots \ldots \ldots \ldots \ldots \ldots$

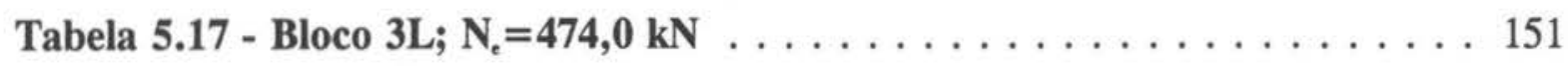

Tabela 5.18 - Bloco $3 \mathrm{~T} ; \mathbf{N e}=\mathbf{4 6 3} \mathbf{~ k N ~ \ldots \ldots \ldots \ldots \ldots \ldots ~ \ldots \ldots ~ \ldots ~} \ldots \ldots 2$

Tabela 5.19 - Bloco $4 ; \mathbf{N}_{\mathrm{e}}=\mathbf{5 9 2 , 3} \mathbf{k N} \ldots \ldots \ldots \ldots \ldots \ldots \ldots$ 


\section{LISTA DE FOTOS}

Foto 4.1 - Tirantes das estacas de reação $\ldots \ldots \ldots \ldots \ldots$

Foto 4.2 - Montagem das armaduras das estacas STRAUSS $\ldots \ldots \ldots 88$

Foto 4.3 - Abertura do furo com auxílio de pilão $\ldots \ldots \ldots$. . . 89

Foto 4.4 - Escavação (retirada do material escavado) . . . . . . . . . . 89

Foto 4.5 - Colocação da armadura $\ldots \ldots \ldots \ldots \ldots \ldots \ldots$

Foto 4.6 - Preparo do concreto das estacas $\ldots \ldots \ldots \ldots \ldots \ldots$

Foto 4.7 - Concretagem da estaca com o tirante já posicionado . . . . . 91

Foto 4.8 - Estaca do tipo BROCA (execução) $\ldots \ldots \ldots \ldots \ldots 2$

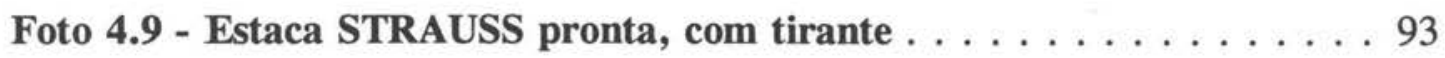

Foto 4.10 - Montagem da armadura de um bloco. . . . . . . . . . 94

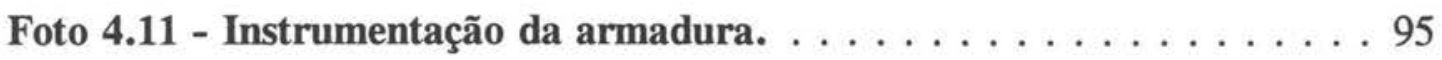

Foto 4.12 - Espaçadores colocados para garantir o cobrimento . . . . . 9 95

Foto 4.13 - Forma do bloco sobre quatro estacas $\ldots \ldots \ldots \ldots \ldots$

Foto 4.14 - Concretagem do bloco $\ldots \ldots \ldots \ldots \ldots \ldots$

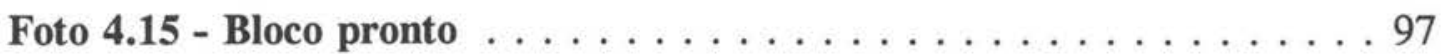

Foto 4.16 - Viga de reação $\ldots \ldots \ldots \ldots \ldots \ldots \ldots \ldots \ldots$

Foto 4.17 - Detalhe de fixação da viga de reação às estacas STRAUSS. . . 99

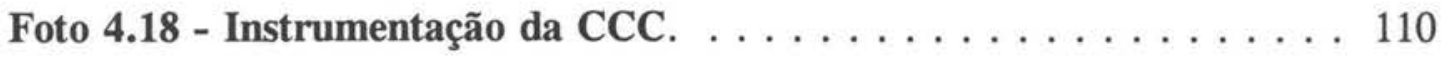

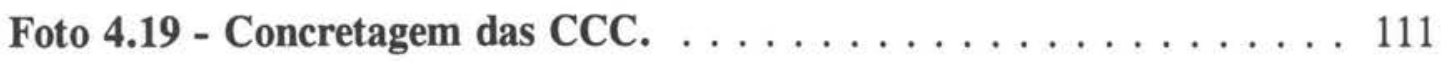

Foto 4.20 - Preparação da superfície $\ldots \ldots \ldots \ldots \ldots \ldots \ldots$

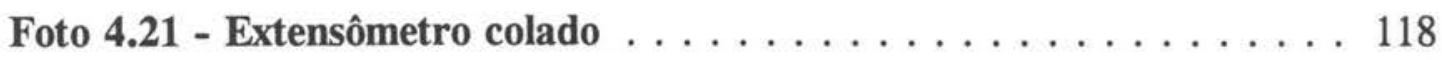

Foto 4.22 - Calibração de uma CCC. . . . . . . . . . . . . . . . 129

Foto 4.23 - Preparação: Transporte da estrutura de reação. . . . . . . . 129

Foto 4.24 - Preparação: Fixação da viga aos tirantes. . . . . . . . . 130

Foto 4.25 - Montagem do sistema de aquisição automática de dados. . . . 130

Foto 4.26 - Sistema de aplicação de carga $\ldots \ldots \ldots \ldots \ldots \ldots \ldots 131$

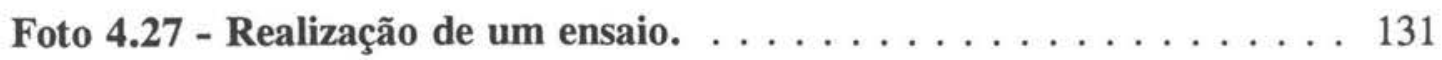




\section{LISTA DE SÍMBOLOS}

$A_{\text {base }} \quad$ Área da base de um bloco

$A_{\text {c }} \quad$ Área da seção transversal geométrica da peça

$A_{0} \quad$ Área da parte carregada de um bloco de apoio

$A_{i} \quad$ Área da seção transversal da estaca $i$

$\boldsymbol{A}_{\text {liq }} \quad$ Área da base do bloco, descontada a área das estacas

$A_{\text {s,ealc }}$ Área de aço calculada

$A_{s, \mathcal{S}}$ Área de aço efetiva

$A_{\star} \quad$ Área de aço dos estribos (malha)

$A_{\text {s,se }} \quad$ Área de aço superior

$A_{s l} \quad$ Área de aço na seção de referência $S_{1}$

a Dimensão da seção transversal do pilar

$a_{1} \quad$ Largura da região de introdução do carregamento

$a_{2} \quad$ Largura da região de apoio ( diâmetro da estaca )

$\boldsymbol{B}$ Menor dimensão da base do bloco

$b_{2} \quad$ Largura do bloco na seção $S_{2}$

C Distância do eixo da estaca até a face do pilar

$C_{a} \quad$ Distância da seção $S_{1}$ até o eixo da estaca mais à direita

CCC Célula de carga de concreto (colocada sobre a cabeça da estaca)

CP Leitura da célula de pressão total (colocada entre o solo e o bloco)

D Diâmetro de corpo-de-prova de concreto

d Altura útil do bloco

$d_{2}$ Altura úutil do bloco na seção $S_{2}$

$d N$ Elemento diferencial da ação aplicada ao bloco pelo pilar

ds largura da biela comprimida de concreto

$\boldsymbol{d} \boldsymbol{R}_{a, i} \quad$ Elemento diferencial do esforço de tração do bloco $i$

$d V_{i} \quad$ Elemento diferencial da reação da estaca $i$

$\boldsymbol{E}_{\text {c }} \quad$ Módulo de elasticidade do concreto 
$\boldsymbol{E}_{\boldsymbol{i}} \quad$ Módulo de elasticidade longitudinal da estaca $\boldsymbol{i}$

$\boldsymbol{E}_{0} \quad$ Módulo de elasticidade do aço

EA Constante de multiplicação para o cálculo do esforço de tração na armadura

$\boldsymbol{e} \quad$ Espaçamento entre as estacas

F Compressão diametral

$F$ esforço de tração medido no ensaio

$F_{i, i+1} \quad$ Esforço que solicita as armaduras periféricas

$F$, Força aplicada em uma barra da armadura

$F_{t} \quad$ Força que provoca o fendilhamento do bloco

$\boldsymbol{F}_{\text {teo }} \quad$ Esforço de tração previsto

$f_{c d}$ Resistência de cálculo do concreto à compressão

$f_{c j} \quad$ Resistência do concreto à compressão com a idade de $j$ dias

$f_{c m} \quad$ Resistência do concreto à compressão aos 28 dias (CEB)

$f_{c k} \quad$ Resistência característica do concreto à compressão

$f_{y k} \quad$ Resistência de início de escoamento do aço

$f_{128} \quad$ Resistência do concreto à tração aos 28 dias

$\boldsymbol{h}$ Altura do bloco

L Maior dimensão da base do bloco

$l_{i} \quad$ Comprimento da estaca $i$

$l_{b} \quad$ Comprimento de ancoragem

$l_{b l} \quad$ Comprimento de ancoragem reta

$l_{b}{ }^{*} \quad$ Comprimento de ancoragem levando em conta $A_{s, e f}$ e $A_{s, \text { calc }}$

M Momento fletor

$M_{d} \quad$ Momento fletor de cálculo

$M$, Momento em torno do eixo $y$

$\boldsymbol{M}_{\boldsymbol{x}} \quad$ Momento em torno do eixo $\boldsymbol{x}$

$N \quad$ Força vertical aplicada pelo pilar no bloco

$\mathrm{Nc} \quad$ Força aplicada no bloco durante o ensaio

$N_{d} \quad$ Ação de cálculo

$N_{u, \text { supo }}$ Capacidade de carga de um grupo de estacas

$N_{u, \text { ind }} \quad$ Capacidade de carga de uma estaca 
$N_{u, \text { ind }} \quad$ Capacidade de carga de uma estaca

$\boldsymbol{n} \quad$ número de estacas do grupo

$\boldsymbol{R} \quad$ Resistência elétrica

$\boldsymbol{R}_{\text {solomed }}$ Reação medida do solo no bloco

$\boldsymbol{R}_{\text {solo,sp }}$ Reação esperada do solo no bloco

$\boldsymbol{R}_{\star} \quad$ Esforço de tração na armadura

$\boldsymbol{R}_{\text {sd }} \quad$ Esforço de tração de cálculo

$\boldsymbol{R}_{\text {sd, lat }}$ Esforço de tração de cálculo para armaduras dispostas segundo os lados do bloco

$\boldsymbol{R}_{\text {sdl }} \quad$ Esforço de tração de cálculo resistido por uma única barra

$\boldsymbol{R}_{\text {mi }} \quad$ Esforço de tração nas armaduras do bloco $i$

$r \quad$ Raio do círculo que circunscreve o polígono determinado pelas posições das estacas

$S_{1} \quad$ Seção de referência onde é avaliado o momento fletor

$S_{2} \quad$ Seção onde é verificado o esforço cortante

$t \quad$ Espaçamento das barras da malha lateral

$\boldsymbol{u} \quad$ Área da superfíe de um cilindro

$V \quad$ Esforço cortante

$V_{d} \quad$ Esforço cortante de cálculo

$V_{u} \quad$ Esforço cortante último

$V_{l u} \quad$ Esforço cortante último devido às tensões de aderência $\left(\tau_{b u}\right)$

$V_{l d}$ Esforço cortante de cálculo devido às tensões de aderência

$V_{i} \quad$ Reação vertical da estaca $i$

$\boldsymbol{x}_{\boldsymbol{i}} ; \boldsymbol{y}_{\boldsymbol{i}}$ Coordenadas da estaca $\boldsymbol{i}$

$\alpha_{i} \quad$ Ângulo entre o vetor posição da estaca $i$ e o eixo $x$

$\alpha_{c} \quad$ Constante (CEB)

$\beta \quad$ Ângulo que a biela forma com a ação vertical $V_{i}$

$\gamma$. Coeficiente de minoração da resistência do concreto

$\Delta L \quad$ Variação do comprimento $L$ do fio condutor

$\Delta l_{b} \quad$ Redução no comprimento de ancoragem

$\Delta M$ Variação do momento fletor 
$\Delta \boldsymbol{R}$ Variação da resistência $\boldsymbol{R}$ do fio condutor

$\Delta \boldsymbol{R}_{\star} \quad$ Variação do esforço de tração $\boldsymbol{R}_{\star}$

$\delta_{i} \quad$ Encurtamento da estaca $i$

$\varepsilon_{i} \quad$ Deformação específica da estaca $i$

$\varepsilon$. Deformação específica do concreto

$\varepsilon$ s Deformação específica do aço

$\theta \quad$ Ângulo entre os esforços de tração $R_{s}$ e $R_{s, \text { lat }}$

$\kappa \quad$ Fator do extensômetro

$v \quad$ Coeficiente de Poisson

$\rho$ Resistividade do material do fio condutor

$\sigma_{i} \quad$ Tensão normal na seção transversal da estaca $i$

$\sigma_{o} \quad$ Ordenada do diagrama de distribuição de tensões de bloco parcialmente carregado

$\sigma_{c}$. Tensão normal no concreto

$\sigma_{s}$ Tensão normal em seção da armadura

$\sigma_{v}$ Tensão devida à ação $N$, na seção tranversal do pilar

$\sigma_{s 1}$ Tensão normal em uma única barra da armadura

$\tau_{b u} \quad$ Tensão de aderência limite

$\varphi \quad$ Ângulo que a biela forma com plano contém as cabeças das estacas 


\section{RESUMO}

Estacas de pequeno diâmetro são bastante empregadas nas pequenas e médias construções no interior do Estado de São Paulo. Neste trabalho são apresentados os métodos comumente utilizados no projeto dos blocos de coroamento de grupos de estacas.

Através de provas-de-carga em protótipos, em condições similares àquelas encontradas nas obras, constatou-se a validade de algumas prescrições daqueles métodos, como a consideração de que a carga que o pilar transmite às fundações se distribui igualmente entre as estacas. Verificou-se também, ser possível desconsiderar a reação do solo sobre o bloco.

As armaduras dos protótipos foram instrumentadas com extensômetros elétricos de resistência, visando comparar os esforços solicitantes surgidos nos ensaios com os previstos no dimensionamento. 


\section{ABSTRACT}

No deep piles with small diameter are largely applied in foundations of small and midle constructions at the State of São Paulo. This dissertation makes a presentation of the most used pile caps design methods.

Through tests with prototypes in the same conditions found at works, can be realized the validity of some prescriptions from those methods, like the consideration that the columns' load are equally distributed betwen piles. Also, is possible neglect the ground's reaction on the pile cap.

Strain gauges were bonded on some positions of the reinforcement's rods to allow comparison betwen tests and theoretical : efforts. 


\section{1 - INTRODUÇÃO}

Grupos de estacas são largamente empregados como fundações. Entretanto, os métodos correntes de projeto de fundações por estacas referem-se a estacas isoladas e, por isso, o comportamento do grupo é previsto a partir do comportamento da estaca isolada.

No que se refere ao dimensionamento dos blocos de coroamento para grupos de estacas, deve-se observar que os mesmos possuem características geométricas bastante distintas de outros elementos estruturais como lajes, vigas ou pilares. Considerados como peças curtas, onde todas as dimensões envolvidas têm a mesma ordem de grandeza, dificilmente pode-se empregar os critérios da Resistência dos Materiais em seu estudo, em virtude da existência de zonas de perturbação envolvendo praticamente todo o elemento.

Também a Teoria da Elasticidade tem o seu emprego restringido devido à possibilidade de ocorrer fissuração, bem como, devido à heterogeneidade do material concreto armado. 
$\mathrm{O}$ reduzido conhecimento experimental conduz a regras de projeto conservativas em demasia. Assim, para o projeto dos blocos, torna-se desejável a obtenção de prescrições fundamentadas em observações e resultados de ensaios.

\section{1 - HISTÓRICO}

Em se tratando de análise experimental pode-se citar, no Brasil, o trabalho de MAUTONI (1972) ${ }^{[01]}$, desenvolvido na Escola Politécnica da Universidade de São Paulo - EPUSP, que consistiu na realização de cinco séries de ensaios em laboratório com blocos sobre dois apoios. .

No exterior, são raras as experimentações com este tipo de elemento estrutural além daquelas executadas por BLEVOT (1967) ${ }^{1021}$, em duas séries de blocos sobre dois, três e quatro apoios. Também estes ensaios foram realizados com modelos em escala reduzida, em laboratório.

\section{2 - OBJETIVOS}

A possibilidade de desenvolvimento deste trabalho, deveu-se ao interesse do Departamento de Geotecnia da Escola de Engenharia de São Carlos Universidade de São Paulo, em realizar pesquisa sobre o comportamento de grupos de estacas escavadas de pequeno diâmetro. Tal trabalho, realizado por equipe chefiada pelo Prof. Dr. José Carlos Ângelo Cintra, requeria a execução de blocos de coroamento para viabilizar a aplicação de carga às estacas. Fizeram parte desta equipe os engenheiros David de Carvalho, Ronald Savoi de Senna Júnior e Maria Elisa Borges Rezende. Este projeto foi financiado pela Fundação de Amparo à 
Pesquisa do Estado de São Paulo, tendo sido apresentada como uma de suas justificativas o largo emprego deste tipo de fundação em obras de pequeno porte no interior deste Estado.

A tendência atual em dimensionar-se as estruturas de concreto armado no estado limite último, torna desejável a fundamentação dos métodos de cálculo em critérios experimentais. Desta maneira, esta pesquisa consiste na realização de provas-de-carga sobre grupos de estacas (duas, três em linha, três em triângulo e quatro), nas condições comumente encontradas nas obras, ou seja, com os protótipos em escala natural. São definidos então, como objetivos:

- Estudar o comportamento dos blocos visando a verificação dos modelos teóricos empregados usualmente no seu projeto;

- Observar a distribuição de carga entre as estacas do grupo em função da posição de cada estaca no mesmo;

- Quantificar a parcela da carga aplicada pelo bloco que é diretamente transmitida ao solo;

- Acompanhar durante os ensaios, os deslocamentos e a fissuração que os blocos sofrem.

$\mathrm{O}$ alcance destes objetivos torna-se relevante à medida em que existem poucos estudos experimentais para blocos de coroamento de estacas, se comparados com a quantidade existente para outros elementos de concreto armado.

\section{3 - APRESENTAÇÃO}

No segundo capítulo desta dissertação, pretende-se apresentar de forma não muito extensa, o Método das Bielas como foi proposto por BLEVOT $(1967)^{\text {[22] }}$ e o Método da Flexão, como é apresentado em boletim do COMITE EUROPÉEN DU BETON - CEB (1970) $)^{[031}$. 
No terceiro capítulo, é feito o dimensionamento dos protótipos submetidos às provas-de-carga, utilizando-se para tanto os métodos expostos no capítulo dois. Assim, os blocos podem ser dimensionados como elementos submetidos à flexão, ou entendido como uma estrutura espacial formada por barras horizontais tracionadas e barras inclinadas comprimidas, estas últimas, comumente chamadas bielas de compressão.

O Campo de provas, bem como os detalhes da sua preparação, são descritos no quarto capítulo, onde também é apresentada a instrumentação utilizada no registro das provas-de-carga.

No capítulo cinco, são apresentados os resultados obtidos dos ensaios. Trata-se estes dados visando a verificação ou não dos modelos teóricos estudados no segundo capítulo.

As conclusões possíveis são mostradas no sexto capítulo, sendo feita ainda uma proposta da maneira pela qual este trabalho pode ser aproveitado como subsídio para novas investigações.

As referências bibliográficas são listadas no capítulo sete, assim como a bibliografia apenas consultada para a elaboração desta dissertação. 


\section{2 - ESTUDO TEÓRICO DOS BLOCOS}

Neste capítulo, são estudados diferentes métodos de cálculo dos blocos de coroamento de estacas, a saber, o Método das bielas e as recomendações do CEB. São mostradas algumas deduções das expressões empregadas no dimensionamento destes elementos estruturais.

\section{1 - MÉTODO DAS BIELAS}

Trata-se de um método apresentado por LEBELLE apud BLEVOT $^{\text {(02) }}$, em 1936, para o dimensionamento de sapatas apoiadas sobre o solo. Estendido aos blocos sobre estacas, este método considera a existência de bielas no 
interior do bloco, partindo da base do pilar em direção à cabeça das estacas. Conforme mostra a figura 2.1, as bielas transmitem às estacas, a ação aplicada no bloco pelo pilar.

Para equilibrar o sistema formado pelo esforço axial de compressão nas bielas e as reações das estacas, é necessária uma força horizontal de tração atuando na base do bloco, a ser resistida por meio de armadura, visto que é quase nula a resistência do concreto a este tipo de esforço.

Um processo simplificado baseado neste método, foi desenvolvido por BLEVOT ${ }^{1021}$, verificando-o através de ensaios sobre modelos reduzidos e em escala natural. Segundo este autor, seu uso deve ser restringido quando tratar-se de blocos sob pilares de seção alongada ou sob pontos de apoio solicitados à flexão.

Para a abordagem de tais casos, pode ser empregado o Processo Elaborado, desenvolvido por FRÉMY ${ }^{[02]}$, também baseado no Método das Bielas.

Neste capítulo, apresenta-se as expressões dadas por estes dois processos, Simplificado e Elaborado, possíveis de serem utilizadas no cálculo dos protótipos ensaiados nesta pesquisa.

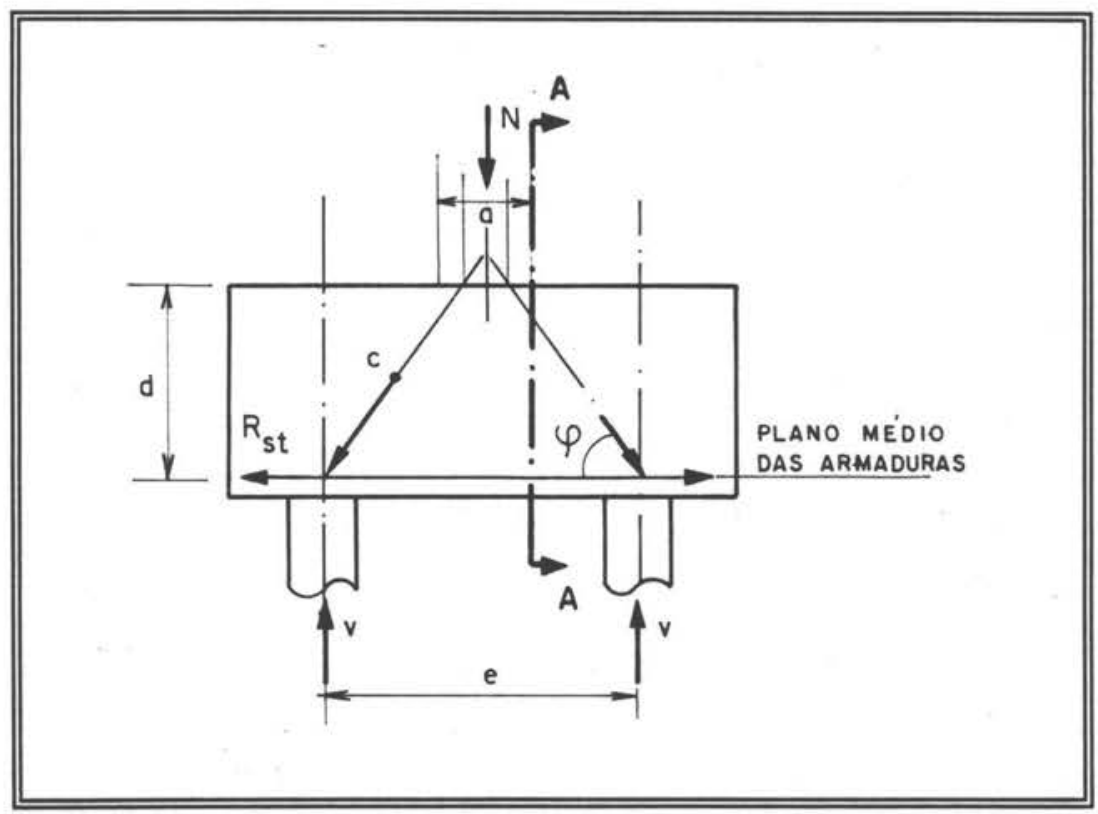

Figura 2.1 - Sistema de forças para bloco sobre duas estacas. 


\subsection{1 - PROCESSO SIMPLIFICADO}

Inicialmente, define-se o traçado para as bielas, que partem da base do pilar em direção às cabeças das estacas, atingindo a interseção entre o plano médio das armaduras e o eixo das estacas.

No plano da base do pilar, admite-se a origem das bielas num ponto tal que se considere a distribuição da carga sobre a superfície do pilar, conforme mostra a figura 2.1 .

A ação que o pilar aplica deve coincidir com o baricentro do bloco, quando visto em planta.

\subsubsection{1 - Blocos sobre duas estacas}

Seguindo a representação do equilíbrio de forças mostrado pela figura 2.1, pode-se desenvolver as expressões:

$$
R_{s t 2}=\frac{V}{\tan \varphi}
$$

sendo, $\quad \tan \varphi=\frac{d}{\frac{e}{2}-\frac{a}{4}}=\frac{4 d}{2 e-a}$

e,

$$
V_{2}=\frac{N}{2}
$$




$$
R_{s t 2}=\frac{N e}{4 d}\left(1-\frac{a}{2 e}\right)
$$

Assim, substituindo-se na expressão 2.1, os valores encontrados para o ângulo $\varphi$, de inclinação das bielas com relação à base do bloco, e, a reação $\boldsymbol{V}$ de uma estaca, à ação $\boldsymbol{N}$ aplicada pelo pilar, chega-se à expressão 2.2 , que representa o esforço de tração $\boldsymbol{R}_{\mathbf{\alpha} 2}$. Este esforço, é resistido por uma armadura colocada na parte inferior do bloco, na direção que une as cabeças das estacas.

Apesar de não serem recomendada para este tipo de elemento estrutural, a Teoria Elementar da Flexão, quando aplicada ao dimensionamento de blocos, conduz a uma expressão que permite o cálculo do esforço momento fletor na seção A-A, indicada na figura 2.1:

$$
\begin{aligned}
& M_{a-a}=V\left(\frac{e}{2}-\frac{a}{4}\right) \\
& M_{a-a}=\frac{N}{2}\left(\frac{2 e-a}{4}\right) \\
& M_{a-a}=\frac{N e}{4}\left(1-\frac{a}{2 e}\right)
\end{aligned}
$$

No cálculo da força de tração $\boldsymbol{R}_{\mathrm{s} 2}$, atuante nas armaduras inferiores do bloco, o momento fletor $\boldsymbol{M}$ pode ser substituído pelo binário com braço de alavanca igual à altura útil do bloco. Daí, chega-se a mesma expressão obtida a partir do Método das Bielas (Processo Simplificado): 


$$
R_{s t 2}=\frac{M}{d}=\frac{N e}{4 d}\left(1-\frac{a}{2 e}\right)
$$

\subsubsection{2 - Blocos sobre três estacas}

Igualmente, o Processo Simplificado do Método das Bielas pode ser aplicado a blocos sobre três estacas, executadas segundo uma disposição triangular, conforme ilustra a figura 2.2 .

A tangente do ângulo $\varphi$, entre uma biela e o plano horizontal contendo a cabeça das estacas, pode ser obtida através da expressão:

$$
\tan \varphi=\frac{d}{\frac{e \sqrt{3}}{3}-0,3 a}=\frac{3 d}{e \sqrt{3}-0,9 a}
$$

Fazendo-se:

$$
V_{3}=\frac{N}{3}
$$

E, observando-se na figura 2.2 , que a força nas armaduras sobre as estacas é dada por:

$$
R_{s t 3}=\frac{V_{3}}{\tan \varphi}
$$

chega-se à expressão para o cálculo de $\boldsymbol{R}_{s 3}$ : 


$$
R_{s t 3}=\frac{N}{9 d}(e \sqrt{3}-0,9 a)
$$

A força de tração $\boldsymbol{R}_{a s}$, calculada pela expressão 2.4 , atua na direção das medianas do triângulo equilátero, cujos vértices determinam a posição das estacas no bloco. No entanto, as armaduras são colocadas, geralmente, na direção dos lados deste triângulo, devendo resistir então, à força:

$$
R_{s t 3,1 a t}=\frac{N e}{9 d}\left(1-\frac{a}{2 e}\right)
$$

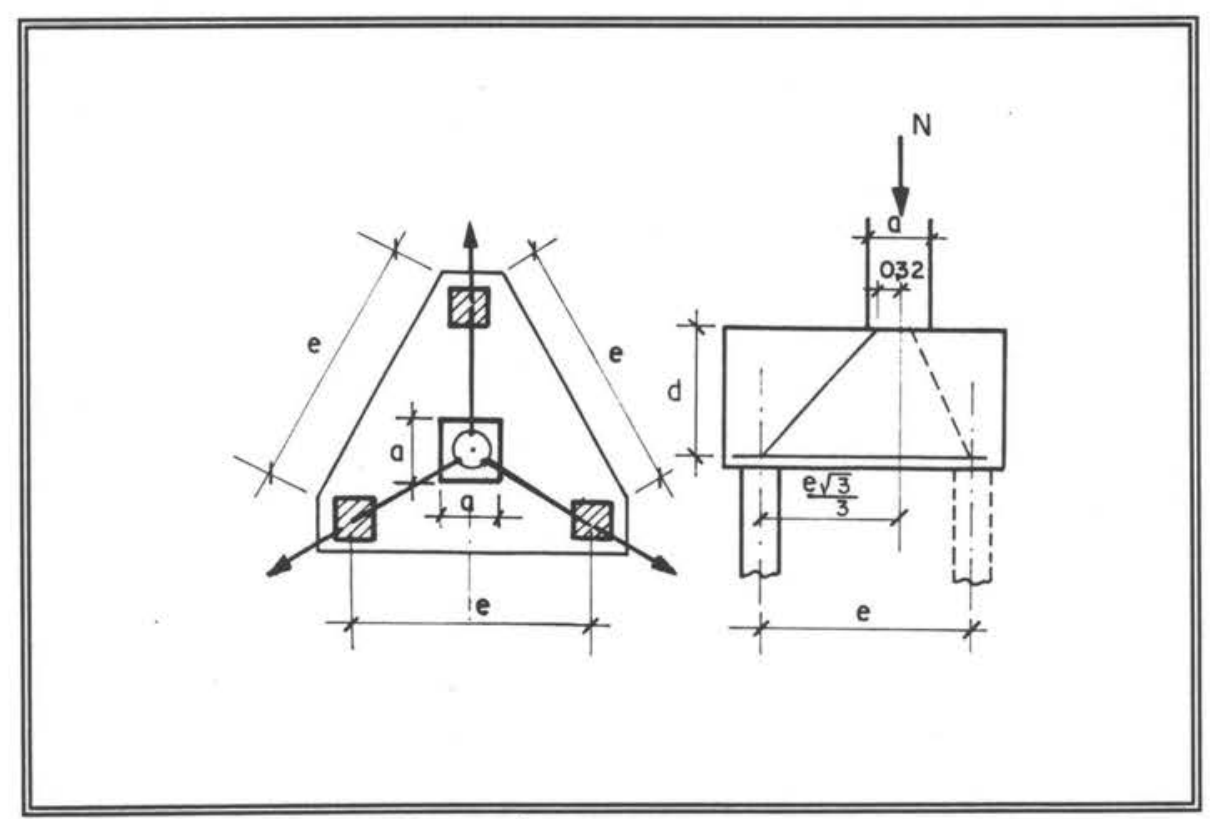

Figura 2.2 - Bloco sobre três estacas. 


\subsubsection{3 - Blocos sobre quatro estacas}

Neste caso, os eixos das estacas coincidem com os vértices de um quadrado de lado $e$. Supondo-se haver uma coincidência entre o centro do pilar de seção transversal quadrada e o centro do bloco, deduzem-se as expressões para o cálculo da força na armadura inferior, $\boldsymbol{R}_{\mathbf{s} A}$, atuando segundo a direção das diagonais:

$$
V_{4}=\frac{N}{4}
$$

da figura 2.4 , obtém-se para o valor da tangente de $\varphi$ :

$$
\tan \varphi=\frac{d}{\frac{e \sqrt{2}}{2}-\frac{a \sqrt{2}}{4}}
$$

mas,

$$
\tan \varphi=\frac{V_{4}}{R_{s t 4}}
$$

a expressão para o cálculo do esforço de tração nas armaduras, na direção ligando cada estaca ao pilar, será:

$$
R_{s t 4}=\frac{N \sqrt{2}}{16 d}(2 e-a)
$$

ou, simplificando: 


$$
R_{s t 4}=\frac{N e \sqrt{2}}{8 d}\left(1-\frac{a}{2 e}\right)
$$

Calculando-se a força nas armaduras segundo os lados do bloco, na direção que une as cabeças das estacas, chega-se à seguinte expressão:

$$
R_{s t 4,1 a t}=\frac{R_{s t 4}}{\sqrt{2}}=\frac{N e}{8 d}\left(1-\frac{a}{2 e}\right)
$$

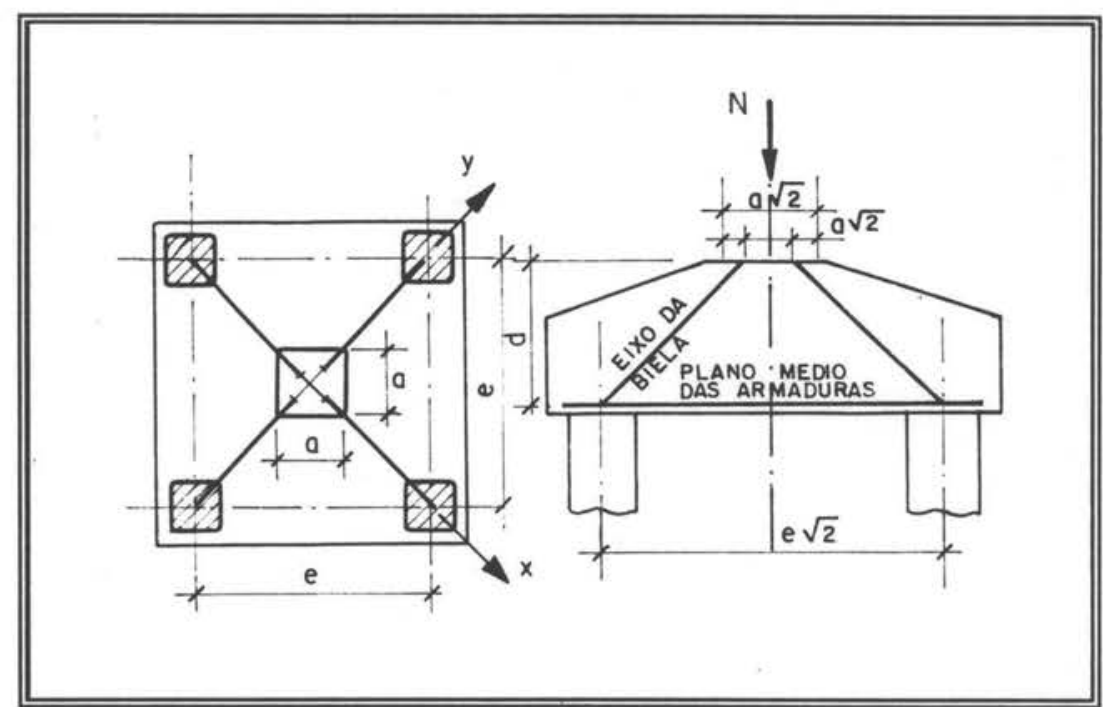

Figura 2.3 - Bloco sobre quatro estacas. 


\subsection{2 - PROCESSO ELABORADO}

Em sua abordagem do método das bielas, FRÉMY ${ }^{[02]}$ adotou, inicialmente, algumas hipóteses consideradas capazes de simplificar o estudo dos blocos sobre estacas, quais sejam:

1 - verticalidade das estacas;

2 - o bloco deve ser rígido o bastante para manter-se plano, em relação à horizontal, após a deformação das estacas;

3 - as estacas de um determinado grupo (duas, três ou quatro estacas), devem ter o mesmo comprimento e um mesmo módulo de deformação longitudinal;

4 - o eixo vertical do pilar, contém o centro de gravidade do grupo de estacas;

5 - a ação vertical do pilar, é transmitida às estacas através de bielas inclinadas que se formam no interior do bloco, sujeitas à um esforço de compressão;

6 - admite-se ser aplicável o princípio da superposição de efeitos, com o intuito de permitir a decomposição das ações em ações elementares. Assim, os esforços produzidos podem ser facilmente avaliados pela integração dos esforços causados pelas mesmas.

BLEVOT $^{\text {(02) }}$, baseado em suas experiências com modelos reduzidos e protótipos, indica que a hipótese 5 é segura para bielas com inclinação em torno 
de $45^{\circ}$, o que implica numa altura para o bloco, tal que, também a segunda hipótese é verificada.

Segundo FRÉMY' ${ }^{[02]}$, o conjunto das componentes horizontais das bielas constituem um sistema de forças coplanares equivalente à força nula. Estas componentes, são forças aplicadas no centro de cada estaca, sendo divergentes em relação ao centro de um círculo circunscrito às estacas. Assim, parece razoável que devam ser utilizadas armaduras periféricas, dispostas segundo os lados do polígono cujos vértices determinam a posição das estacas.

Na sequência, é mostrada de maneira resumida a determinação das reações nas estacas e das conponentes horizontais das bielas ( resultantes de tração segundo os lados ). Serão considerados neste estudo, casos particulares, tais como o caso de blocos sob pilares de seção retangular ( alongada ), bem como, o caso de pilares que transmitem ao bloco um momento fletor.

\subsubsection{1 - Caso geral}

Seja o ponto $i$, de coordenadas $\left(x_{i}, y_{i}\right)$, que determina a posição das estacas no círculo que circunscreve o polígono regular cujos vértices são ocupados pelas mesmas. Ao fazer-se com que o eixo $\boldsymbol{O} \boldsymbol{x}$ passe pelo ponto $\mathbf{1}$, sendo as estacas numeradas no sentido anti-horário, conforme ilustrado pela figura 2.4, chega-se às expressões para o cálculo das coordenadas das estacas:

$$
y_{i}=r \operatorname{sen} \frac{2(i-1) \pi}{n}
$$




$$
x_{i}=r \cos \frac{2(i-1) \pi}{n}
$$

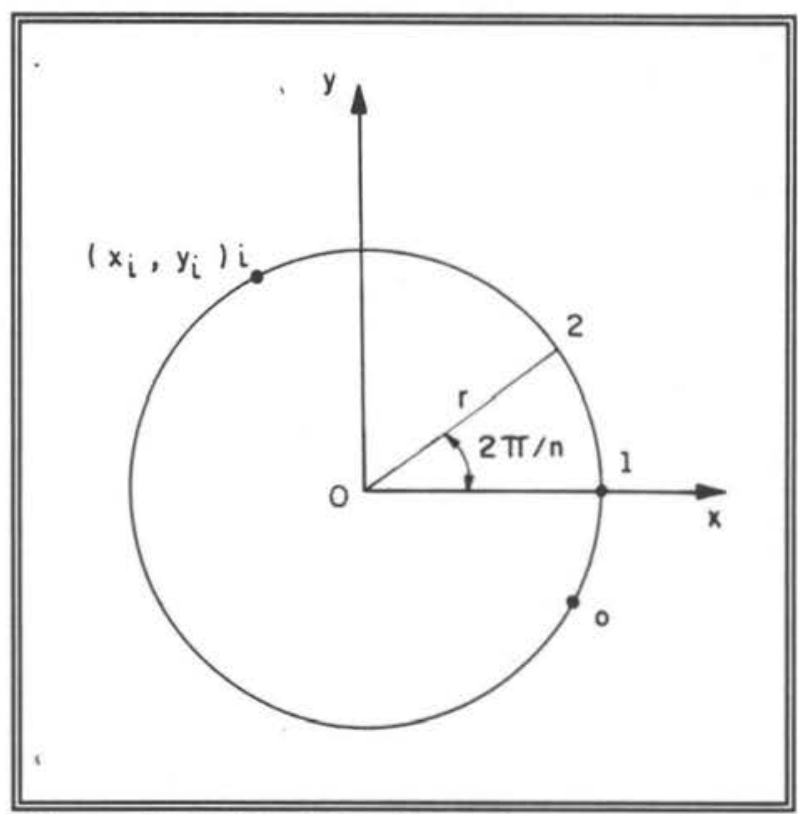

Figura 2.4 - Posição das estacas

A hipótese 2, leva à conclusão que, após as deformações que o bloco sofre, quando submetido a carregamento, as cabeças das estacas permanecem todas num mesmo plano. Por este motivo, estas apresentam deslocamentos que dependem linearmente das suas coordenadas $(\boldsymbol{x}, \boldsymbol{y})$.

Considerando também a hipótese 3 , as reações das estacas $\boldsymbol{V}_{i}$, são função dos deslocamentos sofridos pelas mesmas, conforme é demonstrado na dedução a seguir:

$$
\delta_{z i}=\varepsilon_{i} l_{i} \quad ; \quad \delta_{z i}=f(x, y)
$$


onde, $\quad \delta_{i}$ : deslocamento vertical da cabeça de uma estacas qualquer $i$;

$\varepsilon$ : deformação específica das estacas;

$l_{i}:$ comprimento das estacas.

Aplicando a lei de Hooke, obtém-se:

$$
\sigma_{i}=\varepsilon_{i} E_{i}-\frac{V_{i}}{A_{e s t, i}}=\frac{\delta_{z i}}{I_{i}} E_{i}
$$

onde, $\quad \sigma_{i} \quad$ : tensão em cada estaca;

$\boldsymbol{A}_{e s, i} \quad$ : área da seção transversal de uma estaca;

$\boldsymbol{E}_{\boldsymbol{i}} \quad$ : módulo de deformação longitudinal de uma estaca $\boldsymbol{i}$.

De acordo com a hipótese 3, as reações $\boldsymbol{V}_{i}$ de todas as estacas são proporcionais aos seus deslocamentos por uma mesma constante, ou seja:

$$
V_{i}=\frac{E A_{e s t, i}}{l_{i}} \delta_{z i}
$$

A expressão anterior, calcula o valor da reação $V_{i}$ de cada estaca, o qual irá depender linearmente das coordenadas das estacas, chegando-se então a uma expressão do tipo:

$$
V_{i}=A x_{i}+B y_{i}+C
$$


na qual $\boldsymbol{A}, \boldsymbol{B}$ e $\boldsymbol{C}$, são constantes obtidas a partir das equações de equilíbrio fornecidas pela estática, mostradas a seguir, para o caso de blocos suportando pilares nos quais atua uma ação concentrada $N$ :

$$
\begin{aligned}
& \sum_{1}^{n} V_{i}=N \\
& \sum_{1}^{n} V_{i} x_{i}=N x \\
& \sum_{1}^{n} V_{i} y_{i}=N y
\end{aligned}
$$

onde, $\boldsymbol{x}$ e $\boldsymbol{y}$, são as coordenadas do ponto de aplicação da carga $N$ do pilar.

Substituindo-se então, os valores encontrados para as constantes $\boldsymbol{A}, \boldsymbol{B}$ e $\boldsymbol{C}$, chega-se à expressão que permite calcular a reação de cada estaca, em função de sua posição no grupo:

$$
\begin{aligned}
A & =\frac{2 N}{n r^{2}} x ; B=\frac{2 N}{n r^{2}} y \quad ; \quad C=\frac{N}{n} \\
V_{i} & =\frac{2 N}{n r}\left[x \cos \frac{2(i-1) \pi}{n}+y \operatorname{sen} \frac{2(i-1) \pi}{n}+\frac{r}{2}\right]
\end{aligned}
$$


Para o caso de um pilar sob uma ação vertical, uniformemente distribuída sobre a sua seção transversal, deve-se considerar uma ação elementar $d N$, atuando sobre o elemento de superfície $d x d y$, conforme mostrado na figura seguinte:

$$
d N=\frac{N}{a b} d x d y
$$

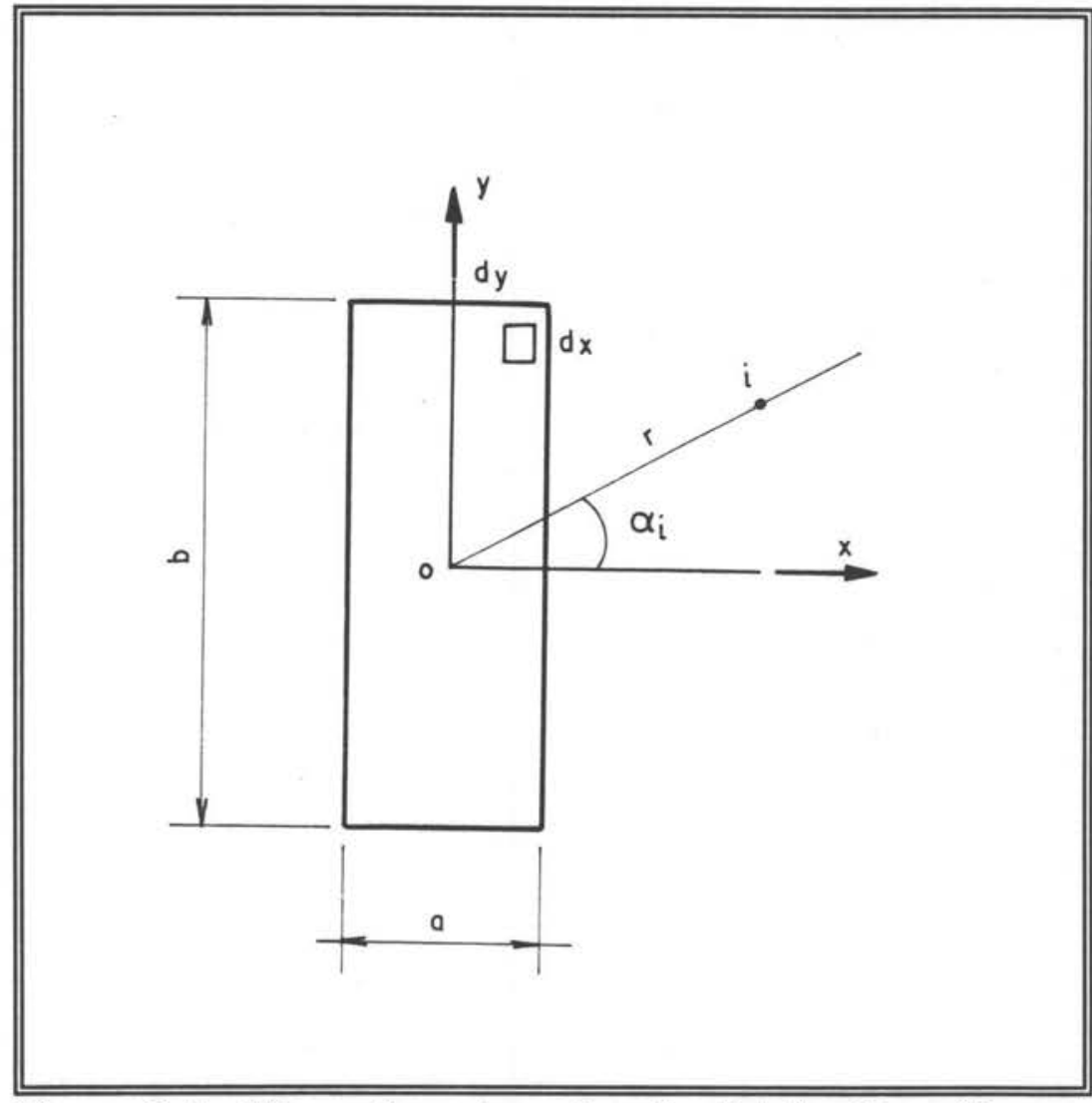

Figura 2.5 - Pilar retangular sob ação distribuída uniforme.

Substituindo na expressão que calcula a reação $V_{i}$, a ação elementar $d N$, chega-se a uma fórmula para a obtenção da reação elementar $d V_{i}$ de uma estaca qualquer: 


$$
d V_{i}=\frac{N}{n r a b}\left(2 x \cos \alpha_{i}+2 y \operatorname{sen} \alpha_{i}+r\right) d x d y
$$

A reação total $\boldsymbol{V}_{i}$, podendo ser obtida através de uma integração tendo como limites as dimensões do pilar, será igual a:

$$
\begin{aligned}
& V_{i}=\frac{N}{n a b r} \int_{-\frac{a}{2}-\frac{b}{2}}^{\frac{a}{2}} \int_{\frac{b}{2}}^{\frac{b}{2}}\left(2 x \cos \alpha_{i}+2 y \operatorname{sen} \alpha_{i}+r\right) d x d y \\
& V_{i}=\frac{N}{n}
\end{aligned}
$$

Este resultado é também empregado pela forma simplificada do método das bielas, embora sem demonstração, sendo esta afirmação baseada essencialmente na segunda hipótese, formulada no início deste item.

Passa-se agora, ao cálculo da componente horizontal da biela, $\boldsymbol{R}_{\mathbf{s}, i}$, partindo do esforço elementar $d \boldsymbol{R}_{a, i}$, tal como mostra a figura 2.6:

$$
\overline{d R}_{s t, i}=d V_{i} \overline{\frac{m i}{d}}
$$

onde $d$ representa a altura útil do bloco, quando se admite que o plano das armaduras é o mesmo no qual é feito o arrasamento das estacas. Projetando-se o vetor $d R_{s, i}$ nas direções dos eixos coordenados, chega-se às equações 2.12 e 2.13 , que integradas nos mesmos limites usados no cálculo de $V_{i}$ fornecem os vetores $\boldsymbol{R}_{(s, i, j) x}$ e $\boldsymbol{R}_{(s, i, j) y}$, conforme ilustra a figura 2.6. 


$$
\begin{aligned}
& d R_{(s t, i) x}=\frac{d V_{i}}{d}\left(r \cos \alpha_{i}-x\right) \\
& d R_{(s t, i) y}=\frac{d V_{i}}{d}\left(I \operatorname{sen} \alpha_{i}-y\right)
\end{aligned}
$$

O vetor $\boldsymbol{R}_{s, i}$, obtido desta maneira, quando decomposto segundo a direção dos lados do polígono formado pelas estacas, resulta nas seguintes expressões:

$$
\begin{aligned}
& R_{(s t, i) x}=\frac{N \cos \alpha_{i}}{n r d}\left(r^{2}-\frac{a^{2}}{6}\right) \\
& R_{(s t, i) y}=\frac{N \operatorname{sen} \alpha_{i}}{n r d}\left(r^{2}-\frac{b^{2}}{6}\right)
\end{aligned}
$$

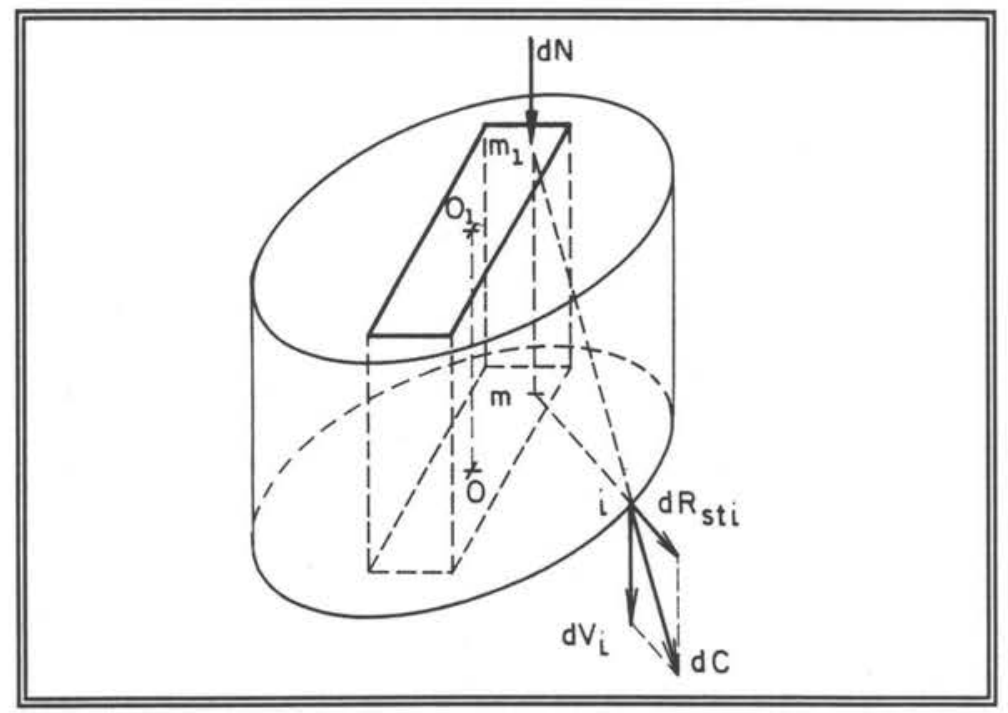

Figura 2.6 - Vetor $d_{R_{x, 1}}$ 
Os ângulos entre as forças de tração segundo os lados e o eixo x, são dados por:

$$
\begin{aligned}
& \theta\left(F_{(i, i+1) x}\right)=\alpha_{i}-\left(\frac{\pi}{2}-\frac{\pi}{n}\right) \\
& \theta\left(F_{(i, i-1) x}\right)=\alpha_{i}+\left(\frac{\pi}{2}-\frac{\pi}{n}\right)
\end{aligned}
$$

onde, $\quad F_{(a, i-1) x}$ : componente na direção do eixo $x$, da força de tração que atua na estaca $i$, voltada para a estaca $i-1$;

$$
\boldsymbol{F}_{(i, i+1) x} \text { : componente na direção do eixo } \boldsymbol{x} \text {, da força de tração que }
$$
atua na estaca $i$, voltada para a estaca $i+1$;

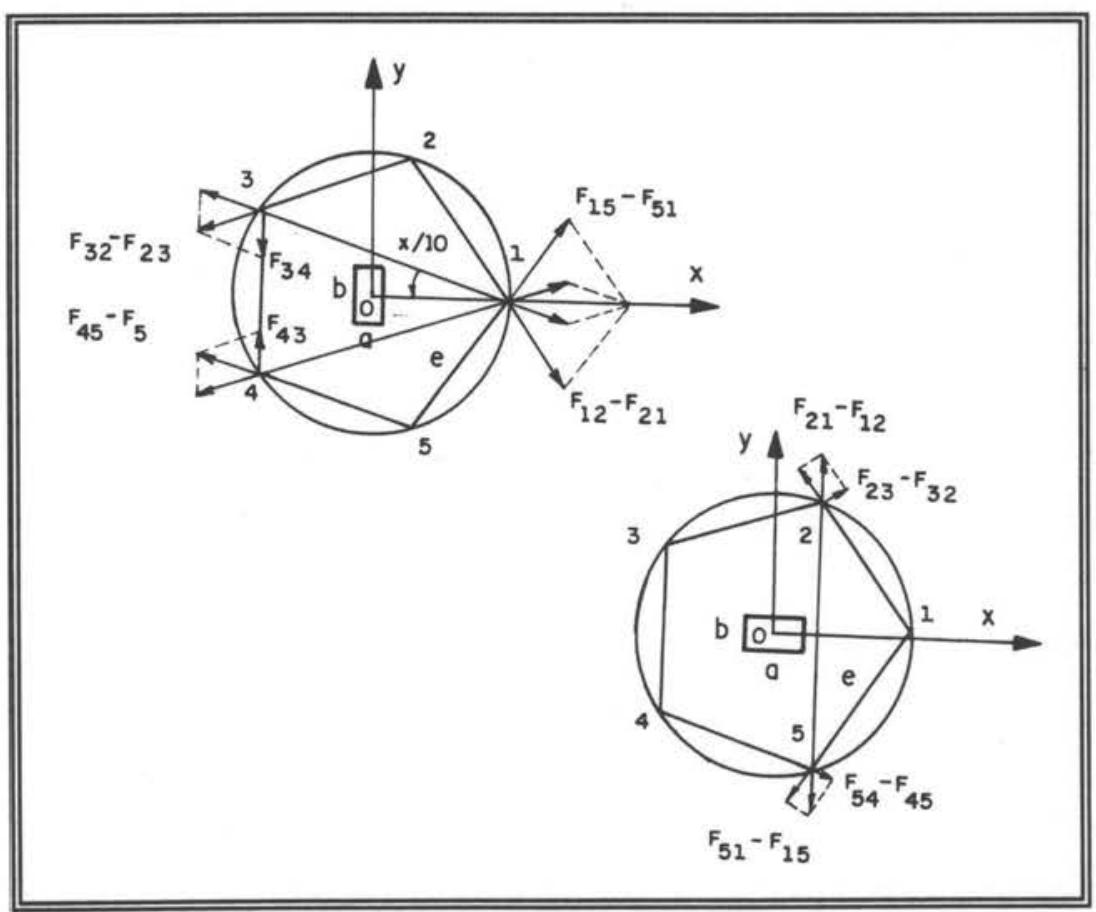

Figura 2.7 - Componentes de tração segundo os lados 
As projeções da força $\boldsymbol{R}_{s, i}$, nos eixos coordenados, podem ser utilizadas na obtenção de expressões que permitam a avaliação de $\boldsymbol{F}_{(i, i-1)}$ e $\boldsymbol{F}_{(i, i+1)}$, sejam elas:

$$
\begin{aligned}
& F_{(i, i-1)}=\frac{N e}{n d}\left\{\frac{1}{4 \operatorname{sen}^{2} \frac{\pi}{n}}-\frac{1}{6}\left[\frac{a^{2}}{e^{2}} \frac{\cos \alpha_{i} \cos \left(\alpha+\frac{\pi}{n}\right)}{\cos \frac{\pi}{n}}+K 1\right]\right\} \\
& K 1=\frac{b^{2}}{e^{2}}\left(1-\frac{\cos \alpha_{i} \cos \left(\alpha_{i}+\frac{\pi}{n}\right)}{\cos \frac{\pi}{n}}\right) \\
& F_{(i, i+1)}=\frac{N e}{n d}\left\{\frac{1}{4 \operatorname{sen}^{2} \frac{\pi}{n}}-\frac{1}{6}\left[\frac{a^{2}}{e^{2}} \frac{\cos \alpha_{i} \cos \left(\alpha_{i}-\frac{\pi}{n}\right)}{\cos \frac{\pi}{n}}+K 2\right]\right\} \\
& K 2=\frac{b^{2}}{e^{2}}\left(1-\frac{\cos \alpha_{i} \cos \left(\alpha_{i}-\frac{\pi}{n}\right)}{\cos \frac{\pi}{n}}\right)
\end{aligned}
$$


Aplicando a primeira das expressões anteriores à estaca $i+1$, não se chega ao mesmo valor fornecido pela segunda destas equações, quando aplicada à estaca $i$. Resultado análogo pode ser encontrado para as estacas $i-1$ e $i$, como mostram as seguintes equações:

$$
\begin{aligned}
& F_{i+1, i}-F_{i, i+1}=\frac{N\left(a^{2}-b^{2}\right)}{6 n e d} \frac{\operatorname{sen} 2\left(\alpha_{i}+\frac{\pi}{n}\right) \operatorname{sen} \frac{3 \pi}{n}}{\cos \frac{\pi}{n}}(2.16) \\
& F_{i, i-1}-F_{i-1, i}=\frac{N\left(a^{2}-b^{2}\right)}{6 n e d} \frac{\operatorname{sen} 2\left(\alpha_{i}-\frac{\pi}{n}\right) \operatorname{sen} \frac{3 \pi}{n}}{\cos \frac{\pi}{n}}(2.17)
\end{aligned}
$$

Com base nestes resultados, FRÉM $Y^{[02]}$ sugere que as armaduras periféricas (segundo os lados), são suficientes quando calculadas para resistir ao maior dos esforços de tração fornecidos pelas expressões 2.16 e 2.17 , para um mesmo lado do polígono formado pelas cabeças das estacas. Considera ainda, que as diferenças mostradas acima, constituem, quando tomadas em conjunto, um sistema equivalente à força nula, e, são equilibradas pelos esforços de compressão na base do bloco. 


\subsubsection{2 - Casos particulares}

Neste item, estudam-se alguns casos especiais, procurando utilizar o equacionamento proposto no item anterior. Isto é feito, determinando-se as reações totais ou elementares através das equações de equilíbrio estático. A partir daí, são obtidas as componentes horizontais das bielas por um processo de integração. Estas componentes, por sua vez, sendo projetadas segundo as direções dos lados do polígono cujos vértices são determinados pela posição das estacas, permitem a obtenção das armaduras, que deverão ser dispostas na base do bloco.

$\mathrm{O}$ primeiro caso abordado, será o de um bloco sob um pilar de dimensões transversais $\boldsymbol{a} \boldsymbol{x} \boldsymbol{b}$, sobre o qual atua um momento $\boldsymbol{M}$ em torno do eixo $\boldsymbol{O x}$. Por conveniência, os eixos $\boldsymbol{O} \boldsymbol{x}$ e $\boldsymbol{O} \boldsymbol{y}$ são orientados de tal maneira que o momento $\boldsymbol{M}_{\boldsymbol{x}}$ seja positivo quando comprime as fibras positivas do pilar, o que implica em situar a excentricidade do lado dos $y$ positivos.

Seja o esforço elementar:

$$
d N=\frac{12 M}{a b^{3}} y d x d y
$$

que aplicado na equação 2.11 , fornece:

$$
V_{i}=\frac{12 M}{n r a b^{3}} \int_{-\frac{a}{2}-\frac{b}{2}}^{\frac{a}{2}} \int_{\frac{b}{2}}^{\frac{b}{2}}\left(2 x \cos \alpha_{i}+2 y \operatorname{sen} \alpha_{i}+r\right) y d x d y
$$

cuja resolução permite encontrar uma expressão para o cálculo da reação $V_{i}$ aplicada ao bloco por qualquer uma das estacas do grupo, qual seja: 


$$
V_{i}=\frac{2 M \operatorname{sen} \alpha_{i}}{n r}
$$

ou,

$$
V_{i}=\frac{4 M \operatorname{sen} \alpha_{i} \operatorname{sen}\left(\frac{\pi}{n}\right)}{n e}
$$

As componentes horizontais das bielas, são obtidas pela substituição, nas equações 2.12 e 2.13 , do esforço elementar $d V_{i}$ cuja integração resultou na equação anterior. Desta forma, as componentes $\boldsymbol{R}_{(s, i) x}$ e $\boldsymbol{R}_{(s, i), j}$, podem ser expressas por:

$$
\begin{aligned}
& R_{(s t, i) x}=\frac{M \operatorname{sen} 2 \alpha_{i}}{n d}=\frac{M}{n d} \cos \left(2 \alpha_{i}-\frac{\pi}{2}\right)(2.19) \\
& R_{(s t, i) y}=-\frac{M \cos 2 \varphi_{i}}{n d}=\frac{M}{n d} \operatorname{sen}\left(2 \alpha_{i}-\frac{\pi}{2}\right)(2.20)
\end{aligned}
$$

Decompondo-se estes esforços de tração na direção dos lados do bloco, chega-se às expressões:

$$
F_{i, i-1}=\frac{M}{n d} \frac{\operatorname{sen}\left(\alpha_{i}-\frac{\pi}{n}\right)}{\operatorname{sen}\left(\frac{2 \pi}{n}\right)}
$$


para

$$
\frac{\pi}{n}<\alpha_{i}<\pi+\frac{\pi}{n} \quad \mathrm{e},
$$

$$
F_{i, i+1}=\frac{M}{n d} \frac{\operatorname{sen}\left(\alpha_{i}+\frac{\pi}{n}\right)}{\operatorname{sen}\left(\frac{2 \pi}{n}\right)}
$$

para $\quad-\frac{\pi}{n}<\alpha_{i}<\pi-\frac{\pi}{n}$

Aplicando a equação 2.21, à estaca $i+1$, e sabendo-se que $\alpha_{i+1}=$ $\alpha_{1}+\pi / \mathbf{n}$, obtém-se o mesmo resultado dado pela equação 2.22 , quando aplicada à estaca $i$.

De maneira análoga, para o caso de um pilar centrado de lados $a$ e $\boldsymbol{b}$, que transmite um momento $\boldsymbol{M}_{\boldsymbol{x}}$, obtém-se as seguintes expressões:

$$
\begin{aligned}
& F_{i, i-1}=\frac{M}{n d} \frac{\cos \left(\alpha_{i}-\frac{\pi}{n}\right)}{\operatorname{sen}\left(\frac{2 \pi}{n}\right)} \\
& F_{i, i+1}=\frac{M}{n d} \frac{\cos \left(\alpha_{i}+\frac{\pi}{n}\right)}{\operatorname{sen}\left(\frac{2 \pi}{n}\right)}
\end{aligned}
$$




\subsection{3 - VERIFICAÇÃO DAS TENSÕES NAS BIELAS}

As tensões de compressão a ser resistidas pelo concreto na região do bloco onde se formam as bielas, devem ser tais que não provoquem o esmagamento do mesmo. Da figura 2.8, pode-se obter equações que satisfazem esta condição com a determinação de uma altura limite para o bloco.

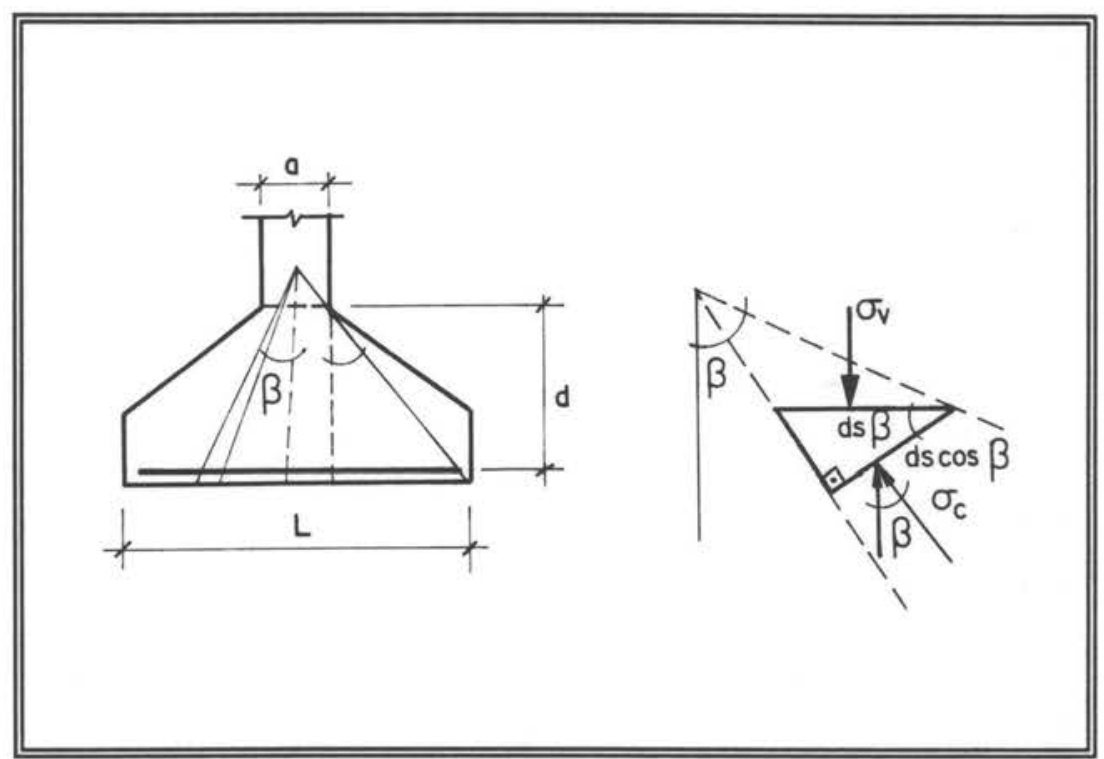

Figura 2.8 - Tensões nas bielas.

Considerando a seguinte equação:

$$
\sigma_{v}=\frac{N}{a b}
$$

onde $\sigma_{v}$ é a tensão causada pela ação $N$, aplicada ao bloco pelo pilar de seção transversal $\boldsymbol{a} \boldsymbol{x} \boldsymbol{b}$, atuante na região de encontro do pilar com o bloco. Fazendo o 
equilíbrio de forças para as resultantes de tensões apresentadas na figura 2.8 , chegase a seguinte expressão:

$$
\sigma_{v} d s=\left(\sigma_{c} d s \cos \beta\right) \cos \beta
$$

sendo $\sigma_{c}$, a tensão de compressão, a que é submetida uma biela que forme um ângulo $\beta$ qualquer com a direção da ação $N$.

Dividindo-se ambos os lados da equação anterior por $d s$, pode-se concluir que:

$$
\begin{aligned}
& \sigma_{v}=\sigma_{c} \cos ^{2} \beta \\
& \sigma_{c}=\sigma_{v} \sec ^{2} \beta \text { ou, } \\
& \sigma_{c}=\sigma_{v}\left(1+t g^{2} \beta\right)
\end{aligned}
$$

$\Rightarrow \quad \sigma_{c}=\sigma_{v} \sec ^{2} \beta$ ou,

Aplicando em 2.27 o valor de $\sigma_{v}$ dado por 2.24 e, considerando o máximo ângulo $\beta$, chega-se à equação:

$$
\sigma_{c, \text { máx }}=\frac{N}{a b}\left(1+\operatorname{tg}^{2} \beta_{\text {max }}\right)
$$

Da figura 2.8, obtém-se: 


$$
\left(\operatorname{tg} \beta_{\max }\right)=\frac{\sqrt{\left(\frac{B-b}{2}\right)^{2}+\left(\frac{L-a}{2}\right)^{2}}}{d}
$$

A NBR-6118 ${ }^{[04]}$, prescreve que, em regiões de introdução de forças de compressão, $\sigma_{c d} \leq 2,2 f_{c d}$. Aplicando este limite à equação 2.28, obtém-se:

$$
2,2 f_{c d} \geq \frac{N_{d}}{a b}\left\{1+\left[\frac{(B-b)^{2}+(L-a)^{2}}{4 d^{2}}\right]\right\}
$$

Assim, na expressão anterior pode-se explicitar $d$, obtendo-se então uma condição para que não ocorra o esmagamento das bielas, qual seja:

$$
d \geq \frac{1}{2} \sqrt{\frac{(B-b)^{2}+(L-a)^{2}}{\left(\frac{2,2 f_{c d} a b}{N_{d}}\right)-1}}
$$




\subsection{4 - BLOCOS SOBRE GRUPAMENTOS DE ESTACAS COM SIMETRIA} POLAR

Considerando a figura que segue, pode-se dizer, de acordo com CASTELO $^{[05]}$, que para carregamento vertical coincidente com o eixo que passa pelo centro de gravidade do grupamento, o mesmo se reparte igualmente entre as estacas, podendo-se admitir dois casos de armação:

Caso se decida armar o bloco para o esforço radial, haverá sobreposição de camadas no centro;

Adontando-se armaduras para resistir aos esforço tangenciais, cuja resultante é o esforço radial, obtém-se o tipo de armação geralmente empregada.

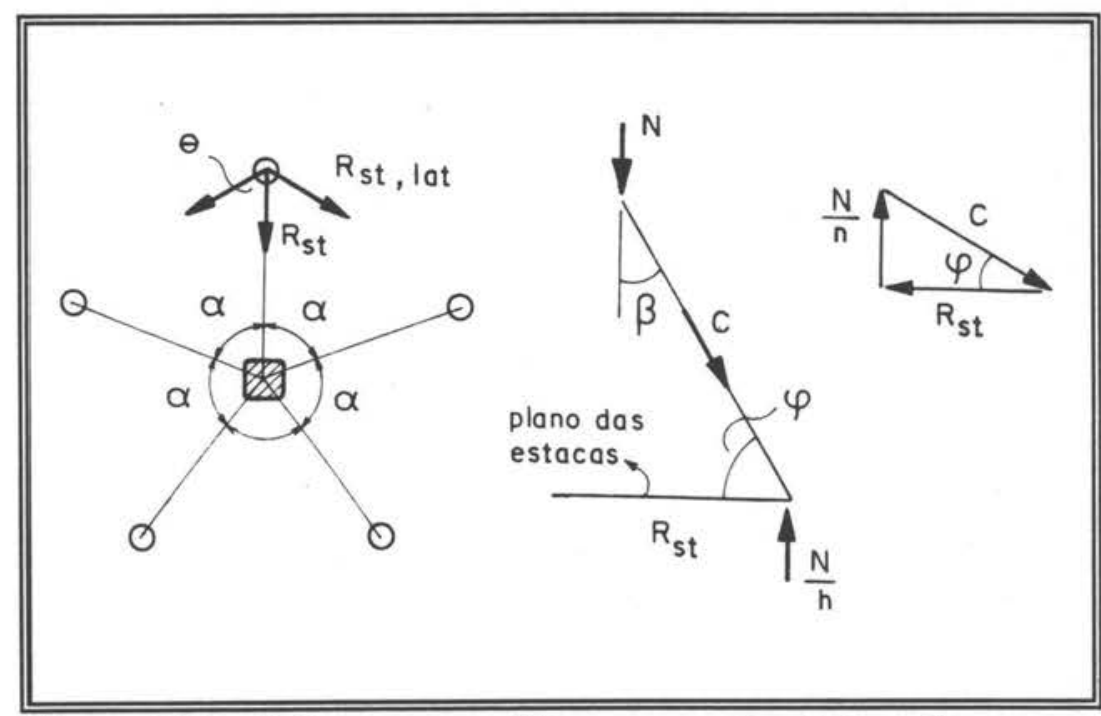

Figura 2.9 - Esforços para blocos com simetria polar 
O esforço radial sendo dado por:

$$
R_{s t d}=\frac{N_{d}}{n} \operatorname{cotg} \varphi
$$

Por sua vez, o esforço tangencial pode ser obtido da seguinte maneira:

$$
\begin{aligned}
& R_{s t d}=2 R_{s t d, 1 a t} \cos \theta \\
& \text { como } \theta=\frac{\pi}{2}-\frac{\alpha}{2} \text { e } \alpha=\frac{2 \pi}{n} \text {, onde } n \text { é o número de }
\end{aligned}
$$

estacas, o esforço $\boldsymbol{R}_{\text {sad, lat }}$ será dado por:

$$
R_{s t d, 1 a t}=\frac{R_{s t d}}{2} \sec \left(\frac{\pi}{2}-\frac{\pi}{n}\right)
$$

ou,

$$
R_{s t d, 1 a t}=\frac{R_{s t d}}{2} \operatorname{cosec} \frac{\pi}{n}
$$




\section{2 - MÉTODO DO CEB-FIP}

Em boletim de 1970, o CEB $^{[03]}$, estabelece algumas recomendações a ser obedecidas no dimensionamento de blocos de coroamento de grupos de estacas.

Segundo este método, considera-se como solicitação dimensionante, o momento fletor avaliado numa seção de referência $S_{1}$, provocado pelas reações das estacas situadas à direita desta seção, permitindo-se desprezar, a favor da segurança, a reação do solo.

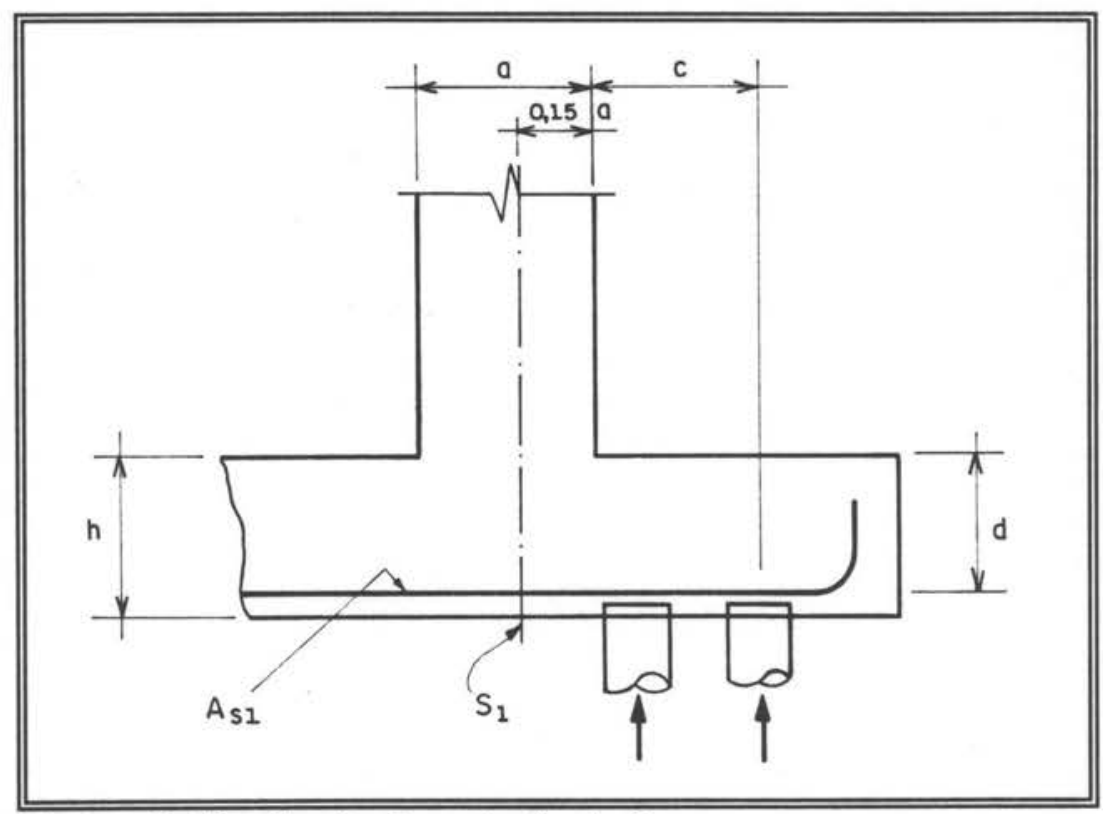

Figura 2.10 - Seção de referência $S_{1}$.

Da figura anterior, obtém-se a posição da seção de referência:

$$
c_{a}=C+0,15 a
$$


sendo, $C_{a}$ : distância da seção $S_{1}$ até o eixo da estaca mais à direita;

$C$ : distância do eixo da estaca até a face do pilar;

$a$ : dimensão do pilar medida na direção perpendicular à seção $S_{1}$.

Para o caso de blocos sobre estacas, as recomendações do CEB $^{[03]}$, estabelecem que a altura dos mesmos deve ser escolhida a partir de um critério geométrico, a saber: $C \leq 1,5 \mathrm{~h}$.

Assim, os blocos cuja altura atenda à condição apresentada no parágrafo anterior, encontram-se no domínio de aplicação das supracitadas recomendações.

\subsection{1 - DETERMINAÇÃO DA ÁREA DE ARMADURA INFERIOR}

Inicialmente, é determinada a altura útil da seção $S_{1}$. Esta deverá ser a altura útil da seção paralela a $S_{1}$, situada na face do pilar, devendo ser respeitada a condição: $d_{1}=d \leq 1,5 C$.

O esforço solicitante utilizado no cálculo desta armadura, é o momento fletor avaliado na seção $S_{1}$, provocado pelas reações das estacas à direita da referida seção.

Uma vez calculado este esforço, a área da seção de armadura principal atravessando $S_{l}$, pode ser obtida como nas vigas submetidas à flexão simples, sendo calculada conforme a expressão dada por PINHEIRO ${ }^{106]}$ :

$$
A_{S 1}=k_{s} \frac{M_{d}}{d}
$$


onde, $\quad \boldsymbol{d}$ : altura útil tomada na seção da face do pilar;

$M_{d}$ : momento fletor de cálculo;

$A_{s l}$ : área da seção de armadura;

$k$, : coeficiente relacionado ao domínio de deformação em que a seção se encontra.

As barras que constituem a armadura inferior, devem ser prolongadas sem redução de seção por todo o comprimento do bloco. A ancoragem deve ser feita a partir do plano que contém o eixo das estacas, considerando-se uma solicitação de tração igual a oitenta por cento do esforço de tração na seção onde a armadura foi calculada.

\subsubsection{1 - Armaduras adicionais}

De acordo com este método, o bloco deve ser provido também de armaduras adicionais, dispostas horizontal e verticalmente.

A armadura vertical é meramente construtiva, ao passo que a armadura horizontal resiste a uma tendência de fendilhamento do bloco, mais pronunciada em blocos com forma retangular ( duas ou três estacas ) ou blocos sobre uma estaca isolada.

Deve ser utilizada também, uma armadura longitudinal na face superior do bloco, disposta ao longo de todo o seu comprimento, com uma seção transversal não inferior a dez por cento da seção da armadura longitudinal inferior.

As armaduras verticais e horizontais formam uma malha nas faces do bloco, sendo a armadura vertical constituída pelos estribos das barras longitudinais superiores e inferiores, a horizontal, pelos estribos da armadura vertical. 
A área da seção de uma barra da malha é calculada por:

$$
A_{s 1}=0,0025 b^{\prime} t
$$

quando forem utilizadas barras lisas;

$$
A_{s 1}=0,0020 b^{\prime} t
$$

quando forem utilizadas barras com saliências ou mossas, sendo que, nestas expressões:

$$
\begin{aligned}
& b^{\prime} \text { : largura do bloco ( em } \mathrm{cm} \text { ); } \\
& t \text { : espaçamento das barras da malha }(\mathrm{em} \mathrm{cm} \text { ). }
\end{aligned}
$$

Caso a largura $b^{\prime}$ exceda a metade da altura do bloco, $\boldsymbol{b}$ ' deve ser tomada como sendo:

$$
b^{\prime}=\frac{h}{2}
$$




\subsection{2 - VERIFICAÇÃO QUANTO AO ESFORÇO CORTANTE}

O esforço cortante de cálculo deve ser avaliado na seção de referência $S_{2}$, como sendo a componente vertical da ações atuando em uma das parte do bloco, definidas por esta seção, por exemplo, pelas forças aplicadas à direita de $S_{2}$ ( reações das estacas ).

A seção mencionada acima, situa-se, em se tratando de blocos sobre estacas, no plano da face do pilar, quando uma ou mais estacas estiverem, em sua totalidade ou em parte, à uma distância desta face inferior à metade da altura útil do bloco. A sua largura fica definida pela expressão:

$$
b_{2}=b+d
$$

O esforço cortante obtido desta maneira, deverá ser inferior, ou no máximo igual, ao esforço cortante limite, dado por:

$$
V_{u}=\frac{2,5}{\gamma_{c}}\left(1-\frac{C}{5 d}\right) b_{2} d_{2} \sqrt{f_{c k}}
$$

sendo $\quad d_{2}$ : altura útil na seção de referência $S_{2}$;

$b_{2}:$ largura de $S_{2}$;

$C$ : distância entre a face do pilar e o eixo da estaca mais afastada;

$d$ : altura útil do bloco;

$\gamma_{\epsilon}$ : coeficiente de minoração da resistência do concreto;

$f_{c k}$ : resistência característica à compressão do concreto. 
A última expressão mostrada, calcula o valor limite da resistência ao esforço cortante do bloco, quando o valor do $f_{c k}$ utilizado é dado em $\mathrm{kgf} / \mathrm{cm}^{2}$. Caso contrário, o valor 2,5 que aparece na equação deverá ser substituido por:

- 0,70 para $f_{c k}$ dado em MPa;

- 0,25 para $f_{c k}$ dado em $\mathrm{kN} / \mathrm{cm}^{2}$.

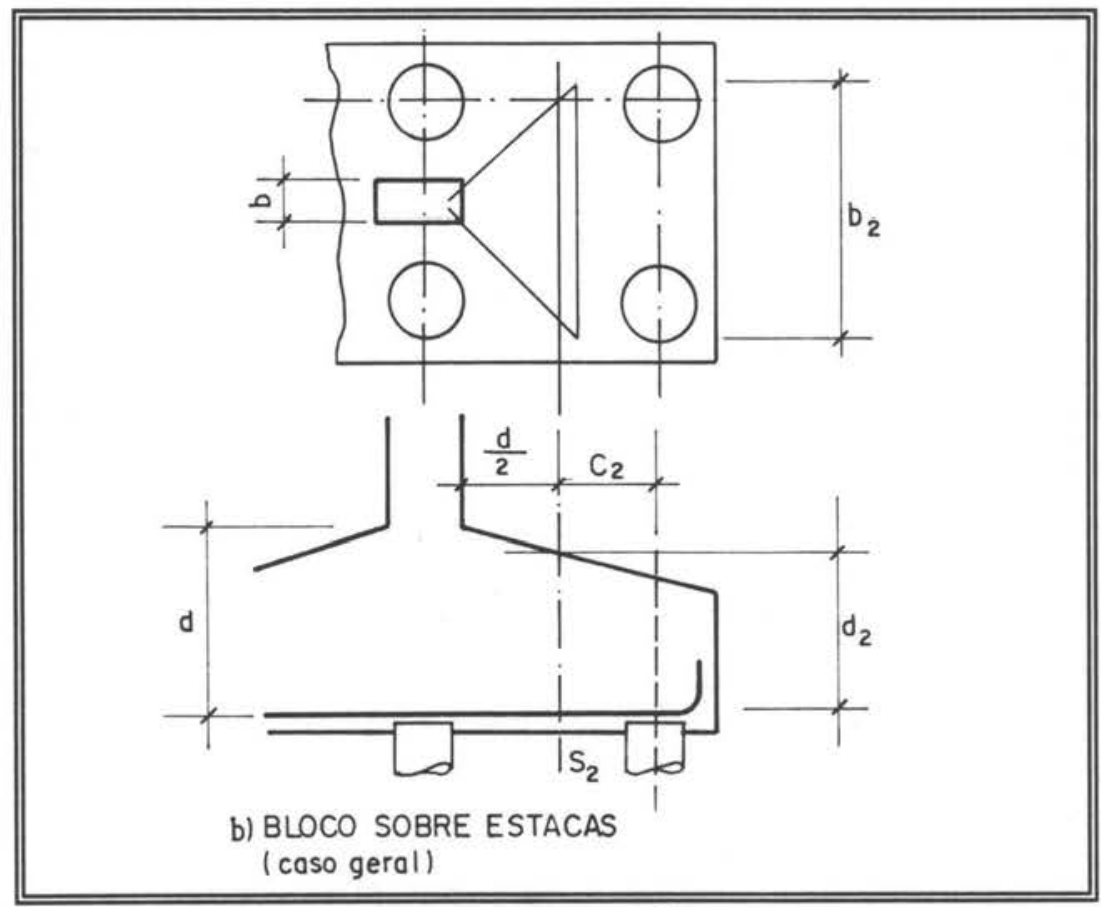

Figura 2.11 - Seção de Referência $S_{2}$ 


\subsection{3 - VERIFICAÇÃO DA ADERÊNCIA NA ARMADURA INFERIOR}

Esta verificação é feita quando o esforço cortante avaliado na seção de referência $S_{1}$, é menor que o esforço limite calculado da maneira que segue:

$$
V_{1 d} \leq 0,9 d n \pi \phi \tau_{b u}
$$

onde, $\quad d$ : altura útil do bloco;

$n$ : numero de barras por unidade de largura;

$\phi$ : diâmetro das barras;

$\tau_{b u}$ : tensão de aderência limite ( dada pela NBR 6118 ${ }^{[04]}$, para barras

de alta aderência: $\quad \tau_{b u}=0,35 \sqrt[3]{f_{c d}{ }^{2}}\left[\mathrm{kN} / \mathrm{cm}^{2}\right]$ )

A equação 2.40 , pode ser obtida da dedução que segue, conforme ilustra a figura 2.12:

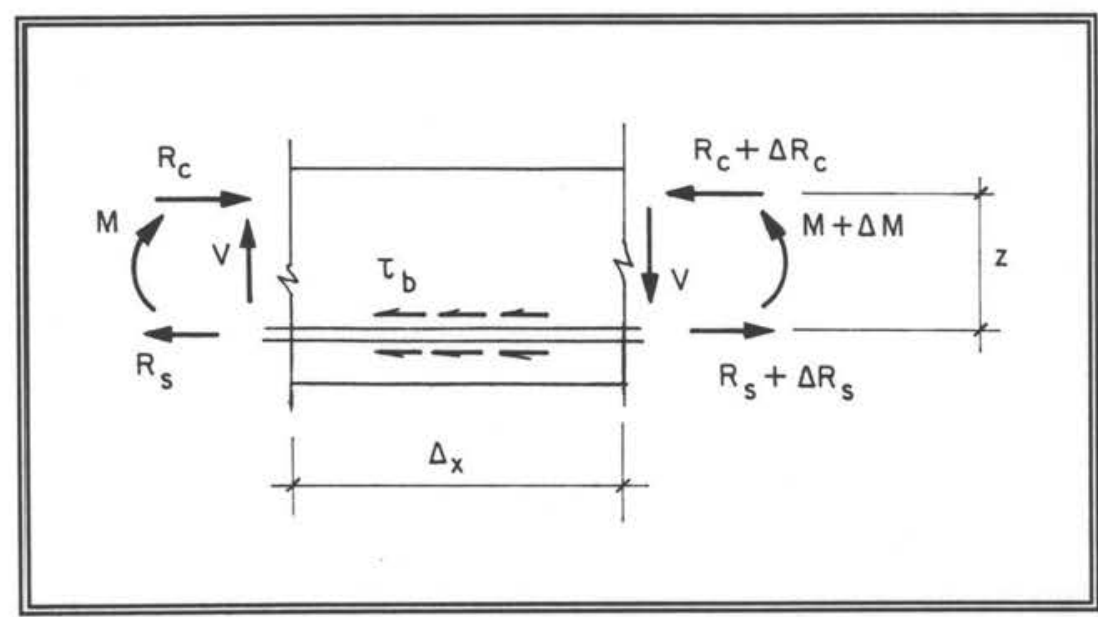

Figura 2.12 - Aderência da armadura inferior. 


$$
\begin{aligned}
& \Delta R_{s t}=\frac{\Delta M}{z} ; \frac{\Delta M}{\Delta x}=V_{1 d} \\
& \Delta R_{s t d}=\tau_{b u} u \Delta x
\end{aligned}
$$

onde $\tau_{b u}$ é a tensão de aderência e $u$, o perímetro equivalente das barras da armadura, calculado pela expressão: $u=n \pi \cdot \phi$.

Então, a partir das expressões que permitem o cálculo de $\boldsymbol{R}_{\boldsymbol{s}}$, dadas anteriormente, obtém-se:

$$
\begin{gathered}
\tau_{b u} u \Delta x=\frac{\Delta M_{d}}{z} \\
\tau_{b u}=\frac{1}{u z} \frac{\Delta M_{d}}{\Delta x}=\frac{1}{u z} V_{1 d} \\
\therefore \quad V_{1 d}=0,9 d n \pi \phi \tau_{b u}
\end{gathered}
$$

Conforme estabelecido na equação 2.40 . 


\subsubsection{1 - Verificação da ancoragem por aderência na armadura inferior}

A verificação quanto à ancoragem das barras da armadura inferior, é feita para um esforço de tração avaliado na seção coincidente com o eixo da estaca mais afastada de $S_{1}$. Admite-se que nesta seção o esforço a ser ancorado é de cerca de oitenta por cento do esforço calculado na seção $S_{1}$, o que leva às expressões:

$$
R_{s t d 1}=\frac{0,8 R_{s t d}}{n}
$$

O esforço $\boldsymbol{R}_{\text {sd, }}$, pode ser obtido a partir do momento fletor que solicita a seção $S_{1}$, ou seja:

$$
R_{s t d}=\frac{M_{d}}{d}
$$

De acordo com a NBR 6118 $^{(\text {|as })}$, admitindo-se uma distribuição uniforme das tensões de aderência ao redor das barras, o comprimento de ancoragem reta $l_{b l}$, para cada barra, será dado por:

$$
I_{b 1}=\frac{\phi}{4} \frac{\sigma_{s d 1}}{\tau_{b u}}
$$

Este comprimento pode ser diminuído caso as barras sejam dobradas a partir da seção de ancoragem. Além disso, se a área efetiva da seção de armadura for maior que a calculada, a tensão nas barras diminui, podendo reduzir-se mais ainda o comprimento de ancoragem. 
Então, o comprimento de ancoragem, calculado segundo as prescrições da Norma Brasileira, é dado pela expressão:

$$
I_{b}=I_{b}^{*}-\Delta I_{b}
$$

onde $l_{b}{ }^{\circ}$ é o comprimento calculado levando-se em conta a diferença entre a área da seção de armadura efetiva e a área calculada, e $\Delta l_{b}$, a redução devida à presença de gancho na extremidade das barras, ou seja:

$$
I_{b}^{*}=\frac{\phi}{4} \frac{\sigma_{s d 1}}{\tau_{b u}} \frac{A_{s, c a l c}}{A_{s, \text { ef }}}
$$

$$
\Delta I_{b}=15 \phi, \text { para aços CA-40, CA-50 e CA-60 }
$$

Contudo, não se admite para $l_{b}$, valores menores que aqueles encontrados com a seguinte desigualdade:

$$
I_{b} \geq \frac{I_{b 1}}{3} \text { ou } 10 \mathrm{~cm}
$$




\section{3 - BLOCO SOBRE UMA ESTACA}

$\mathrm{Na}$ grande maioria dos estudos feitos até agora, são determinadas as tensões que provocam um fendilhamento do bloco, considerando-se para tanto uma idealização bi-dimensional do problema, conforme mostra a figura 2.13. Como exceção a esta regra, pode-se citar a solução analítica por série obtida por IYENGAR $^{107]}$ e a solução de GUYON $^{[08]}$, para prismas de seção quadrada.

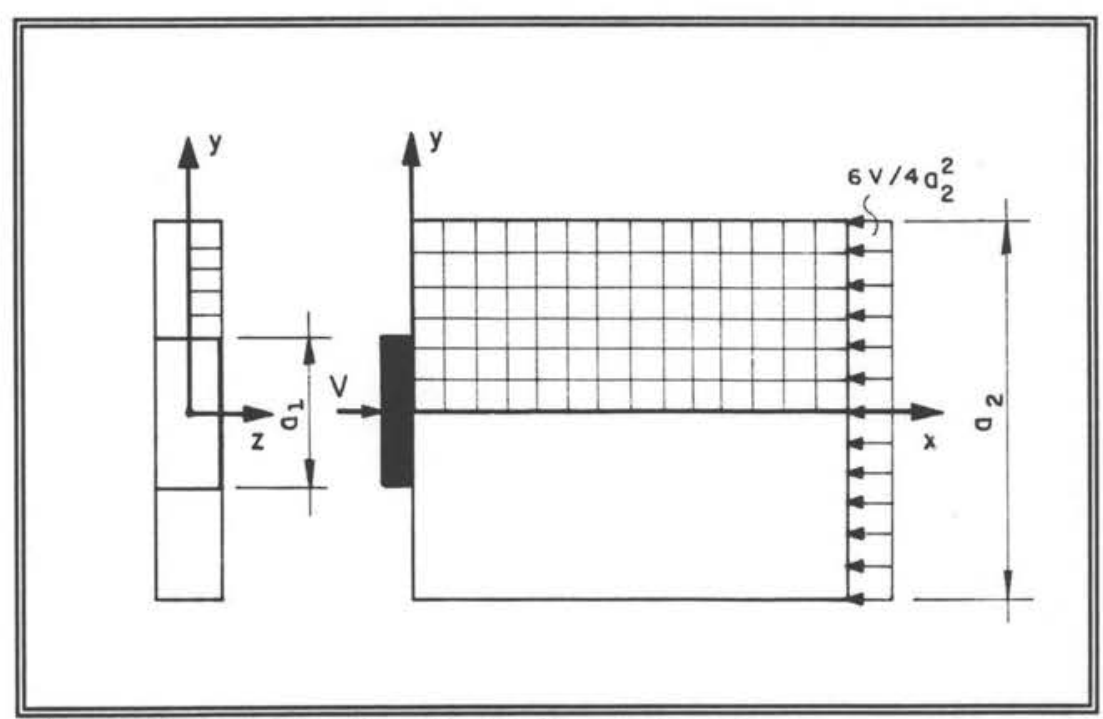

Figura 2.13 - Idealização bi-dimensional

Utilizando a idealização mostrada na figura anterior, YETTRAM $^{[091}$ compara a solução por elementos finitos com a solução analítica obtida por IYENGAR $^{\text {[07]: }}$ 
Tabela 2.1 - Esforço de fendilhamento

$$
F_{t} / N
$$
$a_{1} / a_{2}$
Elementos Finitos
Iyengar
0,2
0,192
0,198
0,5
0,117
0,114

Afortunadamente, as razões de concentração, $a_{1} / a_{2}$ menores que 0,2 não são geralmente encontradas na prática.

Dimensionando-se os blocos sobre uma estaca, para resistir ao esforço de fendilhamento, utilizando-se a formulação proposta por LANGENDONK $^{[10]}$, deve-se considerar desnecessária a utilização de armadura inferior, sendo recomendada apenas uma pequena quantidade de armadura nas faces laterais, para combater o esforço de fendilhamento que tende a surgir na iminência da ruptura, conforme mostra a figura a seguir:

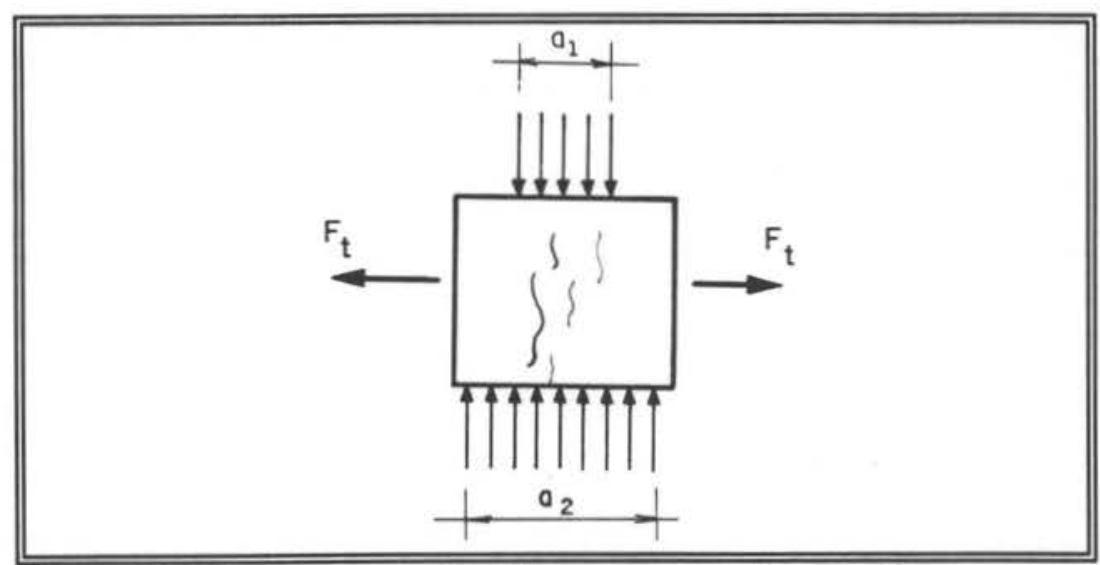

Figura 2.14 - Ruptura devido a esforços de tração. 
É comum adotar-se para blocos parcialmente carregados uma altura maior que a maior das suas dimensões em planta, preferindo-se geralmente, uma planta quadrada.

Segundo a NBR 6118 $^{[04]}$, a tensão na face de aplicação do carregamento, não deve exceder a :

$$
\sigma_{c u}=f_{c d} \sqrt[3]{\frac{A_{c}}{A_{0}}} \leq 2,1 \mathrm{kN} / \mathrm{cm}^{2}
$$

onde, $\quad \sigma_{c u} \quad$ : tensão máxima na face de introdução do carregamento;

$f_{c d}$ : resistência de cálculo do concreto à compressão;

$A_{c} \quad$ : área da seção transversal geométrica da peça;

$A_{o}$ : área da parte carregada de um bloco de apoio.

As tensões de tração e compressão que surgem num bloco, conforme a distribuição mostrada na figura 2.15 , podem ser calculadas igualando-se o momento das resultantes das forças atuando à esquerda do plano de simetria do bloco, com o momento provocado pelas resultantes das tensões. 


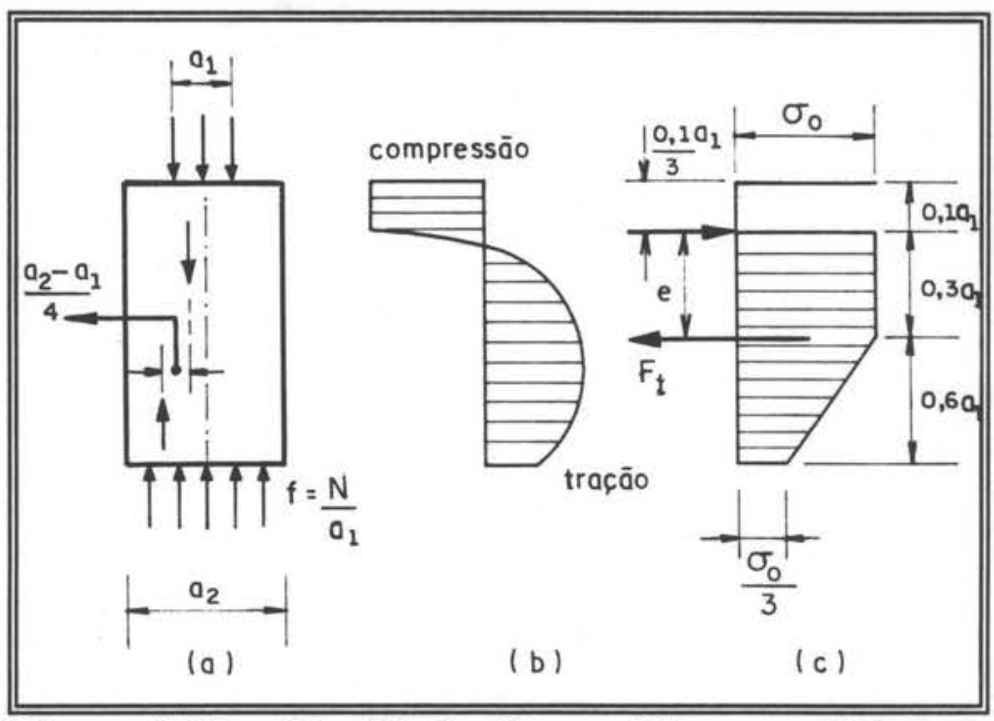

Figura 2.15 - Equilíbrio de um bloco parcialmente carregado.

Assim, chega-se à expressão:

$$
\frac{N}{2}\left(\frac{a_{2}-a_{1}}{4}\right)=f a_{1}\left(\frac{a_{2}-a_{1}}{8}\right)=F_{t} e
$$

Da figura 2.15c, obtem-se:

$$
e=\frac{0,9 \sigma_{0} a_{1}\left(0,45+\frac{0,2}{3}\right)-0,2 \sigma_{0} a_{1}\left(0,9-0,2+\frac{0,2}{3}\right)}{0,9 \sigma_{0}-0,2 \sigma_{0}}
$$

$$
\frac{e}{a_{1}}=\frac{0,9 \sigma_{0}\left(0,45+\frac{0,2}{3}\right)-0,2 \sigma_{0}\left(0,9-0,2+\frac{0,2}{3}\right)}{0,9 \sigma_{0}-0,2 \sigma_{0}}
$$


Levando-se o valor encontrado, $e / a_{1}=0,445$, na equação

2.47, obtém-se a seguinte equação:

$$
F_{t}=\frac{f a_{1}}{e}\left(\frac{a_{2}-a_{1}}{8}\right)=0,28 f\left(a_{2}-a_{1}\right) \quad(2.48)
$$

Mas, $\quad F_{t}=(0,9-0,2) \sigma_{0} a_{2}=0,7 \sigma_{0} a_{2}$

Donde se conclui que:

$$
\sigma_{0}=\frac{0,28 f\left(a_{2}-a_{1}\right)}{0,7 a_{2}}=0,40 f \frac{a_{2}-a_{1}}{a_{2}} \quad(2.49)
$$

onde, $\sigma_{o}$ : ordenada do diagrama de distribuição de tensões na face de aplicação do carregamento;

$f$ : ação aplicada por unidade de largura $\left(N / a_{1}\right)$;

$a_{2}$ : largura da região de apoio ( largura da estaca );

$a_{1}$ : largura da região de introdução do carregamento. 


\section{3 - DIMENSIONAMENTO DOS PROTÓTIPOS}

\section{1 - CONSIDERAÇÕES INICIAIS}

Conforme foi mostrado no capítulo precedente, há dois processos de cálculo mais comumente empregados no dimensionamento de blocos de coroamento de grupos de estacas. Então, para obter-se as armaduras principais de tração destes blocos, pode-se empregar:

1 - Método das bielas comprimidas (simplificado);

2 - Método de flexão de vigas. 
Neste capítulo, são apresentados os cálculos envolvidos na determinação das dimensões dos protótipos, bem como, das seções das armaduras necessárias.

Para o caso de blocos sobre uma única estaca, foram empregadas as expressões obtidas por LANGENDONK ${ }^{[10]}$ em seu estudo sobre blocos de apoio parcialmente carregados.

Dentre os dois métodos aqui citados, o método de dimensionamento à flexão oferece recomendações mais completas quanto ao detalhamento das armaduras. Por este motivo, as quantidades obtidas com este método foram adotadas na montagem das armaduras dos protótipos.

Como não era desejada a ruptura dos blocos de coroamento, em virtude da necessidade de se acompanhar o comportamento das estacas até a ruptura da sua ligação com o solo, as ações consideradas no cálculo dos mesmos foram majoradas em trinta por cento. Este valor, foi recomendado pela equipe do Departamento de Geotecnia ( SGS ) - EESC, responsável pelas estacas.

\section{2 - BLOCO SOBRE UMA ESTACA}

Para o protótipo desta pesquisa, tem-se os seguintes dados:

- dimensões do pilar: $200 \mathrm{~mm} \times 200 \mathrm{~mm}$;

- diâmetro da estaca ( broca ): $\phi=250 \mathrm{~mm}$;

- ação nominal: $N_{k}=120 k N$;

- resistência característica do concreto dos blocos: $f_{c k}=18 \mathrm{MPa}$;

- dimensões do bloco:

altura: $h=500 \mathrm{~mm}$;

seção transversal horizontal: $550 \mathrm{~mm} \times 550 \mathrm{~mm}$ 
A altura do bloco deve obedecer à restrição imposta pela condição:

$$
H \geq 1,5\left(a_{2}-a_{1}\right)
$$

$$
\Rightarrow \quad H \geq 1,5(250-200)=75 \mathrm{~mm}
$$

Logo, a altura adotada é satisfatória.

A ação a ser considerada no dimensionamento consiste na ação nominal acrescida do peso próprio e majorada em $30 \%$ e $40 \%$, sucessivamente. Assim:

$$
\begin{aligned}
& N_{d}=(120+4) 1,3 \times 1,4=226 \mathrm{kN} \\
& f=\frac{N_{d}}{a_{1}}=\frac{226}{20}=11,3 \mathrm{kN} / \mathrm{cm}
\end{aligned}
$$

Empregando-se as equações 2.49 e 2.48 , pode-se concluir sobre a necessidade ou não de armar este bloco, assim como, qual o esforço que a armadura deverá suportar. Então:

$$
\sigma_{0}=0,40 \cdot 11,3 \cdot \frac{(25-20)}{25}=0,9 \mathrm{kN} / \mathrm{cm}^{2}
$$


Sendo a força que tende a provocar o fendilhamento deste bloco igual a:

$$
F_{t d}=0,28 \cdot 11,3 \cdot(25-20)=15,8 \mathrm{kN}
$$

a área da seção tranversal de armadura necessária será: $A_{s}=\frac{F_{t d}}{f_{y d}}$

onde, $\boldsymbol{A}_{s}$ : área da seção transversal da armadura;

$\boldsymbol{F}_{t d}:$ solicitação de tração;

$f_{y d}$ : resistência de escoamento de cálculo do aço.

Como foi utilizado aço CA-50 A, obtém-se o seguinte resultado:

$$
\begin{aligned}
& A_{s}=\frac{15,8 \cdot 1,15}{50}=0,36 \mathrm{~cm}^{2} \\
& \frac{N_{d}}{a_{1}{ }^{2}}=0,57 \mathrm{kN} / \mathrm{cm}^{2}, \quad \text { menor que } \sigma_{c u}, \text { pois: } \\
& \sigma_{c u}=\frac{1,8}{1,4} \sqrt[3]{\frac{3025}{400}}=2,52 \mathrm{kN} / \mathrm{cm}^{2}
\end{aligned}
$$


A pressão que o bloco transmite à estaca é perfeitamente suportada pela mesma. As armaduras adotadas para este bloco, com base nestes cálculos, foi então:

- armadura horizontal: três barras com diâmetro $\phi=8 \mathrm{~mm}$

- armadura vertical: quatro barras com diâmetro $\phi=8 \mathrm{~mm}$

dispostas conforme mostrado nas figuras do Anexo B. 


\section{3 - BLOCOS SOBRE GRUPOS DE ESTACAS}

\subsection{1 - MÉTODO DE DIMENSIONAMENTO À FLEXÃO}

Para estes blocos, tendo sido adotadas alturas constantes, a armadura inferior (principal), é calculada utilizando-se a expressão:

$$
A_{s}=k_{s} \frac{M_{d}}{d}
$$

onde, $\boldsymbol{A}_{s}$ : área da seção transversal da armadura;

$M_{d}$ : esforço solicitante (momento fletor de cálculo);

d : altura útil do bloco;

$\boldsymbol{k}_{s}$ : coeficiente obtido da tabela para o dimensionamento à flexão simples, extraída da publicação "Tabelas e Ábacos" feita por PINHEIRO ${ }^{[0 ๘]}$.

A ação vertical atuando sobre os blocos foi obtida a partir da consideração de que as estacas do tipo broca foram especificadas com um valor para $N_{u}$ igual a $120 \mathrm{kN}$, diâmetro igual a $250 \mathrm{~mm}$ e espaçamento entre estacas de $3 \phi$.

Por exemplo, para o bloco sobre quatro estacas obteve-se, conforme estimativa do professor José C. A. Cintra, a ação máxima suportada pelas estacas:

$$
\begin{aligned}
& N_{u, \text { grupo }}=n \cdot N_{u, \text { individual }} \cdot \text { eficiência } \\
& N_{u, \text { grupo }}=4 \cdot 120 \cdot 1,3=624 \mathrm{kN}
\end{aligned}
$$


Assim, o bloco para um grupo de quatro estacas foi dimensionado para suportar, no máximo, uma ação de aproximadamente $800 \mathrm{kN}$, sendo computado neste número o acréscimo devido à participação do bloco no equilíbrio do conjunto, calculado a partir de uma tensão no solo $\sigma_{\text {swo }}=120 \mathrm{kN} / \mathrm{m}^{2}$ ou seja:

$$
N_{u, 4}=800 \mathrm{kN}
$$

Para os demais casos, obteve-se:

$$
\begin{aligned}
& N_{u, 1}=120 \mathrm{kN}-\text { bloco sobre uma estaca; } \\
& N_{u, 2}=340 \mathrm{kN} \text { - bloco sobre duas estacas; } \\
& N_{u, 3 T}=590 \mathrm{kN} \text { - bloco sobre três estacas }
\end{aligned}
$$

dispostas segundo um triângulo;

$$
N_{u, 3 L}=510 \mathrm{kN} \text { - bloco sobre três estacas }
$$

dispostas em linha.

A figura 2.10 mostra como é definida a posição da seção transversal $S_{1}$, onde se considera atuando o momento fletor de cálculo $M_{d}$, assim como, o significado da altura útil $d$ :

O comprimento de ancoragem , é medido a partir da linha de centro da estaca mais afastada do pilar. 


\subsubsection{1 - Bloco sobre duas estacas}

Das condições requeridas no ítem 3.3.1, chega-se às dimensões do bloco e às demais informações necessárias ao cálculo da armadura, ou seja:

- dimensões do pilar: $200 \mathrm{~mm} \times 300 \mathrm{~mm}$;

- diâmetro das estacas: $250 \mathrm{~mm}$;

$-N_{k}=340 k N$.

a) Geometria do bloco:

$$
\begin{aligned}
& c=375-100=275 \mathrm{~mm} \\
& h \geq 275 / 1,5=183 \mathrm{~mm} \\
& h \leq 2.275=550 \mathrm{~mm}
\end{aligned}
$$

Adotou-se $h=500 \mathrm{~mm}$ e $d=400 \mathrm{~mm}$, o que permite que se calcule o peso próprio, da maneira que segue:

$$
p p \simeq 0,55(0,50 \cdot 1,30) 25 \simeq 9 \mathrm{kN}
$$

Somando-se então o peso próprio e a ação vertical $N_{k}$ e dividindo-se o resultado por 2 , obtém-se a reação de cada estaca $\boldsymbol{V}_{\boldsymbol{k}}$ :

$$
V_{k}=\frac{1}{2}(9+340) \cdot 1,3 \simeq 226 \mathrm{kN}
$$




\section{b) Cálculo da armadura inferior:}

A distância de $V_{k}$ até a seção de referência $S_{1}$ será:

$$
0,15 \cdot 200+275=303 \mathrm{~mm}
$$

O que permite o cálculo do momento fletor naquela seção, resultando em:

$$
M_{k}=226 \cdot 30,3=6848 \mathrm{kNCm}
$$

Majorando-se esta solicitação com um coeficiente $\gamma_{f}$ (ver NB $\left.5^{[11]}\right)$ igual a 1,4 , obtém-se o momento fletor de cálculo $\boldsymbol{M}_{d}$ :

$$
M_{d}=1,4 \cdot 6848=9587 \mathrm{kNCm}
$$

Consultando-se as tabelas elaboradas por PINHEIRO ${ }^{100}$, obtém-se para $\boldsymbol{b}_{w}=\mathbf{5 5 0} \mathbf{m m}$ os seguintes valores para $\boldsymbol{k}_{c}$ e $\boldsymbol{k}_{s}$ :

$$
\begin{aligned}
& k_{c}=\frac{b_{w} \cdot d^{2}}{M_{d}}=\frac{55 \cdot 40^{2}}{9587}=9,18>k_{c, 1 \text { im }}=3,0 \\
& \rightarrow \quad k_{s}=0,024
\end{aligned}
$$$$
\text { Como } A_{s}=k_{s} \frac{M_{d}}{d} \text {, }
$$ 


$$
A_{s}=0,024 \frac{95,87}{0,40}=5,75 \mathrm{~cm}^{2} \quad(5 \phi 12,5 \mathrm{~mm})
$$

c) Verificação quanto ao esforço cortante:

$$
\begin{aligned}
& b_{2}=d+b=400+300=700>b_{d i s p}=500 \mathrm{~mm} \\
& d_{2}=d=400 \mathrm{~mm}
\end{aligned}
$$

Considerando como esforço cortante de cálculo, $V_{d}$, pode-se dizer que:

$$
V_{d}=1,4 . V_{k}=1,4 \cdot 226=316 \mathrm{kN}
$$

Como $b_{2}$ e $d_{2}$ são as dimensões da seção de referência $S_{2}$, na qual o esforço cortante calculado deve ser menor que $V_{u}$, que por sua vez é obtido a partir da aplicação da equação 2.39 , substituindo-se na referida equação os valores dados encontra-se:

$$
V_{u}=\frac{1}{1,4} \cdot 0,25\left(1-\frac{27,5}{5,40}\right) 55 \cdot 40 \sqrt{1,80}=454 \mathrm{kN}
$$

d) Verificação de aderência da armadura:

Utilizando-se a equação 2.40 , calcula-se o valor do esforço cortante devido às tensões de aderência: 


$$
V_{1 d} \leq 47(n \phi)=47 \cdot 5 \cdot 1,25=294 \mathrm{kN}
$$

Considera-se satisfatório o valor assim encontrado, apesar de não atender de forma plena a condição que garante a aderência entre as barras da armadura e o concreto, expressa por:

$$
V_{1 d}=V_{d} \leq V_{1 u}
$$

\section{e) Dimensionamento de armaduras adicionais:}

O cálculo da armadura superior, é feito por meio do critério estabelecido em 2.2.1.1, o que resulta em:

$$
A_{s, \text { sec }}=0,10 A_{s}=0,10 \cdot 6,15=0,61 \mathrm{~cm}^{2}
$$

Tendo-se adotado $2 \phi 8 \mathrm{~mm}$.

Para calcular a armadura lateral, disposta como malha, foi utilizada a expressão 2.36, própria para o caso em que se utilizem barras corrugadas. Assim:

$$
A_{s 1}=0,0020 b^{\prime} t
$$

onde, $\boldsymbol{t}$ é o espaçamento entre as barras e $b$ 'deve ser maior que a metade da altura do bloco, sendo adotada, nos casos em que esta condição não é satisfeita, como sendo $b^{\prime}=h / 2$. Chega-se então a:

$$
A_{s 1}=0,0020 \cdot 25 \cdot 100=5,00 \mathrm{~cm}^{2} / \mathrm{m}
$$


O que leva a adotar-se $2 \phi 8,0 @ 10 \mathrm{~cm}$.

\section{f) Verificação da ancoragem:}

Considerando que o esforço a ancorar corresponde a oitenta por cento do esforço $\boldsymbol{R}_{s d}$, resistido pelas barras da armadura inferior, situadas dentro da faixa de largura $3 \phi$, na seção $S_{1}$, conforme determinado no ítem 2.2.3.1. Pode-se então escrever:

$$
R_{s t d}=\frac{M_{d}}{d}=\frac{95,87}{0,40} \approx 240 \mathrm{kN}
$$

donde, $0,8 R_{a d}=192 \mathrm{kN}$.

A tensão em cada barra será dada pela divisão do esforço de ancoragem por barra, pela área de uma barra:

$$
R_{s t 1 d}=\frac{192}{5}=38,4 \mathrm{kN} / \text { barra }
$$

Sendo $A_{s l} \approx 1,23$, a área da seção transversal de uma única barra com diâmetro $\phi=12,5 \mathrm{~mm}$, chega-se a:

$$
\sigma_{s d 1}=\frac{38,4}{1,23}=31,2 \mathrm{kN} / \mathrm{cm}^{2}
$$

Assim, de acordo com a expressão 2.43, o comprimento de ancoragem pode ser cálculado da maneira que segue: 


$$
I_{b 1}=\frac{\phi}{4} \frac{\sigma_{s d 1}}{\tau_{b u}}=\frac{1,25}{4} \frac{31,2}{0,41} \approx 24 \mathrm{~cm}
$$

Considerando a equação 2.45 , vem:

$$
I_{b}^{*}=I_{b 1} \frac{A_{s, \text { calc }}}{A_{s, \text { ef }}}=24 \frac{6,15}{5,75} \approx 26 \mathrm{~cm}
$$

Além disso, adotando-se $\Delta l_{b}=15 \phi$, na equação 2.44 , obtém-se o comprimento de ancoragem :

$$
I_{b}=I_{b}^{*}-\Delta I_{b}=26-15 \cdot 1,25 \approx 7 \mathrm{~cm}
$$

Entretanto, para que seja obedecida a condição estabelecida em pela expressão 2.46, deve-se adotar: $I_{b}=10 \mathrm{~cm}$. 


\subsubsection{2 - Bloco sobre três estacas ( dispostas em linha )}

Analogamente ao que foi feito no caso do bloco sobre duas estacas, inicialmente determina-se as informações necessárias ao dimensionamento deste bloco, de forma que sejam obedecidas as condições estabelecidas no ítem 3.3. Assim:

- dimensões do pilar: $350 \mathrm{~mm} \times 350 \mathrm{~mm}$;

- diâmetro das estacas: $250 \mathrm{~mm}$;

$-N_{k}=510 k N$.

a) Geometria do bloco:

Conforme ilustra a figura 3.1 , as dimensões que interferem no cálculo deste bloco ficam determinadas da seguinte maneira:

$$
\begin{aligned}
& c=750-175=575 \mathrm{~mm} \\
& h \geq 575 / 1,5=383 \mathrm{~mm} \\
& h<2.575=1150 \mathrm{~mm}
\end{aligned}
$$

Além disso, a altura útil do bloco deve obedecer à condição:

$$
\begin{aligned}
& d<1,5.575=862 \mathrm{~mm}, \text { o que leva a: } \\
& d=700 \mathrm{~mm} \text { e } h=800 \mathrm{~mm} .
\end{aligned}
$$




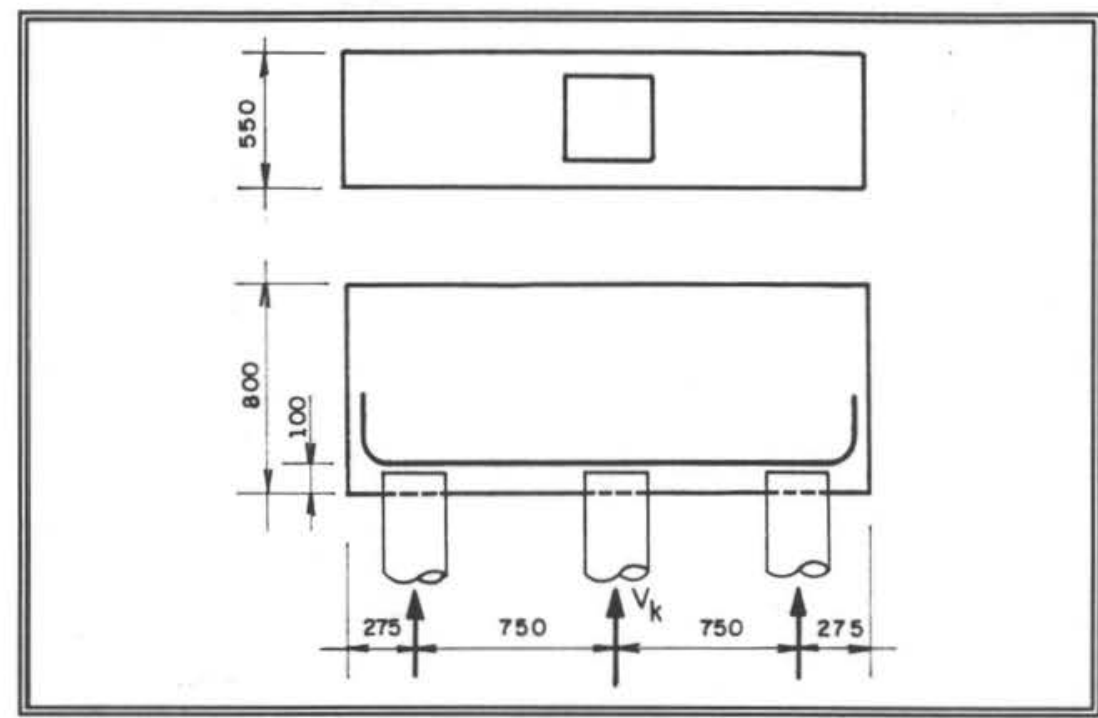

Figura 3.1 - Geometria do bloco sobre três estacas.

O peso próprio pode ser obtido multiplicando-se o volume do bloco pelo peso específico do concreto, ou seja:

$$
p p=0,55(0,80 \cdot 2,05) 25=23 \mathrm{kN}
$$

Dividindo-se por três a soma do peso próprio com a ação vertical $N_{k}$, obtém-se a reação em cada estaca, igual à força cortante $V_{k}$ atuante na seção de referência $S_{\text {, }}$.

$$
V_{k}=\frac{1}{3}(23+510) 1,3=231 \mathrm{kN}
$$

b) Dimensionamento da armadura inferior:

A distância entre a seção de referência $S_{1}$, e a estaca mais afastada da mesma será: 
$0,15 \cdot 350+575=630 \mathrm{~mm}$

Calculando-se então o momento fletor, chega-se a:

$$
M_{k}=231 \cdot 63=14553 \mathrm{kNCm}
$$

que majorado pelo coeficiente $\gamma_{f}=1,4$, fornece:

$$
M_{d}=1,4 \cdot 14553=20374 \mathrm{kNCm}
$$

Considerando-se a seção resistente com largura igual a $550 \mathrm{~mm}$, e, utilizando as tabelas de PINHEIRO ${ }^{106}$, obtém-se o seguinte cálculo:

$$
k_{c}=\frac{55 \cdot 70^{2}}{20374}=13,23>k_{c, 1 \text { im }}
$$

$\rightarrow \quad k_{s}=0,24$

Assim, $A_{s}=0,024 \frac{203,74}{0,70}=6,98 \mathrm{~cm}^{2}$, que pode ser atendida com uma das opções a seguir:

$$
\begin{aligned}
& 4 \phi 16 \mathrm{~mm}\left(A_{s, j}=8 \mathrm{~cm}^{2}\right) ; \\
& 6 \phi 12,5 \mathrm{~mm}\left(A_{s, s}=7,50 \mathrm{~cm}^{2}\right) .
\end{aligned}
$$


c) Verificação quanto ao esforço cortante:

Calculando-se o esforço cortante máximo admitido na seção de referência $S_{2}$, de maneira análoga ao que foi feito para o caso do bloco sobre duas estacas, chega-se a:

$$
b_{2}=b+d=350+700=1050>b_{\text {disp }}=550 \mathrm{~mm}
$$

o que leva à adoção de $b_{2}=550 \mathrm{~mm}$;

Aplicando-se estes dados à equação 2.39, pode-se escrever:

$$
V_{u}=\frac{1}{1,4} \cdot 0,25\left(1-\frac{57,5}{5 \cdot 70}\right) 55 \cdot 70 \sqrt{1,80}=770 \mathrm{kN}
$$

Donde se conclui que o esforço cortante $V_{d}=323 k N$, é aceitável.

d) Verificação quanto à aderência das armaduras:

Para verificar se a condição $V_{l d}<V_{l u}$, inicialmente calcula-se o valor de $V_{l u}$, servindo-se para tanto da expressão 2.40 :

$$
V_{1 d}=0,9 d \pi(n \phi) \tau_{b u}=81(n \phi)
$$


Para as duas opções de armadura encontradas, a condição dada anteriormente é satisfeita pois:

$$
\begin{aligned}
& V_{\text {ld }}=81 \cdot 4 \cdot 1,6=518 \mathrm{kN} ; \\
& V_{\text {ld }}=81 \cdot 6 \cdot 1,25=607 \mathrm{kN} .
\end{aligned}
$$

Na execução do protótipo adotou-se para a armadura inferior, $4 \phi$ $16 \mathbf{m m}$, o que corresponde a uma área efetiva da seção transversal igual a $8 \mathbf{c m}^{2}$.

e) Armaduras adicionais:

Para a obtenção da armadura superior, admitindo-a como sendo dez por cento da área de armadura principal (inferior longitudinal) chega-se ao seguinte cálculo:

$$
A_{s, \mathrm{sec}}=0,10 \cdot 8=0,8 \mathrm{~cm}^{2} \quad(2 \phi 8 \mathrm{~mm})
$$

A armadura lateral em forma de malha, calculada utilizando-se a equação 2.36, será:

$$
A_{s, 1}=0,0020 \cdot 40.100=8 \mathrm{~cm}^{2} / \mathrm{m} \quad(\phi 8 \text { @ } 10 \mathrm{~cm})
$$




\section{f) Cálculo do comprimento de ancoragem:}

O esforço resistido pela armadura principal na seção $S_{l}$, será:

$$
R_{s t d}=\frac{M_{d}}{d}=\frac{203,74}{0,70} \approx 291 \mathrm{kN}
$$

O esforço a ser ancorado, por barra, é dado por:

$$
R_{s t d 1}=\frac{0,8 R_{s t d}}{n}=\frac{0,8 \cdot 291}{4}=58 \mathrm{kN} / \text { barra }
$$

Resultando num valor de tensão normal para cada barra igual a:

$$
\sigma_{s d 1}=\frac{58}{2,00}=29 \mathrm{kN} / \mathrm{cm}^{2}
$$

Pode-se calcular o comprimento de ancoragem, utilizando a equação

2.44:

$$
I_{b}=\frac{\phi}{4} \frac{\sigma_{s d 1}}{\tau_{b u}} \frac{A_{s, c a l c}}{A_{s, \text { ef }}}-\Delta I_{b} \approx 0 \mathrm{~cm}
$$

Adotando-se então, $l_{b}=10 \mathrm{~cm}$. 
3.3.1.3 - Bloco sobre três estacas ( disposição triangular )

São conhecidos os seguintes dados:

- dimensões do pilar: $200 \mathrm{~mm} \times 350 \mathrm{~mm}$;

- diâmetro da estaca: $250 \mathrm{~mm}$;

- ação vertical máxima: $N_{k}=590 k N$.

a) Geometria do bloco:

As dimensões do bloco, são determinadas de acordo com as restrições impostas em 3.3, conforme pode ser visto na figura 3.2. Assim:

$$
\begin{aligned}
& C=433-175=258 \mathrm{~mm} ; \\
& h \leq 2.260=520 \mathrm{~mm} ; \\
& h>260 / 1,5=173 \mathrm{~mm} .
\end{aligned}
$$

Além disso, tem-se a seguinte condição a ser satisfeita pela altura útil do bloco:

$$
d<1,5.260=390 \mathrm{~mm}
$$

Foram então adotados os valores:

$$
\begin{aligned}
& d=400 \mathrm{~mm} ; \\
& h=500 \mathrm{~mm} .
\end{aligned}
$$


O esforço cortante na seção de referência $S_{1}$, é tomado igual à reação nas estacas situadas à direita da mesma, sendo dado por:

$$
p p=0,5\left[\left(\frac{1,70 \cdot 1,47}{2}\right)-3 \cdot 0,042\right] 25=14 \mathrm{kN}
$$

Considerando-se então o peso próprio do bloco no cálculo da reação $V_{k}$, obtém-se o seguinte resultado:

$$
V_{k}=\frac{1}{3}(14+590) 1,3=262 k N
$$

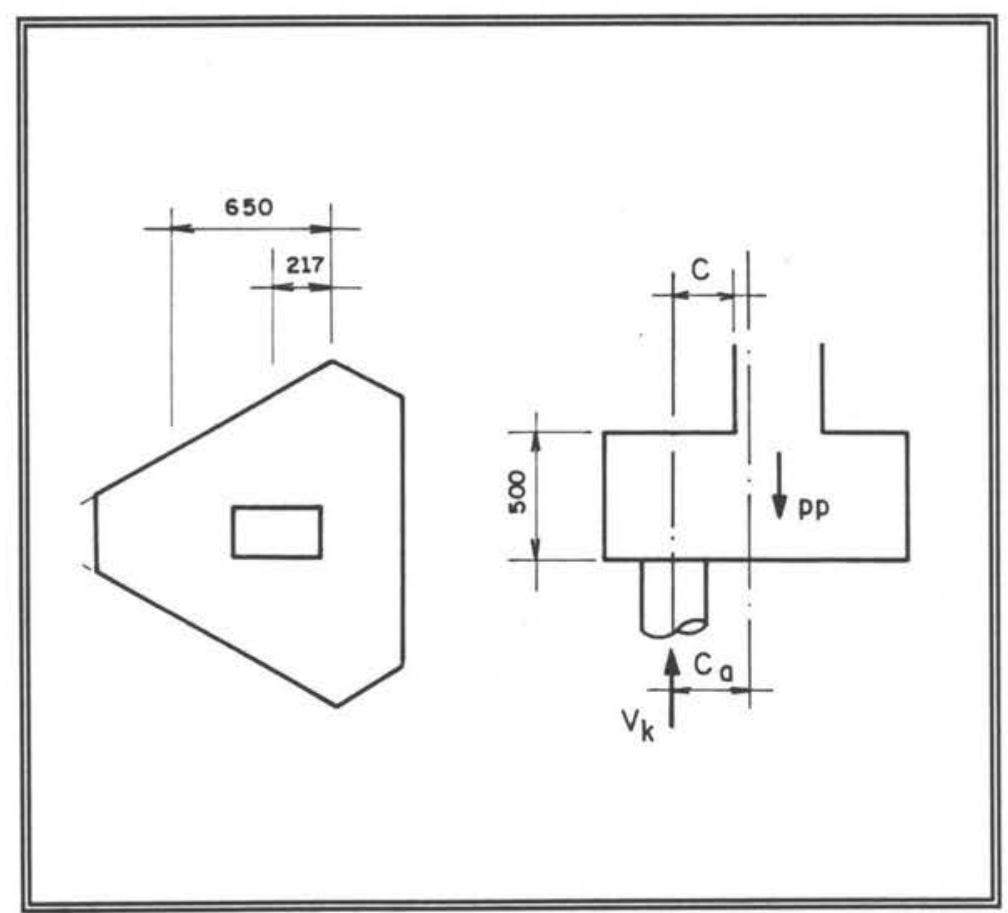

Figura 3.2 - Bloco sobre três estacas ( triangular ). 


\section{b) Cálculo da armadura inferior:}

Para o cálculo da armadura inferior, inicialmente determina-se a posição da seção de referência $S_{1}$, na qual considera-se aplicado o momento fletor $\boldsymbol{M}_{\boldsymbol{d}}$, com o qual a armadura é determinada, ou seja:

A equação 2.33 estabelece que: $\quad C_{a}=C+0,15 a$

$$
\therefore \quad C_{a}=260+0,15 \cdot 350=313 \mathrm{~mm}
$$

Calculando-se então o esforço $\boldsymbol{M}_{\boldsymbol{k}}$, obtém-se:

$$
\begin{aligned}
& M_{k}=262 \cdot 31,3=8200 \mathrm{kNCm} \\
& M_{d}=\gamma_{f} \cdot M_{k}=1,4 \cdot 8200=11480 \mathrm{kNCm}
\end{aligned}
$$

Considerando $b_{w}=550 \mathrm{~mm}$, a largura da seção resistente,

encontra-se com a utilização das tabelas:

$$
k_{c}=\frac{55 \cdot 40^{2}}{11480}=7,67>k_{c, 1 \mathrm{~m}}
$$

$$
\rightarrow \quad k_{s}=0,025
$$


Assim, $\quad A_{s}=0,025 \frac{114,80}{0,40}=7,17 \mathrm{~cm}^{2}$

Projetando na direção que une as cabeças das estacas, a armadura inferior, segundo cada lateral do bloco, será constituída por:

$$
A_{s, p r o j}=\frac{A_{s}}{2 \cos \frac{\pi}{6}}=4,14 \mathrm{~cm}^{2} \quad(4 \phi 12,5 \mathrm{~mm})
$$

c) Verificação do esforço cortante:

Calculando as dimensões da seção de referência $S_{2}$, obedecendo as recomendações apresentadas no ítem 2.2.2, chega-se a:

$$
\begin{aligned}
& b_{2}=d+b=400+550=950 \mathrm{~mm} \\
& b_{2, \text { disp }}=700 \mathrm{~mm} \\
& d_{2}=d=400 \mathrm{~mm} \\
& V_{d}=1,4 . V_{k}=1,4 \cdot 262=367 \mathrm{kN} \\
& V_{u}=\frac{1}{1,4} 0,2\left(1-\frac{26}{5,40}\right) 70.40 \sqrt{1,80}=584 \mathrm{kN}
\end{aligned}
$$

Como $V_{d}<V_{u}$, este bloco satisfaz as condições para resistência ao esforço cortante. 
d) Aderência da armadura:

Calculando-se $\mathbf{V}_{1 u}$, por intermédio da expressão 2.40 , obtém-se os seguintes resultados:

$$
V_{1 d}=V_{d} \leq 47(n \phi)=47 \cdot 4 \cdot 1,25=235 \mathrm{kN}
$$

Como a armadura adotada não é suficiente para satisfazer às condições de aderência, deve-se aumentar a quantidade de barras, ficando, no caso de se continuar com o diâmetro das barras igual a $12,5 \mathrm{~mm}$ :

$$
(7 \phi 12,5 \mathrm{~mm}) \quad \rightarrow \quad V_{1 u}=411 \mathrm{kN}>V_{d}
$$

e) Armaduras adicionais:

$$
\begin{aligned}
& \text { Armadura superior }\left(\boldsymbol{A}_{s, s e c}\right) \text { : } \\
& A_{s, \text { sec }}=0,10 \cdot 8,75=0,9 \mathrm{~cm}^{2} \quad(2 \phi 8 \mathrm{~mm}) \\
& \text { Armadura lateral em malha }\left(\boldsymbol{A}_{s, 1}\right) \text { : } \\
& A_{s, 1}=5,00 \mathrm{~cm}^{2} / \mathrm{m} \quad(\phi 8,0 \text { @ } 10 \mathrm{~cm})
\end{aligned}
$$




\section{f) Ancoragem:}

O esforço de tração máximo que pode ser resistido pela armadura na seção de referência $S_{1}$ é:

$$
R_{s t d}=\frac{M_{d}}{d}=\frac{114,80}{0,40} \approx 287 \mathrm{kN} \text {, com o qual se calcula o }
$$

esforço de tração por barra, a ser ancorado a partir do eixo da estaca, servindo-se para isto da equação 2.41 :

$$
R_{\text {std1 }}=\frac{0,8 \cdot 287}{7}=32,8 \mathrm{kN} / \text { barra }
$$

Com este resultado, chega-se então à tensão normal em uma barra e, consequentemente, ao comprimento de ancoragem $l_{b}$ :

$$
\begin{aligned}
& \sigma_{s d 1}=\frac{32,8}{1,23}=26,67 \mathrm{kN} / \mathrm{cm}^{2} \\
& I_{b}{ }^{*}=\frac{\phi}{4} \frac{\sigma_{s d}}{\tau_{b u}} \frac{A_{s, c a l c}}{A_{s, \text { ef }}}=\frac{1,25}{4} \frac{26,67}{0,41} \frac{7,17}{8,61} \approx 17 \mathrm{~cm}
\end{aligned}
$$

Utilizando-se a equação 2.44 , calcula-se então:

$$
I_{b}=17-15 \cdot 1,25=-1,7 \mathrm{~cm} \rightarrow I_{b, \text { adot }}=10 \mathrm{~cm}
$$




\subsubsection{4 - Bloco sobre quatro estacas}

O bloco sobre quatro estacas foi dimensionado com a consideração dos dados:

- dimensões do pilar: $350 \mathrm{~mm} \times 350 \mathrm{~mm}$;

- diâmetro das estacas: $\phi=250 \mathrm{~mm}$;

- ação vertical: $N_{k}=800 k N$.

\section{a) Geometria do bloco:}

A seguir, são estabelecidas as condições para a escolha da altura do bloco, quais sejam:

$$
\begin{aligned}
& C=280 \mathrm{~mm} ; \\
& h \leq 2 . C=2.280=560 \mathrm{~mm} ; \\
& h>C / 1,5=280 / 1,5=187 \mathrm{~mm} ; \\
& d<1,5 . C=1,5.280=420 \mathrm{~mm} .
\end{aligned}
$$

A reação em cada estaca, utilizada na obtenção do momento fletor na seção de referência, pode ser encontrada somando-se o peso próprio do bloco com a ação vertical máxima admitida e dividindo-se este resultado pelo numero de estacas. Por esta via:

$$
\begin{aligned}
& p p=0,5(1,30 \cdot 1,30) 25=21 \mathrm{kN} \\
& V_{k}=\frac{1}{4}(21+800) 1.3=267 \mathrm{kN}
\end{aligned}
$$


b) Cálculo da armadura inferior:

Calculando a distância $C_{a}$, utilizando a equação 2.33 , chega-se a:

$c_{a}=c+0,15$ a sendo que, $\boldsymbol{a}$ é obtido fazendo-se:

$a=\sqrt{350^{2}+350^{2}}=500 \mathrm{~mm}$

assim,

$C_{a}=280+0,15 \cdot 500=355 \mathrm{~cm}$

Então, o momento fletor será:

$$
M_{k}=V_{k} \cdot C_{a}=267.35,5=9478 \mathrm{kNCm} .
$$

Multiplicado por $\gamma_{s}=1,4$, resulta no valor do momento fletor de cálculo:

$$
M_{d}=\gamma_{f} \cdot M_{k}=1,4 \cdot 9478=13269 \mathrm{kNCm}
$$

Fazendo-se $\quad b_{w}=a+2 d^{\prime}=500+2.100=700 \mathrm{~mm}, \mathrm{e}$

utilizando as tabelas de PINHEIRO ${ }^{106]}$ :

$$
k_{c}=\frac{70 \cdot 40^{2}}{13269}=8,44>k_{c, 1 \text { im }} \Rightarrow k_{s}=0,024
$$


Então, calcula-se a área da seção de armadura:

$$
A_{s}=k_{s} \cdot \frac{M_{d}}{d}=0,024 \cdot \frac{132,69}{0,40}=7,96 \mathrm{~cm}^{2}
$$

que projetada na direção da lateral do bloco resulta em:

$$
\begin{gathered}
A_{s, 1 a t}=\frac{A_{s}}{2 \cos \left(\frac{\pi}{4}\right)}=\frac{7,96}{2 \times 0,707}=5,63 \mathrm{~cm}^{2} \\
\left(3 \phi 16 \mathrm{~mm} \rightarrow A_{s, \text { ef }}=6,03 \mathrm{~cm}^{2}\right)
\end{gathered}
$$

c) Verificação do esforço cortante:

A seção de referência $S_{2}$, terá suas dimensões dadas pelas equações enunciadas no ítem 2.2.2:

$$
\begin{aligned}
& b_{2}=b+d=350+400=750 \mathrm{~mm}<b_{d i s p} \\
& d_{2}=d=400 \mathrm{~mm}
\end{aligned}
$$




$$
\begin{gathered}
V_{u}=\frac{1}{1,4} \cdot 0,25\left(1-\frac{28}{5.40}\right) 75 \cdot 40 \sqrt{1,80} \rightarrow \\
\rightarrow \quad V_{u}=618 \mathrm{kN}>V_{d}=1,4.267=374 \mathrm{kN}
\end{gathered}
$$

d) Verificação quanto à aderência:

Calculando o valor de $V_{l d}$, e comparando-o com $V_{d}$, pode-se chegar ao diâmetro e quantidade de barras tais que a condição de aderência estabelecida no ítem 2.2.3 seja obedecida. Desta forma:

$$
V_{1 d} \leq 47(n \phi) \text {, que com a substituição dos valores de } n \text { e }
$$

$\phi$, resulta em:

$$
\begin{aligned}
& V_{1 d} \leq 47 \cdot 4 \cdot 1,60=301 \mathrm{kN} \text { ou, } \\
& V_{1 d} \leq 47 \cdot 5 \cdot 1,60=376 \mathrm{kN}
\end{aligned}
$$

este sendo um valor aceitável, uma vez que $V_{d}=374 \mathrm{kN}$.

Logo a armadura inferior, disposta segundo a direção das laterais do bloco, que atende às condições impostas será:

$$
\left(5 \phi 16 \mathrm{~mm} \Rightarrow A_{s, s}=10,05 \mathrm{~cm}^{2}\right)
$$


e) Armaduras adicionais:

Armadura superior:

$$
A_{s, s u}=0,10 \cdot 10,05=1,00 \mathrm{~cm}^{2}(2 \phi 8 \mathrm{~mm})
$$

Armadura lateral ( malha ):

$$
A_{s 1}=5,00 \mathrm{~cm}^{2} / \mathrm{m} \quad(\phi 8 @ 10 \mathrm{~cm})
$$

e) Cálculo do comprimento de ancoragem:

O esforço de tração nas barras na seção de referência $S_{l}$, é dado por:

$$
R_{\text {std }}=\frac{M_{d}}{d}=\frac{132,69}{0,40}=332 \mathrm{kN}
$$

Na seção a partir de onde deve ser medido o comprimento de ancoragem, coincidente com o eixo da estaca, o esforço de tração em cada barra, é obtido da maneira que segue:

$$
R_{s t d 1}=\frac{0,8 R_{s t d}}{n}=\frac{0,8 \cdot 332}{5}=53,1 \mathrm{kN} / \text { barra }
$$

que por sua vez, é utilizado na determinação da tensão em cada barra, ou seja: 


$$
\sigma_{s d 1}=\frac{R_{s t d 1}}{A_{s 1}}=\frac{53,1}{2,00}=26,5 \mathrm{kN} / \mathrm{cm}^{2}
$$

Pode-se então, calcular o comprimento de ancoragem por intermédio da equação 2.44 :

$$
I_{b}=I_{b}^{*}-\Delta I_{b} \approx-12 \mathrm{~cm}
$$

sendo então, necessário adotar o comprimento de ancoragem fornecido pela condição expressa por meio da equação 2.46 , ou seja:

$$
I_{b}=10 \mathrm{~cm}
$$




\subsection{2 - MÉTODO DAS BIELAS}

Neste método, considera-se a existência de bielas irradiando a partir da interface do pilar com o bloco, em direção às cabeças das estacas, conforme foi mostrado na figura 2.1. Havendo simetria polar, admite-se que cada estaca do grupo deve suportar uma ação de valor igual a $N_{k} / n$, sendo $N_{k}$ a ação aplicada ao bloco e $\boldsymbol{n}$ o número de estacas do grupo.

$\mathrm{O}$ dimensionamento dos blocos por este método, leva em conta o diâmetro das estacas e a distância que guardam entre si, sendo necessário contudo obedecer às hipóteses simplificadoras enunciadas no ítem 2.1.2. Assim, para equilibrar a ação de compressão atuando nas bielas, surge uma solicitação de tração, contida no plano horizontal que passa pelo topo das estacas, para a qual será dimensionada a armadura.

A armadura pode ser disposta de maneira que resista à solicitação radial $\boldsymbol{R}_{\text {udd }}$ ou à solicitação tangencial $\boldsymbol{R}_{\text {asulas. }}$.

A tensão de compressão nas bielas, deve ser verificada junto às cabeças das estacas e junto ao pilar, para que não haja ruptura por esmagamento do concreto nestas posições.

\subsubsection{1 - Bloco sobre duas estacas}

Utilizando-se as expressões encontradas em 2.1.4, com os dados apresentados em 3.3.1.1, obtém-se:

$$
N_{k}=1,3\left(N_{u}+p p\right)=1,3(340+9)=454 k N
$$


O ângulo $\varphi$, que mede a inclinação da biela com um plano horizontal que contém o topo das estacas, obtido a partir das dimensões adotadas para este bloco é igual a $46,8^{\circ}$, o que é perfeitamente compatível com a condição dada pela expressão 2.30 , ou seja: $\varphi \geq 38^{\circ}$.

Pode-se então calcular:

$$
R_{s t d}=\frac{N_{d}}{n} \operatorname{cotg} \varphi=298 \mathrm{kN}
$$

A armadura inferior será dada então por:

$$
A_{s}=\frac{298}{43,48}=6,85 \mathrm{~cm}^{2} \quad(6 \phi 12,5)
$$

Na ausência de recomendações quanto às demais armaduras, utilizase neste trabalho as mesmas indicações do "método da flexão".

\subsubsection{2 - Bloco sobre três estacas dispostas em linha}

Conhecendo-se o peso próprio do bloco, calculado em 3.3.1.2, pode-se calcular o valor da ação vertical $\boldsymbol{N}_{\boldsymbol{k}}$ :

$$
N_{k}=1,3\left(N_{u}+p p\right)=1,3(510+23)=693 \mathrm{kN}
$$


Da condição de que não ocorra o esmagamento do concreto das bielas, obtém-se o limite inferior $\varphi \geq 38^{\circ}$, satisfeito por:

$$
\varphi=\operatorname{arctg}\left(\frac{d}{e}\right)=\operatorname{arctg}\left(\frac{700}{750}\right)=43^{\circ}
$$

Calculando-se o esforço de tração, $\boldsymbol{R}_{\text {sdd }}$, chega-se a:

$$
R_{s t d}=\frac{N_{d}}{n} \operatorname{cotg} \varphi=\frac{1,4.693}{3} \operatorname{cotg} 43^{\circ}=347 \mathrm{kN}
$$

Pode-se então, a partir deste resultado, calcular a área da seção da armadura inferior, da maneira que segue:

$$
A_{s}=\frac{R_{s t d}}{f_{y d}}=7,98 \mathrm{~cm}^{2} \quad(4 \phi 16 \mathrm{~mm})
$$

\subsubsection{3 - Bloco sobre três estacas ( dispostas em triângulo )}

Adotando-se as mesmas dimensões calculadas para este bloco no ítem 3.3.1.3, o peso próprio é conhecido e igual a $14 \mathrm{kN}$. Então, a ação vertical $N_{k}$, pode ser obtida fazendo-se: 


$$
N_{k}=1,3\left(N_{u}+p p\right)=1,3(590+14)=785 \mathrm{kN}
$$

Calculando-se o valor limite do ângulo $\varphi$, com o auxílio da equação

2.28, obtém-se: $\varphi \geq 54^{\circ}$

Neste caso, o bloco não tem altura suficiente para que seja satisfeita a condição dada no parágrafo anterior, uma vez que:

$$
\varphi=\operatorname{arctg}\left(\frac{400}{559}\right)=35,5^{\circ}
$$

Com este resultado, calcula-se então as solicitações de tração $\boldsymbol{R}_{\text {sdd }}$ e $\boldsymbol{R}_{\text {sal, lat }}$, de acordo com as expressões:

$$
\begin{aligned}
& R_{\text {std }}=\frac{N_{d}}{n} \operatorname{cotg} \varphi=514 \mathrm{kN} \\
& R_{\text {std, 1at }}=\frac{R_{\text {std }}}{2} \operatorname{cosec}\left(\frac{\pi}{n}\right) \approx 297 \mathrm{kN}
\end{aligned}
$$

Optando-se por dispor a armadura segundo a direção paralela aos lados do bloco, utiliza-se para o cálculo da mesma o esforço $\boldsymbol{R}_{\text {sdd,at }}$, o que leva ao resultado:

$$
A_{s, 1 a t}=\frac{R_{s t d, 1 a t}}{f_{y d}}=6,81 \mathrm{~cm}^{2} \quad(6 \phi 12,5 \mathrm{~mm})
$$




\subsubsection{4 - Bloco sobre quatro estacas}

Tomando o peso próprio obtido no ítem 3.3.1.4, calcula-se o valor da ação vertical $\boldsymbol{N}_{k}$, a ser considerada no dimensionamento deste protótipo:

$$
N_{k}=1,3\left(N_{u}+p p\right)=1,3(800+21)=1067 \mathrm{kN}
$$

$\mathrm{O}$ valor limite para o ângulo que a biela forma com o plano das cabeças das estacas será: $\varphi \geq 41^{\circ}$

As dimensões adotadas para este bloco, são então aceitáveis, embora também não atendam à condição estabelecida, a exemplo do que ocorreu para o bloco sobre três estacas com disposição triangular. Isto pode ser constatado com o cálculo que segue:

$$
\beta=\operatorname{arctg}\left(\frac{400}{533}\right)=37^{\circ}
$$

Calculando-se, a partir deste resultado, o valor das solicitações de tração, nas direções radial e lateral, respectivamente, encontra-se:

$$
R_{\text {std }}=\frac{N_{d}}{n} \operatorname{cotg} \varphi=495 \mathrm{kN}
$$




$$
R_{s t d, 1 a t}=\frac{R_{s t d}}{2} \operatorname{cosec}\left(\frac{\pi}{n}\right)=350 \mathrm{kN}
$$

Dispondo-se a armadura paralelamente aos lados do bloco, unindo as cabeças das estacas, chega-se a:

$$
A_{s, 1}=\frac{R_{s t d, 1 a t}}{f_{y d}}=8,05 \mathrm{~cm}^{2} \quad(4 \phi 16 \mathrm{~mm})
$$




\section{4- DESCRIÇÃO DO CAMPO EXPERIMENTAL}

\section{1- INTRODUÇÃO}

A realização de ensaios em protótipos e modelos, como forma de elaborar ou confirmar métodos para o dimensionamento de estruturas, encontra por vezes a resistência dos profissionais de engenharia.

Dentre as razões deste comportamento, pode-se destacar a total confiança que alguns depositam no estudo analítico dos fenômenos da natureza. Para estes, é bastante desagradável lidar com medidas cujos valores podem estar afetados por dispersões, incertezas, etc.

Embora as premissas adotadas no cálculo analítico nem sempre traduzam o comportamento de uma dada estrutura, o cálculo parece satisfazer a ânsia do engenheiro pela precisão e exatidão, ainda que aparentes. 


\subsection{1 - OBJETIVOS}

No presente trabalho, pretende-se verificar alguns métodos de cálculo de blocos de coroamento de grupos de estacas, face aos resultados de provas de carga sobre protótipos construídos para este fim específico.

Com este propósito, instalou-se um campo experimental em área interna ao campus USP - São Carlos contíguo àquele montado pelo Departamento de Geotecnia da Escola de Engenharia de São Carlos, por ocasião da pesquisa desenvolvida por CARVALHO (1991) ${ }^{[1]]}$.

\section{2- DESCRIÇÃO DO CAMPO EXPERIMENTAL}

No período de setembro à novembro de 1991 foram moldadas diversas estacas do tipo STRAUSS, com o propósito de se montar a estrutura necessária à aplicação de ações nos blocos durante a realização das provas de carga. Nesta operação foi empregado um tripé provido de um pilão pesando $3 \mathrm{kN}$ e, um conjunto de tubos metálicos recuperáveis, usados no "encamisamento" dos furos das estacas.

Empregou-se também, um balde sonda (piteira) para a escavação e retirada do material escavado, conforme recomendações da NB 51 (1985) ${ }^{[13]}$.

Executaram-se ainda, várias estacas do tipo BROCA, isoladas e em grupos, sobre as quais foram moldados os blocos de coroamento. 
No Anexo A, apresenta-se a planta de locação das estacas, onde visualizam-se suas posições relativas e seus respectivos diâmetros.

\subsection{1 - ESTACAS}

\subsubsection{1 - Estacas de reação (STRAUSS)}

Construídas para trabalharem à tração, nelas foram embutidos tirantes de aço DIWIDAG com $32 \mathrm{~mm}$ de diâmetro e $3 \mathrm{~m}$ de comprimento, aos quais seria presa a estrutura de reação, descrita mais adiante.

Estes tirantes, de acordo com a foto a seguir, transferem para as estacas STRAUSS a força que o macaco hidráulico aplica à estrutura metálica ao se promover o carregamento dos blocos.

O concreto utilizado na moldagem das estacas foi dosado visando-se obter uma resistência característica à compressão igual a $15 \mathrm{MPa}$. Foi coletado um total de 14 corpos-de-prova, cujos ensaios à compressão simples apresentaram como resultados os valores mostrados na tabela 4.1. 
Tabela 4.1 - Resistência à compressão simples do concreto das estacas

$\begin{array}{cr}\text { No. do c.P. } & \text { fc2 ( } \\ 01 & 11,88 \\ 02 & 12,45 \\ 03 & 6,79 \\ 04 & 6,34 \\ 05 & 16,52 \\ 06 & 32,82 \\ 07 & 17,88 \\ 08 & 19,41 \\ 09 & 18,96 \\ 10 & 28,58 \\ 11 & 24,56 \\ 12 & 22,24 \\ 13 & 21,79 \\ 14 & 20,98\end{array}$

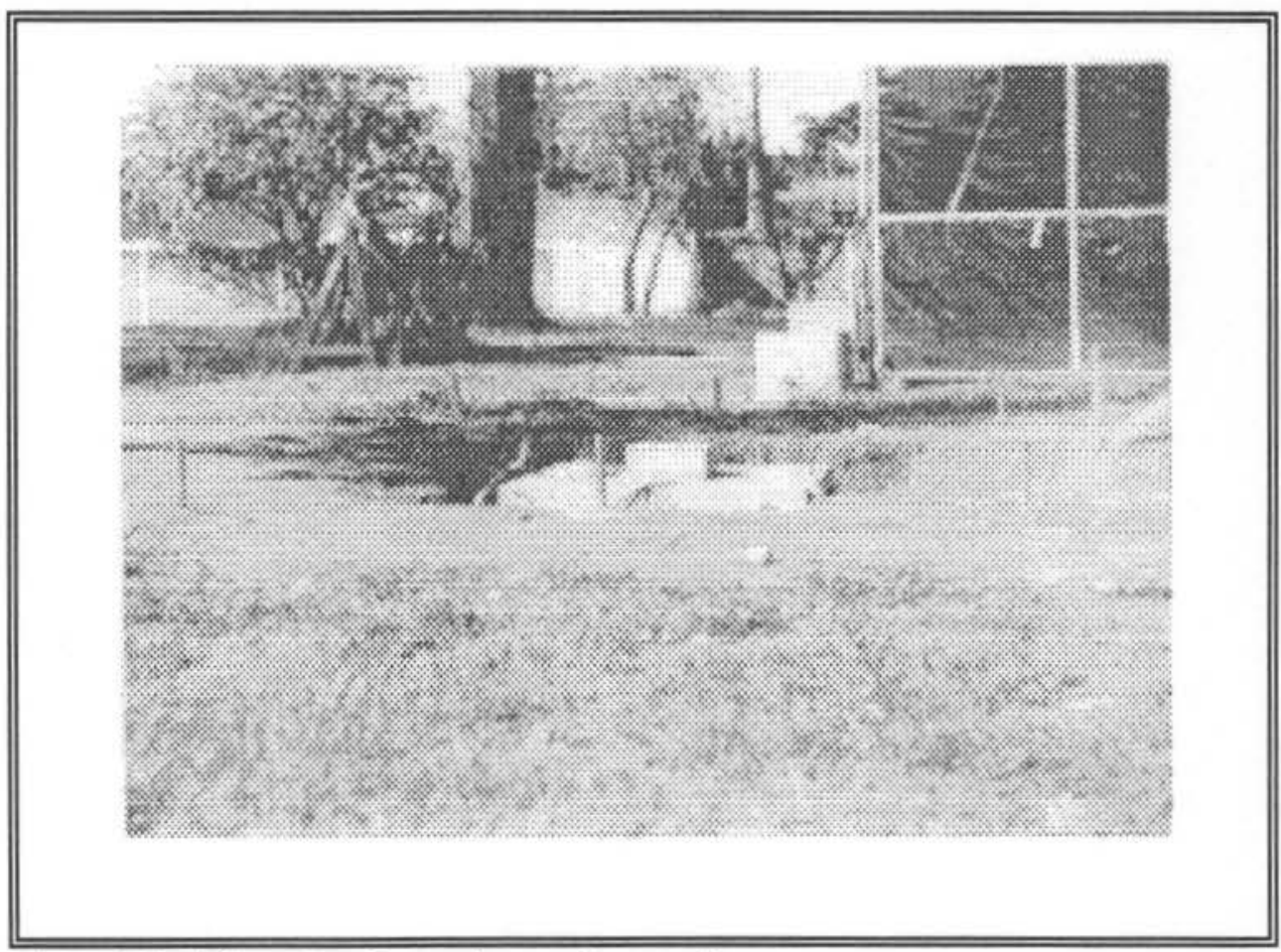

Foto 4.1 - Tirantes das estacas de reação 


\subsubsection{2 - Grupos de estacas (BROCAS)}

Nestas, empregou-se um trado mecânico helicoidal para a etapa de escavação. $\mathrm{O}$ concreto, atendia ao mesmo traço daquele empregado na execução das estacas STRAUSS, sendo utilizada para sua preparação uma betoneira com 350 litros de capacidade. Na série de fotos seguintes, são mostradas as várias etapas de execução das estacas, tanto do tipo BROCA como do tipo STRAUSS:

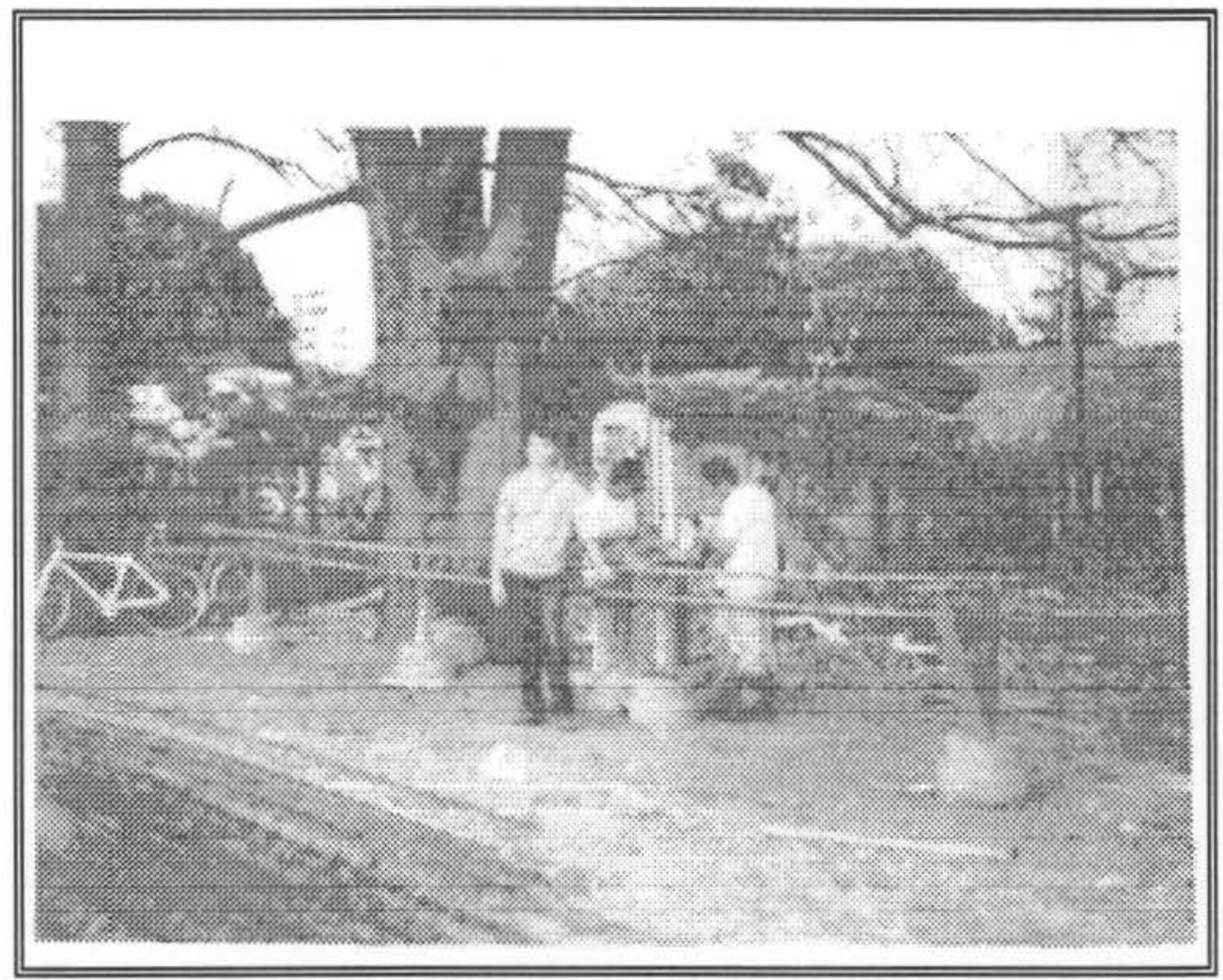

Foto 4.2 - Montagem das armaduras das estacas STRAUSS 


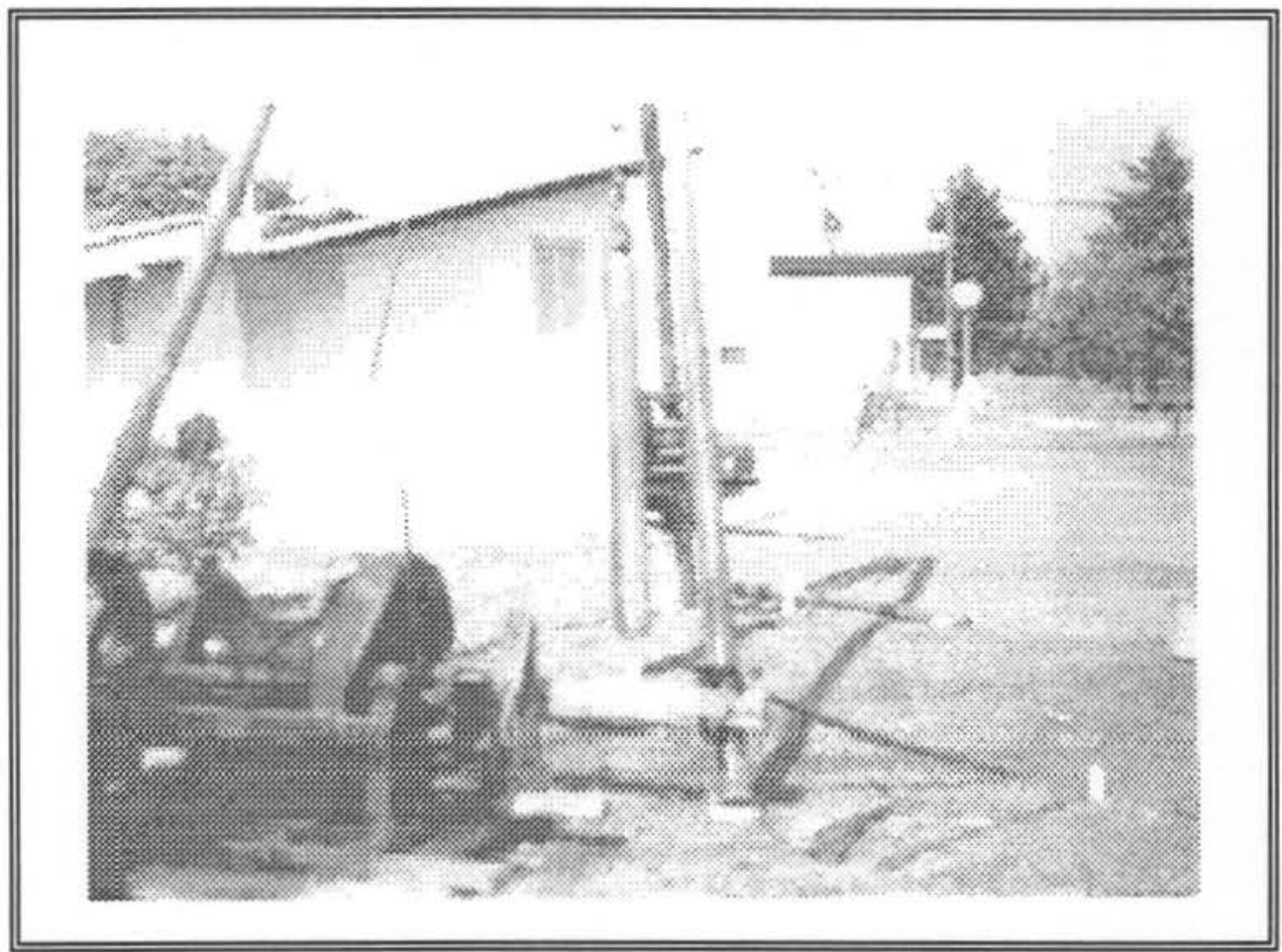

Foto 4.3 - Abertura do furo com auxílio de pilão

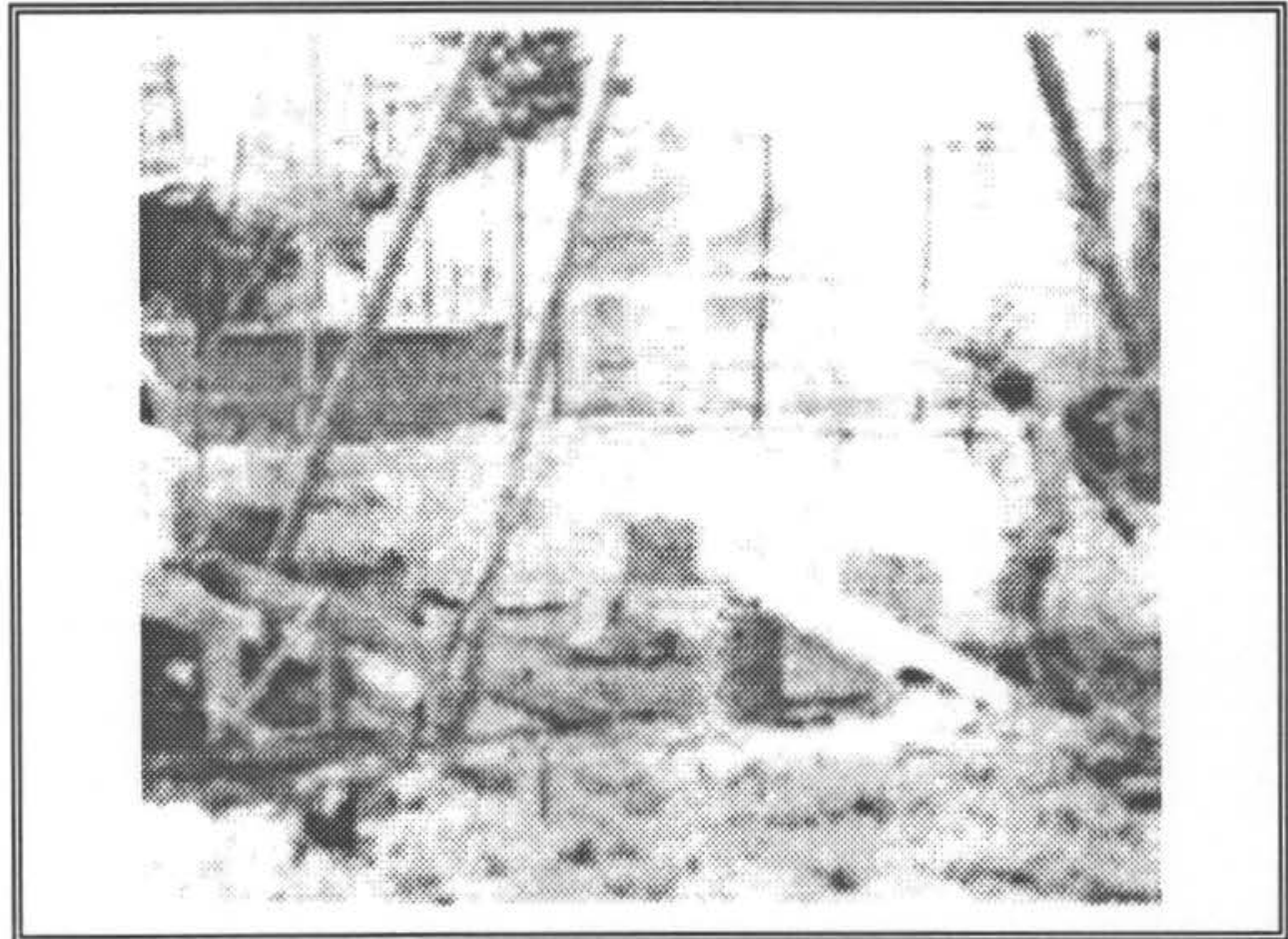

Foto 4.4 - Escavação (retirada do material escavado) 


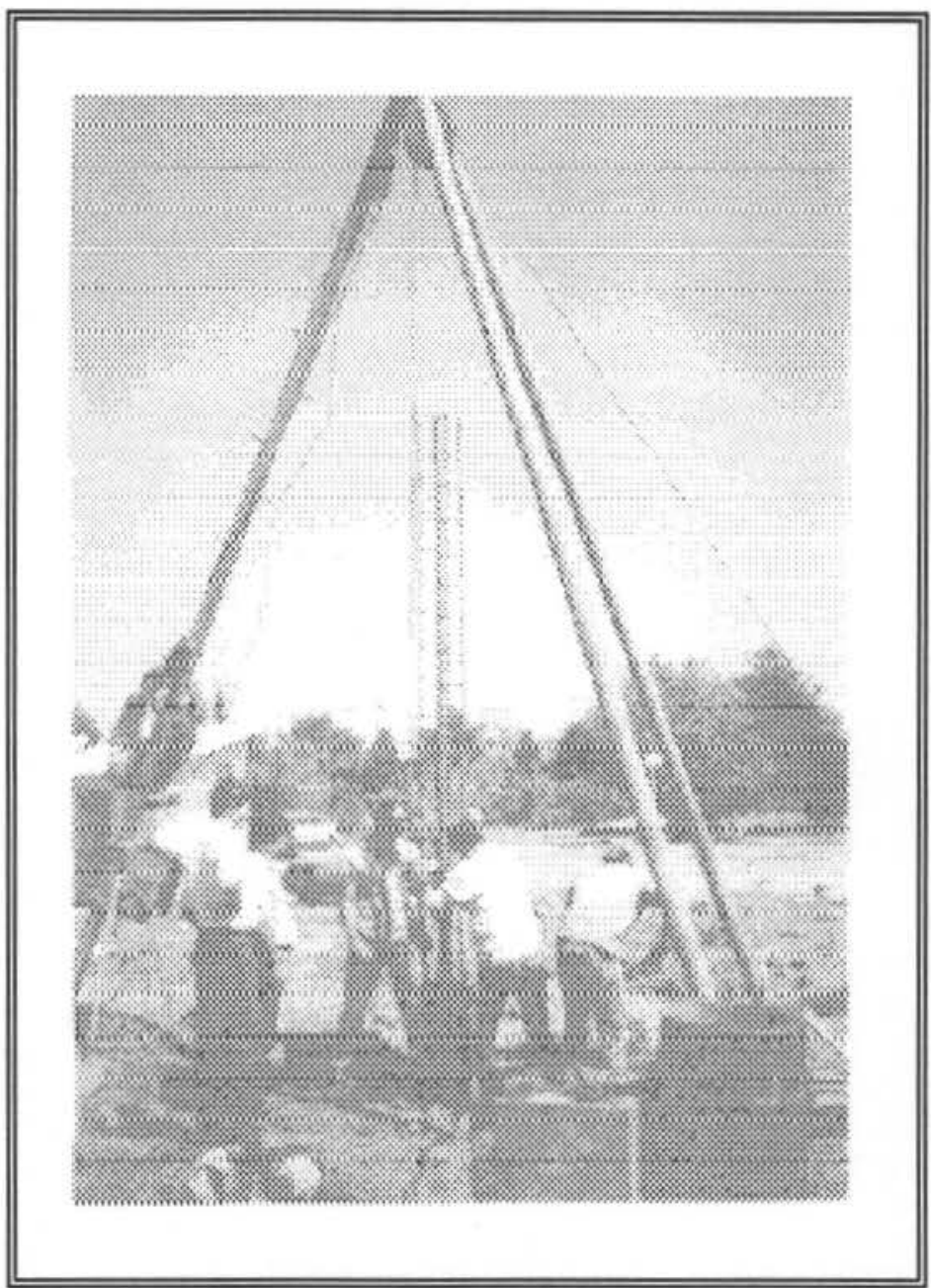

Foto 4.5 - Colocação da armadura 


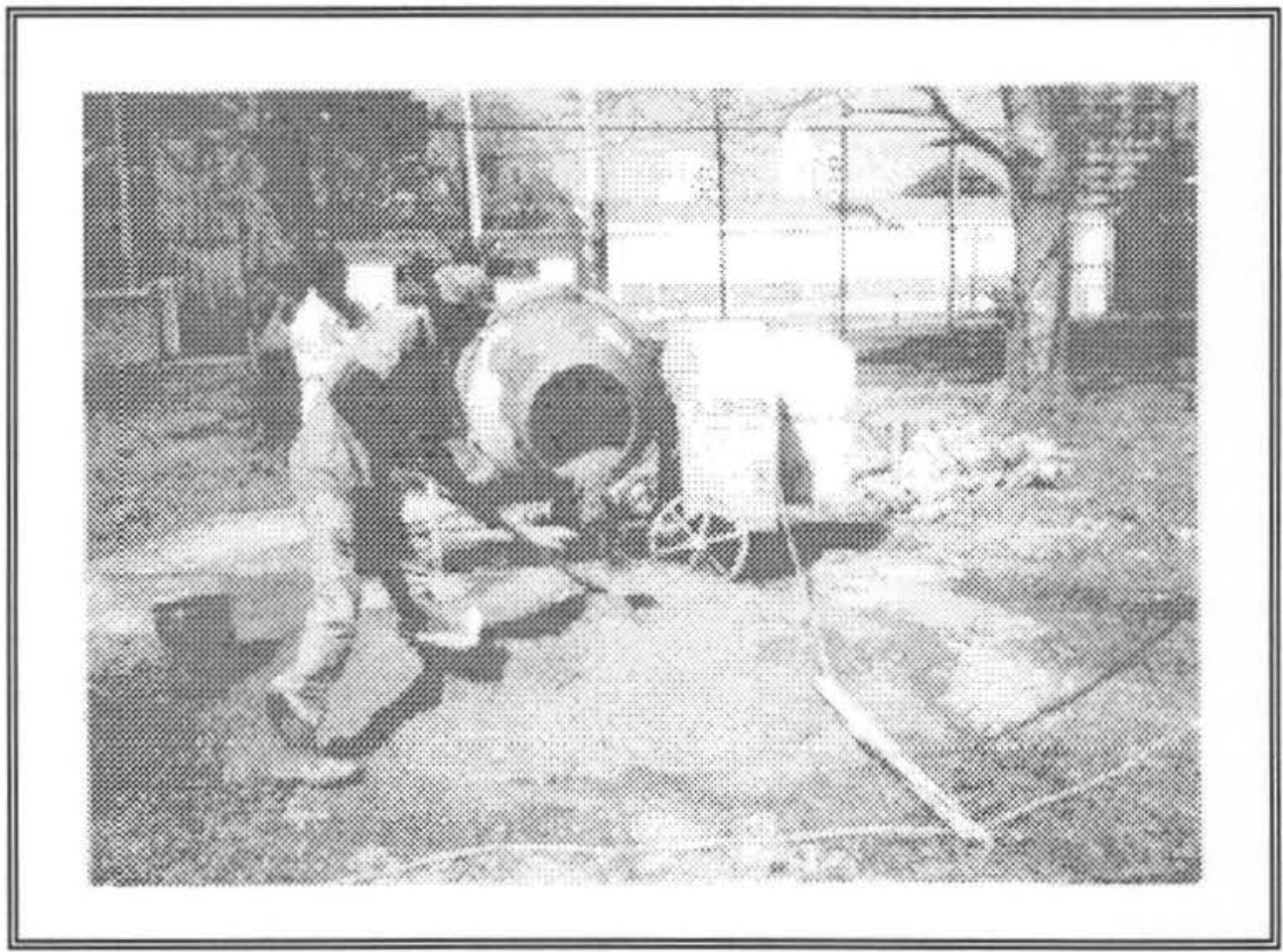

Foto 4.6 - Preparo do concreto das estacas

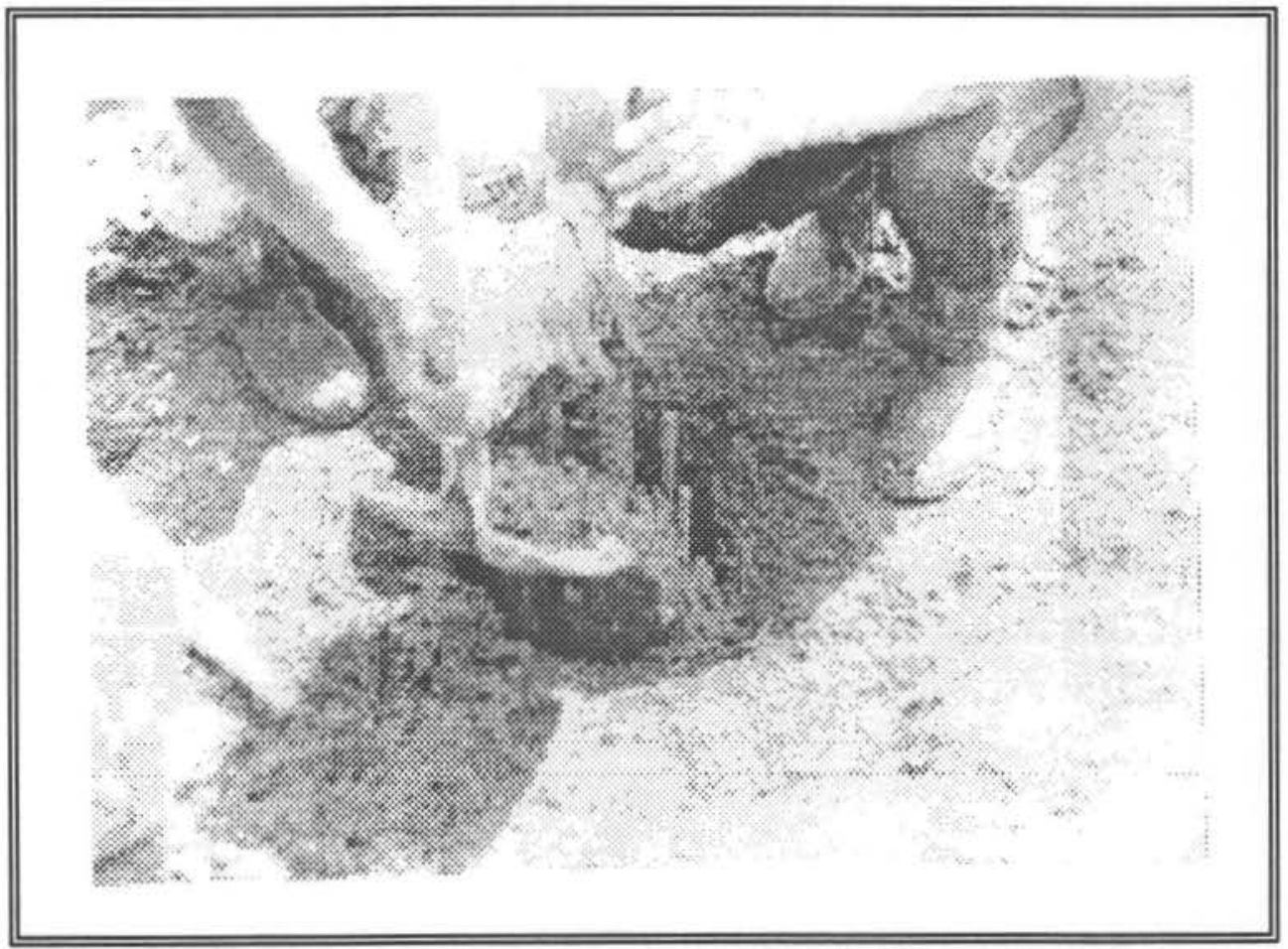

Foto 4.7 - Concretagem da estaca com o tirante já posicionado 


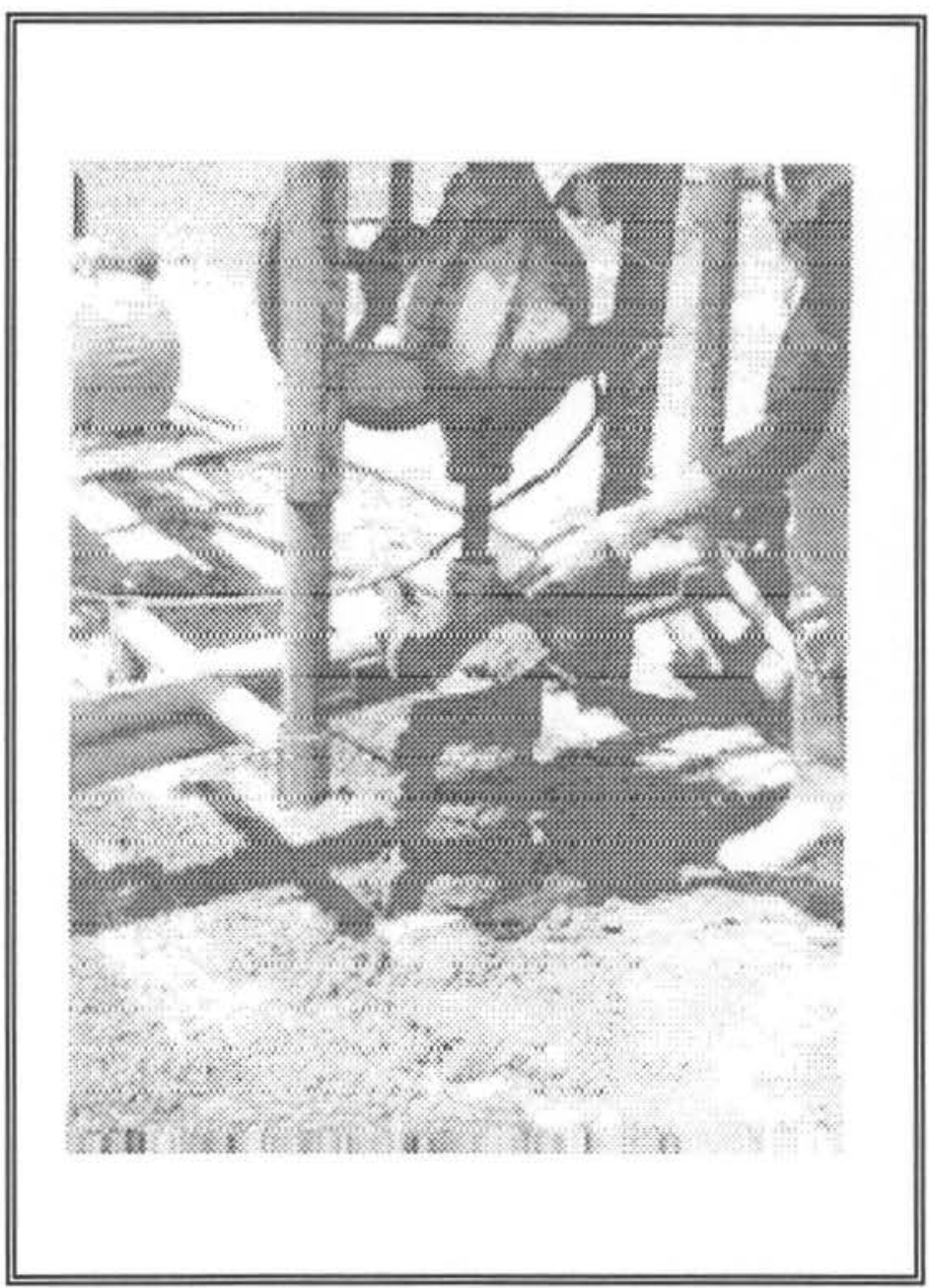

Foto 4.8 - Estaca do tipo BROCA (execução) 


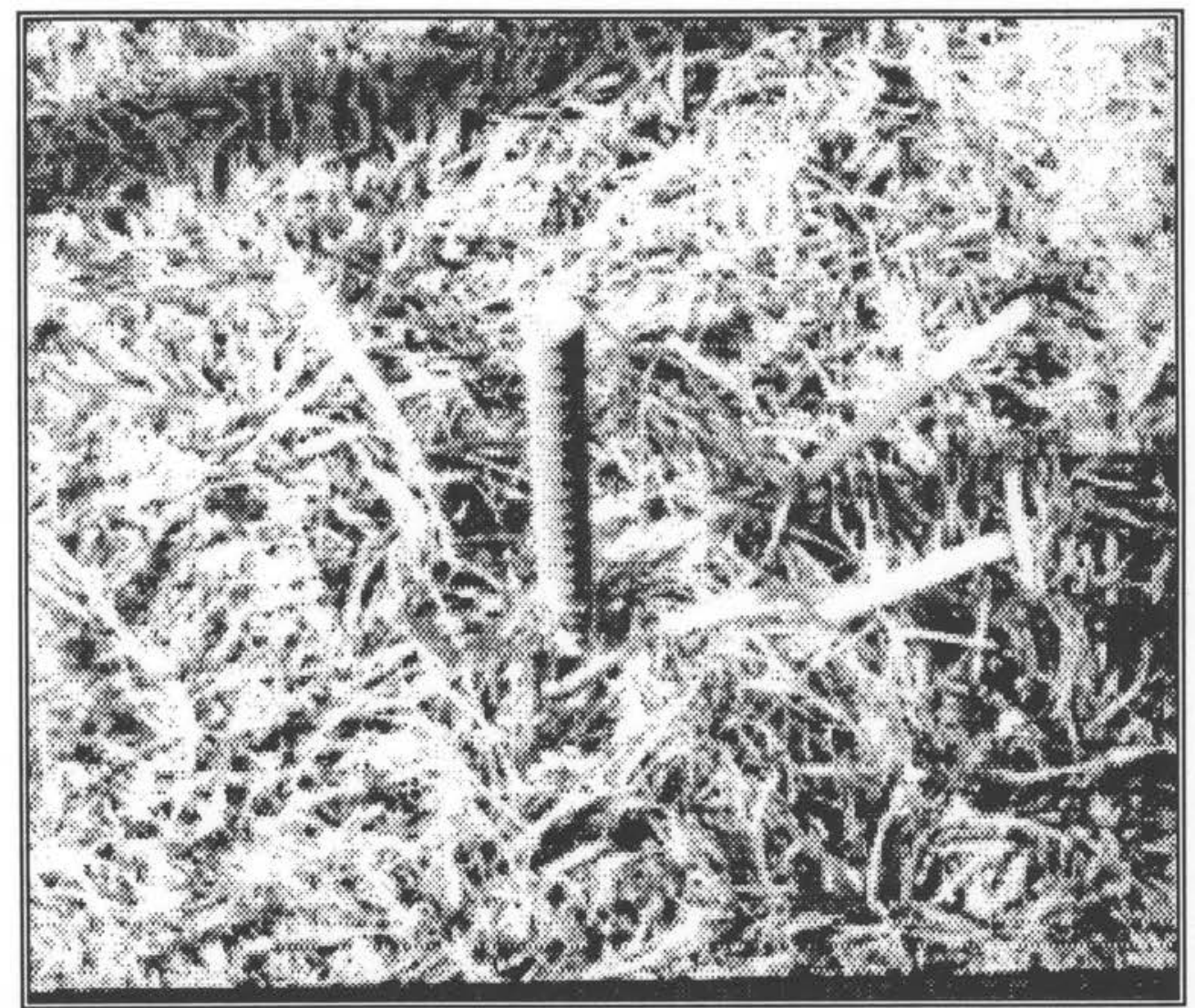

Foto 4.9 - Estaca STRAUSS pronta, com tirante 


\subsection{2 - BLOCOS}

Os blocos de coroamento das estacas foram concretados no dia 18 de dezembro de 1991, empregando-se concreto de usina, pré-misturado, fornecido pela firma Concrebrás $\mathrm{S} / \mathrm{A}$, atendendo às especificações definidas mais adiante no item 4.3.

As formas, fabricadas na marcenaria da EESC-USP de acordo com projeto executivo feito a partir das dimensões obtidas do projeto dos blocos, foram concebidas de modo a facilitar sua montagem e reaproveitamento. Isto foi conseguido, utilizando-se parafusos na sua montagem ao invés de pregos.

Podem ser observadas na próxima sequência de fotografias as etapas de montagem das armaduras, das formas e, finalizando, a concretagem dos blocos.

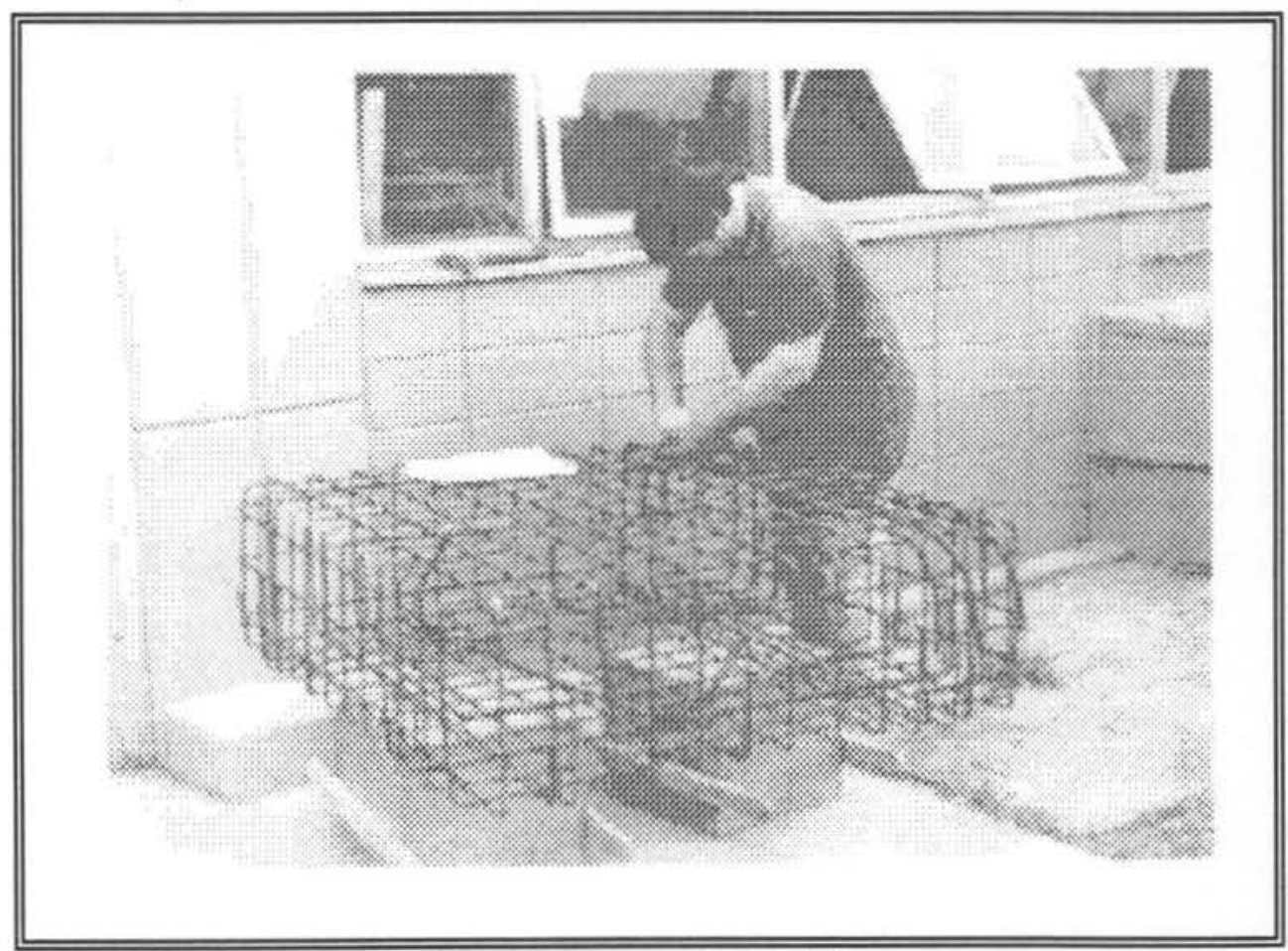

Foto 4.10 - Montagem da armadura de um bloco. 


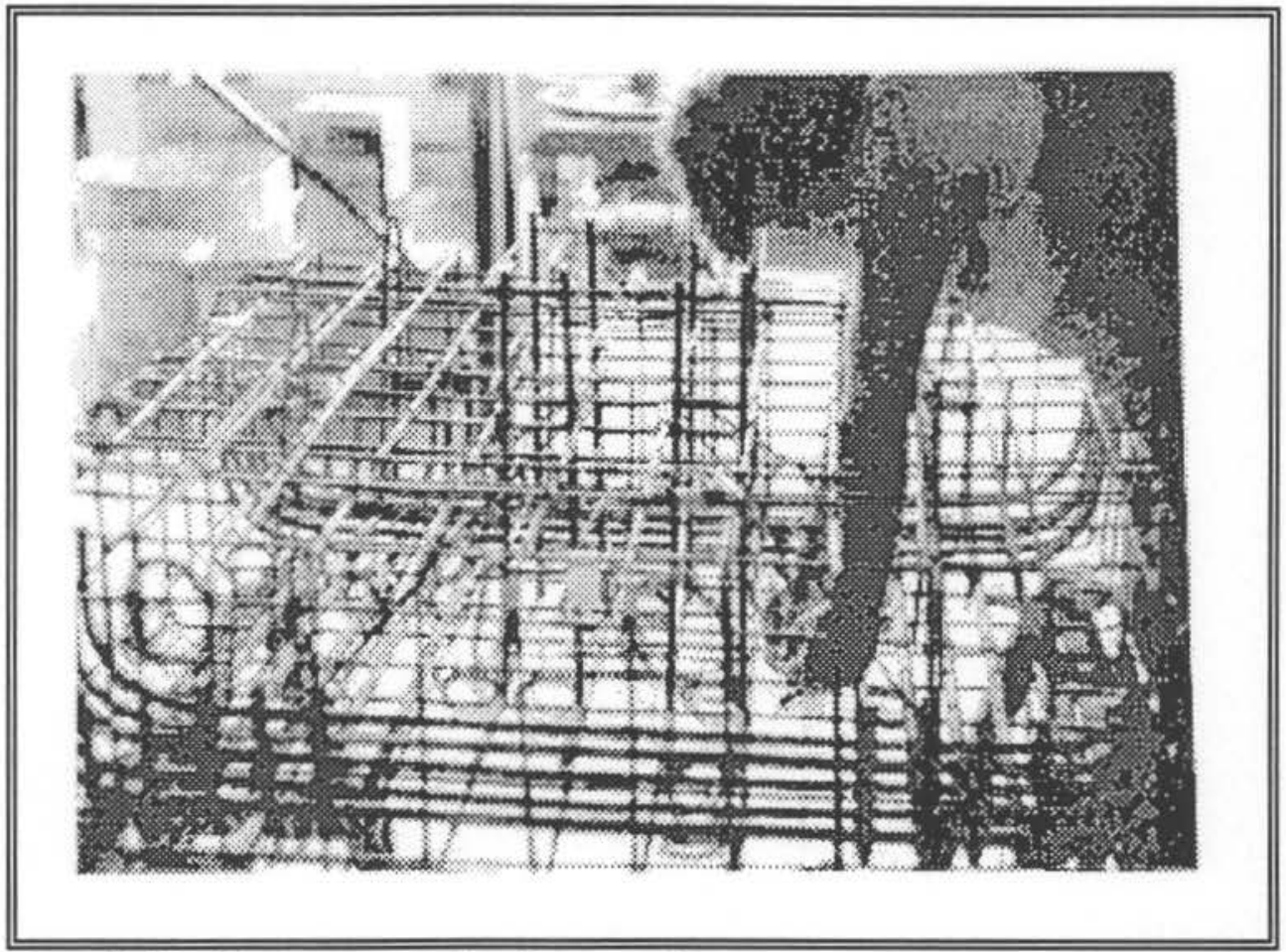

Foto 4.11 - Instrumentação da armadura.

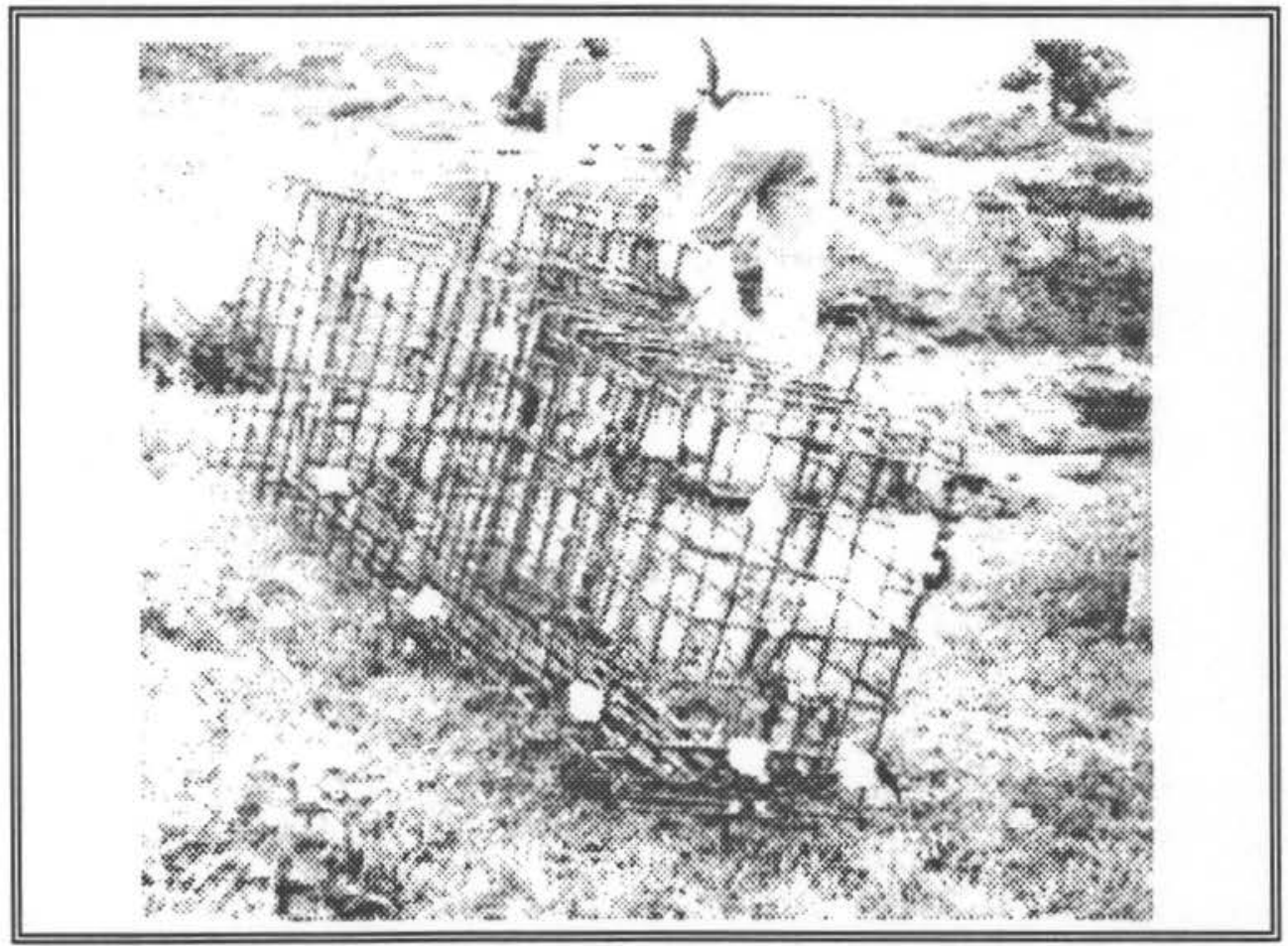

Foto 4.12 - Espaçadores colocados para garantir o cobrimento 


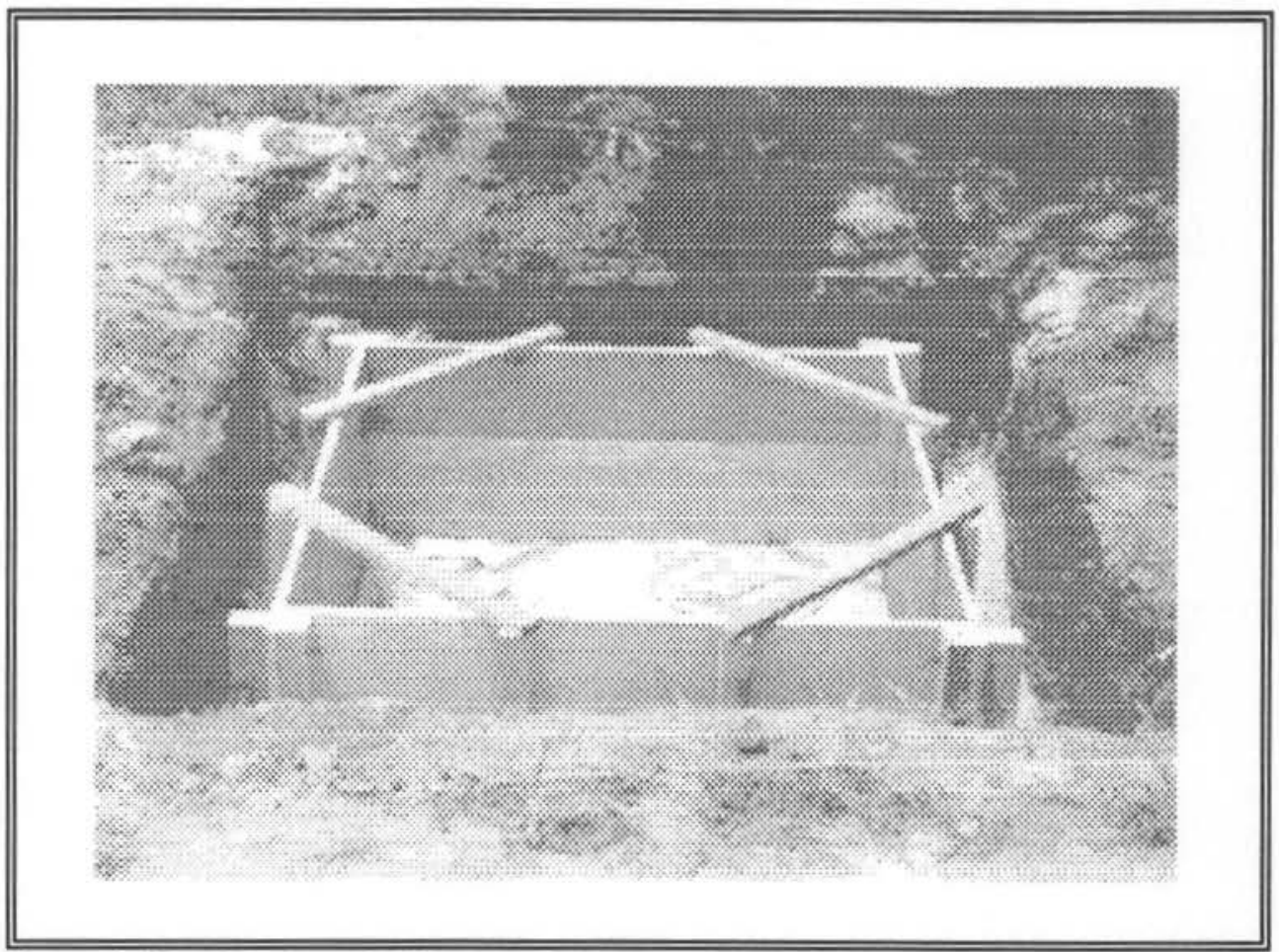

Foto 4.13 - Forma do bloco sobre quatro estacas

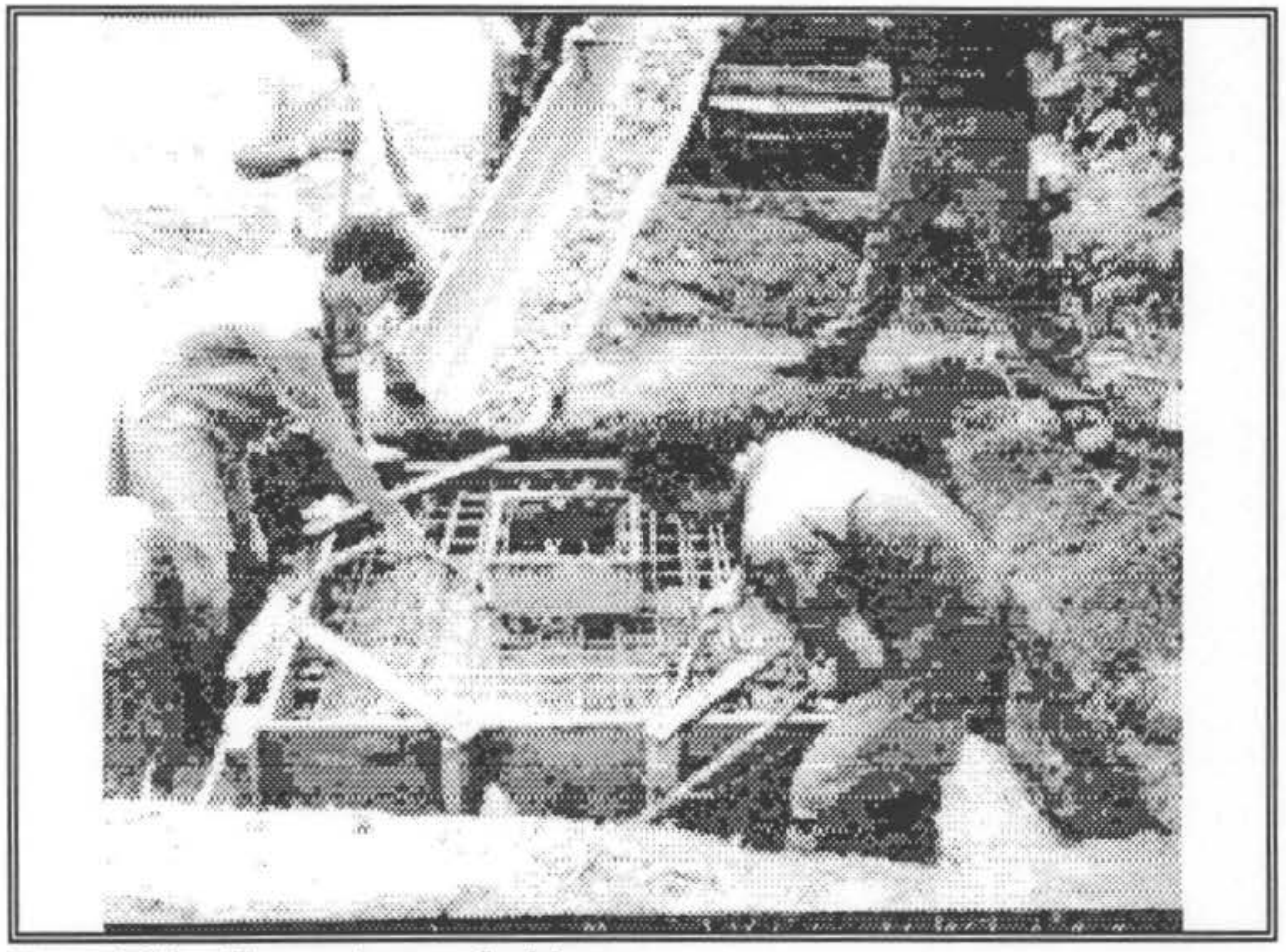

Foto 4.14 - Concretagem do bloco 


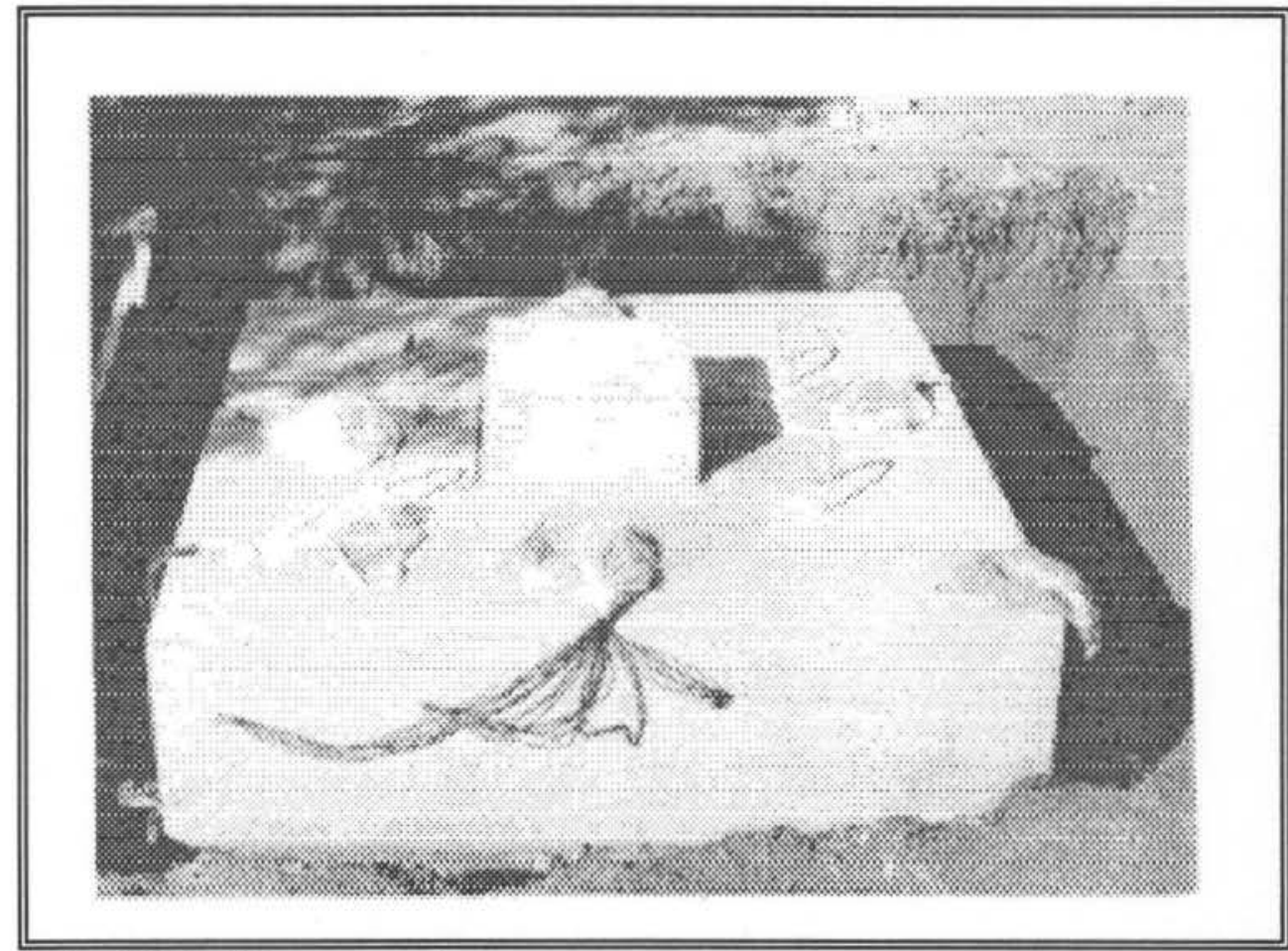

Foto 4.15 - Bloco pronto

\subsection{3 - ESTRUTURA PARA REALIZAÇÃO DAS PROVAS DE CARGA}

Empregou-se como estrutura de reação, a mesma utilizada na pesquisa "Provas de Carga de Estacas Instrumentadas", realizada pelo Departamento de Geotecnia da EESC-USP, entre 1988 e 1991.

Esta estrutura, consiste essencialmente em quatro perfis I metálicos ligados entre si através de parafusos. Conforme mostram as figuras 4.1 e 4.2 , foram utilizados também tirantes ligando o centro dos perfis centrais às extremidades dos perfis laterais com a finalidade de estabilizar o conjunto.

Com capacidade de suportar até $2 \mathrm{MN}$ aplicados em seu centro e uma massa total de $1926 \mathrm{~kg}$, esta estrutura foi projetada visando a sua reutilização 
em outras pesquisas, como esta aqui relatada, em função do alto custo deste equipamento.

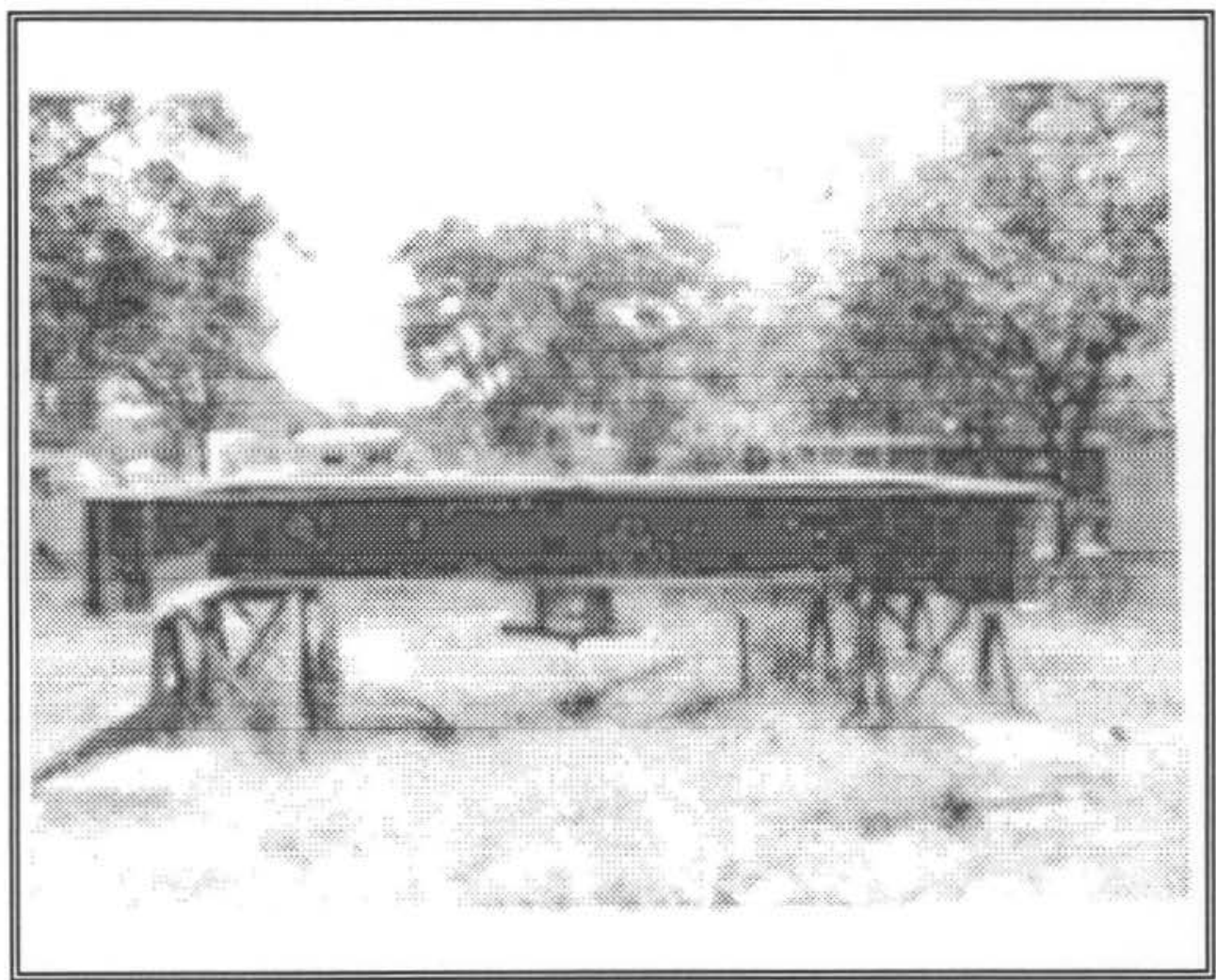

Foto 4.16 - Viga de reação 


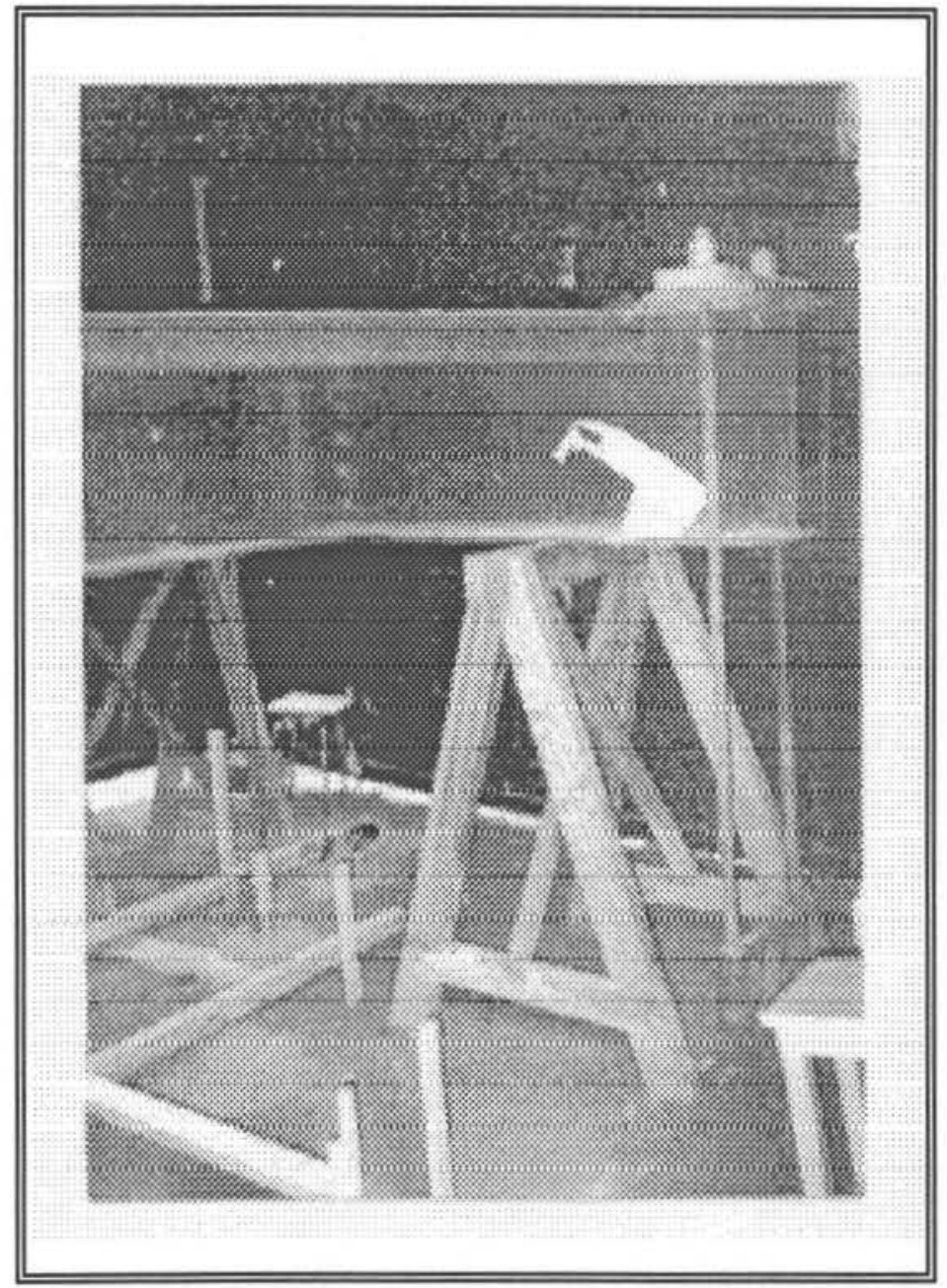

Foto 4.17 - Detalhe de fixação da viga de reação às estacas STRAUSS. 


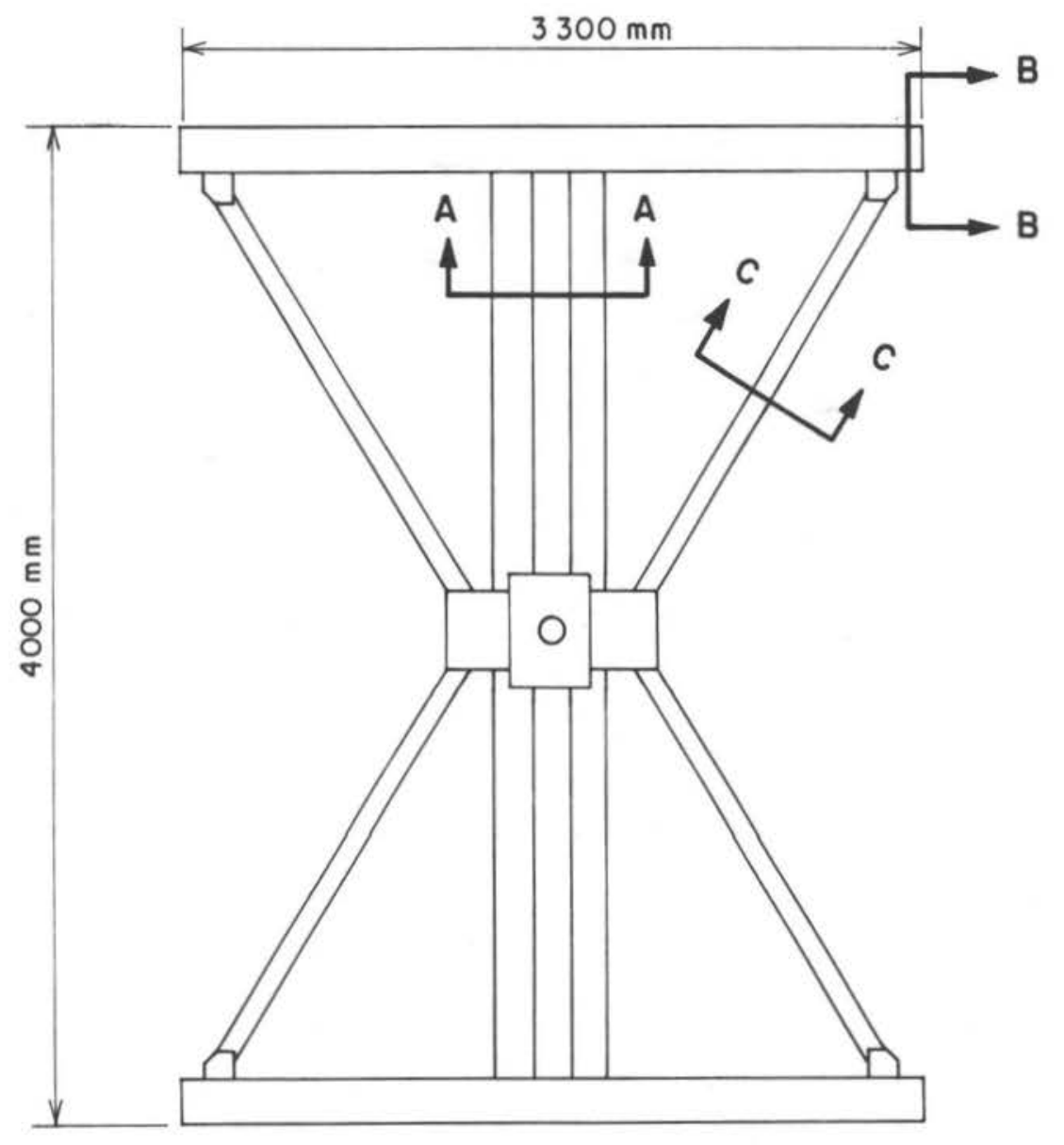

100

FIGURA 4.1: Estrutura Metálica para Reaçāo-Planta
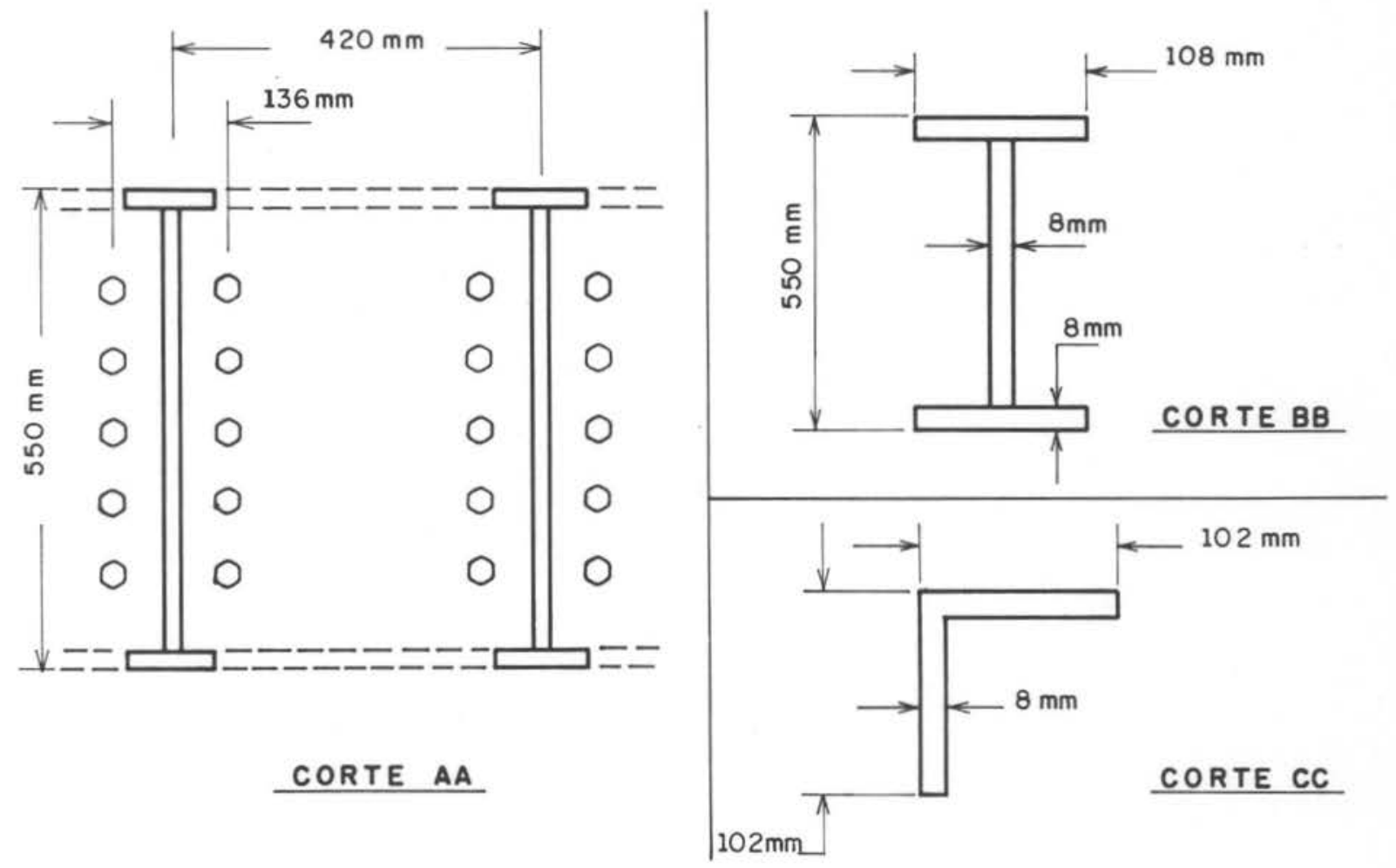

CORTE AA

FIGURA 4.2: Estrutura Metálica para Reaçāo- Cortes 


\section{3 - MATERIAIS}

Os protótipos foram executados em concreto armado, empregando-se barras e fios de aço conforme as prescrições da EB 3 (1981) ${ }^{[14]}$ e concreto pré-misturado com resistência característica especificada igual a $18 \mathrm{MPa}$.

Para a caracterização destes materiais, fez-se uma amostragem dos mesmos e, consequentemente, realizou-se ensaios com vistas à obtenção dos respectivos módulos de deformação longitudinal, resistências e comportamento mecânico.

\subsection{1 - CONCRETO}

O concreto empregado, foi adquirido de uma empresa da região de São Carlos, de onde procedem a areia e a pedra britada utilizados em sua preparação.

Para cada metro cúbico de concreto produzido, a empresa fornecedora utilizou as seguintes quantidades:

- $360 \mathrm{~kg}$ de cimento;

- $1040 \mathrm{~kg}$ de areia grossa ( umidade $=5 \%$ );

- 1402 kg de pedra britada No. 1;

- 120 litros de água;

chegando-se assim ao traço em massa:

$$
1: 2,89: 3,89: 0,48 \text {. }
$$


No adensamento do concreto foram utilizados dois vibradores mecânicos de agulha com diâmetro igual a $45 \mathrm{~mm}$. Feito o ensaio de abatimento do tronco de cone com amostras retiradas de 2 caminhões, obtiveram-se os valores 60 $\mathrm{mm}$ e $55 \mathrm{~mm}$. Foram moldados 24 corpos-de-prova cilíndricos conforme as recomendações da MB 2 (1989) ${ }^{[1]}$. Deste total, 6 foram ensaiados à compressão diametral para a determinação da resistência à tração.

Os demais foram ensaiados à compressão simples, sendo 6 aos 28 dias e 12 distribuídos entre as idades de 62, 85 e 104 dias.

Executados de acordo com a MB 212 (1989) $)^{11 \oplus}$, os ensaios à compressão diametral forneceram os seguintes valores para a resistência do concreto à tração:

Tabela 4.2 - Resultados dos ensaios do concreto à compressão diametral

\begin{tabular}{ccc}
\hline No.do c.P. & AçÃo (kN) & $\mathbf{f t 2 8 ~ ( M P a ) ~}$ \\
01 & 172 & 2,4 \\
02 & 121 & 1,7 \\
03 & 177 & 2,5 \\
04 & 151 & 2,1 \\
05 & 127 & 1,8 \\
06 & 147 & 2,1
\end{tabular}

sendo que, $\quad f_{t 28}=\frac{2 F}{\pi D L}$

onde, $\quad \mathbf{f}_{\mathrm{cas}}$ : resistência do concreto à tração aos 28 dias;

F : ação atuando sobre o corpo-de-prova;

D : diâmetro do corpo-de-prova;

L : comprimento do corpo-de-prova; 
Mas, de acordo com SUSSEKIND ${ }^{[1]}$, esta relação é válida quando as tensões de tração são contantes ao longo da seção, o que não ocorre nos ensaios de compressão diametral. Para compensar a existência de compressão próxima aos bordos carregados, aplica-se um coeficiente corretivo igual à 0,85 , obtendo-se desta forma:

$$
f_{t 28}=0,55 \frac{F}{D L}
$$

A expressão assim obtida permite, a partir dos dados da tabela 4.2, o seguinte valor médio para a resistência à tração: $f_{t, 28}=1,8 \mathrm{MPa}$

Para seis corpos-de-prova rompidos num ensaio de compressão axial, obteve-se:

Tabela 4.3 - Resultado dos ensaios do concreto à ompressão axial aos 28 dias

No. do C.P. 07

08

09

10

11

12 fc28 ( MPa)

$$
\begin{aligned}
& 31,6 \\
& 30,3 \\
& 32,8 \\
& 30,8 \\
& 32,3 \\
& 29,4
\end{aligned}
$$


Assim, o concreto utilizado nos blocos atende à um valor de resistência característica de até $24 \mathrm{MPa}$. Este valor é obtido da expressão prescrita pela NBR $6118(1978)^{[04]}$ :

$$
f_{c k}=f_{c j}-1,65 s_{d}
$$

onde, $f_{c k}$ : resistência característica do concreto;

$f_{c j}$ : resistência do concreto aos j dias;

$s_{d}$ : desvio padrão de dosagem.

Adotando-se $s_{d}$ igual a $4 \mathrm{MPa}$ e $f_{\text {c2s }}$ igual a $31,2 \mathrm{MPa}$, chega-se à resistência característica anteriormente referida.

Os corpos-de-prova 10, 11 e 12 foram previamente instrumentados com extensômetros elétricos para obter-se suas respectivas deformações durante a aplicação do carregamento. Assim, foi possível construir diagramas tensão $\mathbf{x}$ deformação, úteis na determinação do módulo de deformação longitudinal do concreto.

Conforme os diferentes problemas apresentados pela utilização do concreto como material de construção, há várias formas de definir-se este módulo, a saber:

1 - MÓDULO TANGENTE - coeficiente angular da tangente geométrica no ponto considerado do diagrama $\sigma_{\mathrm{e}} \mathbf{x} \varepsilon_{\mathrm{c}}$;

2 - MÓDULO SECANTE - coeficiente angular da reta unindo a origem à tensão dada no diagrama $\sigma_{\mathrm{c}} \mathbf{x} \boldsymbol{\varepsilon}_{\mathrm{c}}$;

3 - MÓDULO obtido das linhas de carga e descarga no diagrama $\sigma_{\mathrm{c}} \mathbf{x} \varepsilon_{\mathrm{c}}$. 
No presente trabalho, é de especial interesse a determinação do módulo tangente, necessário para o cálculo das tensões quando ocorrem modificações no carregamento dos protótipos.

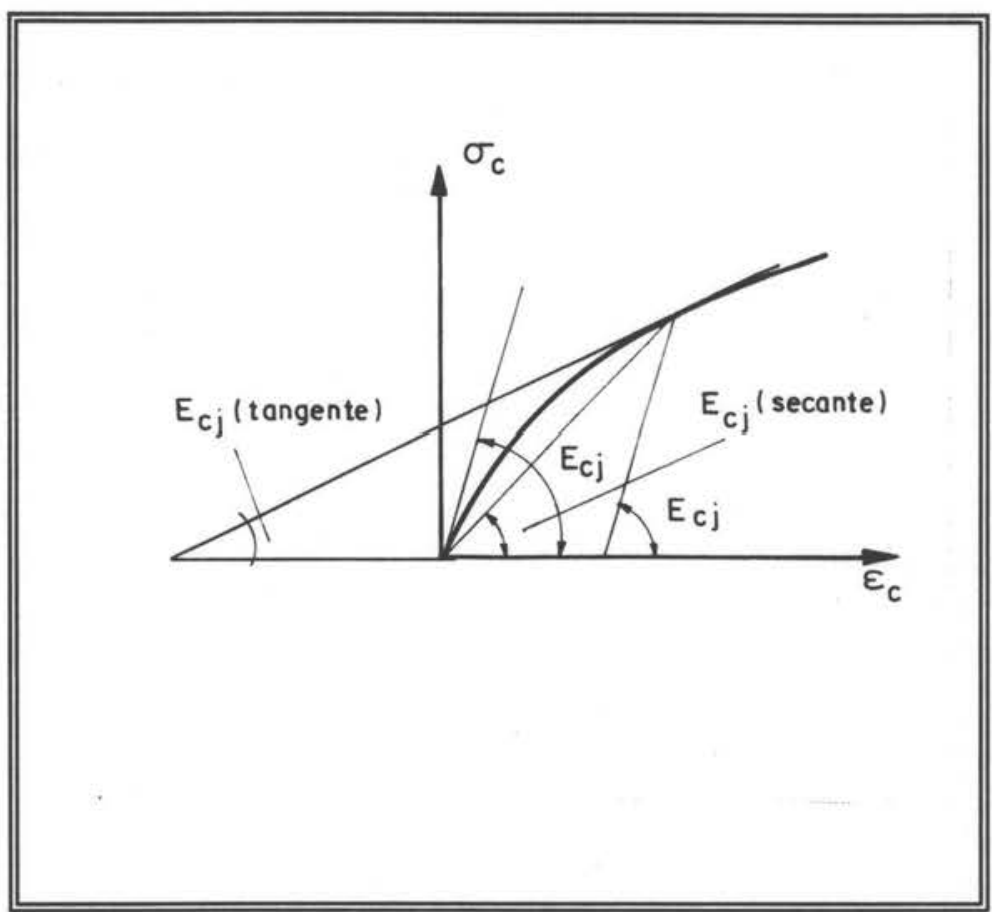

Figura 4.3 - Interpretação geométrica do módulo de deformação.

De acordo com o Código Modelo do CEB (1991) ${ }^{[18]}$, quando a resistência à compressão do concreto na idade de 28 dias, $f_{c m}$, é conhecida, $\boldsymbol{E}_{c}$ pode ser estimado através da equação:

$$
E_{c}=\alpha_{c}\left[\frac{f_{c m}}{f_{c m o}}\right]^{1 / 3}
$$

onde, $\quad \boldsymbol{E}_{c}$ : Módulo Tangente; 


$$
\begin{aligned}
& \boldsymbol{\alpha}_{c}=2,15 \times 10^{4} \mathrm{MPa} \\
& f_{\text {emo }}=10 \mathrm{MPa}
\end{aligned}
$$

dando para $f_{\mathrm{cm}, 28}=31,21 \mathrm{MPa}$, o valor $\boldsymbol{E}_{c}=31420 \mathrm{MPa}$.

Igualmente, a NBR $6118(\mathbf{1 9 7 8})^{[0 \times]}$, na falta de dados experimentais, prescreve que o cálculo do módulo de deformação obedeça à expressão:

$$
E_{c}=6600 \sqrt{E_{c j}}
$$

$$
\text { onde, } f_{c j}=f_{c k}+3,5 \mathrm{MPa}\left(f_{c k} \mathrm{em} \mathrm{MPa}\right)
$$

então, para $f_{c j}=31,21 \mathrm{MPa}$, obtém-se: $E_{c}=36872 \mathrm{MPa}$

PETRUCCI $^{[19]}$ cita duas relações entre tensão e deformação, a saber, a equação de Hooke e a equação de Bach. A primeira delas, não se verifica em nenhuma etapa do carregamento devido ao fato do concreto não ser um material perfeitamente elástico. É expressa na forma: $\sigma_{c}=E_{c} \varepsilon_{c}$

A relação de Bach representa melhor o comportamento do material e, pode ser escrita da seguinte maneira:

$$
\boldsymbol{\varepsilon}_{c}=\alpha_{c} \sigma_{c}^{m}
$$

onde, $\alpha_{c}=1 / E_{c} \quad$ com $m=1,10$ a 1,16 
Ajustando-se as curvas tensão $\mathrm{x}$ deformação obtidas dos ensaios dos corpos-de-prova instrumentados, pela relação de Bach, pode-se obter um valor médio do módulo de deformação longitudinal, ou seja: $E_{c}=37842 \mathrm{MPa}$

Tabela 4.4 - Resultados de ensaios à compressão simples

\begin{tabular}{|c|c|c|c|c|}
\hline No. do C.P. & IDADE (dias) & AçÃo & $(\mathrm{kN})$ & RESISTENCIA (MPa) \\
\hline 13 & 62 & & 632 & 35,8 \\
\hline 14 & & & 603 & 34,1 \\
\hline 15 & & & 661 & 37,4 \\
\hline 16 & & & 664 & 37,6 \\
\hline 17 & 85 & & 664 & 37,6 \\
\hline 18 & & & 674 & 38,1 \\
\hline 19 & & & 660 & 37,4 \\
\hline 20 & & & 662 & 37,5 \\
\hline 21 & & & 690 & 39,1 \\
\hline 22 & 104 & & 670 & 37,9 \\
\hline 23 & & & 682 & 38,6 \\
\hline 24 & & & 691 & 39,1 \\
\hline
\end{tabular}




\subsection{2 - AÇO}

Para a montagem das armaduras dos protótipos, utilizou-se aço CA-50 A, comprado do comércio local ( região de São Carlos ). A partir das quantidades adquiridas, pode-se calcular o consumo de aço por metro cúbico de concreto, chegando-se ao valor $99,67 \mathrm{~kg} / \mathrm{m}^{3}$.

Tabela 4.5 - Quantidade de aço empregado nos protótipos

DIÂMETRO (mm) 5 8 12,5

16
QUANTIDADE EMPREGADA (kg)

6
150
80
69

Também deste material foram retiradas amostras para ensaio. Estas, foram devidamente instrumentadas a fim de obter-se algumas de suas propriedades mecânicas como a sua resistência à tração, seu módulo de deformação longitudinal e também, seu comportamento tensão $\mathrm{x}$ deformação.

Os resultados destes ensaios, bem como dos ensaios à compressão simples dos corpos-de-prova de concreto, são apresentados em anexo, na forma de gráficos.

Na realização dos ensaios, foi empregada a máquina universal de ensaios AMSLER, do Laboratório de Estruturas de Madeira da EESC, com capacidade de tração de até 25 toneladas. Também foi utilizada a máquina de ensaios à compressão AMSLER, do Laboratório de Construção Civil da EESC. 


\section{4 - INSTRUMENTAÇÃO DOS BLOCOS}

Com a instrumentação dos blocos, desejava-se obter a parcela da carga transferida à cada estaca de um grupo, bem como os deslocamentos (recalques) de cada bloco durante os ensaios e, as tensões provocadas pelo carregamento em diversas posições das armaduras. Para tanto, foram empregados instrumentos como:

- relógios comparadores;

- extensômetros elétricos de resistência;

- transdutores indutivos de deslocamentos;

- células de pressão;

- células de carga.

Para a coleta dos dados, empregou-se o sistema de aquisição automática de dados do Laboratório do Departamento de Estruturas da EESC-USP. Neste mesmo laboratório foram fabricadas células de carga especiais, de concreto, para serem colocadas no topo das estacas, conforme mostra a figura 4.4.

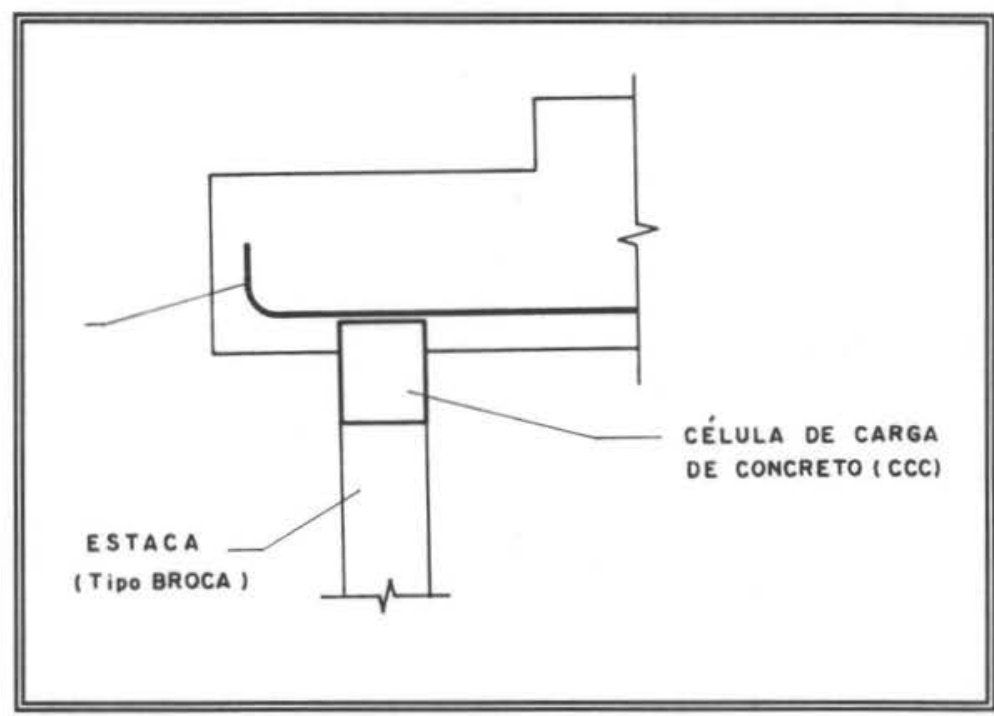

Figura 4.4 - Posição das CCC's 


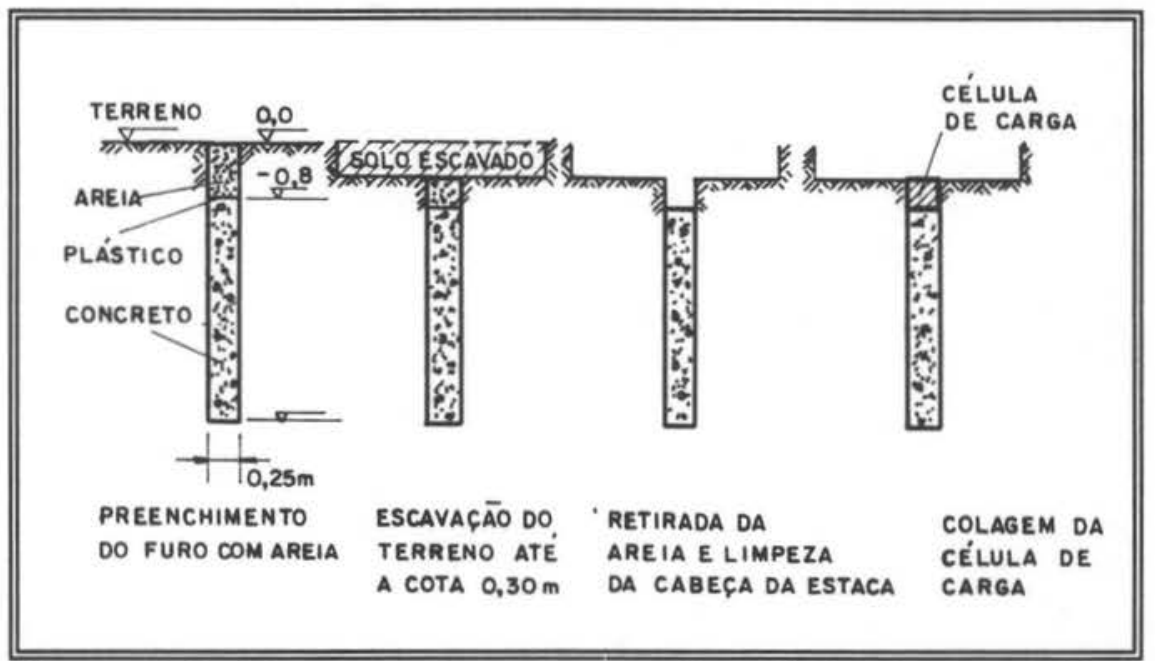

Figura 4.5 - Esquema da montagem das células de carga de concreto.

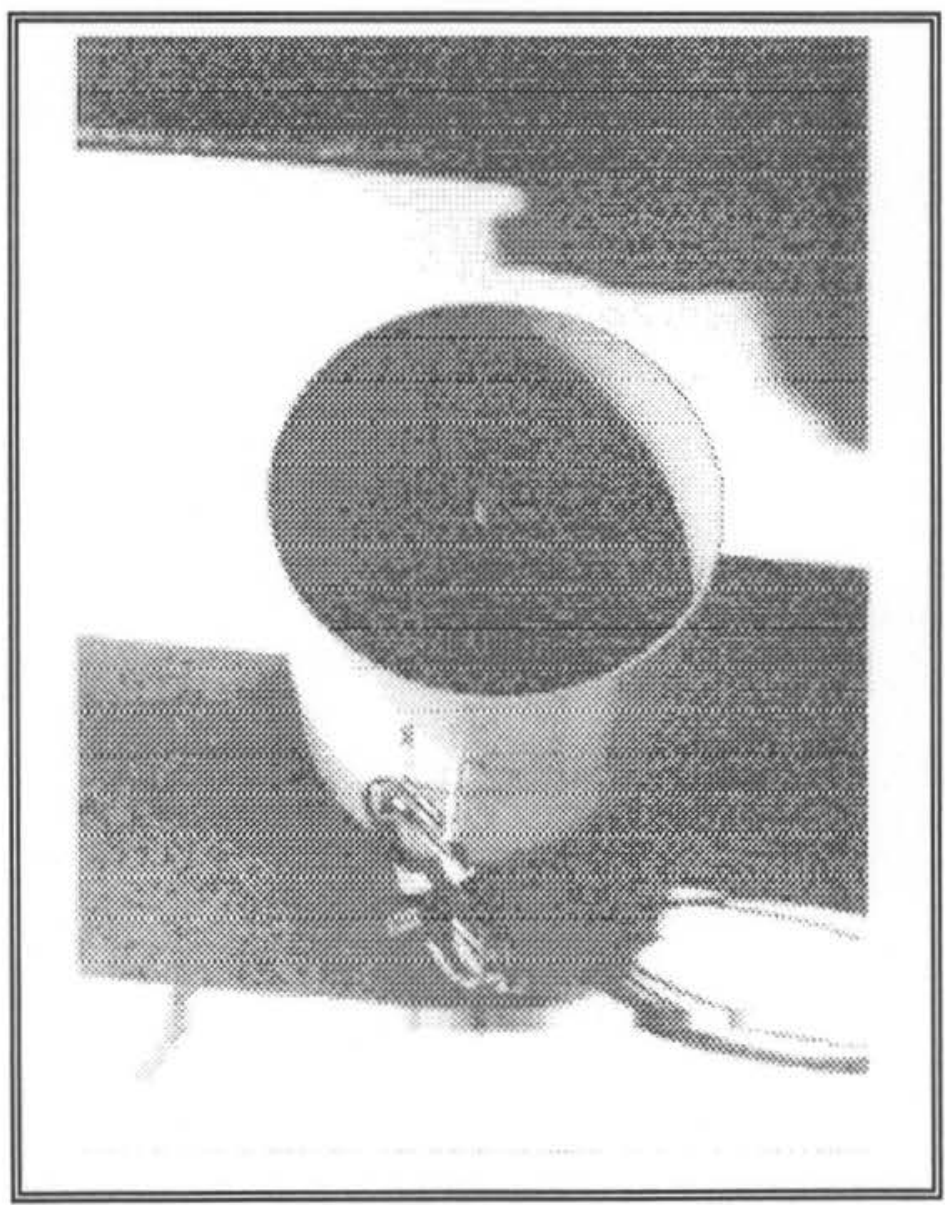

Foto 4.18 - Instrumentação da CCC. 
111

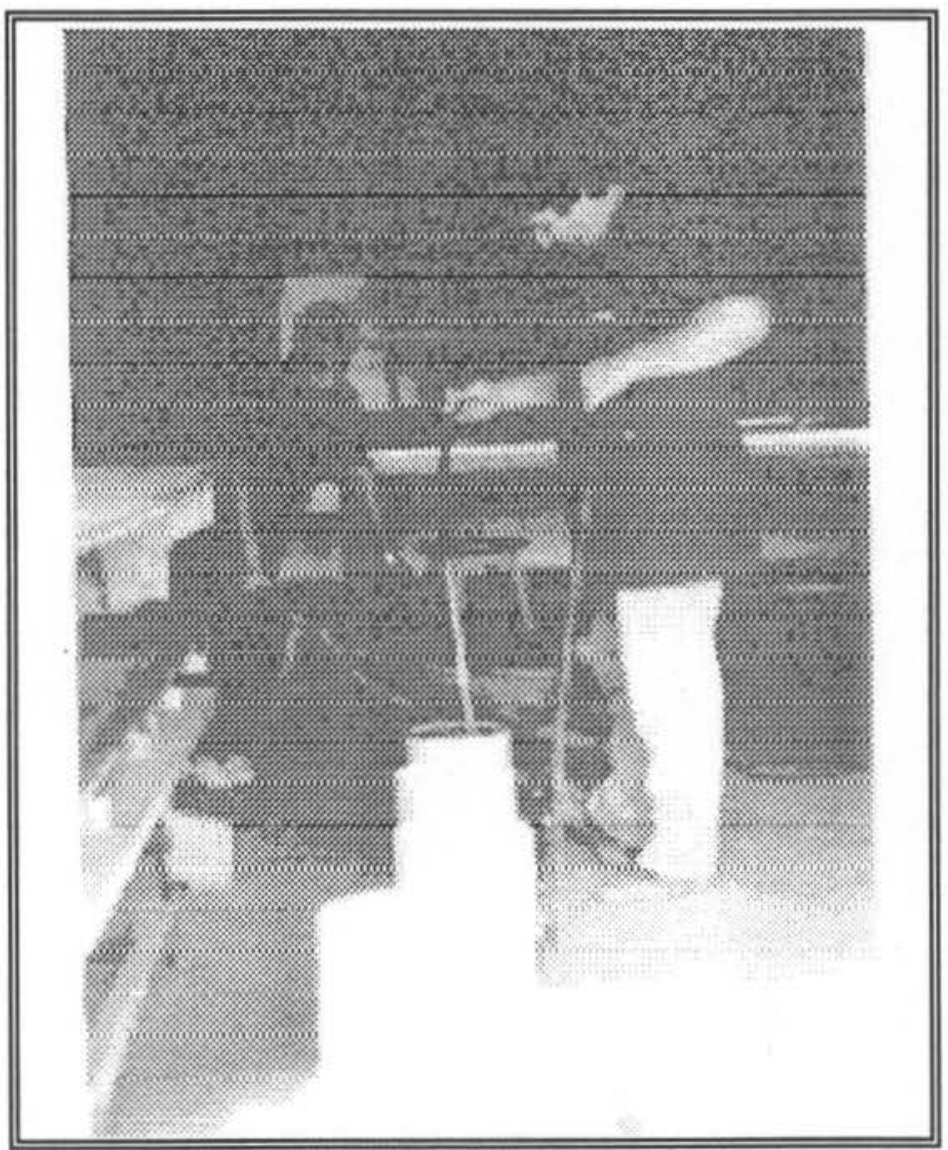

Foto 4.19 - Concretagem das CCC. 


\subsection{1 - INSTRUMENTAÇÃO DAS ARMADURAS DOS BLOCOS}

As armaduras foram intrumentadas com extensômetros elétricos ("strain gages") cujo funcionamento baseia-se na relação existente entre suas dimensões e consequentes variações de suas resistências elétricas.

As primeiras aplicações do princípio de funcionamento destes instrumentos datam de 1938-1939, por ocasião das experiências de Edward Simons e Arthur Rudge.

O emprego de extensômetros elétricos apresenta características bastante vantajosas para experimentos, dentre as quais pode-se destacar:

- precisão de medida;

- linearidade (proporcionalidade);

- desde que adequadamente protegidos, podem funcionar em condições ambientais adversas, podendo ser utilizados inclusive, imersos em água;

- os dados obtidos, podem ser registrados à distância.

\subsubsection{1 - Princípios fundamentais de extensometria}

A partir da observação dos fenômenos que envolvem a eletricidade, pode-se concluir que ao deformar-se um condutor elétrico de comprimento $L$, sua resistência elétrica sofrerá uma variação unitária, $\Delta R / R$, proporcional à deformação sofrida, $\varepsilon=\Delta L / L$.

De acordo com fundamentos da Eletricidade, a resistência elétrica de um condutor pode ser expressa por $R=\rho L / A$, onde $R$ é a resistência em 
omhs, $\boldsymbol{A}$ é a área da seção transversal, $\boldsymbol{L}$ é o comprimento e $\rho$, a resistividade do condutor.

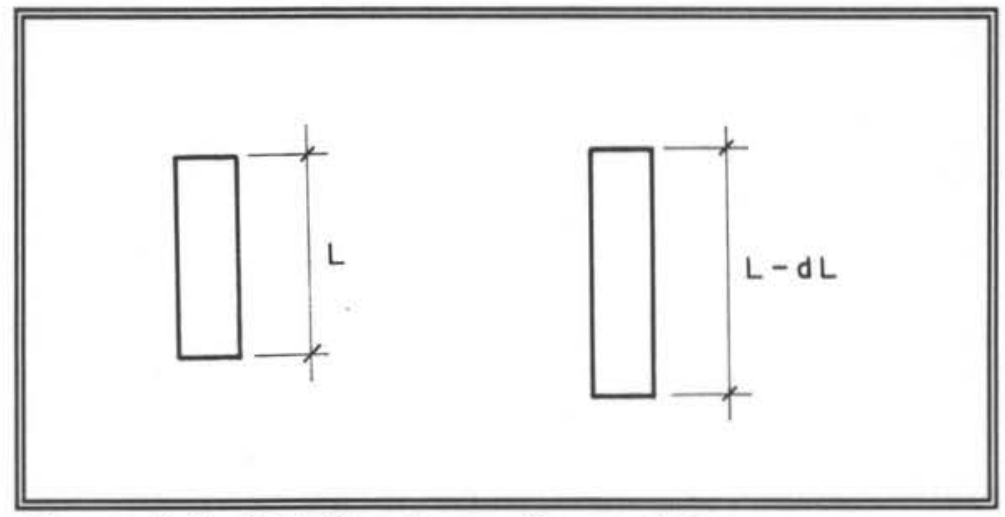

Figura 4.6 - Detalhe de um fio condutor

Submetendo-se o fio da figura 4.6 a uma deformação $d L$, pode-se escrever:

$$
d R=\frac{\rho}{A} d L+\frac{L}{A} d \rho-\frac{\rho L}{A^{2}} d A
$$

O volume do fio, que antes de sofrer a deformação, vale $V=L A$, após a mesma, apresenta uma variação igual a:

$$
d V=L d A+A d L
$$


Também pode-se escrever esta variação na forma:

$$
d V=(L+d L) \frac{\pi}{4}(\phi+d \phi)(\phi+d \phi)
$$

$$
d V=(L+d L) \frac{\pi}{4}\left(\phi^{2}+\phi d \phi+\phi d \phi+d \phi^{2}\right)-A L
$$

$$
d V=(L+d L) \frac{\pi}{4}(\phi-\phi v \varepsilon \phi-\phi v \varepsilon \phi)-A L
$$

$$
d V=(L+d L) \frac{\pi \phi^{2}}{4}(1-2 v \varepsilon)-A L
$$

$$
d V=L A(1-2 v \varepsilon+\varepsilon)-A L
$$

$$
d V=L A \varepsilon(1-2 v)
$$

Substituindo a equação 4.3 em 4.2,

$$
L A+A d L=L A \varepsilon(1-2 v), \operatorname{mas} \varepsilon=\frac{d L}{L}
$$


$L d A+A d L=A d L+2 L A v$

$$
L d A=-2 L A v \varepsilon
$$

Substituindo 4.4 em 4.1 tem-se:

$$
\begin{aligned}
& d R=\frac{\rho}{A} d L+\frac{L}{A} d \rho+\frac{\rho}{A^{2}} 2 L A \rho \varepsilon \quad \text { ou: } \\
& d R=\frac{\rho}{A} d L+\frac{L}{A} d \rho+2 v \rho \frac{d L}{A}
\end{aligned}
$$

Que dividida por $\quad R=\frac{\rho L}{A} \quad$, fornece:

$$
\frac{d R}{R}=\frac{d L}{L}+\frac{d \rho}{\rho}+2 v \frac{d L}{L}
$$

$$
\text { Assim, } \frac{d R / R}{d L / L}=1+2 v+\frac{d \rho / \rho}{d L / L}
$$

O último termo, é geralmente considerado constante para o material condutor empregado na fabricação de extensômetros. Assim, toda a expressão é uma constante chamada Fator do Extensômetro $(\boldsymbol{\kappa})$. 
Com este resultado, fica estabelecida a relação entre a deformação sofrida pelo extensômetro colado em um determinado corpo e a sua respectiva variação de resistência elétrica, ou seja:

$$
\frac{d R / R}{d L / L}=\kappa \text { ou, } \quad d R=\kappa \varepsilon R
$$

\subsubsection{2 - Tipos de extensômetros elétricos de resistência}

Conforme o objetivo a ser atingido, utilizam-se diferentes tipos de extensômetros, disponíveis de acordo com os seguintes critérios de classificação:

1 - Classificação através dos materiais resistivos:

- extensômetro de fio;

- extensômetro de lâmina;

- extensômetro semicondutor;

- extensômetro semicondutor por difusão;

2 - Classificação através do material da base:

- extensômetro com base de papel;

- extensômetro com base de baquelite;

- extensômetro com base de polyester;

- extensômetro com base de poliamida, etc.

3 - Classificação conforme a configuração:

- extensômetro axial único;

- extensômetro axial múltiplo;

- extensômetro com modelos especiais. 


\subsubsection{3 - Colagem dos extensômetros}

Empregou-se nas armaduras extensômetros do tipo colado, KFC-5-C1-11 da KYOWA Eletronic Instruments Co. LTD., mostrado na figura 4.7.

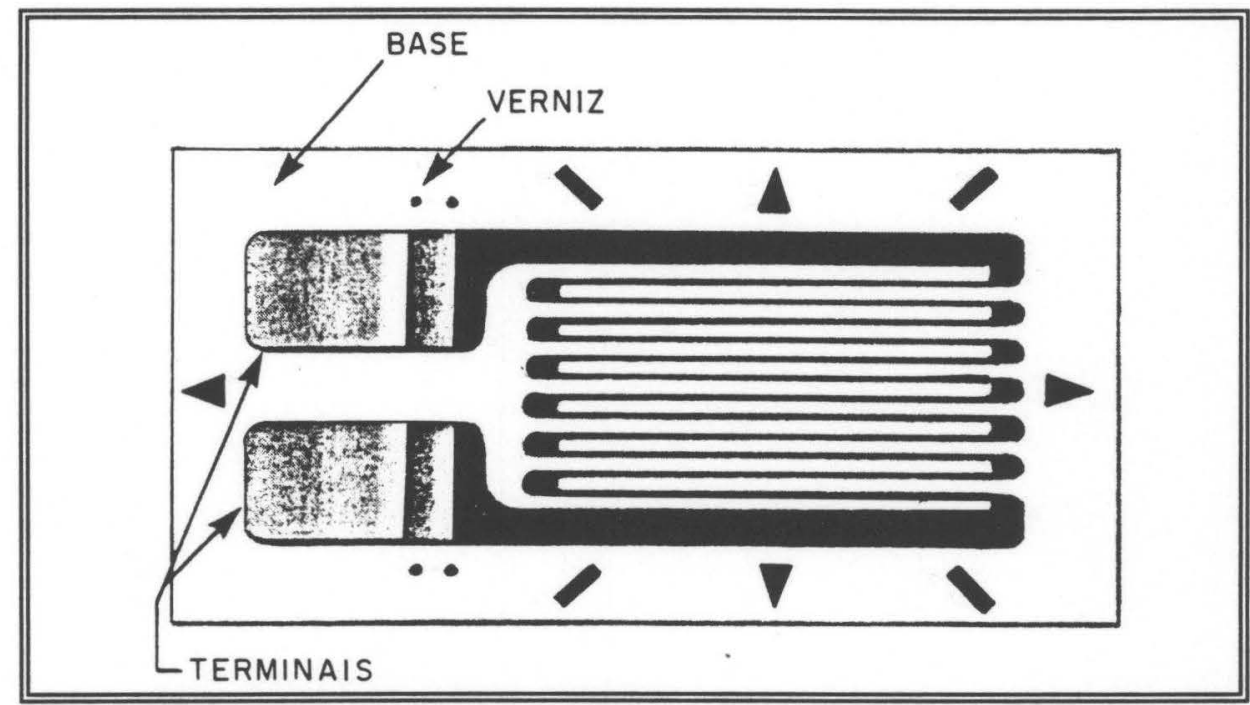

Figura 4.7 - Extensômetro elétrico de resistência

A colagem foi feita com adesivo Superbonder da LOCTITE BRASIL LTDA. A superfície das barras foi previamente lixada, sofrendo em seguida um tratamento com clorotene.

Nas fotos a seguir, são mostrados detalhes desta operação: 


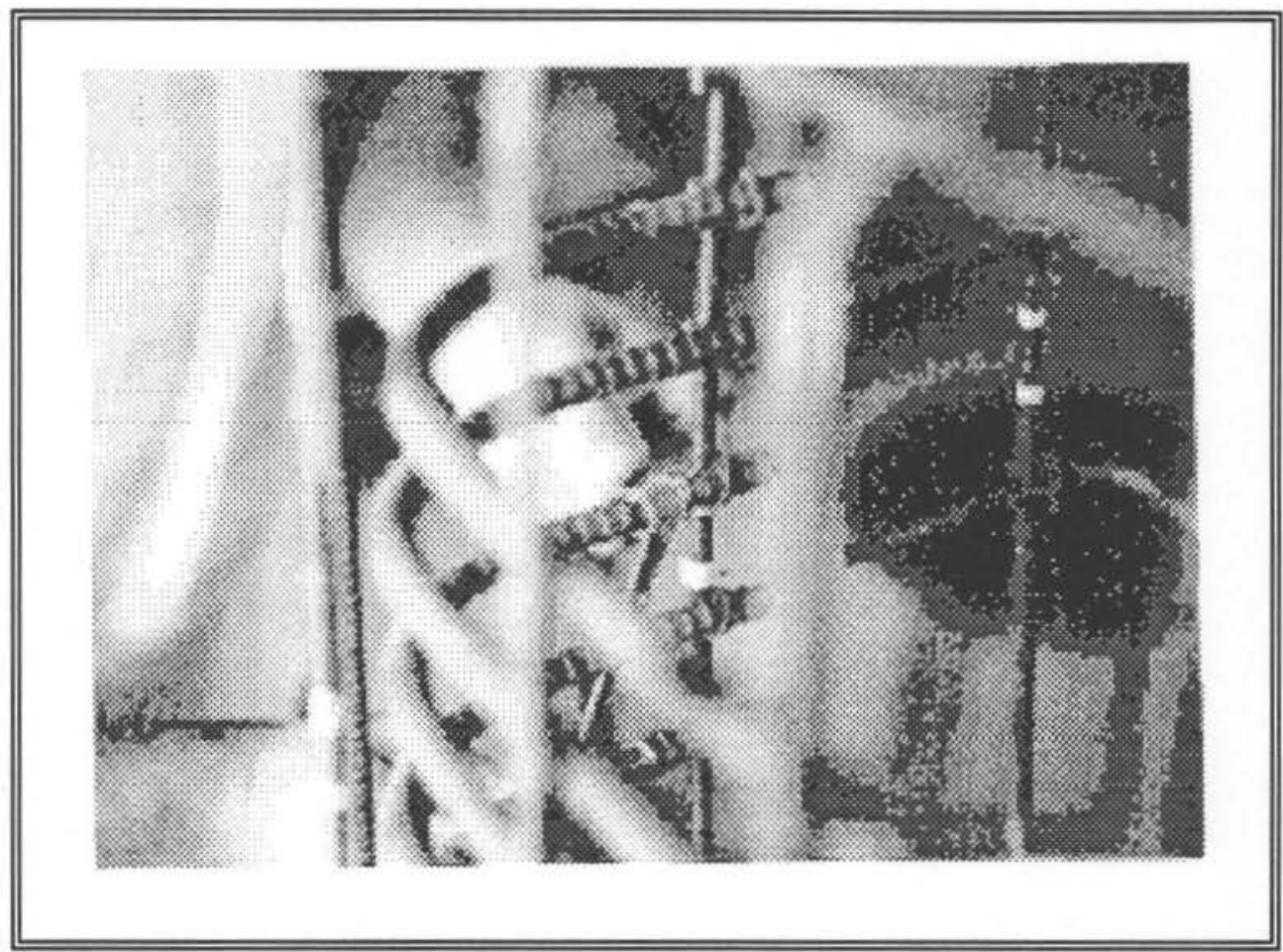

Foto 4.20 - Preparação da superfície

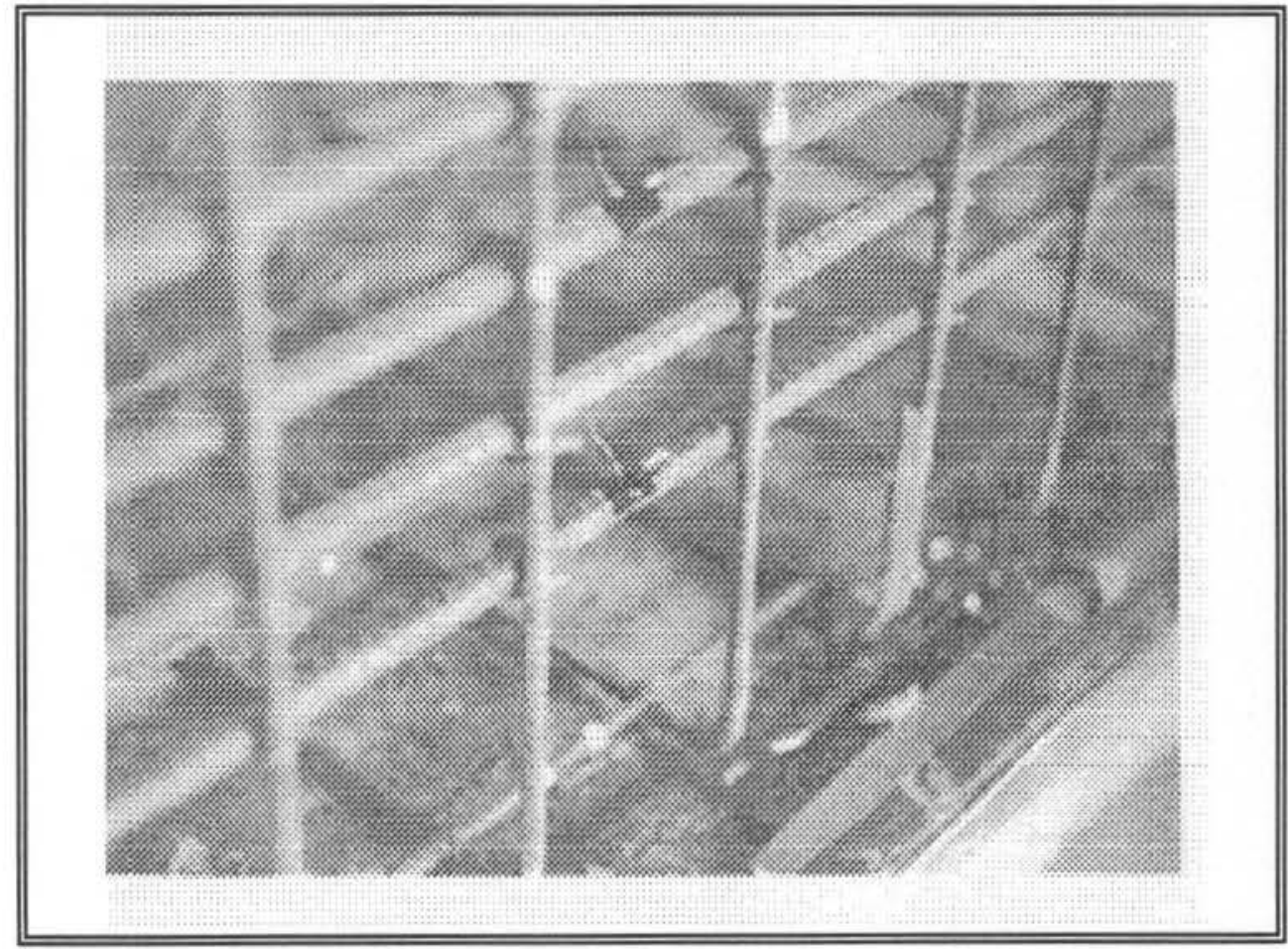

Foto 4.21 - Extensômetro colado 
Foi utilizado um total de aproximadamente 170 extensômetros, localizados nas barras através do sitema de orientação mostrado a seguir:

\section{- Bloco sobre uma estaca:}

estribos horizontais:
1 - B1HX1
4 - B1HY1
2 - B1HX2
5 - B1HY2
3 - B1HX3
6 - B1HY3

estribos verticais:

$$
\begin{array}{ll}
7 \text { - B1VX1T (leste) } & 10-\text { B1VX1B (leste) } \\
8-\mathrm{B} 1 \mathrm{~V} 2 \mathrm{~T} & 11-\mathrm{B} 1 \mathrm{VX} 2 \mathrm{~B} \text { (CCC-18) } \\
9 \text { - B1VX3T (oeste) } & 12-\mathrm{B} 1 \mathrm{VX} 3 \mathrm{~B} \text { (oeste) } \\
& 13-\mathrm{B} 1 \mathrm{~B} \text { (biela) }
\end{array}
$$

$$
\begin{array}{ll} 
& \text { B - base } \\
\text { onde, } & \text { T - topo } \\
\text { H - indica que a barra está na posição horizontal } \\
\text { X - direção arbitrária voltada para o leste } \\
\text { Y - direção arbitrária voltada para o sul }
\end{array}
$$

$\mathrm{O}$ primeiro número identifica o bloco e o segundo, a ordem da numeração das barras.

Com o extensômetro B1B, pretende-se registrar o esforço de compressão na região onde é prevista a formação da biela. Para tanto, o mesmo é colado numa barra disposta segndo a direção de formação da biela, procedimento repetido para os demais blocos. 
- Bloco sobre duas estacas:

estribos horizontais:

$\begin{array}{ll}1 \text { - B2HX1 } & 4 \text { - B2HY1 } \\ 2 \text { - } \mathrm{B} 2 \mathrm{HX} 2 & 5 \text { - B2HY2 } \\ 3 \text { - B2HX3 } & 6 \text { - B2HY3 }\end{array}$

estribos verticais:

$\begin{array}{ll}7-\mathrm{B} 2 \mathrm{VX} 1 \mathrm{~B} \text { (oeste) } & 10-\mathrm{B} 2 \mathrm{VZ1} \\ 8-\mathrm{B} 2 \mathrm{VX} 2 \mathrm{~B} & 11-\mathrm{B} 2 \mathrm{VZ2} \text { sul } \\ 9-\mathrm{B} 2 \mathrm{VX} 3 \mathrm{~B} \text { (leste) } & 12-\mathrm{B} 2 \mathrm{VZ3}\end{array}$

armadura inferior:

$$
\begin{aligned}
& 13 \text { - B2LI1E1 (CCC-5 - oeste) } \\
& 14 \text { - B2LI1M } \\
& 15 \text { - B2LI1E2 (CCC-11 - leste) } \\
& 16 \text { - B2LI2Z (oeste) } \\
& 17 \text { - B2LI2E1 (CCC-5 - oeste) } \\
& 18 \text { - B2LI2M } \\
& 19 \text { - B2LI2E2 (CCC-11 - leste) } \\
& 20 \text { - B2LI3E1 (CCC-5 - oeste) } \\
& 21 \text { - B2LI3M } \\
& 22 \text { - B2LI3E2 (CCC-11 - leste) }
\end{aligned}
$$

armadura superior:

$$
\begin{aligned}
& 23 \text { - B2LS1E } \\
& 24 \text { - B2LS1M }
\end{aligned}
$$


bielas:

$$
\begin{aligned}
& 25-\mathrm{B} 2 \mathrm{~B} 1 \text { (oeste) } \\
& 26-\mathrm{B} 2 \mathrm{~B} 2 \text { (leste) } \\
& 27-\mathrm{B} 2 \mathrm{P}
\end{aligned}
$$

$$
\begin{aligned}
& \text { En - estaca sob o referido ponto } \\
& \text { LI - armadura longitudinal inferior ligando a cabeça das } \\
& \quad \text { estacas } \\
& \text { LS - armadura longitudinal superior } \\
& \text { M - ponto médio }
\end{aligned}
$$

- Bloco sobre três estacas (disposição triangular):

estribos horizontais:

$$
\begin{array}{ll}
1 \text { - B3TH1X (oeste) } & 4 \text { - B3TH2X (oeste) } \\
2 \text { - B3TH1E (norte) } & 5 \text { - B3TH2E (norte) } \\
3 \text { - B3TH1D (sul) } & 6 \text { - B3TH2D (sul) }
\end{array}
$$

$$
\begin{aligned}
& 7 \text { - B3TH3X (oeste) } \\
& 8 \text { - B3TH3E (norte) } \\
& 9 \text { - B3TH3D (sul) }
\end{aligned}
$$


estribos verticais:

$$
\begin{aligned}
& 10-\text { B3TV1XZ (sul - oeste) } \\
& 11 \text { - B3TV2X } \\
& 12 \text { - B3TV2XZ (sul) } \\
& 13 \text { - B3TV3X (leste) } \\
& 14-\text { B3TV3XZ (sul) } \\
& 15-\text { B3TV1Y } \\
& 16-\text { B3TV1YZ (oeste - norte) } \\
& 17 \text { - B3TV2Y } \\
& 18 \text { - B3TV2YZ (oeste) } \\
& 19-\text { B3TV3Y } \\
& 20-\text { B3TV3YZ (oeste - norte) }
\end{aligned}
$$

armadura inferior

21 - B3TLIXZ (CCC-3 - norte)

22 - B3TLIXE1 (CCC-3 - oeste-norte)

23 - B3TLIXI (oeste)

24 - B3TLIXE3 (CCC-17 - oeste-sul)

25 - B3TLIEE1 (CCC-3 - norte-oeste)

26 - B3TLIEI (norte)

27 - B3TLIEE2 (CCC-16 - norte-leste)

28 - B3TLIEZ (CCC-16 - leste)

29 - B3TLIDE2 (CCC-16 - sul-leste)

30 - B3TLIDI (sul)

31 - B3TLIDE3 (CCC-17 - sul-oeste)

32 - B3TLIDZ (CCC-17 - oeste) 
armadura superior

$$
\begin{aligned}
& 33 \text { - B3TLSX (oeste) } \\
& 34 \text { - B3TLSE (norte) } \\
& 35 \text { - B3TLSD (sul) }
\end{aligned}
$$

bielas

$$
\begin{aligned}
& 36 \text { - B3TB1 (CCC-3 - oeste-norte) } \\
& 37 \text { - В3ТВ2 (CCC-16 - leste) } \\
& 38 \text { - В3ТB3 (CCC-17 - oeste-sul) } \\
& 39 \text { - В3TBV }
\end{aligned}
$$

$$
\begin{array}{ll} 
& \text { En - estaca sob o referido ponto } \\
\text { onde, } & \text { E - esquerda } \\
\text { D - direita } \\
\text { LI - armadura inferior } \\
\text { LS - armadura superior }
\end{array}
$$

- Bloco sobre três estacas (dispostas em linha):

estribos horizontais:

$$
\begin{array}{ll}
1 \text { - B3HX1 } & 3 \text { - B3HY1 } \\
2 \text { - B3HX2 oeste } & 4 \text { - B3HY2 sul } \\
& 5-\text { B3HY3 }
\end{array}
$$


estribos verticais:

$$
\begin{aligned}
& 6 \text { - B3VX1B (oeste) } \\
& 7 \text { - B3VX2B } \\
& 8 \text { - B3VX3B (leste) } \\
& 9 \text { - B3VZ1 (sul-oeste) } \\
& 10-\text { B3VZ2 (sul) } \\
& 11-\text { B3VZ3 (sul-leste) }
\end{aligned}
$$

$$
\text { armadura inferior }
$$

$$
\begin{aligned}
& 12 \text { - B3LI1E1 (CCC-9 - oeste) } \\
& 13 \text { - B3LI1I1 } \\
& 14 \text { - B3LI1E2 (CCC-15) } \\
& 15 \text { - B3LI112 } \\
& 16 \text { - B3LI1E3 (CCC-12 - leste) } \\
& 17 \text { - B3LI2Z (oeste) } \\
& 18 \text { - B3LI2E1 (CCC-9 - oeste) } \\
& 19 \text { - B3LI2I1 } \\
& 20 \text { - B3LI2E2 (CCC-15) } \\
& 21 \text { - B3LI2I2 } \\
& 22 \text { - B3LI2E3 (CCC-12 - leste) }
\end{aligned}
$$

armadura superior

$$
\begin{aligned}
& 23 \text { - B3LS1E2 (norte) } \\
& 24 \text { - B3LS1I1 (norte-oeste) }
\end{aligned}
$$


bielas

25 - B3B1 (CCC-9 - oeste)

26 - B3B2 (CCC-12 - leste)

27 - B3B3 (CCC-15 - vertical)

- Bloco sobre quatro estacas:

estribos horizontais estribos verticais

1 - B4H1X1 (oeste) 9 - B4V1XZ (norte-leste)

2 - B4H1Y1 (norte) $10-\mathrm{B} 4 \mathrm{~V} 2 \mathrm{XZ}$ (norte)

3 - B4H1X2 (leste) $11-\mathrm{B} 4 \mathrm{~V} 2 \mathrm{XB}$ (fundo)

4 - B4H1Y2 (sul) 12 - B4V3XZ (norte-oeste)

5 - B4H2X1 (oeste) 13 - B4V1YZ (oeste-norte)

6 - B4H2Y1 (norte) 14 - B4V2YZ (oeste)

7 - B4H2X2 (leste) 15 - B4V2YB (fundo)

8 - B4H2Y2 (sul) 16 - B4V3YZ (oeste-sul)

armadura inferior

17 - B4LI1X1E1 (CCC-6 - oeste-norte)

18 - B4LI1X1I (oeste)

19 - B4LI1X1E4 (CCC-7 - oeste-sul)

20 - B4LI2X1E1 (CCC-6 - oeste-norte)

21 - B4LI2X1I (oeste)

22 - B4LI2X1E4 (CCC-7 - oeste-sul)

23 - B4LI2X1Z (oeste-sul)

24 - B4LI3X1E1 (CCC-6 - oeste-norte) 


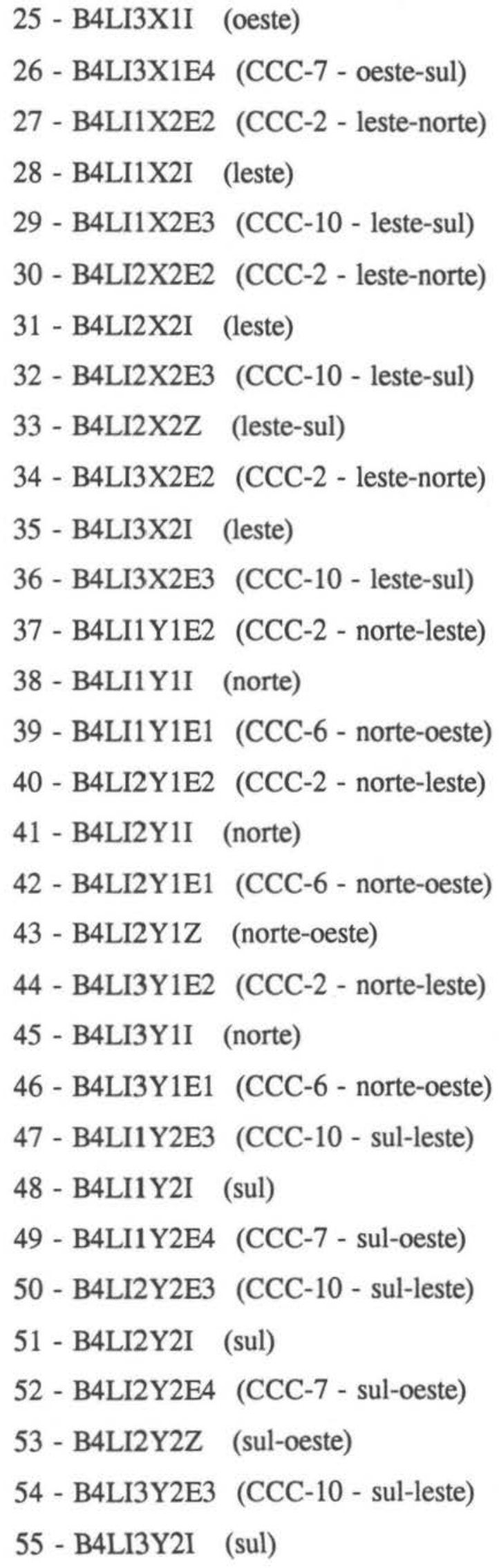


56 - B4LI3Y2E4 (CCC-7 - sul-oeste)

armadura superior bielas

\begin{tabular}{|c|c|}
\hline 57 - B4LS1X (oeste) & 61 - B4B1 (CCC-6) \\
\hline 58 - B4LS2X (leste) & $62-\mathrm{B} 4 \mathrm{~B} 2(\mathrm{CCC}-2)$ \\
\hline 59 - B4LS1Y (norte) & 63 - B4B3 (CCC-10) \\
\hline 60 - B4LS2Y (sul) & $64-\mathrm{B} 4 \mathrm{~B} 4$ \\
\hline & $65-\mathrm{B} 4 \mathrm{BV}$ \\
\hline
\end{tabular}

\subsubsection{4 - Medidas com extensômetros}

Os extensômetros são geralmente ligados a um circuito conhecido como Ponte de Wheatstone. Este, é formado pelos extensômetros elétricos e por resistores-padrão, internos, do aparelho utilizado na leitura das deformações. Na foto 4.27, é mostrado um modelo deste aparelho, chamado indicador de deformações.

Neste trabalho, os extensômetros foram ligados diretamente ao sistema de aquisição automática de dados do Laboratório do Departamento de Estruturas da EESC-USP. Foi empregada uma ligação em 1/4 de ponte, ajustando-se previamente a leitura de cada canal em zero, quando não havia carregamento atuando sobre o protótipo ensaiado.

Utilizaram-se indicadores de deformação apenas como controle auxiliar da aplicação de carga durante os ensaios. 


\subsection{2 - CÉLULAS DE CARGA DE CONCRETO}

Empregadas na avaliação da parcela de carregamento suportada individualmente por cada estaca, estes instrumentos foram fabricados conforme a concepção mostrada na figura 4.8. Para a calibração destas células, foi utilizada a prensa rígida servo-controlada MTS-815 do Laboratório de Mecânica dos Solos do Departamento de Geotecnia da EESC-USP.

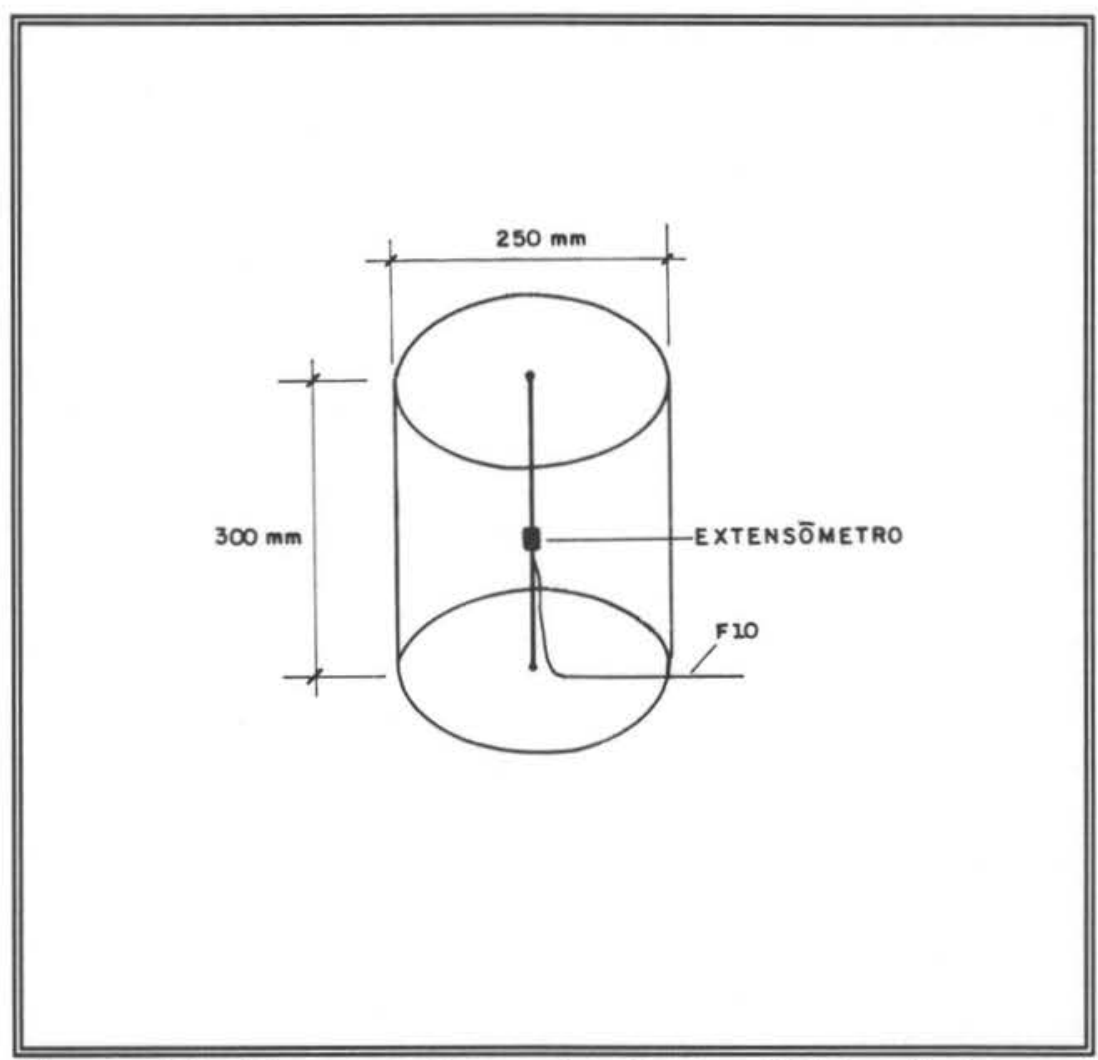

Figura 4.8 - Esquema de construção das Células de Carga.

As fotos seguintes mostram as células de carga prontas e a sua calibração, assim como, detalhes da preparação e execução dos ensaios (provas-decarga) dos protótipos: 


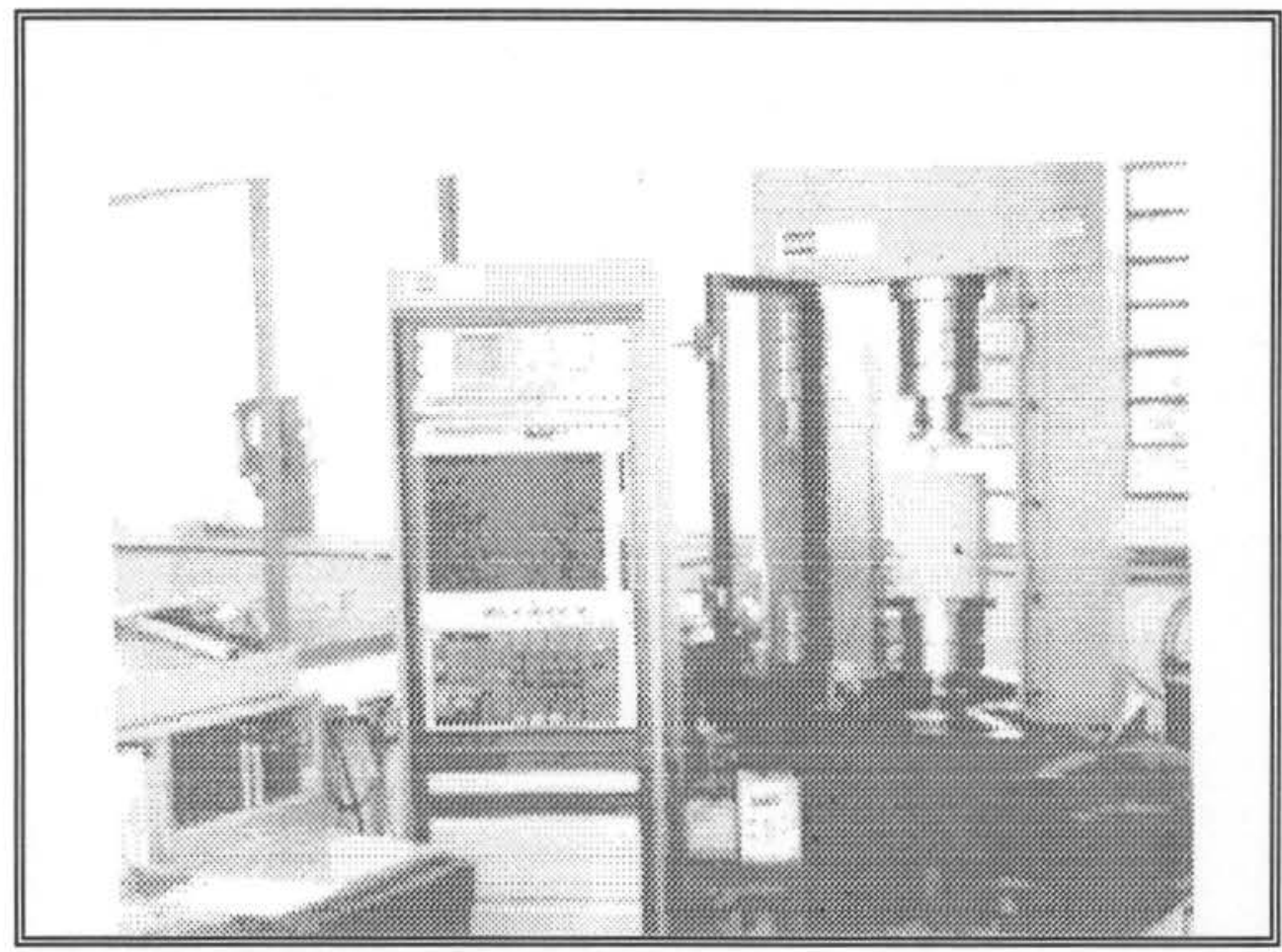

Foto 4.22 - Calibração de uma CCC.

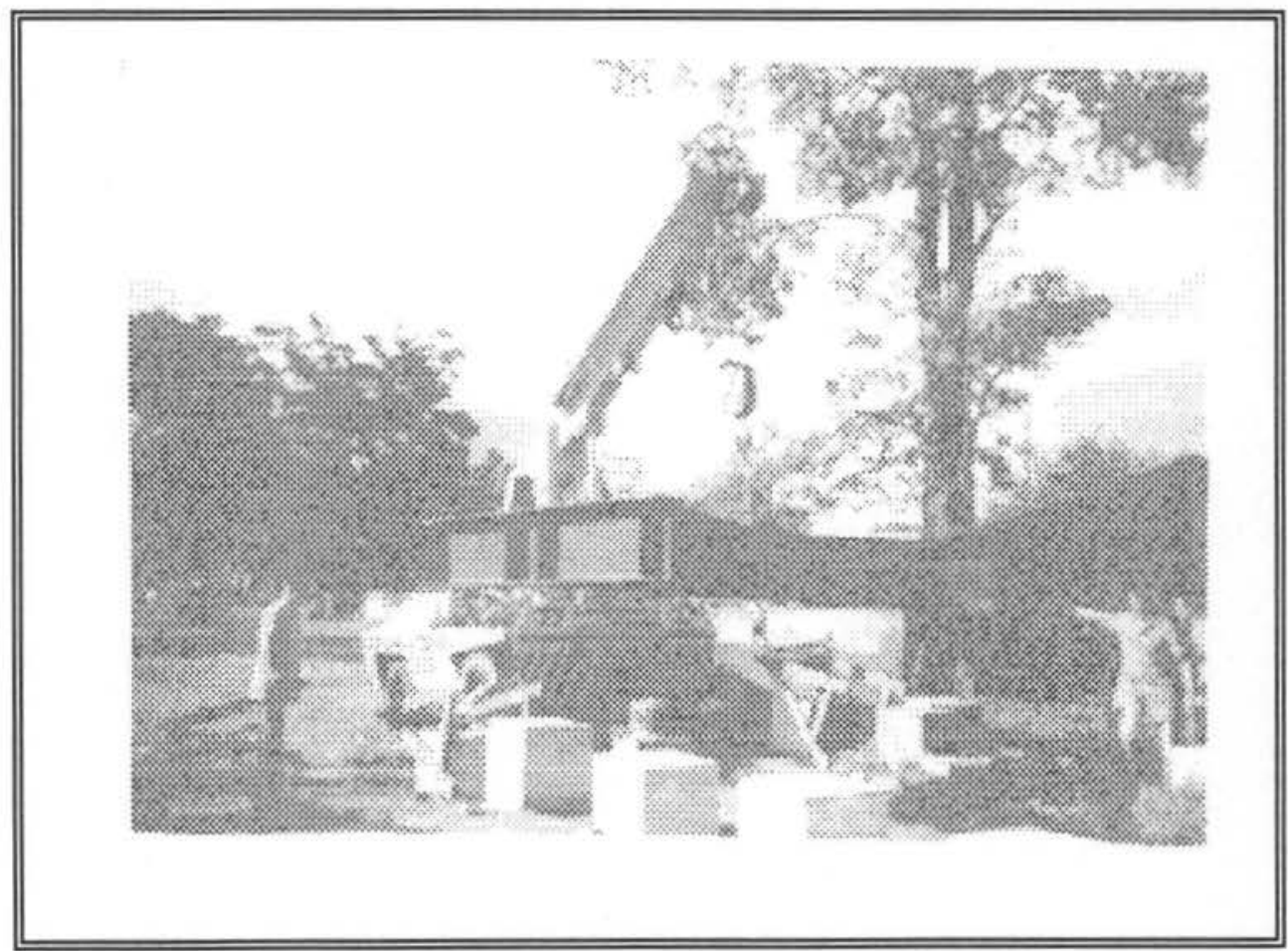

Foto 4.23 - Preparação: Transporte da estrutura de reação. 


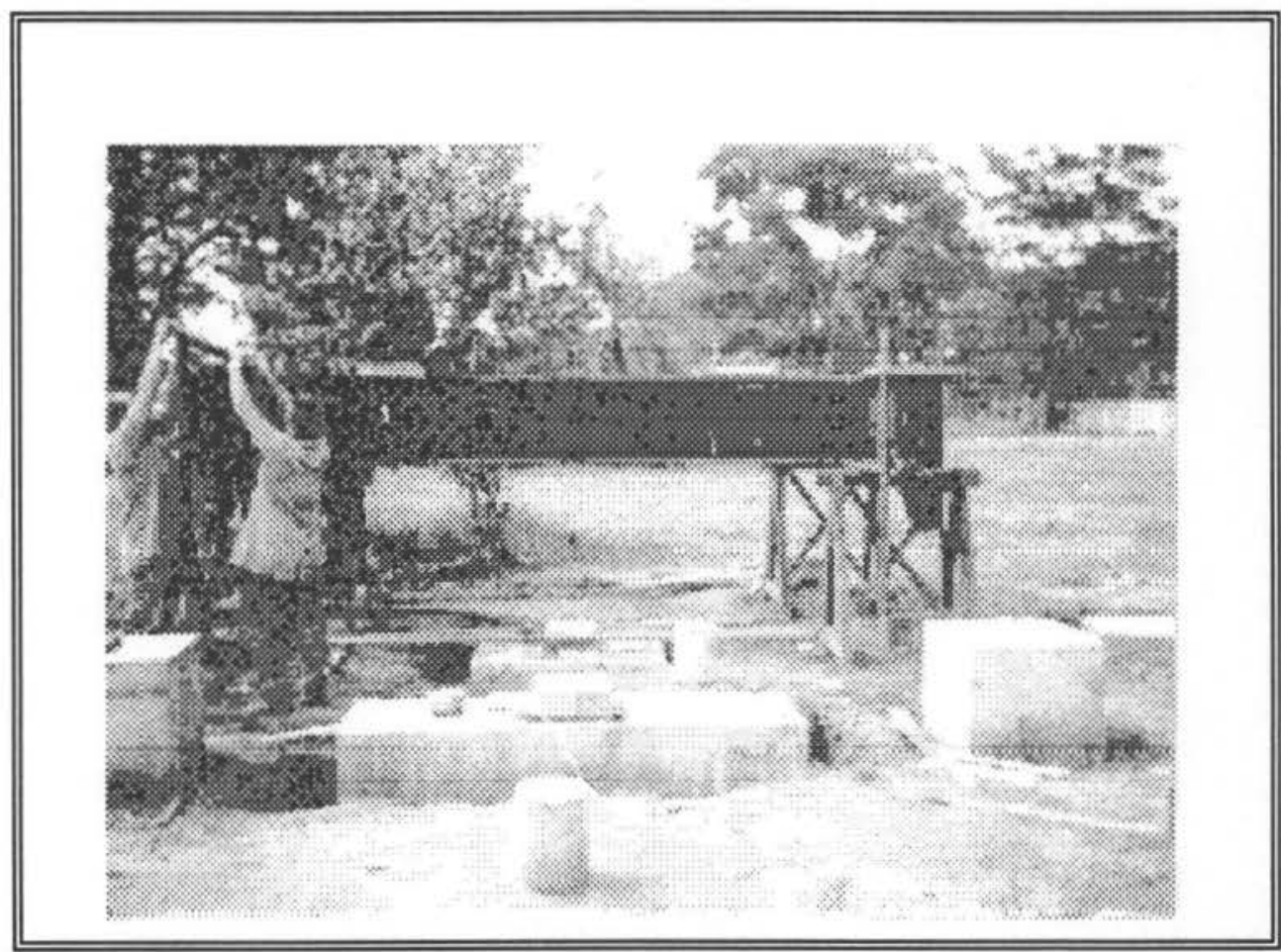

Foto 4.24 - Preparação: Fixação da viga aos tirantes.

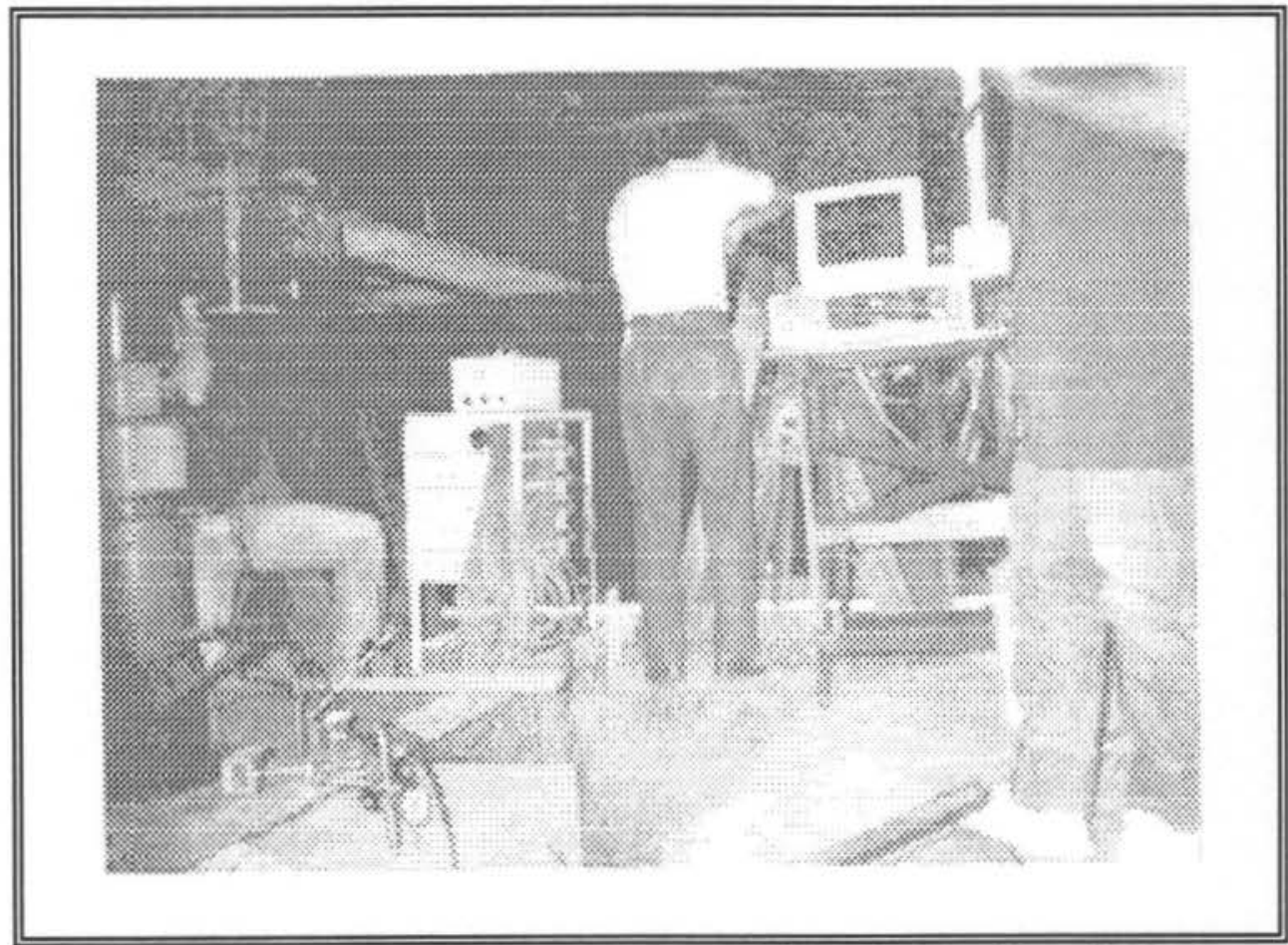

Foto 4.25 - Montagem do sistema de aquisição automática de dados. 


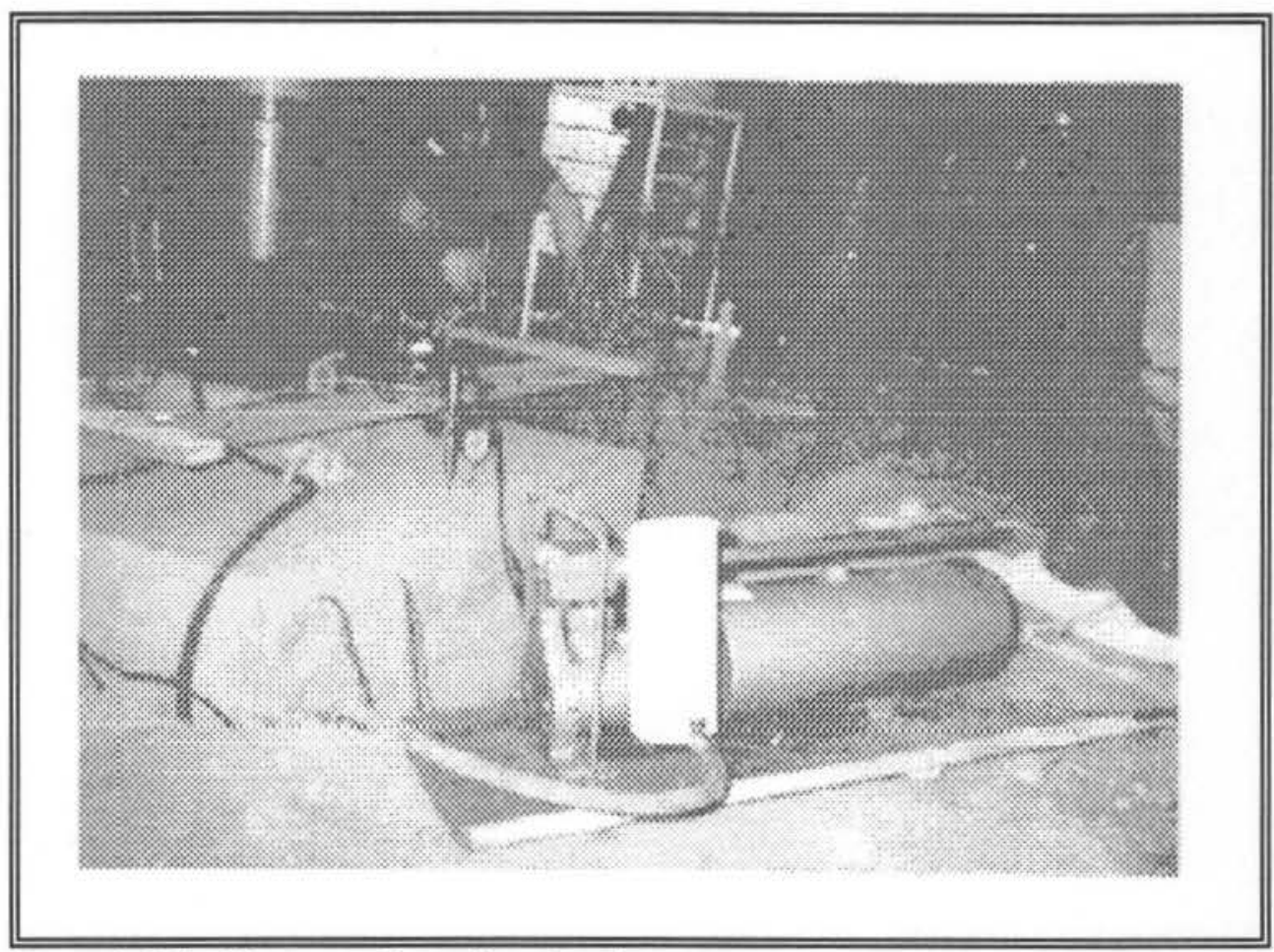

Foto 4.26 - Sistema de aplicação de carga

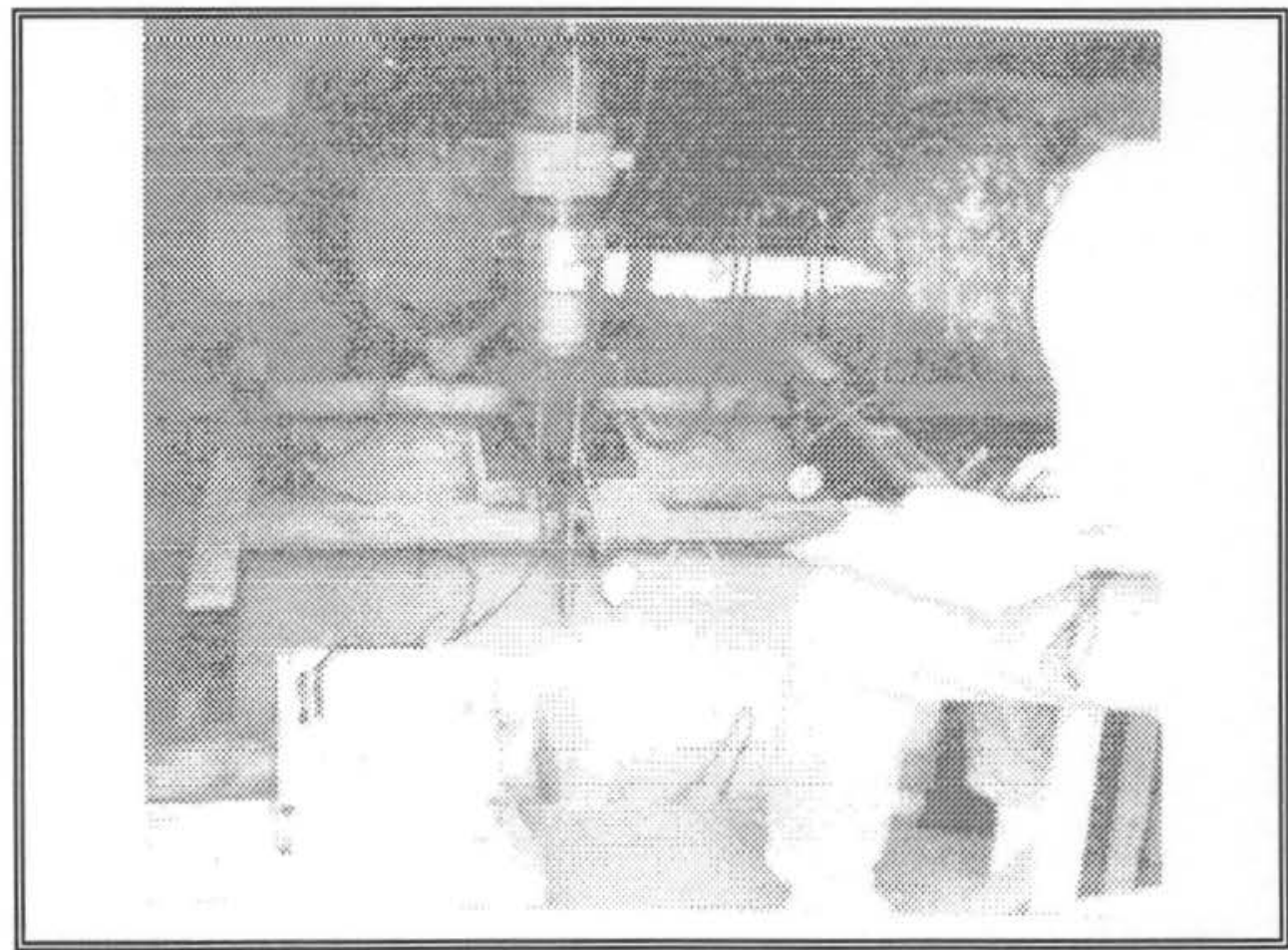

Foto 4.27 - Realização de um ensaio. 


\section{5 - RESULTADOS EXPERIMENTAIS}

\section{1 - INTRODUÇÃO}

Neste capítulo, são determinados os esforços a que foram submetidas as armaduras durante as provas-de-carga partindo-se das deformações medidas por intermédio dos extensômetros elétricos de resistência. Uma vez conhecidos, os esforços são comparados com os valores previstos no dimensionamento dos protótipos, conforme os diferentes processos de cálculo empregados.

Considerando os resultados dos ensaios de tração realizados com amostras do aço empregado na confecção das armaduras, cujos resultados são apresentados no Anexo C, pode-se obter, a partir da Lei de Hooke, uma expressão para calcular a força nas barras em função das deformações sofridas pelas mesmas, ou seja: 


$$
\sigma_{s}=\varepsilon_{s} E_{s}
$$

onde, $\quad \sigma_{s}:$ tensão na armadura;

$\varepsilon_{s}$ : deformação na armadura;

$\boldsymbol{E}$, : módulo de deformação.

Sabendo-se que $\sigma_{s}=\frac{F_{s}}{A_{s}}$, onde $F$, é a força aplicada em uma barra da armadura e $A_{s}$, a área da seção transversal da mesma, chega-se à expressão:

$$
F_{s}=\varepsilon_{s} E_{s} A_{s} \times 10^{-3}
$$

Para os diferentes diâmetros das barras empregadas, obtém-se diferentes valores para a constante $\boldsymbol{E A}$, conforme mostra a tabela a seguir:

Tabela 5.1 - Constante de multiplicação das deformações

\begin{tabular}{ccrrr}
\hline$\phi[\mathrm{mm}]$ & AREA $\left[\mathrm{cm}^{2}\right]$ & $\mathrm{E}\left[\mathrm{cm}^{2}\right]$ & $\mathrm{EA}[\mathrm{kN}]$ & $\mathrm{EA}\left[\mathrm{x} 10^{-3}\right]$ \\
5 & 0,181 & 20500 & 3710 & 3,71 \\
8 & 0,454 & 21000 & 9534 & 9,53 \\
12,5 & 1,150 & 19500 & 22425 & 2,42 \\
16 & 1,863 & 20000 & 37260 & 37,26 \\
& & & & \\
\hline
\end{tabular}

Os valores de $\boldsymbol{E} \boldsymbol{A}$ devem ser previamente multiplicados por $10^{-3}$, uma vez que as deformações medidas pelos extensômetros são apresentadas, nos gráficos, em $\mathrm{mm} / \mathrm{m}$. 


\section{2 - RESULTADOS PARA O BLOCO SOBRE UMA ESTACA}

Os extensômetros colados na armadura deste bloco, num total de 13, foram posicionados conforme o código de orientação estabelecido no ítem 4.4.1.3. Para confeccionar a armadura destes blocos, foram utilizadas barras de $8 \mathrm{~mm}$.

Os extensômetros B1HX1 e B1HY1, por estarem situados à mesma altura no interior do bloco, deveriam registrar uma mesma deformação, correspondente ao esforço de fendilhamento previsto pela expressão 2.48. O mesmo ocorre com os pares (B2HX2,B2HY2) e (B3HX3,B3HY3), estando estes, colados em barras situadas na altura média e na base do bloco, respectivamente.

Admite-se, neste caso, como deformação das barras horizontais da armadura, para verificação do esforço de fendilhamento, a média dos valores registrados por dois extensômetros colados em cada barra ( valores máximos alcançados na prova-de-carga ), conforme é mostrado na tabela 5.2: 
Tabela 5.2 - Bloco 1: Força de fendilhamento; $N_{e}=110,1 \mathrm{kN} ; \quad N_{d}=225,6 \mathrm{kN}$

\begin{tabular}{|c|c|c|c|c|c|}
\hline PONTO & POSIÇÃO & $\varepsilon[\mathrm{mm} / \mathrm{m}]$ & $\mathrm{F}_{\mathrm{e}}[\mathrm{kN}]$ & $\mathbf{F}_{\text {teo }}[\mathbf{k N}]$ & $\mathbf{F}_{\mathrm{e}} / \mathbf{F}_{\text {teo }}[\%]$ \\
\hline 1 & B1HX1 & 47 & 0,45 & & 5,84 \\
\hline 2 & B1HX2 & 52 & 0,50 & 7,71 & 6,49 \\
\hline 3 & B1HX3 & 50 & 0,48 & & 6,23 \\
\hline 4 & B1HY1 & 40 & 0,38 & & 4,93 \\
\hline 5 & B1HY2 & 52 & 0,50 & 7,71 & 6,49 \\
\hline 6 & B1HY3 & 47 & 0,45 & & 5,84 \\
\hline 7 & B1VX1T & 34 & 0,32 & & \\
\hline 8 & B1VX2T & PERDIDO & - & & \\
\hline 9 & B1VX3T & 38 & 0,36 & & \\
\hline 10 & B1VX1B & 27 & 0,25 & & \\
\hline 11 & $\mathrm{~B} 1 \mathrm{VX} 2 \mathrm{~B}$ & 42 & 0,40 & & \\
\hline 12 & B1VX3B & 71 & 0,67 & & \\
\hline 13 & B1B & -25 & $-0,24$ & & \\
\hline
\end{tabular}

Aplicando na expressão 2.48, o valor da ação vertical $N_{e}=110,1 \mathrm{kN}$, obtido no ensaio, pode-se calcular o esforço que tende a provocar o fendilhamento do bloco, conforme prevê o modelo idealizado por LANGENDONCK $^{(10)}$. Assim, chega-se a:

$$
F_{\text {teo }}=0,28(5,51)(55-20) \approx 54 k N
$$


Esta força é considerada atuando na altura média do bloco, onde os extensômetros B1HY2 e B1HX2 registraram, para a mesma ação vertical, a força média de $0,5 \mathrm{kN}$, conforme mostra a tabela 5.2.

\section{3 - RESULTADOS PARA OS BLOCOS SOBRE DUAS ESTACAS}

Examinando as deformações sofridas pelas barras da armadura inferior, observa-se que as leituras indicadas pelos extensômetros colocados no meio destas barras vai diminuindo à medida em que se aproxima das suas extremidades. No caso do bloco sobre duas estacas, estas armaduras possuem diâmetro $\phi=12,5 \mathrm{~mm}$, para o qual o produto entre a área da seção tranversal da barra e o módulo de elasticidade é dado por: $E A=22,42 \mathrm{kN}$.

Assim, as tabelas a seguir mostram os valores do esforço de tração atuando nas barras da armadura inferior, medidos pelos extensômetros, bem como os valores previstos pela teoria empregada no dimensionamento destas armaduras. Considera-se neste caso, uma ação vertical $N_{e}=323,4 \mathrm{kN}$, que a estrutura transmite ao bloco. 
Tabela 5.3 - Barra 1 (lateral); $N_{c}=323,4 \mathrm{kN} ; N_{d}=635 \mathrm{kN}$

\begin{tabular}{ccrrrr}
\hline PONTO & POSIÇÃO & $\varepsilon[\mathrm{mm} / \mathbf{m}]$ & $\mathbf{F}_{e}[\mathbf{k N}]$ & $\mathbf{F}_{\text {teo }}[\mathbf{k N}]$ & $\mathbf{F}_{\text {f }} / \mathbf{F}_{\text {teo }}[\%]$ \\
& & & & & \\
13 & B2LI1E1 & 155 & 3,5 & 19,6 & 17,86 \\
14 & B2LI1M & 198 & 4,4 & 24,5 & 17,96 \\
15 & B2LI1E2 & 52 & 1,2 & 19,6 & 6,12
\end{tabular}

Tabela 5.4 - Barra 2 (central); $N_{c}=323,4 \mathrm{kN} ; N_{d}=635 \mathrm{kN}$

\begin{tabular}{clrrrc}
\hline PONTO & POSIÇÃO & $\varepsilon[\mathrm{mm} / \mathbf{m}]$ & $\mathbf{F}_{e}[\mathbf{k N}]$ & $\mathbf{F}_{\text {leo }}[\mathbf{k N}]$ & $\mathbf{F}_{\mathbf{e}} / \mathbf{F}_{\text {leo }}[\%]$ \\
16 & B2LI2Z & 54 & 1,2 & 19,6 & 6,12 \\
17 & B2LI2E1 & 177 & 4,0 & 19,6 & 20,41 \\
18 & B2LI2M & 317 & 7,1 & 24,5 & 28,98 \\
19 & B2LI2E2 & 306 & 6,9 & 19,6 & 35,20 \\
\hline
\end{tabular}

Tabela 5.5 - Barra 3 (lateral); $\mathrm{N}_{\epsilon}=323,4 \mathrm{kN} ; \mathrm{N}_{\mathrm{d}}=635 \mathrm{kN}$

\begin{tabular}{clrrrr}
\hline PONTO & POSIÇÃO & $\varepsilon[\mathrm{mm} / \mathbf{m}]$ & $\mathbf{F}_{e}[\mathbf{k N}]$ & $\mathbf{F}_{\text {teo }}[\mathbf{k N}]$ & $\mathbf{F}_{e} / \mathbf{F}_{\text {too }}[\%]$ \\
& & & & & \\
20 & B2LI3E1 & 80 & 1,8 & 19,6 & 9,18 \\
21 & B2LI3M & 253 & 5,7 & 24,5 & 23,27 \\
22 & B2LI3E2 & 46 & 1,0 & 19,6 & 5,10
\end{tabular}


Nas demais armaduras do bloco sobre duas estacas, a saber, N2, N3 e N4, também foram colados extensômetros, como por exemplo, nas barras que constituem os estribos. A constante $\boldsymbol{E A}$ para estas barras, com diâmetro $\phi=8 \mathrm{~mm}$, será, conforme a tabela 5.2, $E A=9,53 \mathrm{kN}$.

A tabela a seguir fornece as leituras de deformação obtidas dos extensômetros colados nestas armaduras, para uma força vertical aplicada $N_{e}=323,4 \mathrm{kN}$. Neste caso, a força teórica, com a qual a força obtida do ensaio será comparada, será aquela correspondente à resistência ao escoamento do aço empregado:

Tabela 5.6 - Armaduras secundárias; $N_{e}=323,4 \mathrm{kN} ; \mathrm{N}_{\mathrm{d}}=635 \mathrm{kN}$

\begin{tabular}{llcrrr}
\hline PONTO & POSIÇÃo & $\boldsymbol{\varepsilon}[\mathbf{m m} / \mathbf{m}]$ & $\mathbf{F}_{\mathbf{e}}[\mathbf{k N}]$ & $\mathbf{F}_{\text {teo }}[\mathbf{k N}]$ & $\mathbf{F}_{\text {e }} / \mathbf{F}_{\text {teo }}[\%]$ \\
1 & B2HX1 & 83 & 0,8 & 19,7 & 4,06 \\
2 & B2HX2 & 174 & 1,7 & 19,7 & 8,63 \\
3 & B2HX3 & 34 & 0,3 & 19,7 & 1,52 \\
4 & B2HY1 & 6 & 0,1 & 19,7 & 0,51 \\
5 & B2HY2 & 43 & 0,4 & 19,7 & 2,03 \\
6 & B2HY3 & 68 & 0,6 & 19,7 & 3,05 \\
7 & B2VX1B & 50 & 0,5 & 19,7 & 2,54 \\
8 & B2VX2B & 145 & 1,4 & 19,7 & 7,11 \\
9 & B2VX3B & 38 & 0,4 & 19,7 & 2,03 \\
10 & B2VZ1 & 30 & 0,3 & 19,7 & 1,52 \\
11 & B2VZ2 & 324 & 3,1 & 19,7 & 15,74 \\
12 & B2VZ3 & 55 & 0,5 & 19,7 & 2,54 \\
25 & B2B1 & Perdido & - & - & - \\
26 & B2B2 & 88 & 0,8 & 19,7 & 4,06 \\
27 & B2V & -32 & $-0,3$ & 19,7 & 1,52
\end{tabular}




\section{4 - RESULTADOS PARA O BLOCO SOBRE TRÊS ESTACAS EM LINHA}

$\mathrm{Na}$ confecção da armadura inferior deste bloco empregaram-se quatro barras com diâmetro $\phi=16 \mathrm{~mm}$, tendo a constante EA o valor $E A=37,26 \mathrm{kN}$. Conforme as expressões definidas no capítulo 2, o esforço de tração máximo esperado numa destas barras pode ser obtido aplicando-se à expressão 2.42 o momento fletor calculado com a força $N_{e}=474 \mathrm{kN}$. Na seção que contém o eixo das estacas extremas este esforço deve ser considerado reduzido em $20 \%$, em acordo com a equação 2.41 .

$\mathrm{Na}$ tabela que segue, são apresentadas os esforços medidos por meio dos extensômetros colados em diversas posições de duas barras da armadura inferior, localizados observando-se o código adotado no ítem 4.4.1.3.

Tabela 5.7 - Bloco 3L: armaduras inferiores; $N_{\epsilon}=474,0 \mathrm{kN} ; N_{d}=970 \mathrm{kN}$

$\begin{array}{clcccc}\text { PONTO } & \text { POSIÇÃO } & \varepsilon[\mathbf{m m} / \mathbf{m}] & \mathbf{F}_{e}[\mathbf{k N}] & \mathbf{F}_{\text {teo }}[\mathbf{k N}] & \mathbf{F}_{e} / \mathbf{F}_{\text {teo }}[\%] \\ & & & & & \\ 12 & \text { B3LI1E1 } & 67 & 2,5 & 28,4 & 8,80 \\ 13 & \text { B3LI1I1 } & \text { perdido } & - & 28,4 & - \\ 14 & \text { B3LI1E2 } & \text { perdido } & - & 35,5 & - \\ 15 & \text { B3LI1I2 } & 150 & 5,6 & 28,4 & 19,72 \\ 16 & \text { B3LI1E3 } & 153 & 5,7 & 28,4 & 20,07 \\ 17 & \text { B3LI2Z } & 63 & 2,3 & 28,4 & 8,10 \\ 18 & \text { B3LI2E1 } & 67 & 2,5 & 28,4 & 8,80 \\ 19 & \text { B3LI2I1 } & \text { perdido } & - & 28,4 & - \\ 20 & \text { B3LI2E2 } & 425 & 15,8 & 35,5 & 44,51 \\ 21 & \text { B3LI2I2 } & 91 & 3,4 & 28,4 & 11,97 \\ 22 & \text { B3LI2E3 } & 76 & 2,8 & 28,4 & 9,86\end{array}$


Para as demais armaduras deste bloco, executadas em barras de diâmetro $\phi=8 \mathrm{~mm}$, a constante $E A$ assume o valor $E A=9,53$, sendo apropriado comparar-se o esforço nestas barras devido à máxima força aplicada no ensaio com o esforço que corresponde à resistência ao início de escoamento da categoria de aço empregada. Tal procedimento é necessário devido à inexistência no método de dimensionamento utilizado de expressões prevendo o esforço nestas armaduras, razão pela qual as mesmas são consideradas meramente como armaduras construtivas. Na tabela que segue, são apresentados então os esforços registrados no ensaio e os valores últimos:

Tabela 5.8 - Armaduras adicionais; $N_{e}=474,0 \mathrm{kN} ; N_{d}=970 \mathrm{kN}$

\begin{tabular}{clcccc}
\hline PONTO & POSIÇÃO & $\varepsilon[\mathbf{m m} / \mathbf{m}]$ & $\mathbf{F}_{\mathbf{e}}[\mathbf{k N}]$ & $\mathbf{F}_{\text {leo }}[\mathbf{k N}]$ & $\mathbf{F}_{e} / \mathbf{F}_{\text {teo }}[\%]$ \\
1 & B3HX1 & 458 & 4,4 & 19,7 & 22,34 \\
2 & B3HX2 & 160 & 1,5 & 19,7 & 7,61 \\
3 & B3HY1 & 29 & 0,3 & 19,7 & 1,52 \\
4 & B3HY2 & perdido & - & - & - \\
5 & B3HY3 & 112 & 1,1 & 19,7 & 5,58 \\
6 & B3VX1B & 65 & 0,6 & 19,7 & 3,05 \\
7 & B3VX2B & 802 & 7,6 & 19,7 & 38,58 \\
8 & B3VX3B & 143 & 1,4 & 19,7 & 7,11 \\
9 & B3VZ1 & 35 & 0,3 & 19,7 & 1,52 \\
10 & B3VZ2 & 9 & 0,1 & 19,7 & 0,51 \\
11 & B3VZ3 & 49 & 0,5 & 19,7 & 2,53 \\
& & & & & \\
23 & B3LS1E2 & 3979 & 37,9 & 19,7 & 192,38 \\
24 & B3LS1I1 & 3516 & 33,5 & 19,7 & 170,05 \\
& & & & & \\
25 & B3B1 & 58 & 0,6 & 19,7 & 3,05 \\
26 & B3B2 & 27 & 0,3 & 19,7 & 1,52 \\
27 & B3V & 308 & 2,9 & 19,7 & 14,72 \\
& & & & & \\
& & & & & \\
\hline
\end{tabular}




\section{5 - RESULTADOS PARA O BLOCO TRIANGULAR}

Em acordo com os cálculos efetuados no ítem 3.3.1.3, foram empregadas na armadura inferior deste bloco 7 (sete) barras com diâmetro $\phi=12,5 \mathrm{~mm}$, dispostas segundo a direção paralela a cada uma das faces laterais do mesmo. Para estas barras a constante de multiplicação para obter-se o esforço atuante será, conforme a tabela 5.1, $E A=22,43$.

Tabela 5.9 - Bloco 3T: Armadura inferior; $N_{\mathrm{e}}=463,0 \mathrm{kN} ; \mathrm{N}_{\mathrm{d}}=1099 \mathrm{kN}$

\begin{tabular}{clcccc}
\hline PONTO & POSIÇÃO & $\varepsilon[\mathbf{m m} / \mathbf{m}]$ & $\mathbf{F}_{e}[\mathbf{k N}]$ & $\mathbf{F}_{\mathbf{k e o}}[\mathbf{k N}]$ & $\mathbf{F}_{e} / \mathbf{F}_{\mathbf{l e o}}[\%]$ \\
& & & & - & - \\
21 & B3TLIXZ & perdido & - & - & - \\
22 & B3TLIXE1 & perdido & - & - & 148,00 \\
23 & B3TLIXI & 659 & 14,8 & 10 & 16,25 \\
24 & B3TLIXE3 & -59 & $-1,3$ & 8 & \\
& & & & & 10,00 \\
25 & B3TLIEE1 & 37 & 0,8 & 8 & 57,00 \\
26 & B3TLIEI & 235 & 5,7 & 10 & 76,25 \\
27 & B3TLIEE2 & -273 & $-6,1$ & 8 & 8,75 \\
28 & B3TLIEZ & 31 & 0,7 & 8 & \\
& & & & & 16,25 \\
29 & B3TLIDE2 & 57 & 1,3 & 8 & 195,00 \\
30 & B3TLIDI & 869 & 19,5 & 10 & - \\
31 & B3TLIDE3 & 43 & 1,0 & 8 & 10,00 \\
32 & B3TLIDZ & perdido & - & - & \\
& & & & & \\
\hline
\end{tabular}

Para as demais armaduras deste bloco, $\boldsymbol{A}_{s e}$ e $\boldsymbol{A}_{\boldsymbol{s}}$, respectivamente armadura superior e armadura lateral (estribos horizontais e verticais), utilizou-se barras com $\phi=8 \mathrm{~mm}$ para as quais adota-se $E A=9,53 \mathrm{kN}$. Como a 
determinação destas armaduras envolveu critérios meramente construtivos, não tendo sido previsto valor dos esforços a solicitá-las, irá se comparar os esforços medidos no ensaio com o esforço que provoca o escoamento destas armaduras, a exemplo do que foi feito para os demais blocos. Assim, considerando a área de seção transversal indicada na tabela 5.1 para barras com este diâmetro, o esforço que provoca tensões iguais à rresistência de início de escoamento $f_{\text {gk }}$, será $F_{\text {teo }}=19,74 \mathrm{kN}$, sendo possível então escrever a seguinte tabela: 
Tabela 5.10 - Bloco 3T: Armaduras adicionais; $N_{\mathrm{e}}=463,0 \mathrm{kN} ; \mathrm{N}_{\mathrm{d}}=1099 \mathrm{kN}$

\begin{tabular}{|c|c|c|c|c|c|}
\hline PONTO & POSIÇÃO & $\varepsilon[\mathrm{mm} / \mathbf{m}]$ & $\mathrm{F}_{\mathrm{e}}[\mathrm{kN}]$ & $F_{\text {teo }}[k N]$ & $\mathbf{F}_{\mathrm{e}} / \mathbf{F}_{\text {teo }}[\%]$ \\
\hline 1 & B3TH1X & 28 & 0,3 & 19,7 & 1,52 \\
\hline 4 & B3TH2X & 294 & 2,8 & 19,7 & 14,21 \\
\hline 7 & В3ТН3X & 80 & 0,8 & 19,7 & 4,06 \\
\hline 2 & B3TH1E & 18 & 0,2 & 19,7 & 1,02 \\
\hline 5 & B3TH2E & 39 & 0,4 & 19,7 & 2,03 \\
\hline 6 & В3ТН3E & 37 & 0,4 & 19,7 & 2,03 \\
\hline 3 & B3TH1D & 2147 & 20,5 & 19,7 & 104,06 \\
\hline 6 & B3TH2D & 129 & 1,2 & 19,7 & 6,09 \\
\hline 9 & B3TH3D & 207 & 2,0 & 19,7 & 10,15 \\
\hline 10 & B3TV1XZ & -27 & $-0,3$ & 19,7 & 1,52 \\
\hline 12 & B3TV2XZ & 46 & 0,4 & 19,7 & 2,03 \\
\hline 14 & B3TV3XZ & 29 & 0,3 & 19,7 & 1,52 \\
\hline 11 & B3TV2X & 44 & 0,4 & 19,7 & 2,03 \\
\hline 13 & B3TV3X & 57 & 0,5 & 19,7 & 2,54 \\
\hline 15 & B3TV1Y & 380 & 3,6 & 19,7 & 18,27 \\
\hline 17 & B3TV2Y & 61 & 0,6 & 19,7 & 3,05 \\
\hline 19 & B3TV3Y & 62 & 0,6 & 19,7 & 3,05 \\
\hline 16 & B3TV1YZ & perdido & - & - & - \\
\hline 18 & B3TV2YZ & 18 & 0,2 & 19,7 & 1,02 \\
\hline 20 & B3TV3YZ & 514 & 4,9 & 19,7 & 24,87 \\
\hline 33 & B3TLSX & 13 & 0,1 & 19,7 & 0,51 \\
\hline 34 & B3TLSE & -10 & $-0,1$ & 19,7 & 0,51 \\
\hline 35 & B3TLSD & 45 & 0,4 & 19,7 & 2,03 \\
\hline 36 & B3TB1 & -22 & 0,2 & 19,7 & 1,01 \\
\hline 37 & B3TB2 & 37 & 0,4 & 19,7 & 2,03 \\
\hline 38 & B3TB3 & 173 & 1,6 & 19,7 & 8,12 \\
\hline 39 & B3TBV & -26 & 0,2 & 19,7 & 1,02 \\
\hline
\end{tabular}




\section{6 - RESULTADOS PARA O BLOCO SOBRE QUATRO ESTACAS}

Para este protótipo, os valores máximos das deformações medidas pelos extensômetros ocorreram, em diferentes posições no interior do mesmo, em etapas diferentes do carregamento, ao serem atingidas as forças $360,2 \mathrm{kN} ; 390,2 \mathrm{kN}$; $510,1 \mathrm{kN} ; 541,5 \mathrm{kN} ; 592,3 \mathrm{kN}$.

A armadura deste bloco constituiu-se de 5 (cinco) barras com diâmetro $\phi=16 \mathrm{~mm}$ para a armadura inferior de tração, dispostas conforme as direções de cada face lateral. As demais armaduras, de caráter meramente construtivo, foram executadas com barras de diâmetro $\phi=8 \mathrm{~mm}$. Calculando-se então os esforços na armadura inferior, admitindo para tanto, $E A=37,26 \mathrm{kN}$, chega-se às tabelas:

TABELA 5.11 - Armadura inferior: Lado oeste; $N_{d}=1494 \mathrm{kN}$

\begin{tabular}{|c|c|c|c|c|c|}
\hline PONTO & POSIÇÃO & $\varepsilon[\mathrm{mm} / \mathrm{m}]$ & F. [kN] & $\mathbf{F}_{\text {teo }}[\mathrm{kN}]$ & $\mathbf{F} / \mathbf{F}_{\text {tee }}[\%]$ \\
\hline 17 & B4LI1X1E1 & 27 & 1,0 & 14,9 & 6,71 \\
\hline 18 & B4LI1X1I & 1099 & 40,9 & 18,6 & 219,89 \\
\hline 19 & B4LI1X1E4 & -10 & $-0,4$ & 14,9 & 2,68 \\
\hline 20 & B4LI2X1E1 & 66 & 2,5 & 9,8 & 25,51 \\
\hline 21 & B4LI2X1I & 137 & 5,1 & 12,2 & 41,80 \\
\hline 22 & B4LI2X1E4 & 53 & 2,0 & 9,8 & 20,41 \\
\hline 23 & B4LI2X1Z & 30 & 1,1 & 9,8 & 11,22 \\
\hline 24 & B4LI3X1E1 & 45 & 1,7 & 9,8 & 17,35 \\
\hline 25 & B4LI3X1I & 1450 & 54,0 & 12,2 & 443,62 \\
\hline 26 & B4LI3X1E4 & 40 & 1,5 & 9,8 & 15,31 \\
\hline
\end{tabular}


A tabela anterior refere-se às barras colocadas paralelamente à face oeste do bloco, ligando as cabeças das estacas 6 e 7. Aquelas dos tipos LI1 e LI3 sendo barras externas e a do tipo LI2, a barra central. Em seguida , apresenta-se as tabelas referentes às demais direções segundo as quais foram colocadas as barras da armadura inferior:

Tabela 5.12 - Armadura inferior: Norte, Sul e Leste; $N_{d}=1494$ kN

\begin{tabular}{|c|c|c|c|c|c|}
\hline PONTO & POSIÇÃO & $\varepsilon[\mathrm{mm} / \mathrm{m}]$ & $F_{e}[\mathbf{k N}]$ & $\mathbf{F}_{\text {teo }}[\mathbf{k N}]$ & $\mathbf{F} / \mathbf{F}_{\text {teo }}[\%]$ \\
\hline 27 & B4LI1X2E2 & 616 & 23,0 & 14,9 & 154,36 \\
\hline 28 & B4LI1X2I & 1044 & 38,9 & 18,6 & 209,14 \\
\hline 29 & B4LI1X2E3 & 435 & 16,2 & 14,9 & 108,72 \\
\hline 30 & B4LI2X2E2 & perdido & - & - & - \\
\hline 31 & B4LI2X2I & 677 & 25,2 & 17,0 & 148,24 \\
\hline 32 & B4LI2X2E3 & 34 & 1,3 & 13,6 & 9,56 \\
\hline 33 & B4LI2X2Z & 21 & 0,8 & 13,6 & 5,88 \\
\hline 34 & B4LI3X2E2 & 116 & 4,3 & 9,8 & 43,88 \\
\hline 35 & B4LI3X2I & perdido & - & 12,2 & - \\
\hline 36 & B4LI3X2E3 & 56 & 2,1 & 9,8 & 21,43 \\
\hline 37 & B4LI1Y1E2 & 58 & 2,2 & 14,9 & 14,77 \\
\hline 38 & B4LI1Y1I & 679 & 25,3 & 18,6 & 136,02 \\
\hline 39 & B4LI1Y1E1 & 71 & 2,6 & 14,9 & 17,45 \\
\hline 40 & B4LI2Y1E2 & 38 & 1,4 & 14,9 & 9,40 \\
\hline 41 & B4LI2Y1I & 256 & 9,5 & 18,6 & 51,08 \\
\hline 42 & B4LI2Y1E1 & 33 & 1,2 & 14,9 & 8,05 \\
\hline 43 & B4LI2Y1Z & 188 & 7,0 & 14,9 & 46,98 \\
\hline 44 & B4LI3Y1E2 & perdido & - & 14,9 & - \\
\hline 45 & B4LI3Y1I & 875 & 32,6 & 18,6 & 175,27 \\
\hline 46 & B4LI3Y1E1 & 47 & 1,7 & 14,9 & 11,41 \\
\hline 47 & B4LI1Y2E3 & 242 & 9,0 & 14,9 & 60,40 \\
\hline 48 & B4LI1Y2I & 5993 & 223,3 & 18,6 & 1200,54 \\
\hline 49 & B4LI1Y2E4 & 151 & 5,6 & 14,9 & 37,58 \\
\hline 50 & B4LI2Y2E3 & 26 & 1,0 & 13,6 & 7,35 \\
\hline 51 & B4LI2Y2I & 200 & 7,4 & 17,0 & 43,53 \\
\hline 52 & B4LI2Y2E4 & 127 & 4,7 & 13,6 & 34,56 \\
\hline 53 & B4LI2Y2Z & 6 & 0,2 & 13,6 & 1,47 \\
\hline 54 & B4LI3Y2E3 & 303 & 11,3 & 14,9 & 75,84 \\
\hline 55 & B4LI3Y2I & 437 & 16,3 & 18,6 & 87,64 \\
\hline 56 & B4LI3Y2E4 & 22 & 0,8 & 14,9 & 5,37 \\
\hline
\end{tabular}


Para as armaduras adicionais, superior e malha lateral, os esforços obtidos a partir das deformações medidas pelos extensômetros serão comparados com o esforço que provoca o escoamento destas armaduras. Tendo sido executadas com barrras de diâmetro $\phi=8 \mathrm{~mm}$, tal esforço será $F_{\text {teo }}=19,7 \mathrm{kN}$. A constante que deverá ser multiplicada pela leitura dos extensômetros, permitindo assim o cálculo dos esforços nas barras, será: $E A=9,53 \mathrm{kN}$.

Tabela 5.13 - Armaduras adicionais: $N_{c}=592,3 \mathrm{kN} ; N_{d}=1494$ kN

\begin{tabular}{llllll}
\hline PONTO & POSIÇÃO & $\varepsilon[\mathbf{m m} / \mathbf{m}]$ & $\mathbf{F}_{e}[\mathbf{k N}]$ & $\mathbf{F}_{\text {teo }}[\mathbf{k N}]$ & $\mathbf{F}_{\mathbf{c}} / \mathbf{F}_{\text {teo }}[\%]$ \\
1 & B4H1X1 & 467 & 4,4 & 19,7 & 22,33 \\
5 & B4H2X1 & 5337 & 198,9 & 19,7 & 1009,64 \\
2 & B4H1Y1 & 29 & 0,3 & 19,7 & 1,52 \\
6 & B4H2Y1 & 67 & 2,5 & 19,7 & 12,69 \\
3 & B4H1X2 & 31 & 1,2 & 19,7 & 6,09 \\
7 & B4H2X2 & 591 & 22,0 & 19,7 & 111,67 \\
4 & B4H1Y2 & 108 & 4,0 & 19,7 & 20,30 \\
8 & B4H2Y2 & 16 & 0,6 & 19,7 & 3,05 \\
9 & B4V1XZ & 94 & 3,5 & 19,7 & 17,77 \\
10 & B4V2XZ & 406 & 15,1 & 19,7 & 76,6 \\
12 & B4V3XZ & 34 & 1,3 & 19,7 & 6,60 \\
13 & B4V1YZ & -229 & $-8,5$ & 19,7 & 43,15 \\
14 & B4V2YZ & -19 & $-0,7$ & 19,7 & 3,55 \\
16 & B4V3YZ & 117 & 4,4 & 19,7 & 22,33 \\
11 & B4V2XB & 335 & 12,5 & 19,7 & 63,45 \\
15 & B4V2YB & 38 & 1,4 & 19,7 & 7,11 \\
57 & B4LS1X & -67 & $-2,5$ & 19,7 & 12,69 \\
58 & B4LS2X & -4 & $-0,1$ & 19,7 & 0,51 \\
59 & B4LS1Y & -48 & $-1,8$ & 19,7 & 9,14 \\
60 & B4LS2Y & 84 & 3,1 & 19,7 & 15,74 \\
61 & B4B1 & -815 & $-30,4$ & 19,7 & 154,31 \\
62 & B4B2 & -20 & $-0,7$ & 19,7 & 3,55 \\
63 & B4B3 & -49 & $-1,8$ & 19,7 & 9,14 \\
64 & B4B4 & -78 & $-2,9$ & 19,7 & 14,72 \\
65 & B4BV & -27 & $-1,0$ & 19,7 & 5,08 \\
& & & & & \\
\hline & & & & & \\
\hline
\end{tabular}


Uma outra comparação pode ser feita entre o esforço normal de tração, calculado segundo o Método das Bielas, esperado nas armaduras inferiores dos blocos e o esforço efetivamente medido durante as etapas de carrregamento das provas-de-carga realizadas. Desta maneira, a tabela que segue fornece :

\section{Tabela 5.14 - Esforços (Método das Bielas)}

\begin{tabular}{lccc}
\hline PROTÓTIPO & $\mathbf{N}_{\mathrm{e}}[\mathbf{k N}]$ & $\mathbf{F}_{\text {teo, }}[\mathbf{k N}]$ & EQUAÇÃO EMPREGADA \\
& & & 2.3 \\
Bloco 2 & 323,4 & 151,8 & 2.3 \\
Bloco 3L & 474,0 & 169,4 & 2.5 \\
Bloco 3T & 463,0 & 124,9 & \\
& & & 2.7 \\
Bloco 4 & 592,3 & 138,9 & \\
& 390,2 & 91,5 & \\
& 541,5 & 127,0 & \\
& & & \\
\hline
\end{tabular}

\section{7 - RESULTADOS PARA ESTACAS E SOLO - REAÇÕES}

Tendo sido observadas, no dimensionamento dos protótipos, as condições estabelecidas no ítem 2.1.2, a partir das quais foi deduzida a expressão 2.11, esperava-se comprovar a validade desta por intermédio das células de carga de concreto. Assim, descontada a resultante devida às pressões no solo, medidas com uma célula de pressão, esperava-se que as CCC's apresentassem valores de reação que somados fossem iguais ao valor da ação vertical aplicada num bloco. Os resultados encontrados foram os seguintes: 


\subsection{1 - BLOCO SOBRE DUAS ESTACAS}

Para uma ação aplicada ao grupo, $N_{e}=323,4 \mathrm{kN}$, as reações medidas em cada estaca foram:

Tabela 5.15 - Reações no bloco 2; $\mathrm{N}_{\mathrm{e}}=323,4 \mathrm{kN}$

$\begin{array}{ccc}\mathbf{N}_{\circ} \text {. CCC } & \text { LOCALIZAÇão } & \text { REAÇÃo [kN] } \\ 5 & \text { oeste } & 137,9 \\ 11 & \text { leste } & 115,3\end{array}$

Onde o valor esperado da reação é obtido da expressão:

$$
R_{\text {solo, esp }}=N_{e}-\sum_{i}^{n} R_{i}
$$

Sendo, $\quad N_{\ell}$ : ação aplicada no protótipo;

$\boldsymbol{R}_{i}$ : reação medida na estaca $i$.

Assim, para os valores dados na tabela 5.15, tem-se: 


$$
R_{\text {solo, esp }}=323,4-(137,9+115,3)=70,2 \mathrm{kN}
$$

A reação medida no solo será o produto da área da base de um bloco pelo correspondente valor de pressão no solo medido por uma célula de pressão. Desta forma, pode-se escrever as equações:

$$
\begin{aligned}
& R_{\text {solo, med }}=A_{11 q} \cdot C P \\
& A_{11 q}=A_{\text {base }}-\sum_{i}^{n} A_{i}
\end{aligned}
$$

Onde, $\quad \boldsymbol{R}_{\text {solo,med }}$ : reação medida do solo;

$\boldsymbol{A}_{\text {liq }}$ : área da base do bloco, descontada a área das estacas;

$\boldsymbol{C P}$ : leitura da célula de pressão, colocada entre o solo e o

bloco. 
A área líquida, calculada a partir das dimensões dos protótipos, determinadas no capítulo 3, será, para cada um dos mesmos:

Tabela 5.16 - Área líquida; $A_{\text {Iq }}$

\begin{tabular}{cc}
\hline PROTÓTIPO & $\mathbf{A}_{\mathrm{lq}}\left[\mathbf{m}^{2}\right]$ \\
& \\
Bloco 2 & 0,62 \\
Bloco 3L & 0,98 \\
Bloco 3T & 1,01 \\
Bloco 4 & 1,49 \\
\hline
\end{tabular}

Substituindo-se na equação $5.3, C P=86,40 \times 10^{-4} \mathrm{kN} / \mathrm{cm}^{2}$ chega-se ao resultado: $R_{\text {solo, med }}=53,6 \mathrm{kN}$.

A participação de cada elemento (estacas e solo) no equilíbrio da ação aplicada ao bloco, será, em porcentagem:

Estaca CCC-5: 42,6\%

Estaca CCC-11: 35,7\%

Solo: $16,6 \%$

A relação entre a reação medida no solo e o valor esperado da mesma ficou então dada por $\frac{R_{\text {solo, med }}}{R_{\text {sol, esp }}}=0,76$. 


\subsection{2 - BLOCO SOBRE TRÊS ESTACAS EM LINHA}

Ação aplicada ao protótipo: $N_{e}=474,0 \mathrm{kN}$

As reações medidas nas estacas serão:

Tabela 5.17 - Bloco 3L; $\mathrm{N}_{\mathrm{e}}=474,0 \mathrm{kN}$

\begin{tabular}{ccc}
\hline No. CCC & LOCALIZAÇÃO & REAÇÃo $[\mathbf{k N}]$ \\
12 & LESTE & 130,8 \\
15 & CENTRO & 131,5 \\
9 & OESTE & 108,0 \\
\hline
\end{tabular}

O valor da reação esperada no solo, é obtido suubstituindo-se os dados da tabela anterior na expressão 5.2, ou seja: $R_{\text {solo, esp }}=103,70 \mathrm{kN}$. Este valor, deve ser comparado com a reação medida a partir da média das leituras de duas células de pressão utilizadas neste bloco, a saber:

CP 100: $65,76 \mathrm{kPa}=65,76 \times 10^{-4} \mathrm{kN} / \mathrm{cm}^{2}$
CP 101: $62,47 \mathrm{kPa}=62,47 \times 10^{-4} \mathrm{kN} / \mathrm{cm}^{2}$

Tomando da tabela 5.16, $A_{11 q}=0,98 \mathrm{~m}^{2}$, chega-se ao valor da reação medida no solo: $R_{\text {solo, med }}=62,8 \mathrm{kN}$. A relação entre as reações, 
medida e esperada será $\frac{R_{\text {solo, med }}}{R_{\text {solo, esp }}}=0,61$, sendo que cada elemento participa da seguinte maneira para o equilíbrio:

CCC-12: $27,6 \%$

CCC-15: $27,7 \%$

CCC-9: $22,8 \%$

Solo: $13,3 \%$

\subsection{3 - BLOCO SOBRE TRÊS ESTACAS - TRIÂNGULO}

Ação aplicada ao grupo: $N_{e}=463 \mathrm{kN}$

Reação medida em cada estaca:

Tabela 5.18 - Bloco 3T; $\mathrm{Ne}=463 \mathrm{kN}$

\begin{tabular}{ccc} 
No. CCC & LOCALIZAÇÃO & REAÇÃO [kN] \\
3 & OESTE-NORTE & 134,7 \\
16 & LESTE & 128,3 \\
17 & OESTE-SUL & 154,3 \\
& & \\
\hline
\end{tabular}

Reação esperada no solo: $R_{\text {solo, esp }}=45,7 \mathrm{kN}$; 
Neste caso, tem-se apenas uma célula de pressão, com a qual foi registrada uma pressão igual a $37,50 \mathrm{kPa}$, o que leva a:

$$
R_{\text {solo, med }}=37,1 \mathrm{kN}
$$

Assim, tem-se a relação: $\frac{R_{s o l o, \text { med }}}{R_{\text {solo, esp }}}=0,81$. A participação de cada elemento fica estabelecida da seguinte maneira:

CCC-3: $29,1 \%$

CCC-16: $27,7 \%$

CCC-17: $33,3 \%$

Solo: $\quad 8,0 \%$

\subsection{4 - BLOCO SOBRE QUATRO ESTACAS}

Ação aplicada ao grupo: $N_{e}=592,3 \mathrm{kN}$

A seguir, são apresentadas as reações medidas nas estacas do bloco 4, por meio das células de carga de concreto: 
Tabela 5.19 - Bloco 4; $\mathrm{N}_{\mathrm{e}}=592,3 \mathrm{kN}$

\begin{tabular}{lcc}
\hline No. $\mathbf{C C C}$ & LOCALIZAÇÃO & REAÇÃo $[\mathbf{k N}]$ \\
6 & OESTE-NORTE & 116,7 \\
2 & LESTE-NORTE & 126,9 \\
10 & LESTE-SUL & 134,7 \\
7 & OESTE-SUL & 149,6 \\
& & \\
\hline
\end{tabular}

Da expressão 5.2, a partir dos dados mostrados nesta tabela, chega-se ao resultado: $R_{\text {solo, esp }}=64,4 \mathrm{kN}$. Para uma leitura de $41,52 \mathrm{kPa}$ fornecida pela célula de pressão colocada sob este bloco, e sabendo-se que a área líquida para este bloco é de $1,49 \mathrm{~m}^{2}$, conforme a tabela 5.16, calcula-se então:

$$
R_{\text {solo, med }}=61,8 \mathrm{kN} \text {. Neste caso, } \frac{R_{\text {solo, } m e d}}{R_{\text {solo, esp }}}=0,96 \text {, ficando a }
$$

distribuição do carregamento entre ons elementos estacas e solo da maneira que segue:

CCC-6: $19,7 \% \quad ; \quad$ CCC-10: $22,7 \%$

CCC-2: $21,4 \% \quad ; \quad$ CCC-7: $25,3 \%$

Solo: $10,4 \%$ 


\section{6 - CONCLUSÕES}

\section{1 - ESFORÇOS NAS ARMADURAS}

Partindo dos esforços obtidos para comparação no capítulo 5, pode-se afirmar que o nível de carregamento atingido nas provas-de-carga dos protótipos não

foi suficiente para que as deformações fossem significativas, o que dificulta o estabelecimento de relações entre as cargas aplicadas nos blocos e as consequentes solicitações nas armaduras.

Este fato não foi totalmente surpreendente, visto que a interrupção dos ensaios ficou condicionada ao instante em que os recalques sofridos pelos blocos fossem da ordem de $50 \mathrm{~mm}$. Isto ocorreu para valores de ação vertical bastante inferiores à ação $\mathbf{N}_{\mathrm{d}}$ para a qual os protótipos foram projetados. 
Desta forma, as deformações registradas pelos extensômetros colados na armadura foram, em sua maioria, da mesma ordem de grandeza da precisão destes instrumentos. Contudo, pode-se dizer que, para as cargas de serviço, as armaduras adicionais, de caráter construtivo, são pouco solicitadas.

Assim, conclui-se que, para melhor estudar o comportamento das armaduras longitudinais inferiores, e por conseguinte, verificar os métodos de dimensionamento apresentados neste trabalho, é desejável executar novos ensaios em condições que permitam carregar os blocos até a sua ruptura.

\section{2 - CARGA TRANSMITIDA Às ESTACAS}

Descontada a parcela do carregamento resistida pelo solo, verifica-se que cada estaca absorveu, aproximadamente, a mesma parcela da ação total aplicada aos blocos.

A diferença entre a ação aplicada e o total das reações das estacas e do solo deve-se, principalmente, à deficiência das medidas feitas com as CCC's. Segundo SENNA JÚNIOR ${ }^{[20]}$, rugosidades e outras irregularidades no topo e na base das Células de Carga de Concreto, a despeito de sua aparência plana, podem, em conjunto com más condições de posicionamento e carregamento, ser causadoras daquela diferença. A imprecisão dos dispositivos foi verificada pela dispersão nas curvas de calibração feitas em laboratório.

Da calibração em campo, o pesquisador citado obteve constantes de multiplicação para cada CCC, que permitiram ajustar o valor da força registrada por cada uma delas. 


\section{3 - CONTRIBUIÇÃO DO SOLO}

A participação do solo no suporte de um bloco apoiado em estacas revelou-se pequena, se comparada com a parcela do carregamento absorvida pelas estacas. De acordo com o que foi mostrado no capítulo 5 , a reação resultante das tensões no solo variam de $8 \%$ a $17 \%$, aproximadamente, ficando a média em $12 \%$.

Pode-se considerar, no projeto de fundações por estacas escavadas, em condições similares àquelas encontradas nesta pesquisa, toda a ação vertical aplicada ao bloco sendo suportada unicamente pelas estacas, sem que isto acarrete aumento considerável do quinhão absorvido por cada uma delas. Tal procedimento é favoravel à segurança da estrutura, sem aumentar, necessariamente, as dimensões da mesma.

\section{4 - CONTINUIDADE DA PESQUISA}

A necessidade levantada no item 6.1, de executar novas experimentações com os blocos, levando-os à ruptura, será atendida com a continuidade desta pesquisa. Numa etapa seguinte, pretende-se transportar os protótipos para o Laboratório de Estruturas do Departamento de Estruturas da EESC, onde serão realizados ensaios visando alcançar a ruptura daqueles, sem as restrições constituídas pela impossibilidade das estacas de suportar níveis de carregamento superiores aos atingidos no presente trabalho. É possível que como medida complementar, seja necessára a execução de outros protótipos.

Tal empreendimento é desejável uma vez que, além de constituir parte das atividades do doutorado do autor, suscita novos trabalhos de mestrado, permitindo significativa contribuição deste departamento na investigação do assunto aqui apresentado. 


\section{REFERÊNCIAS BIBLIOGRÁFICAS}

[ 01 ] MAUTONI, M. (1972). Blocos sobre dois apoios. São Paulo, Tese ( doutorado ) - Escola Politécnica da Universidade de São Paulo.

[ 02 ] BLEVOT, J.; FRÉMY, R. (1967). Semelles sur pieux. Annales de ITBTP, n. 230 , fev.

[ 03 ] COMITE EUROPÉEN DU BETON. (1970). Recommandations particulieres au calcul et à l'execution des semelles de fondation. CEB Buletin D'information, n.73.

[ 04 ] ASSOCIAÇÃO BRASILEIRA DE NORMAS TÉCNICAS. (1978). NBR 6118 - Projeto e execução de obras de concreto armado. Rio de Janeiro.

[ 05 ] CASTELO, R. (1988). Notas de aula da disciplina "Estruturas de Fundação". Vitória, UFES.

[ 06 ] PINHEIRO, L. M. (1986). Concreto armado: tabelas e ábacos. São Carlos, EESC - USP.

[ 07 ] IYENGAR, K. T. S. R.; PRABHAKARA, C. V. (1971). Anchor zone stresses in prestressed concrete beams. J. Struct. Div., ASCE, v. 97, n. 3, p. $807-824$.

[08 ] GUYON, Y. (1951). constraintes dans les piéces prismatiques soumises à des forces apliquées sur leurs bases, au voisinage de ces bases., Memoires., Association Internationale des Ponts et Charpentes, v. 11, p. 165 - 226.

[ 09 ] YETTRAM, A. L. (1969). Anchorage zone stressed in axially post-tensioned members of uniform retangular section. Mag. Concr. Res., v. 21, n. 67, p. $103-112$.

[ 10 ] LANGENDONK, T. (1944). Cálculo de concreto armado. São Paulo, $\mathrm{ABCP}$. 
[ 11 ] ASSOCIAÇÃO BRASILEIRA DE NORMAS TÉCNICAS. (1980). NB 5 Cargas para o cálculo de estruturas de edificações. Rio de Janeiro.

[ 12 ] CARVALHO, D. (1991). Análise de cargas últimas à tração de estacas escavadas, intrumentadas, em campo experimental de São Carlos - SP. São Carlos, Tese (doutorado) - Escola de Engenharia de São Carlos, Universidade de São Paulo.

[ 13 ] ASSOCIAÇÃO BRASILEIRA DE NORMAS TÉCNICAS. (1985). NB 51 Projeto e execução de fundações. Rio de Janeiro.

[ 14 ] ASSOCIAÇÃO BRASILEIRA DE NORMAS TÉCNICAS. (1985). EB 3 Barras e fios de aço destinados a armaduras para concreto armado. Rio de Janeiro.

[ 15 ] ASSOCIAÇÃO BRASILEIRA DE NORMAS TÉCNICAS. (1983). MB 2 Moldagem e cura de corpos-de-prova de concreto cilíndricos ou prismáticos. Rio de Janeiro.

[ 16] ASSOCIAÇÃO BRASILEIRA DE NORMAS TÉCNICAS. (1982). MB 212 - Argamassas de concretos: determinação da resistência à tração por compressão diametral de corpos-de-prova cilíndricos. Rio de Janeiro.

[ 17 ] SÜSSEKIND, J. C. (1989). Curso de concreto: concreto armado. São Paulo, Globo, v. 1.

[ 18 ] CEB - FIP model code 1990, final draft. (1991). CEB Bulletin D'information, n. 203 - 205, July.

[ 19 ] PETRUCCI, E. G. (1983). Concreto de cimento Portland. Rio de Janeiro, Globo.

[ 20 ] SENNA JÚNIOR, R. S. (1993). Distribuição de cargas em grupos de estacas escavadas de pequeno diâmetro. São Carlos, Dissertação (mestrado) - Escola de Engenharia de São Carlos, Universidade de São Paulo. 


\section{BIBLIOGRAFIA COMPLEMENTAR}

AMERICAN CONCRETE INSTITUTE. (1984). Design handbook. volume 1: Beams, one-way slabs, brackets, footings and pile caps. (ACI 340.1R - 84) ACI SP-17.

BARROSO, P. M. (1974). Blocos e sapatas de fundação. São Carlos, Dissertação (mestrado) - Escola de Engenharia de São Carlos, Universidade de São Paulo.

BELL, B. J. (1985). Fundações em concreto armado. Rio de Janeiro.

CINTRA, J. C. A.; ALBIERO, J. H. (1985). Capacidade de carga de estacas. São Carlos. EESC - USP.

DOUGLAS, D. J.; TRAHAIR, N. S. (1960). An examinationof the stress in the anchorage zone of a post-tensioned prestressed concrete beam. Mag. Concr. Res., v. 12 , n. 34 , p. $9-18$.

JIMENEZ MONTOYA, P. et alii. (1984). Hormigon armado. 7. ed. Barcelona, Gustavo Gili. 2v.

LEONHARDT, F.; MONNIG, E. (1978). Construções de concreto. Rio de Janeiro, Interciência, v. 2.

LEONHARDT, F.; MONNIG, E. (1978). Construções de concreto. Rio de Janeiro, Interciência, v. 3.

TAKEYA, T. (1988). Introdução à análise experimental de estruturas. São Carlos, EESC - USP.

TIMOSHENKO, S. P.; GOODIER, J.N. (1980). Teoria da elasticidade. Rio de Janeiro, Guanabara Dois.

UNIVERSIDADE DE SÃO PAULO. Escola de Engenharia de São Carlos. Serviço de Biblioteca. (1993). Diretrizes para elaboração de dissertações e teses na EESC - USP. São Carlos, EESC - USP. 


\section{ANEXO A}

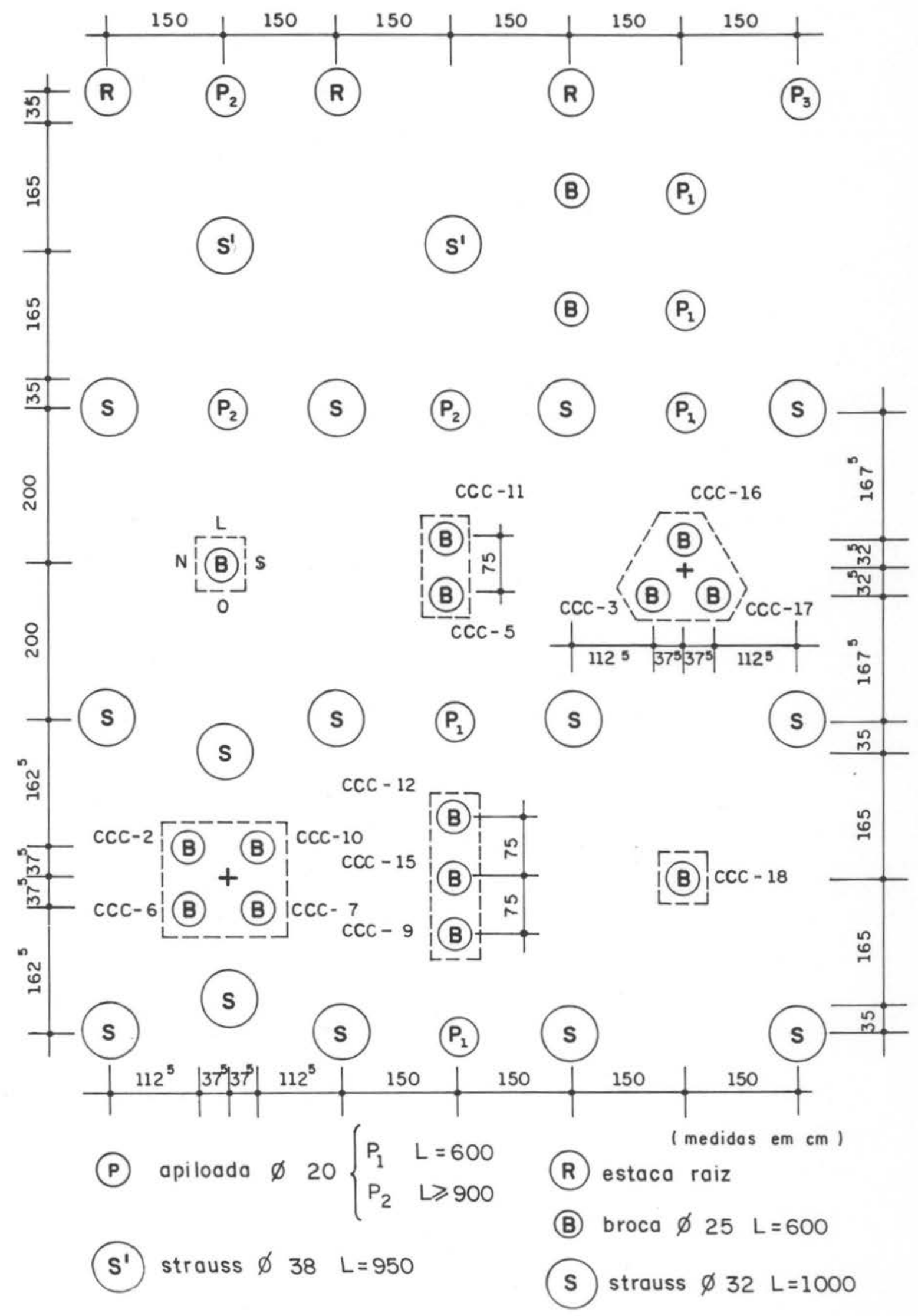


ANEXO B 


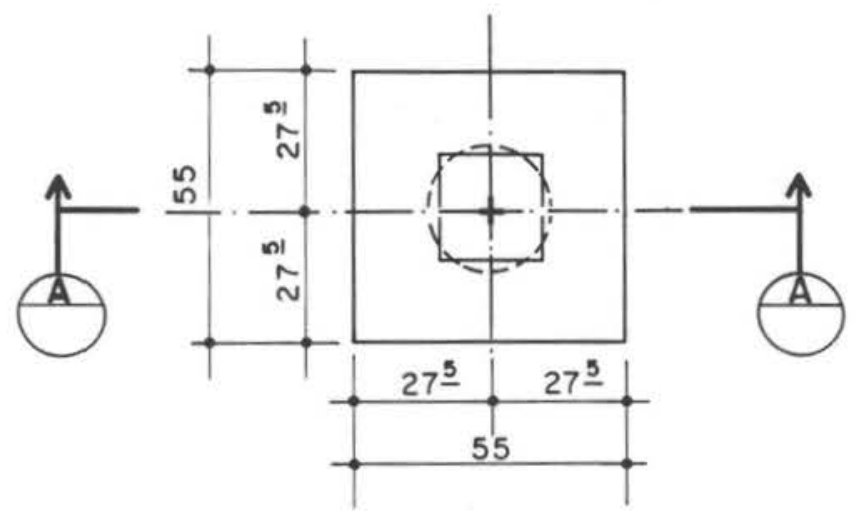

\section{PLANTA}

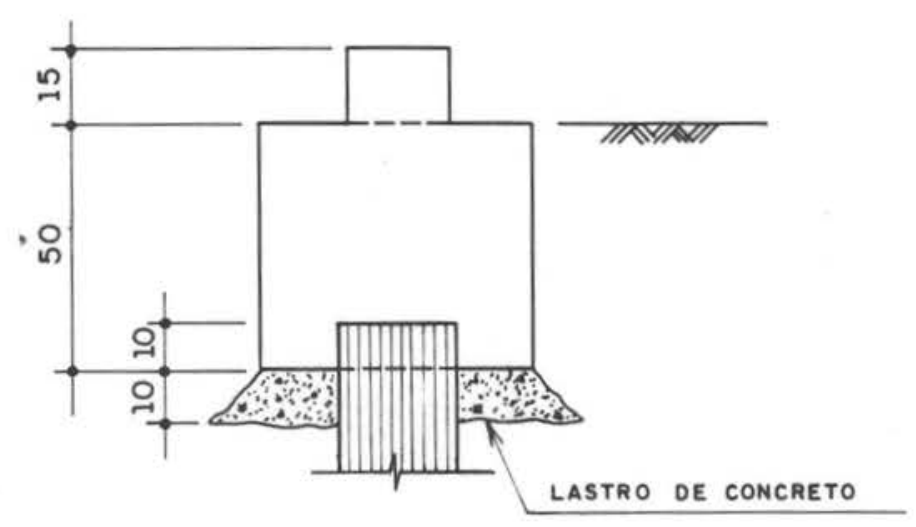

CORTE A

MEDIDAS EM CENTIMETROS

ESC. 1:20

FORMA DO BLOCO SOBRE I ESTACA 


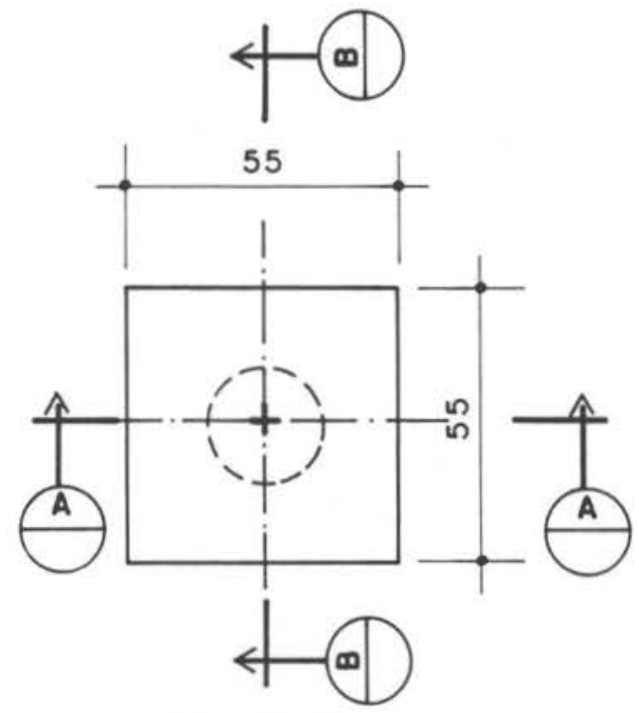

\section{PLANTA}

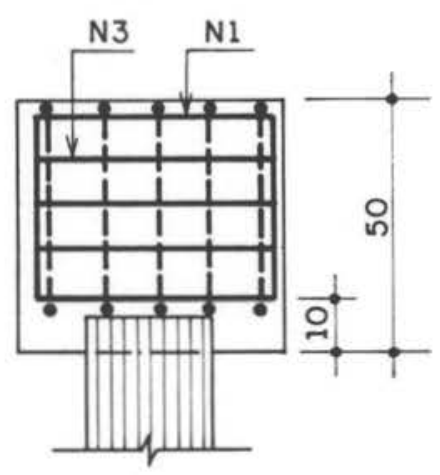

CORTE A

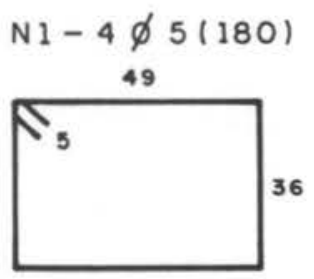

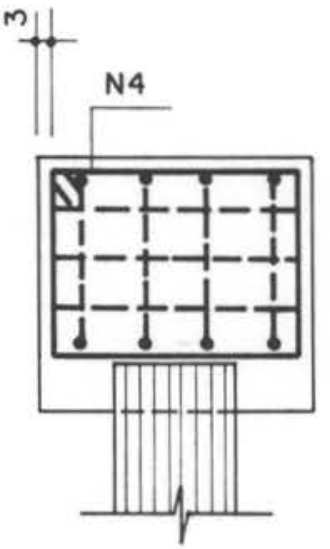

CORTE B
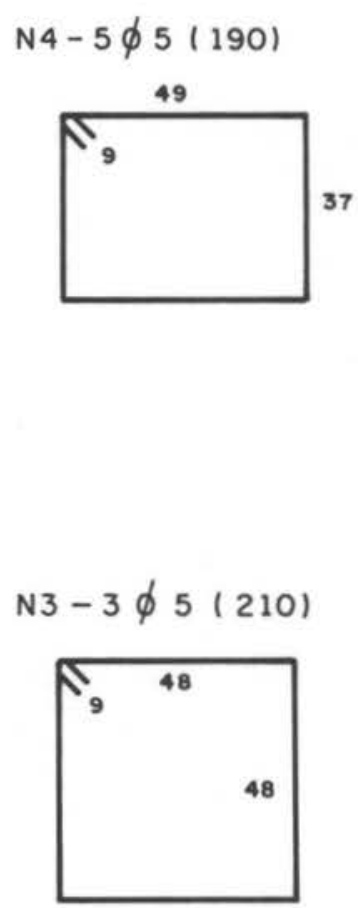

MEDIDAS EM CENTIMETROS

ESC. $1: 20$

ARMAÇÃO DO BLOCO PARA I ESTACA 

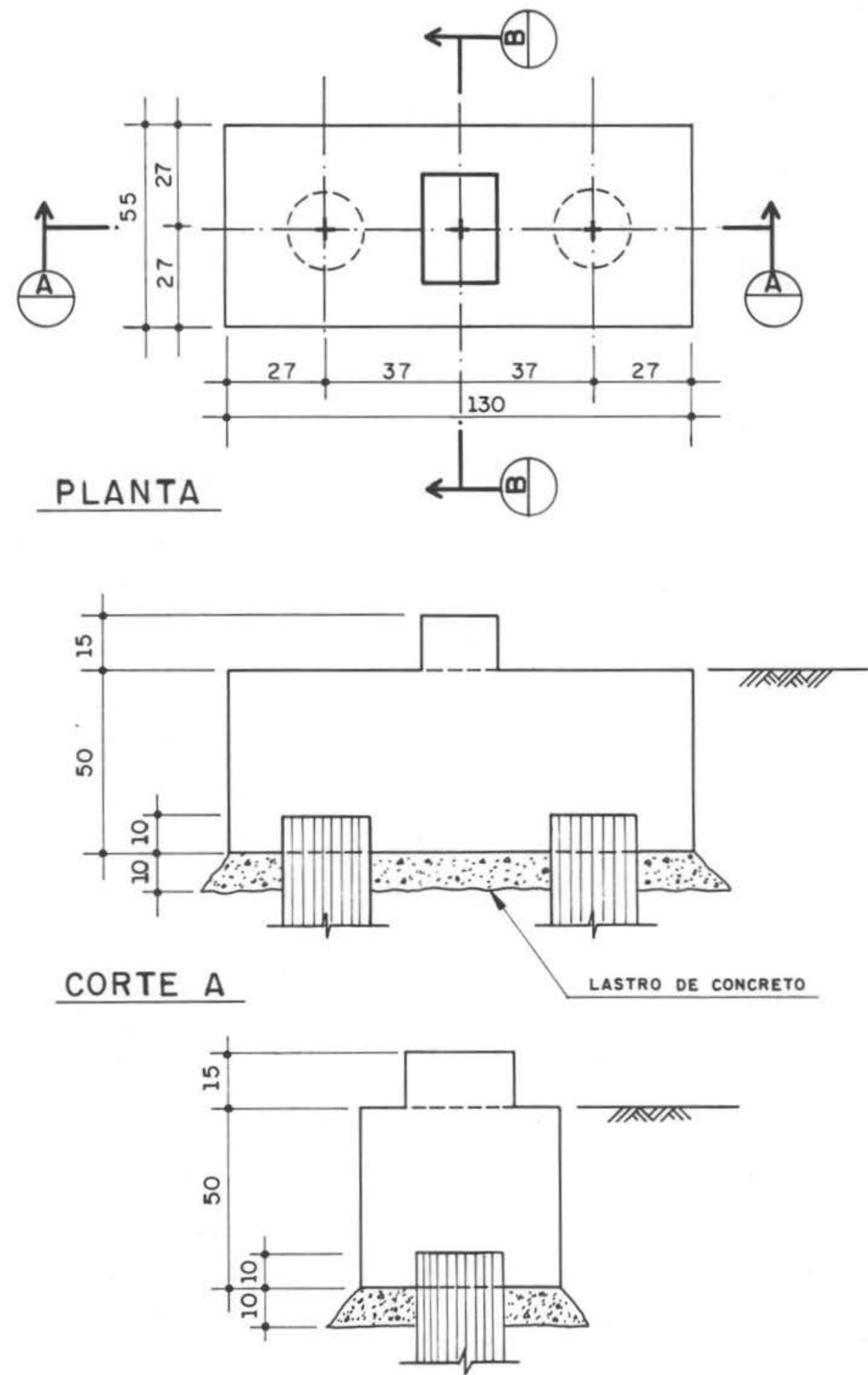

CORTE B 


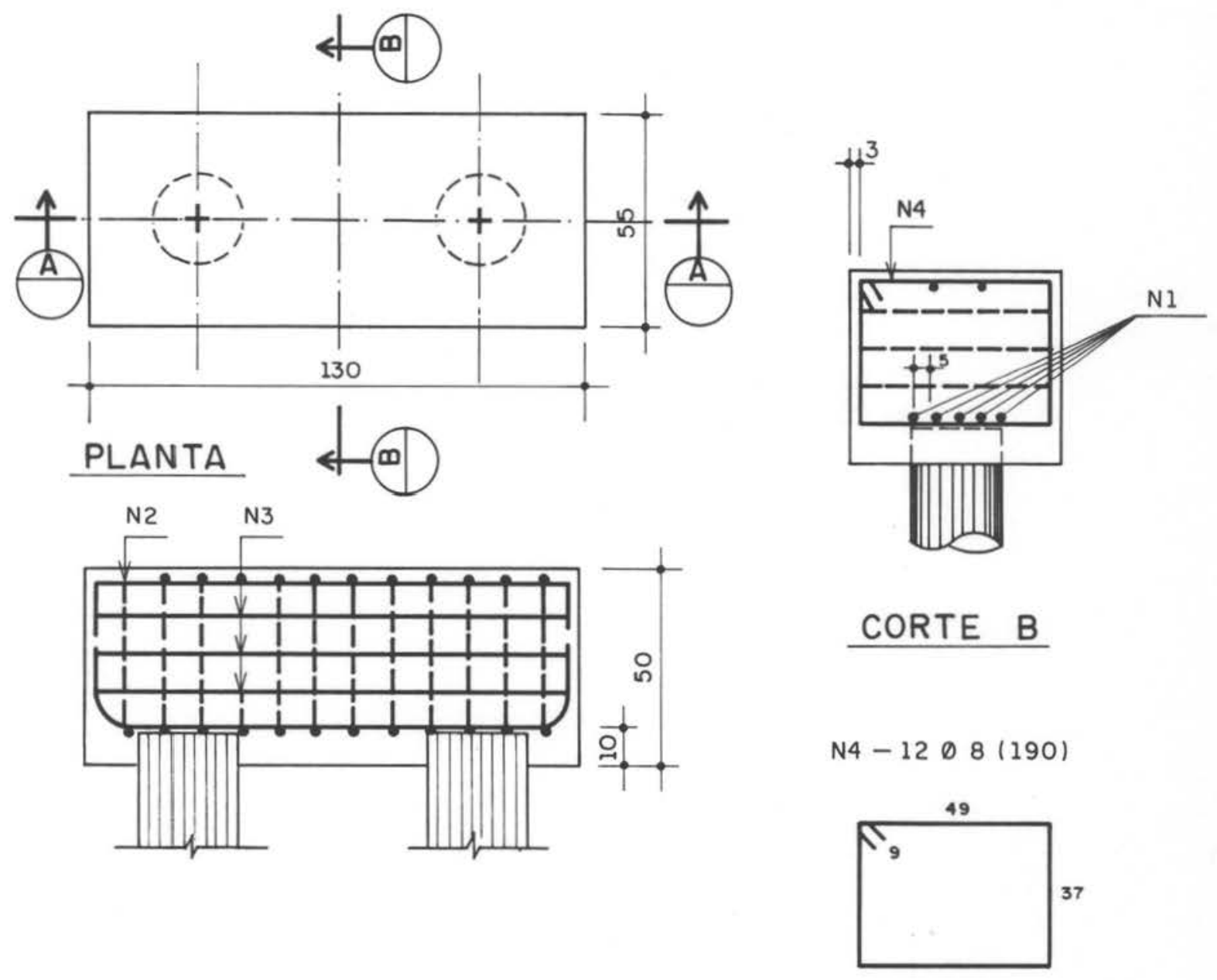

CORTE A
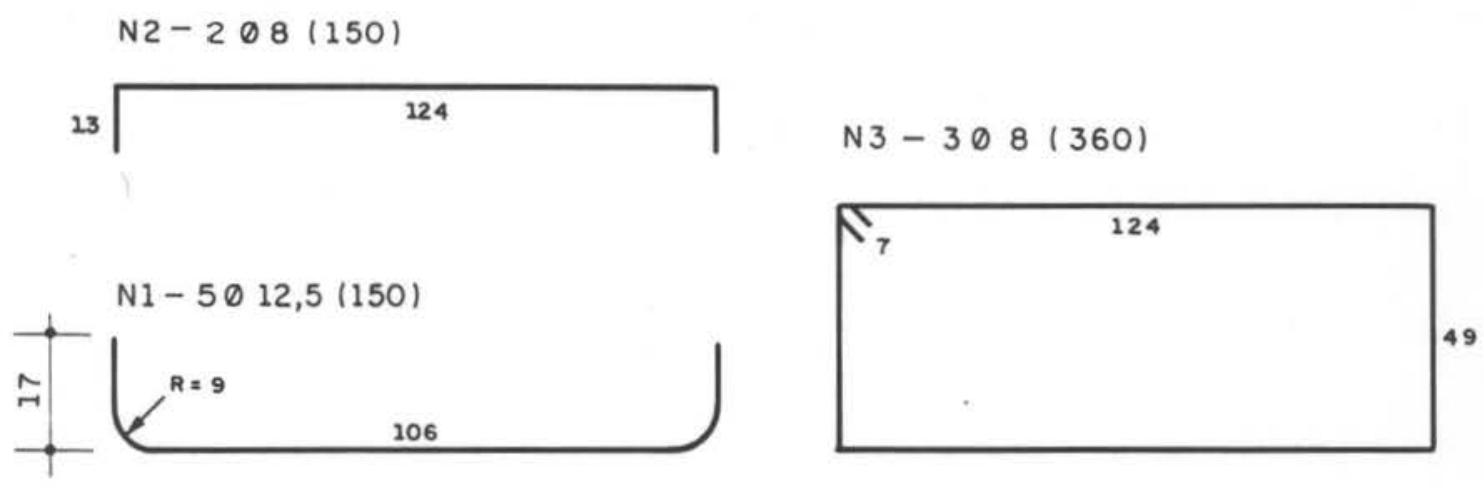

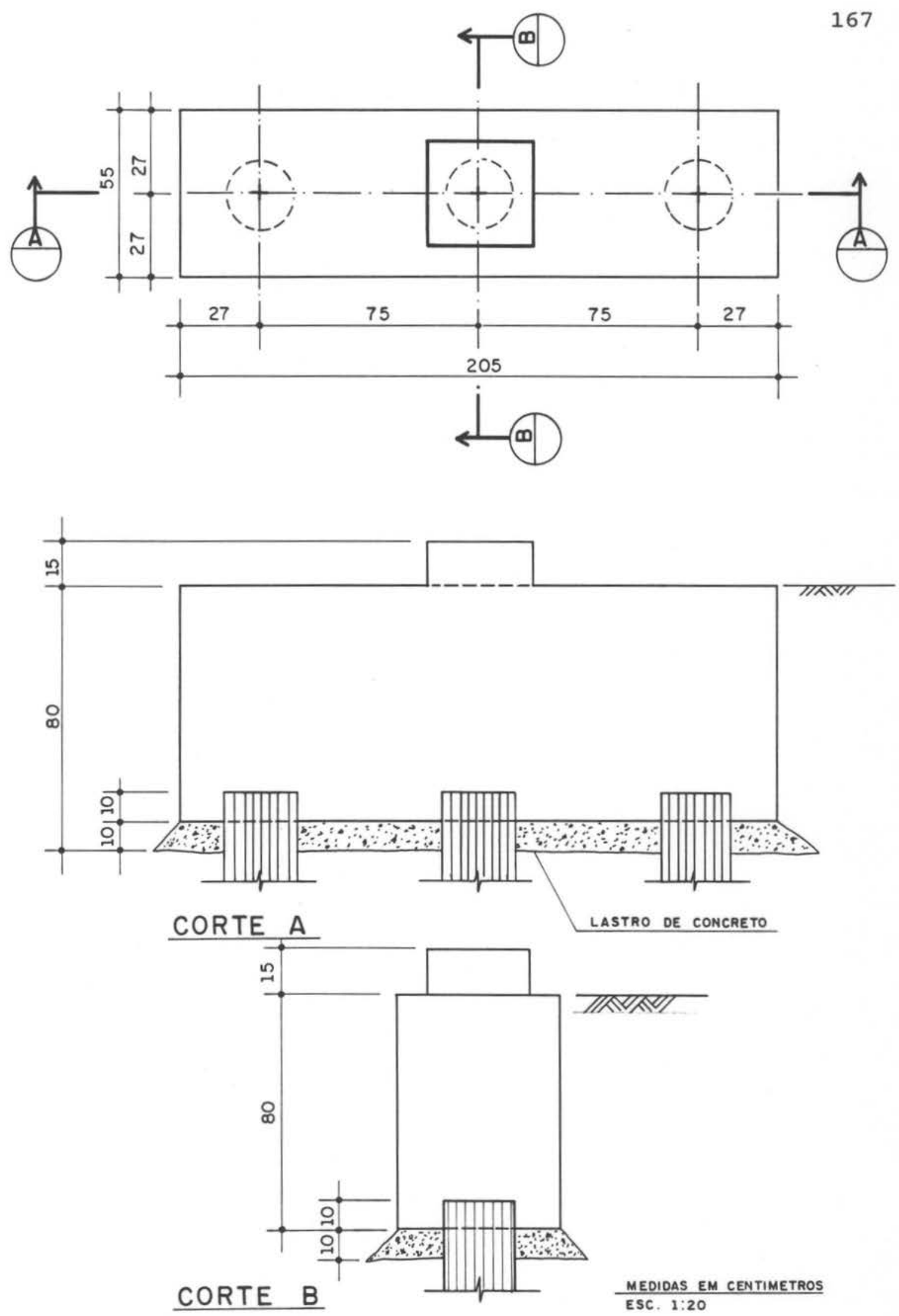

FORMA DO BLOCO SOBRE 3 ESTACAS (EM LINHA) 


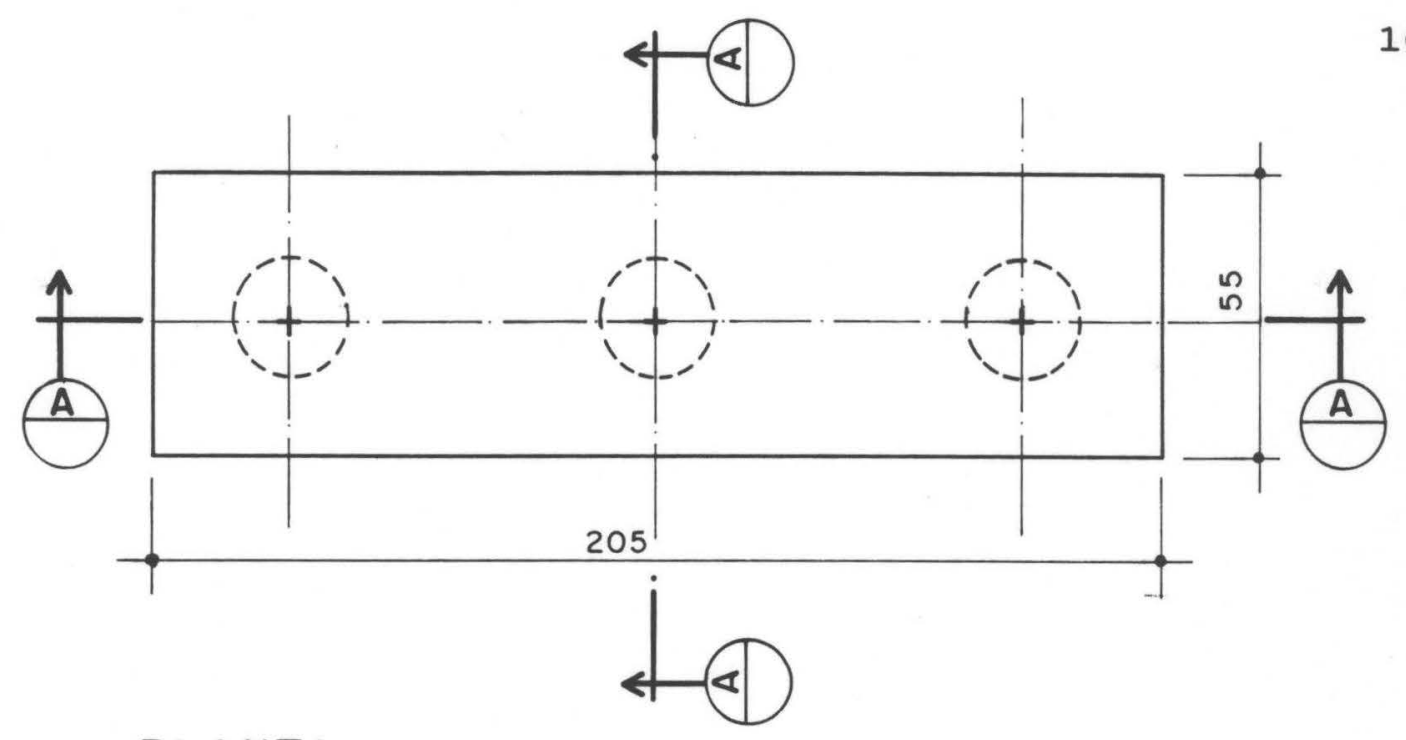

PLANTA

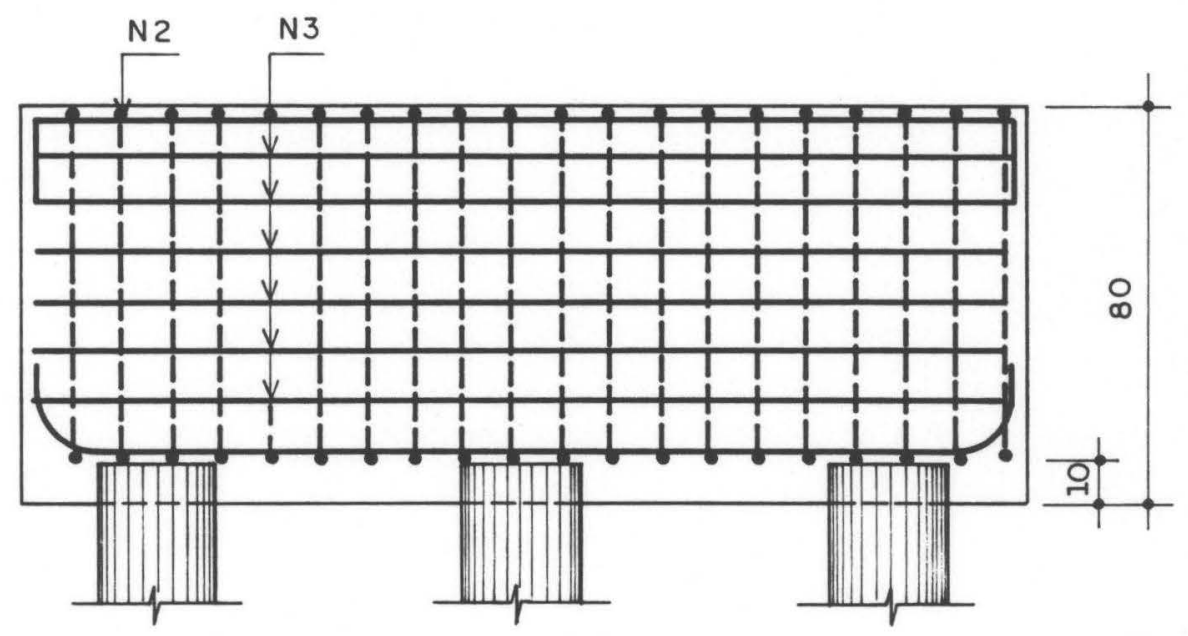

CORTE A

$$
N 2-208(235)
$$

199

18

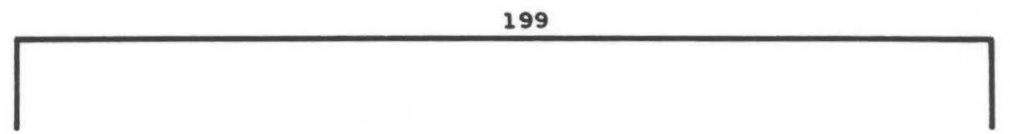

$N I-4016(225)$

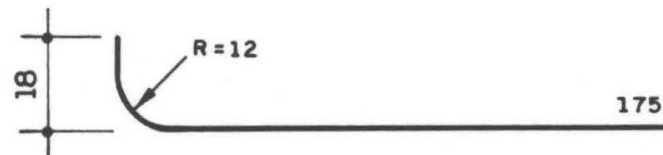

MEDIDAS EM CENTIMETROS

ESC. 1:20 


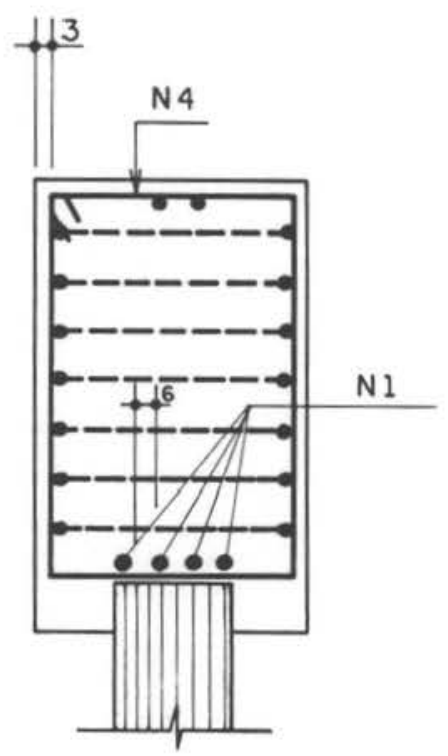

$$
N 4-2008(250)
$$

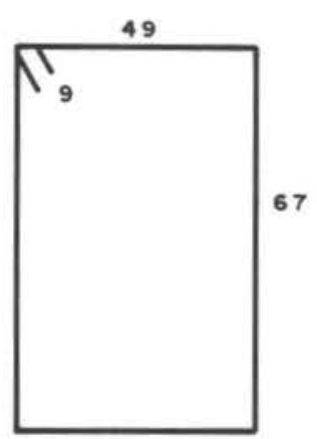

CORTE B

$$
N 3-608(510)
$$

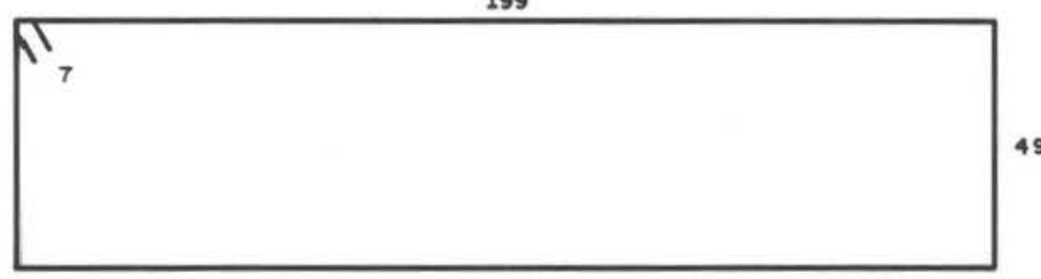



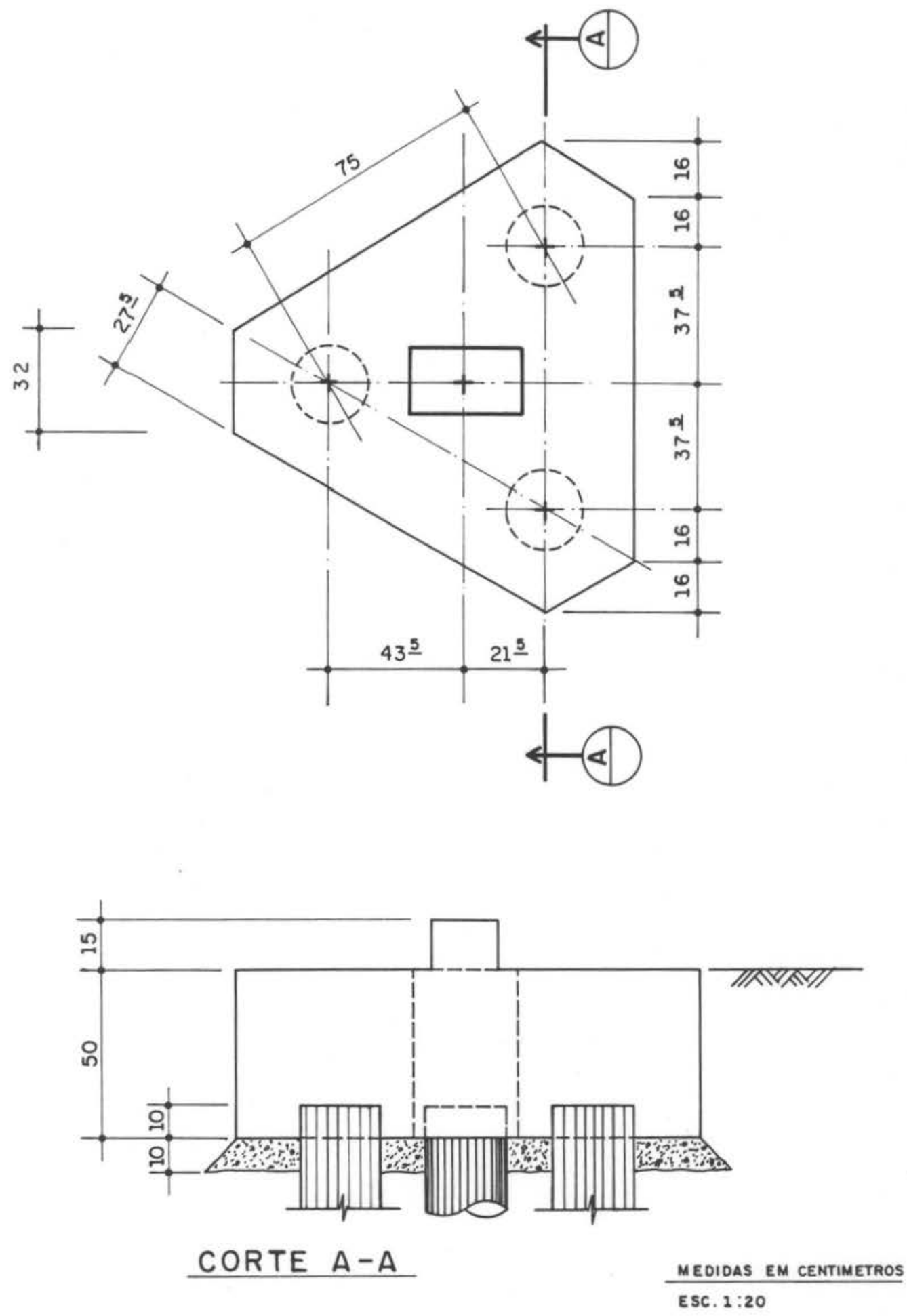

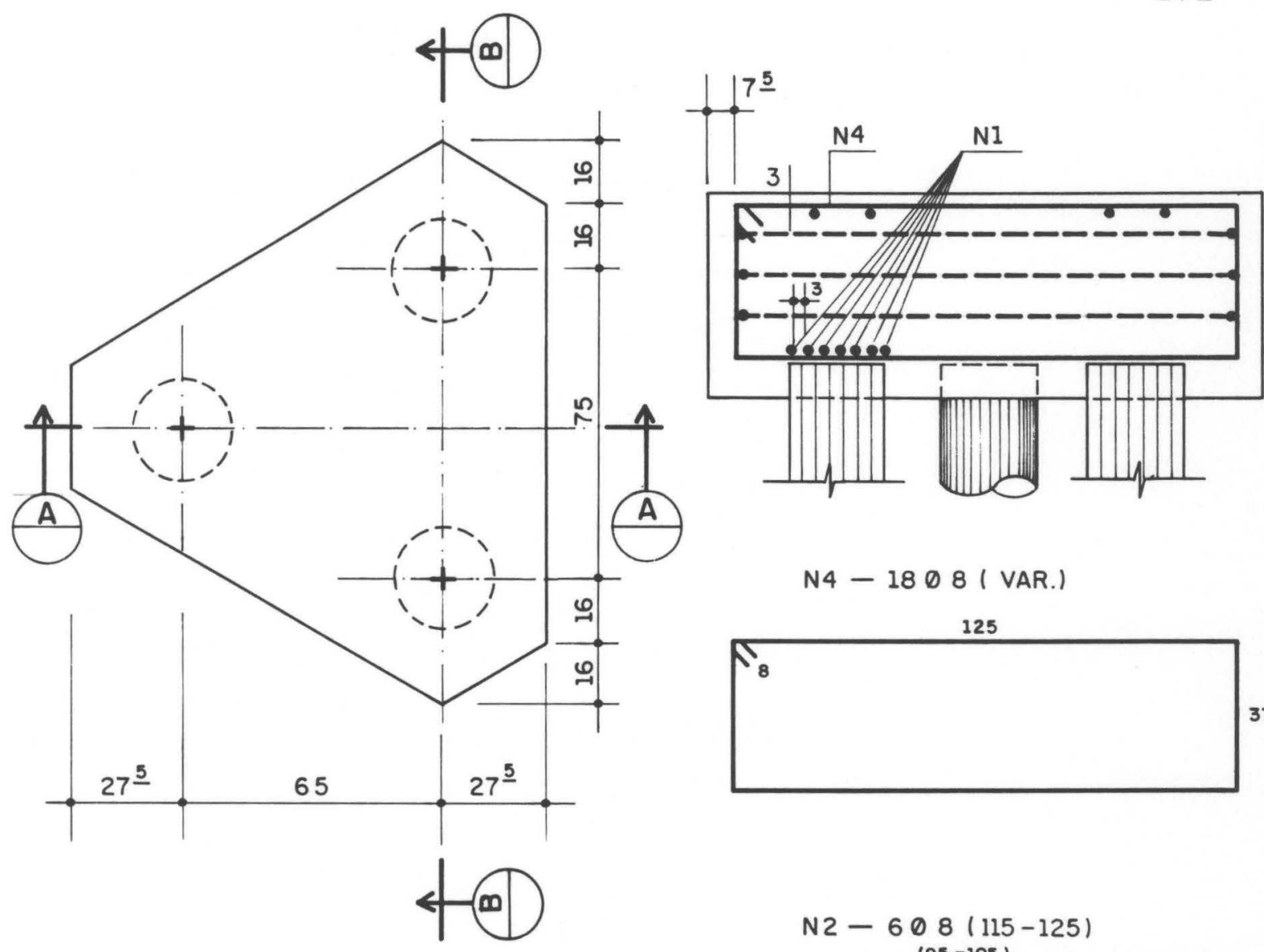

N4 - 1808 ( VAR.)

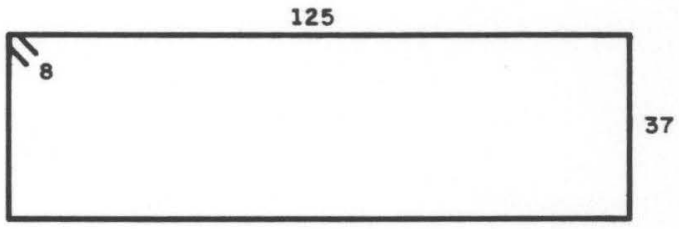

$\mathrm{N} 2-608(115-125)$ $(95-105)$
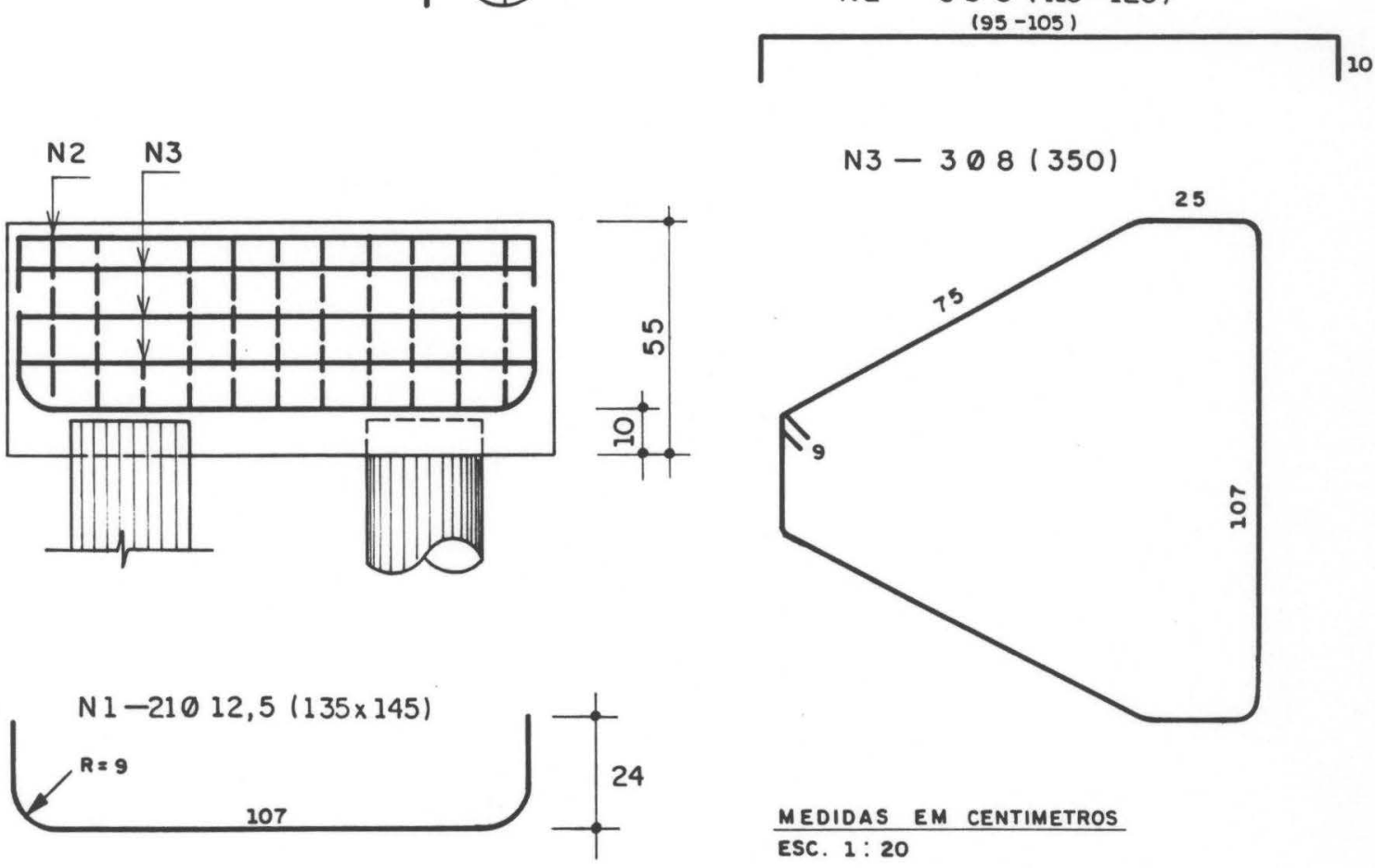

ARMACĀO DO BLOCO TRIANGULAR

( 3 ESTACAS ) 


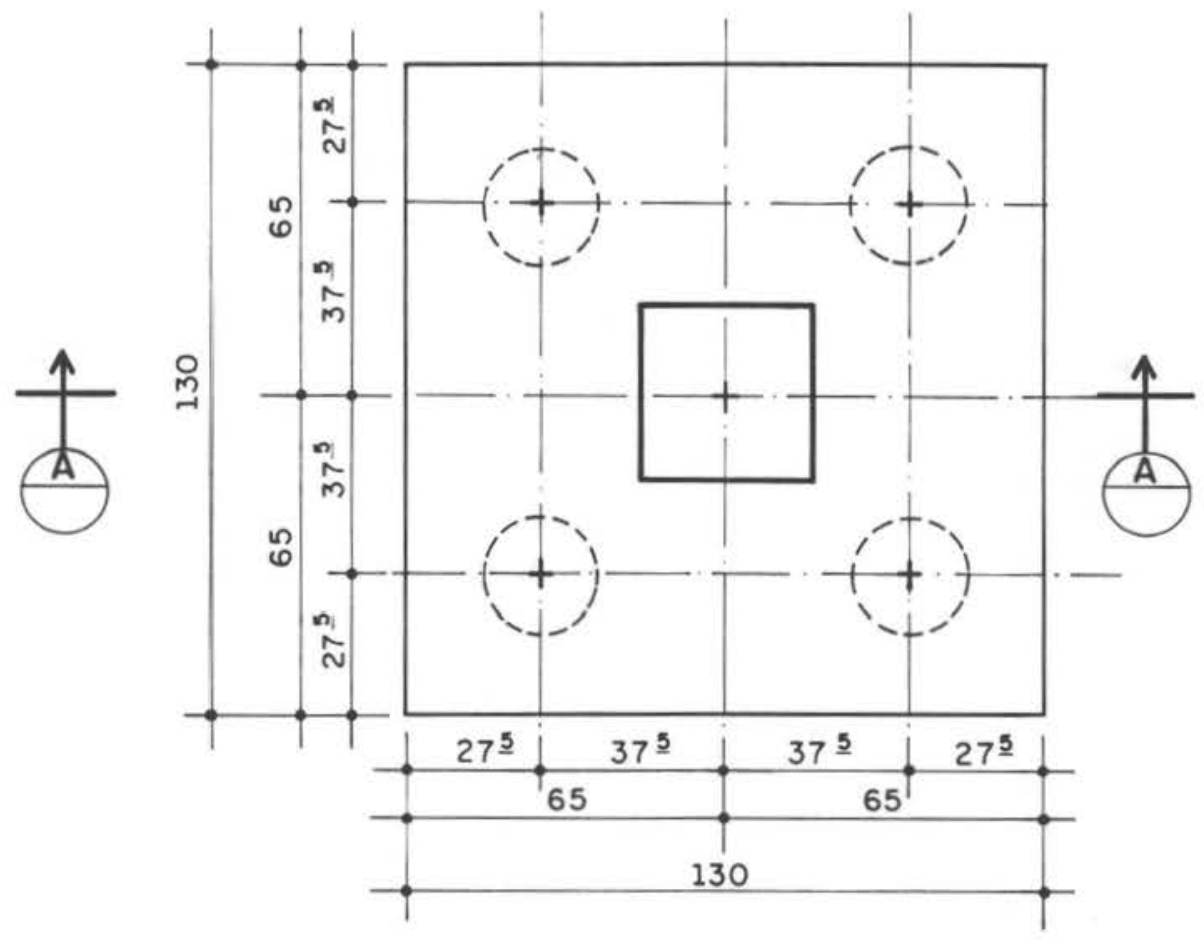

PLANTA

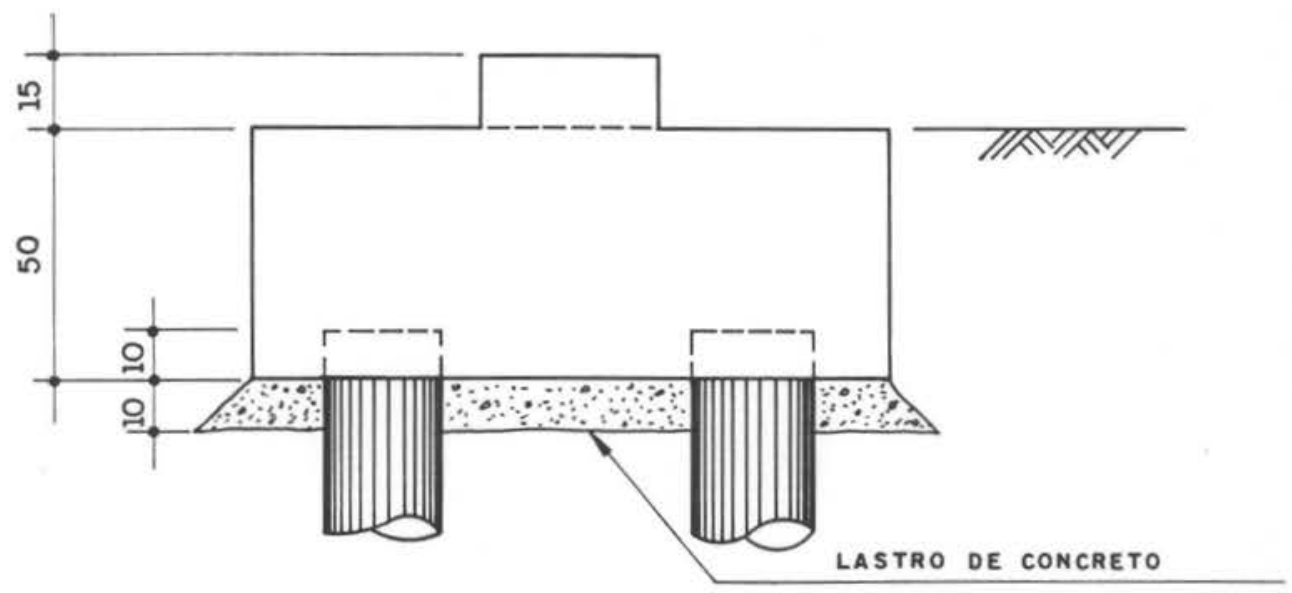

CORTE A

MEDIDAS EM CENTIMETROS

ESC. 1: 20

FORMA DO BLOCO SOBRE 4 ESTACAS 

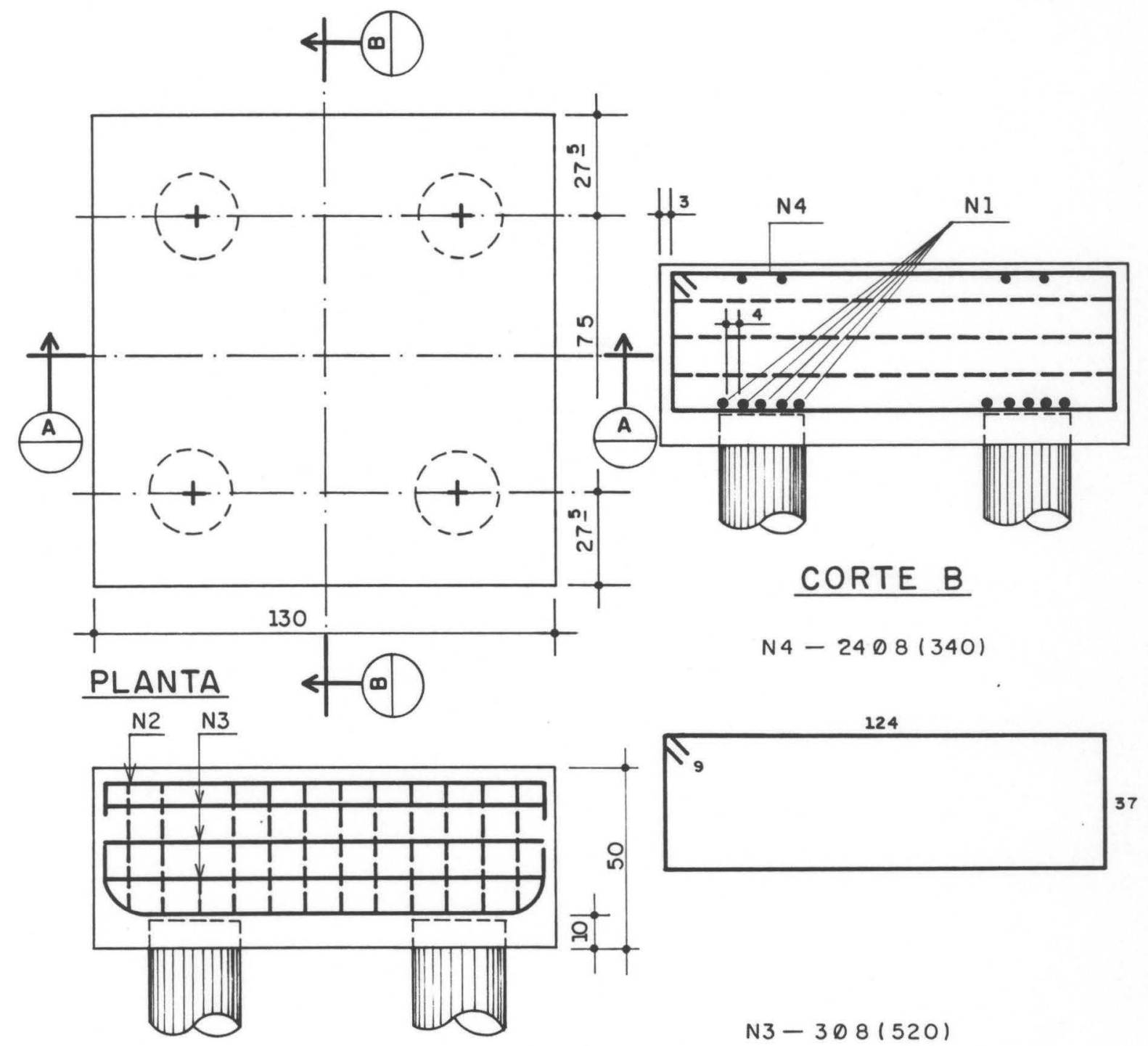

CORTE A
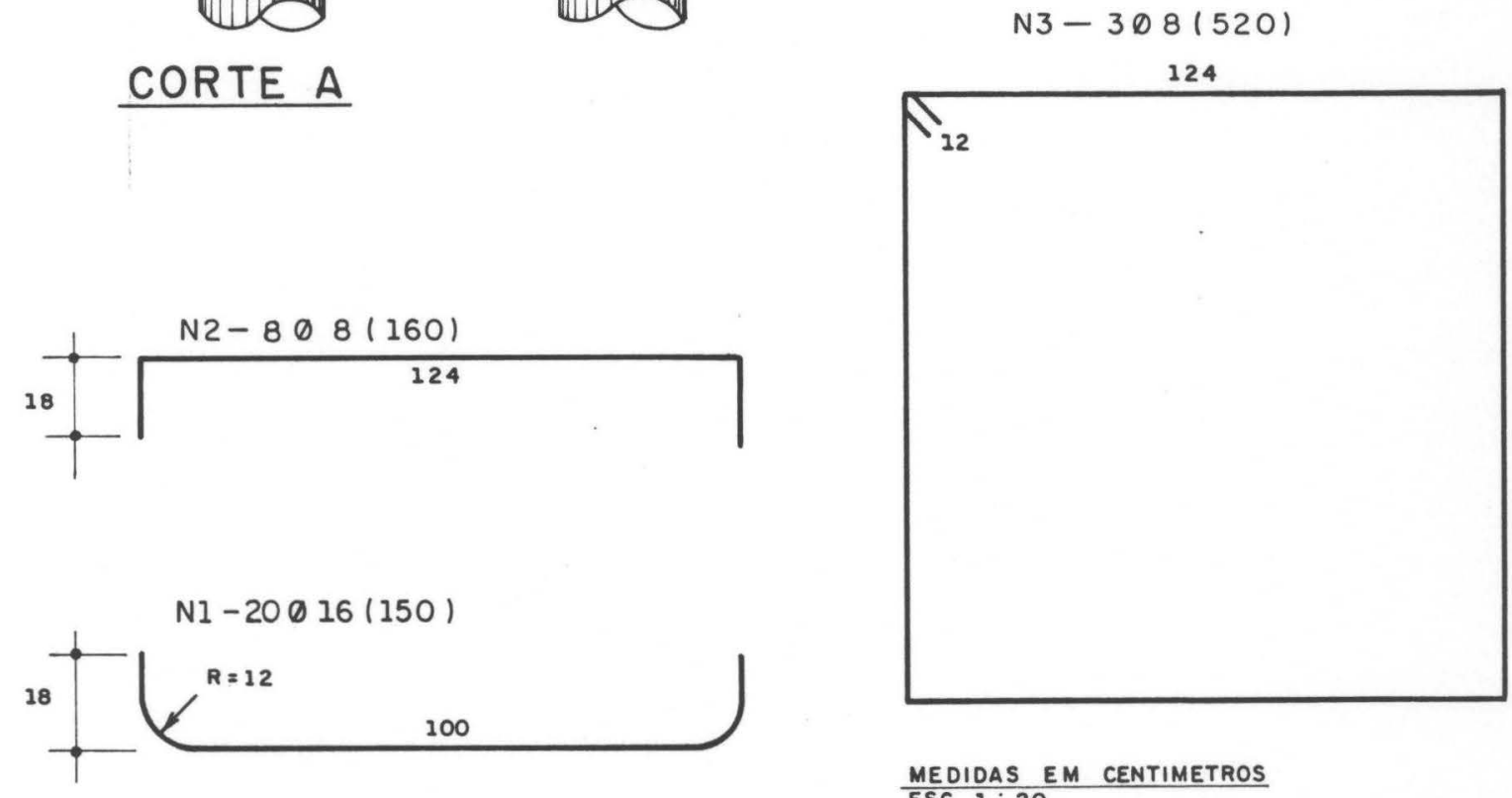
TABELA

ARMAÇĀO

\begin{tabular}{|c|c|c|c|c|}
\hline B LOCOS & $T I P O$ & $\begin{array}{l}\text { QUANTIDADE } \\
1\end{array}$ & $\underset{(m, m)}{\varnothing}$ & $\begin{array}{c}\text { COMPRIMENTT } \\
(\mathrm{cm})\end{array}$ \\
\hline \multirow[t]{4}{*}{1 ESTACA } & N 1 & 4 & 12,5 & 75 \\
\hline & N 2 & 2 & 8 & 75 \\
\hline & N 3 & 3 & 8 & 110 \\
\hline & N 4 & 5 & 8 & 190 \\
\hline \multirow[t]{4}{*}{2 ESTACAS } & N 1 & 5 & 12,5 & 150 \\
\hline & N 2 & 2 & 8 & 150 \\
\hline & N3 & 3 & 8 & 360 \\
\hline & N 4 & 12 & 8 & 190 \\
\hline \multirow{4}{*}{$\begin{array}{l}3 \text { ESTACAS } \\
\text { ( EM LINHA) }\end{array}$} & $\mathrm{N} I$ & 4 & 16 & 225 \\
\hline & N 2 & 2 & 8 & 235 \\
\hline & N 3 & 6 & 8 & 510 \\
\hline & N 4 & 20 & 8 & 250 \\
\hline \multirow{4}{*}{$\begin{array}{l}3 \text { ESTACAS } \\
\text { ( TRIANGULAR) }\end{array}$} & N 1 & 21 & 12,5 & 165 \\
\hline & N 2 & 6 & 8 & 145 \\
\hline & N 3 & 3 & 8 & 350 \\
\hline & N 4 & 22 & 8 & (VAR) \\
\hline \multirow[t]{4}{*}{4 ESTACAS } & $\mathrm{N} 1$ & 20 & 16 & 150 \\
\hline & N 2 & 8 & 8 & 160 \\
\hline & N 3 & 3 & 8 & 520 \\
\hline & N4 & 22 & 8 & 340 \\
\hline
\end{tabular}

RESUMO - ACCO CA-5OA

\begin{tabular}{|c|c|c|c|}
\hline $\begin{array}{c}\text { DIA METRO } \\
(\mathrm{mm})\end{array}$ & $\begin{array}{c}\text { COMPRIMENTO } \\
(\mathrm{m})\end{array}$ & $\begin{array}{c}\text { MASSA }+10 \% \\
(\mathrm{~kg})\end{array}$ & QUANT. BARRAS \\
\hline 8 & 340,20 & 149,70 & 32 \\
12,5 & 45,15 & 49,67 & 5 \\
16,0 & 39,00 & 68,64 & 4 \\
\hline
\end{tabular}


ANEXO C 


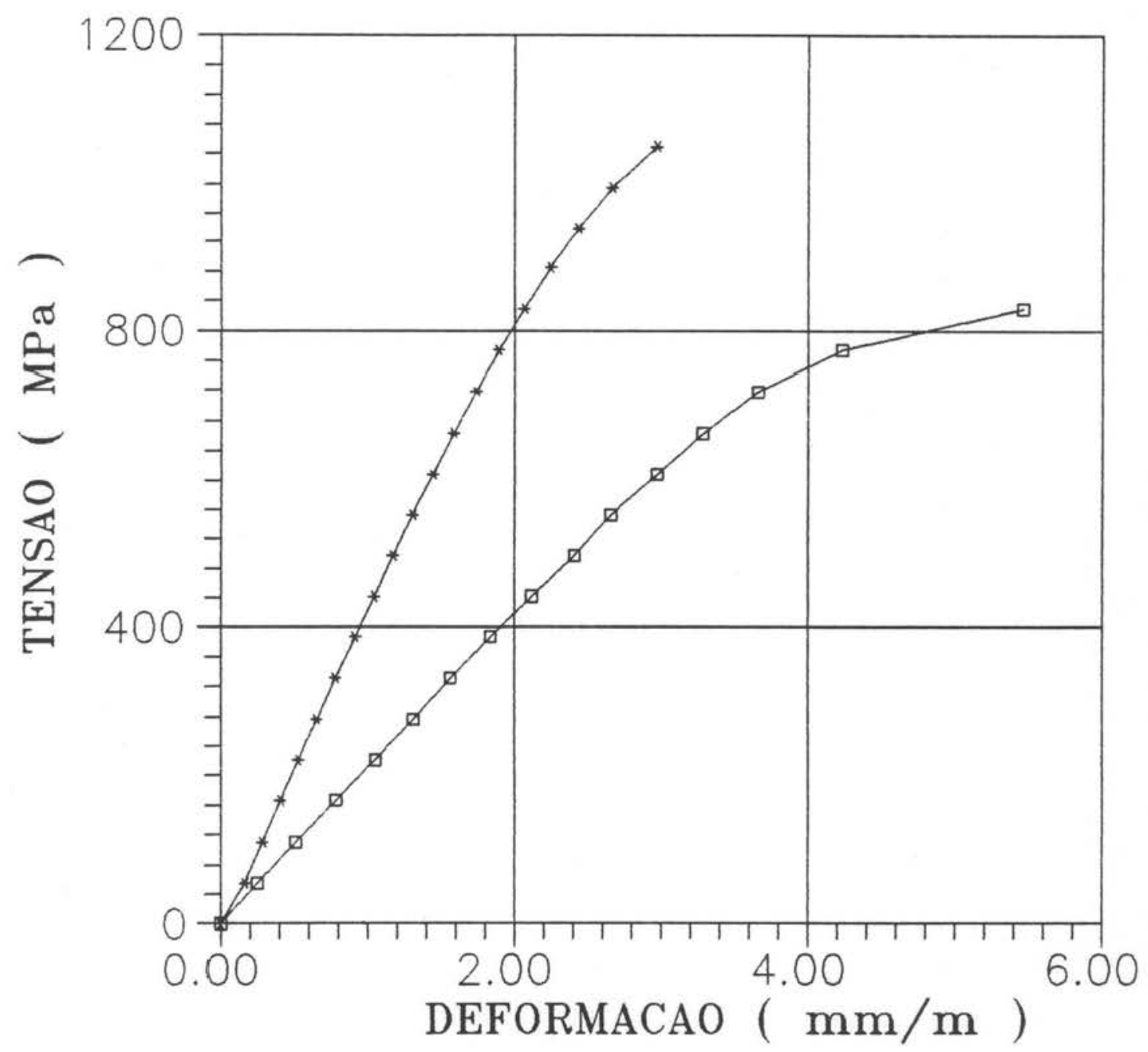

*****orup $=1088.40 \mathrm{MPa}$

orup $=911.60 \mathrm{MPa}$

1 - DIAGRAMA TENSAO $\mathrm{x}$ DEFORMACAO

( NOMINAL: $5 \mathrm{~mm}$ ) 


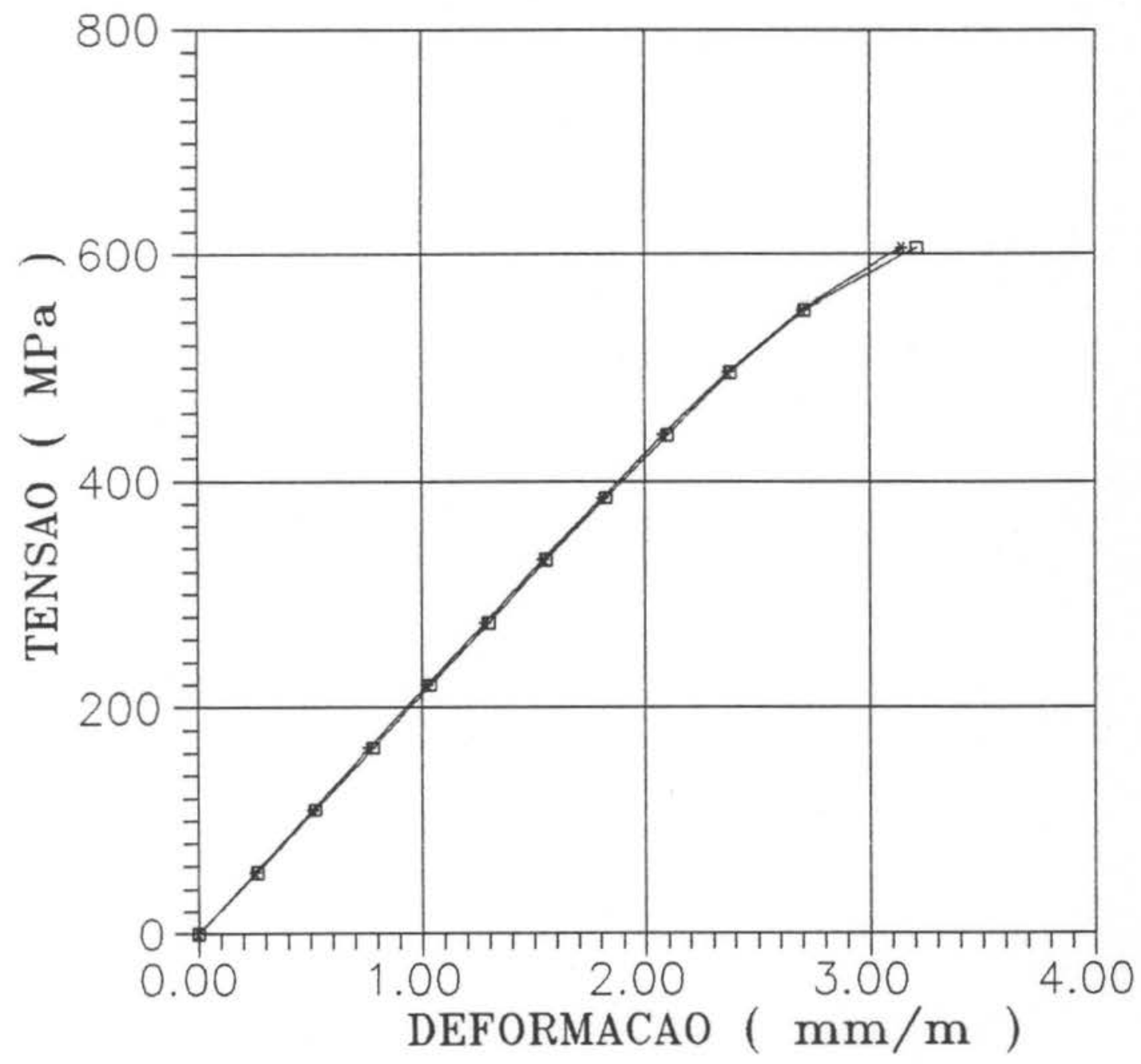

* $\nleftarrow$ rup $=948.90 \mathrm{MPa}$

orup $=964.76 \mathrm{MPa}$

2 - DIAGRAMA TENSAO $\mathrm{x}$ DEFORMACAO

( \$NOMINAL: $8 \mathrm{~mm}$ ) 


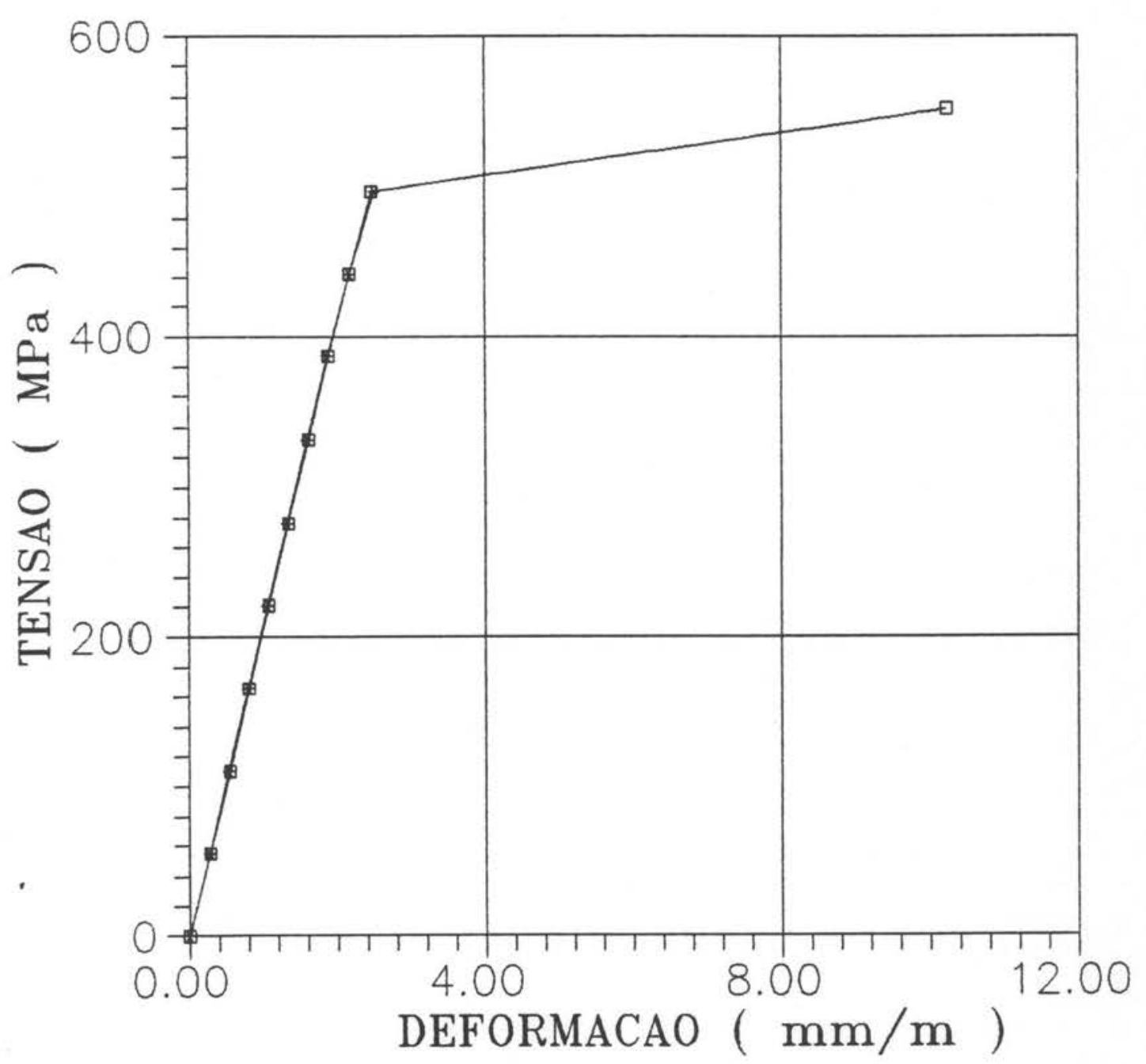

orup $=901.93 \mathrm{MPa}$
orup $=888.12 \mathrm{MPa}$

3 - DIAGRAMA TENSAO $x$ DEFORMACAO \$NOMINAL: $10 \mathrm{~mm}$ ) 


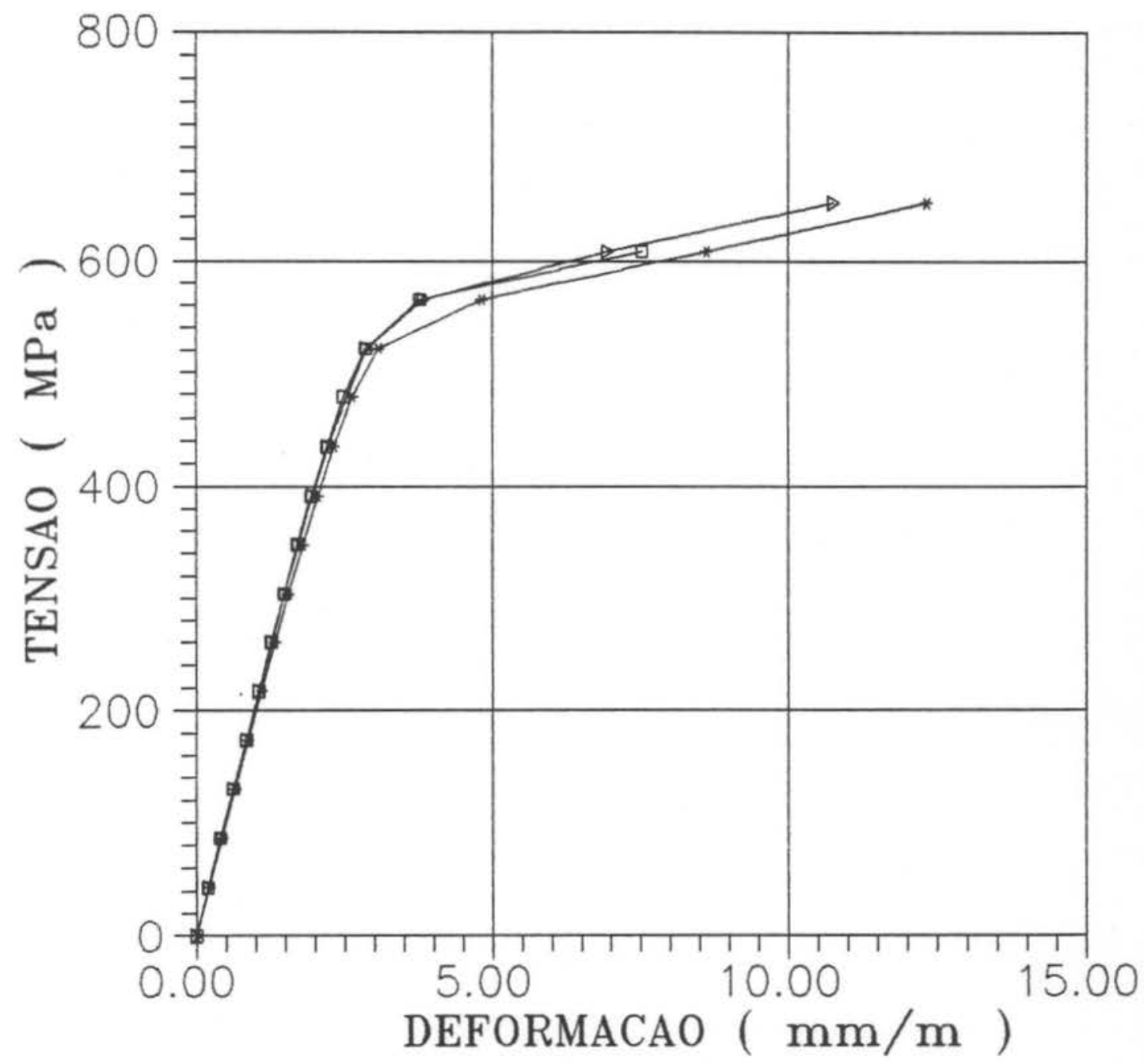

$*$ orup $=913.04 \mathrm{MPa}$
orup $=926.09 \mathrm{MPa}$
orup $=943.48 \mathrm{MPa}$

4 - DIAGRAMA TENSAO x DEFORMACAO ( NOMINAL: $12.5 \mathrm{~mm}$ ) 


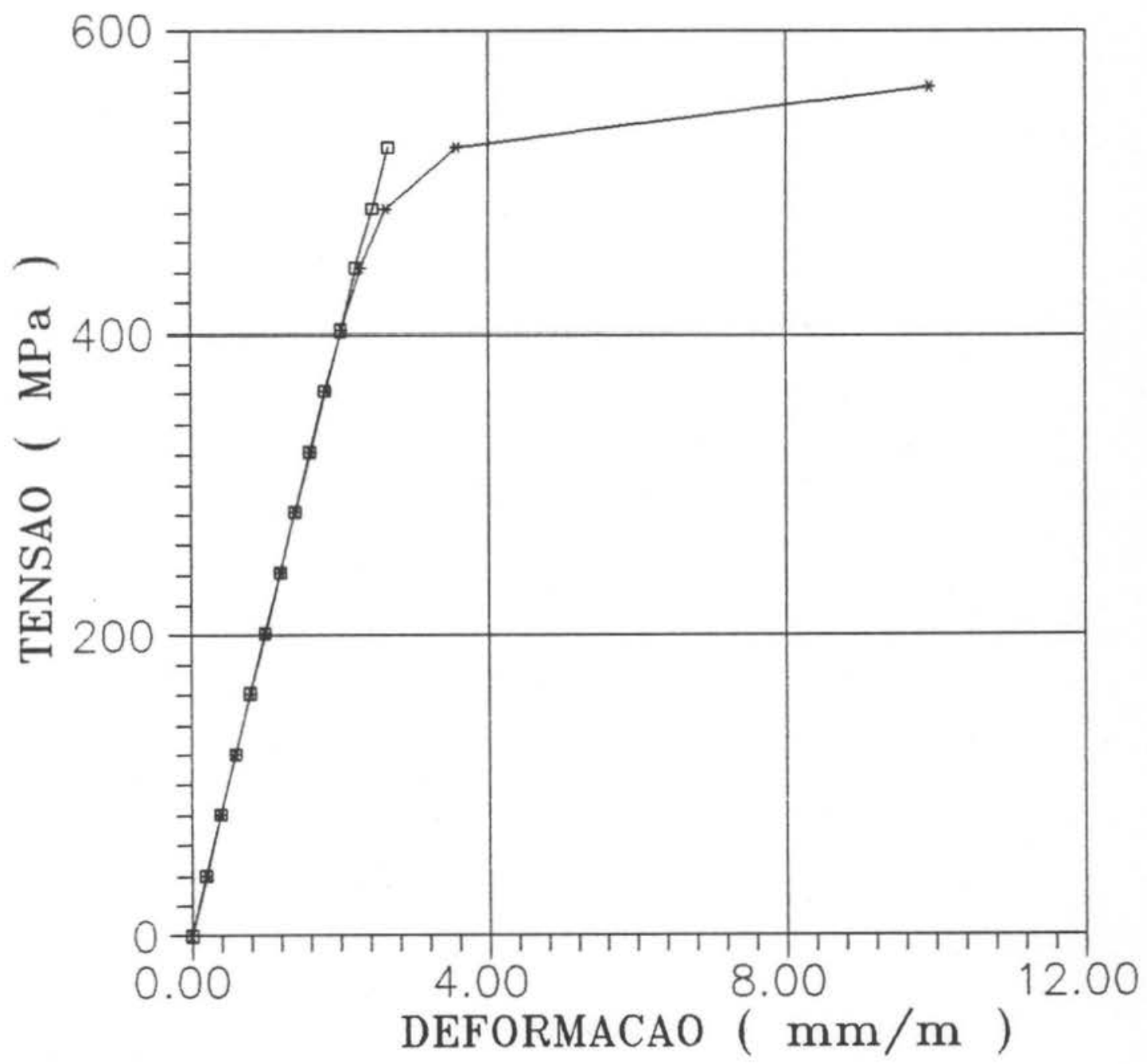

orup $=831.99 \mathrm{MPa}$
orup $=831.99 \mathrm{MPa}$

5 - DIAGRAMA TENSAO $\mathrm{x}$ DEFORMACAO ( \$NOMINAL: $16 \mathrm{~mm}$ ) 


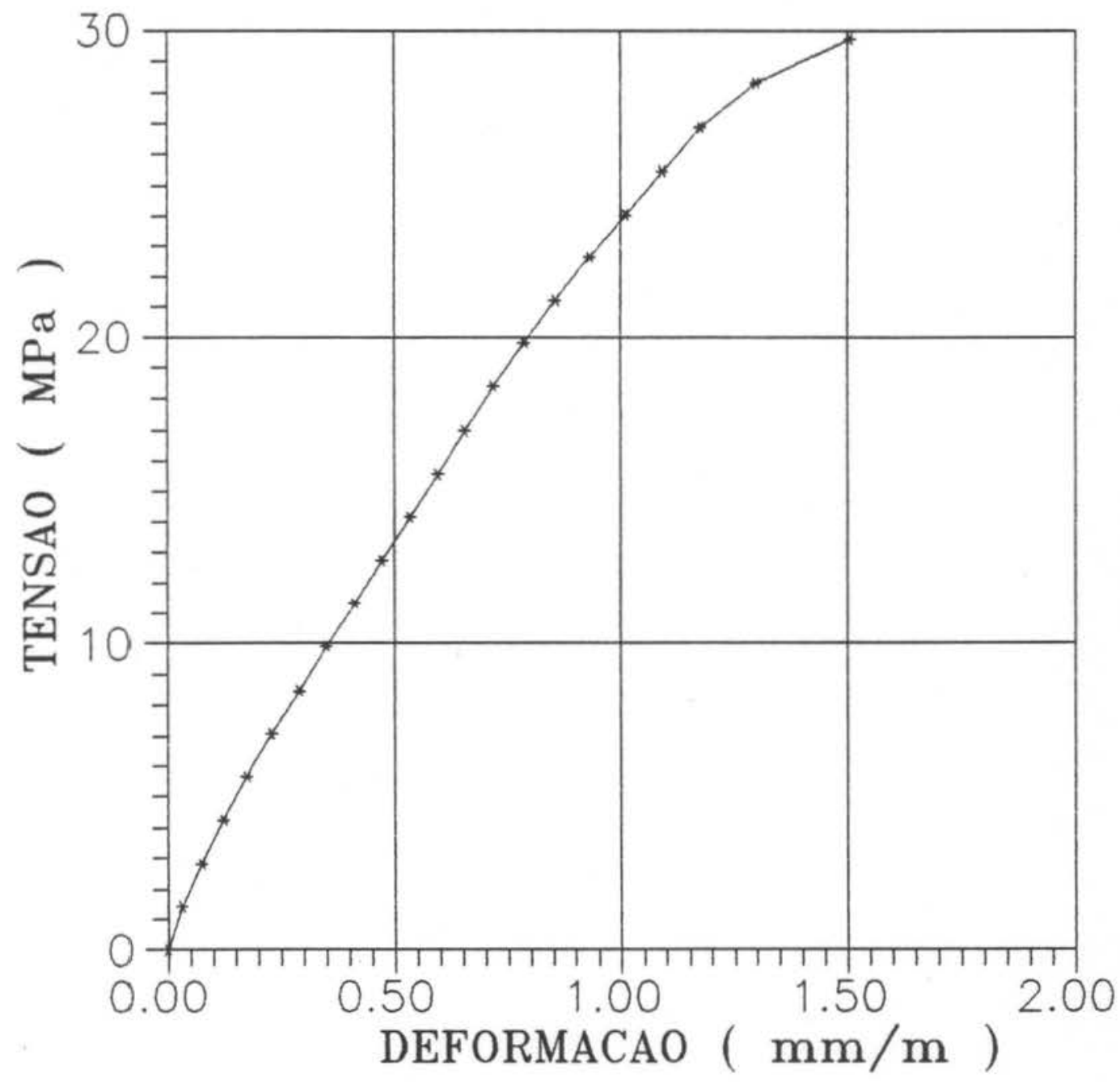

$* * * * *$ CURVA $\sigma_{c} \times \varepsilon_{c}$

$$
6 \text { - DIAGRAMA TENSAO } \mathrm{x} \text { DEFORMACAO DO }
$$
CONCRETO ( CORPO-DE-PROVA No. 1 ) 


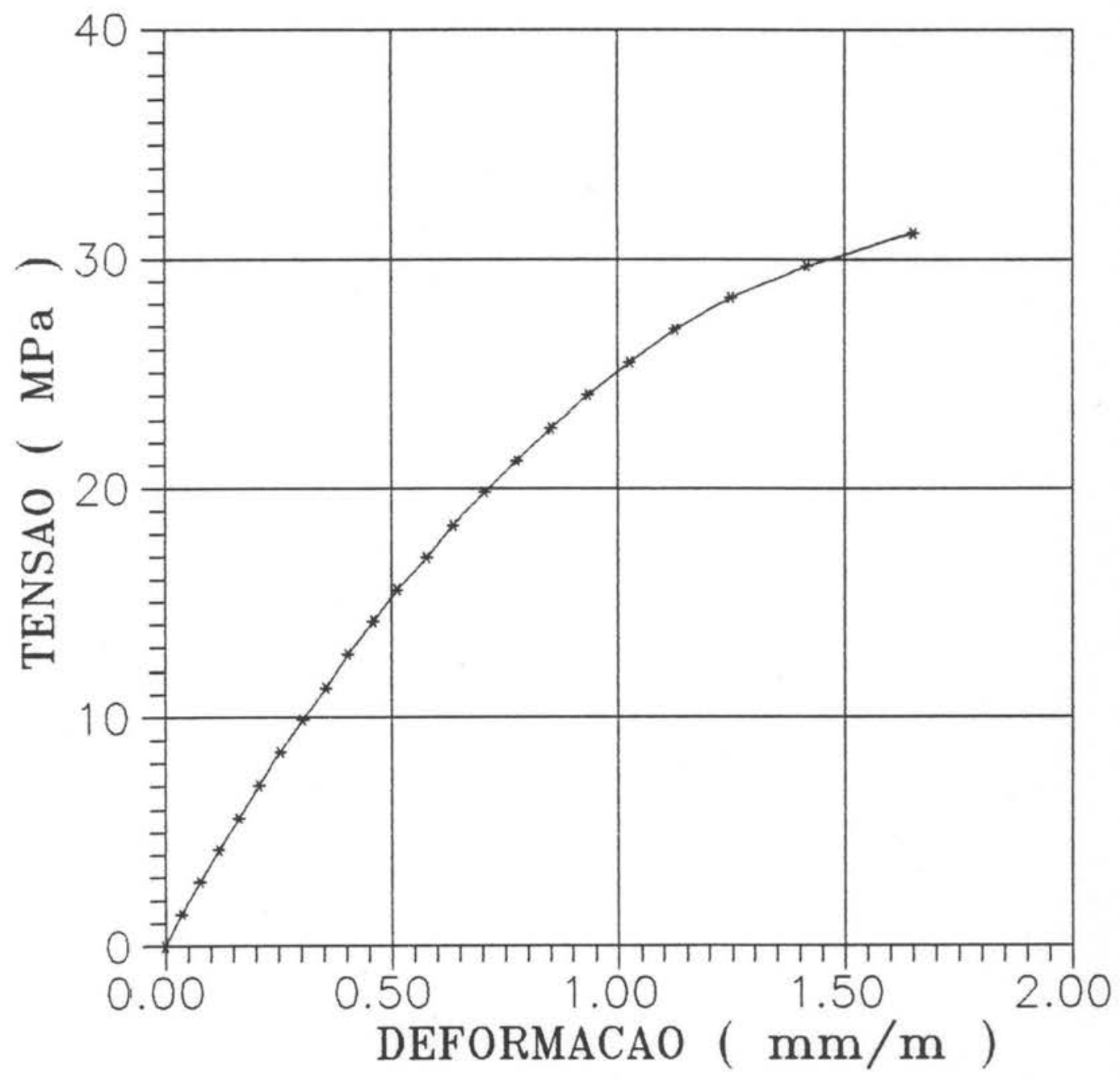

$* * * * *$ CURVA $\sigma_{c} \times \varepsilon_{c}$

7 - DIAGRAMA TENSAO $x$ DEFORMACAO DO CONCRETO ( CORPO-DE-PROVA NO. 2 ) 


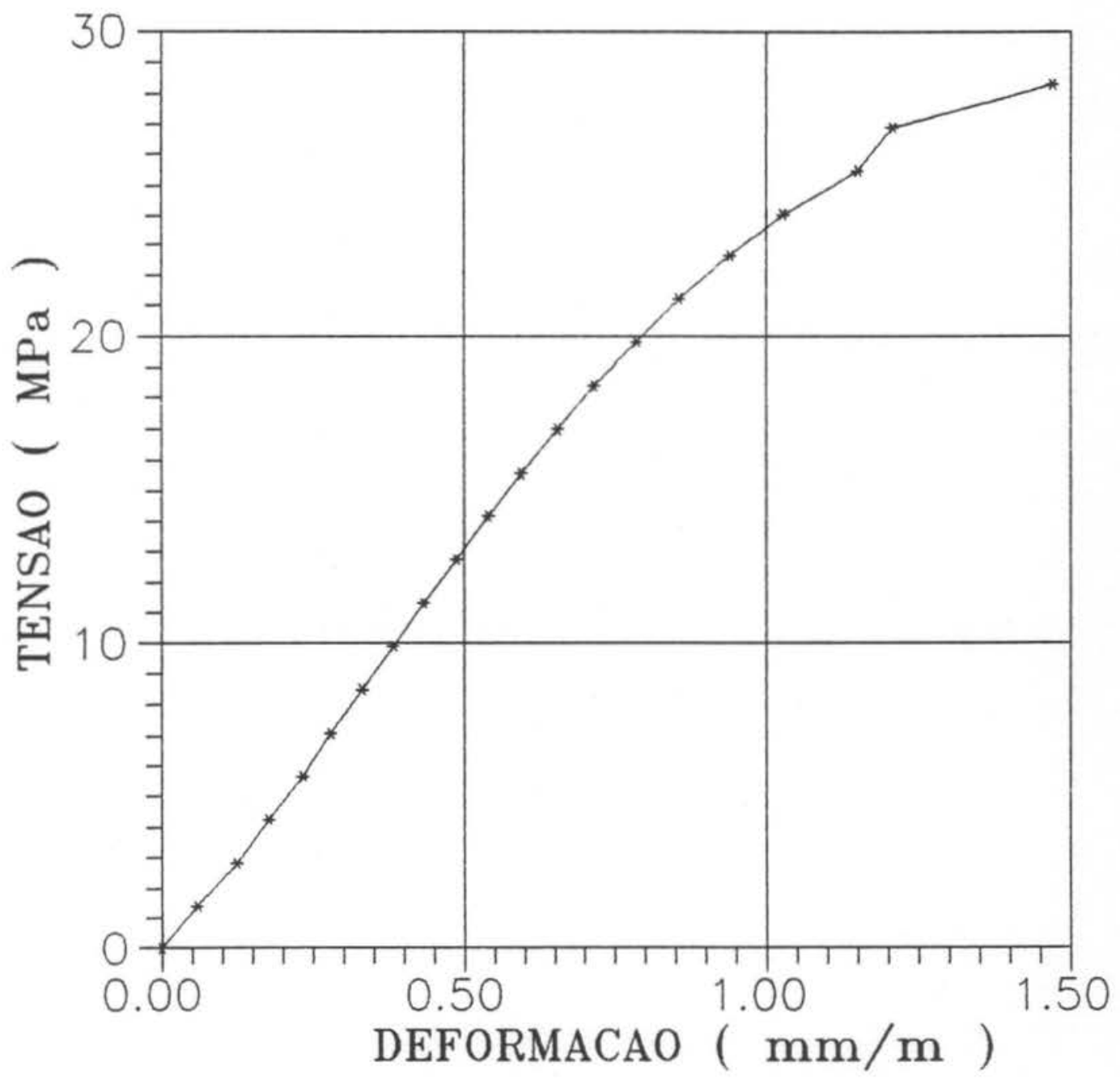

$* * * * *$ CURVA $\sigma_{c} \times \varepsilon_{c}$ CONCRETO ( CORPO-DE-PROVA No. 3 ) 
ANEXO D 


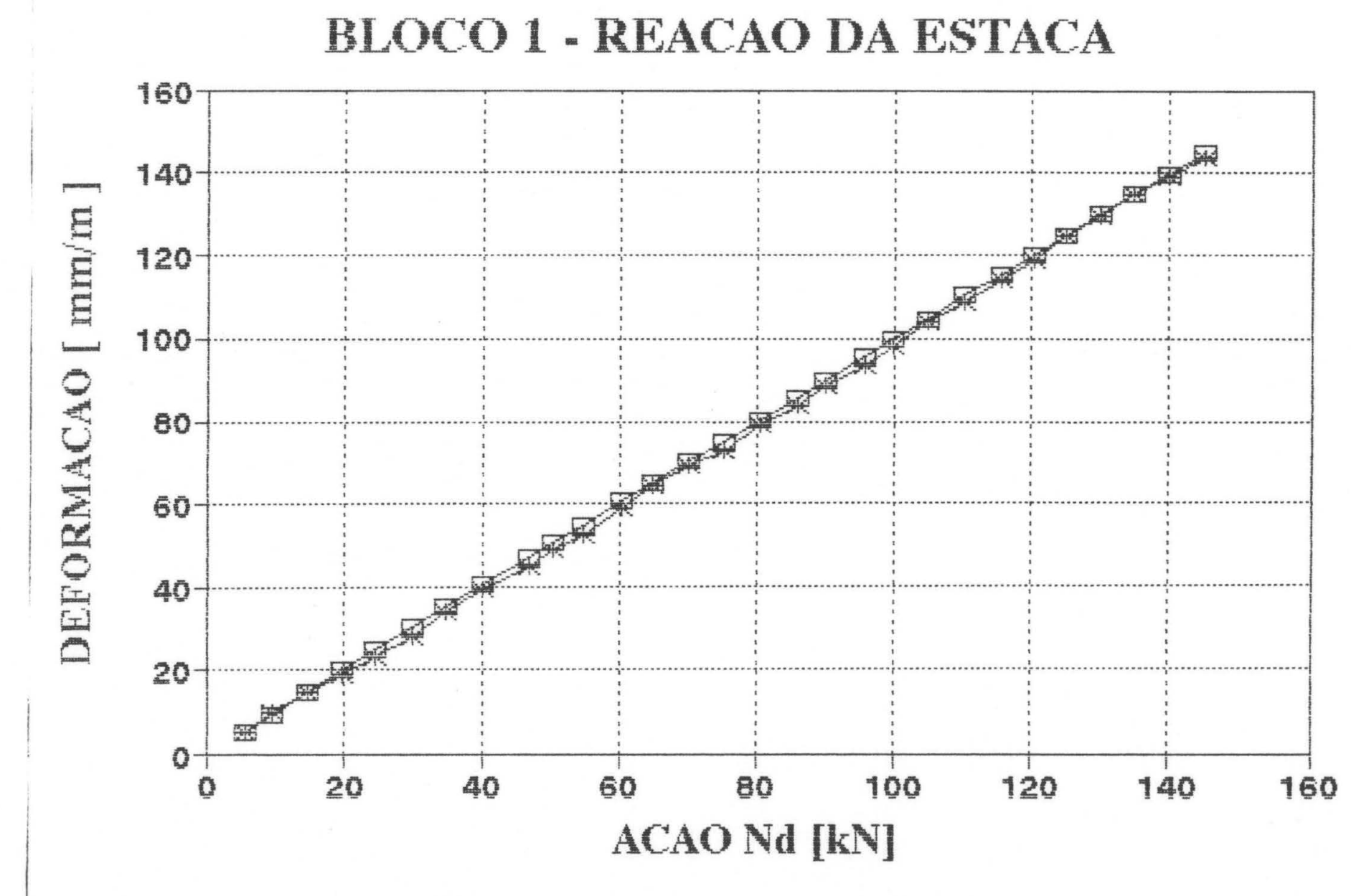

* CPC-18 $\square$ FORCA APLICADA




\section{BLOCO 1 - ESTRIBOS HORIZONTAIS (LESTE)}

EXTENSOMETROS 1, 2 E 3

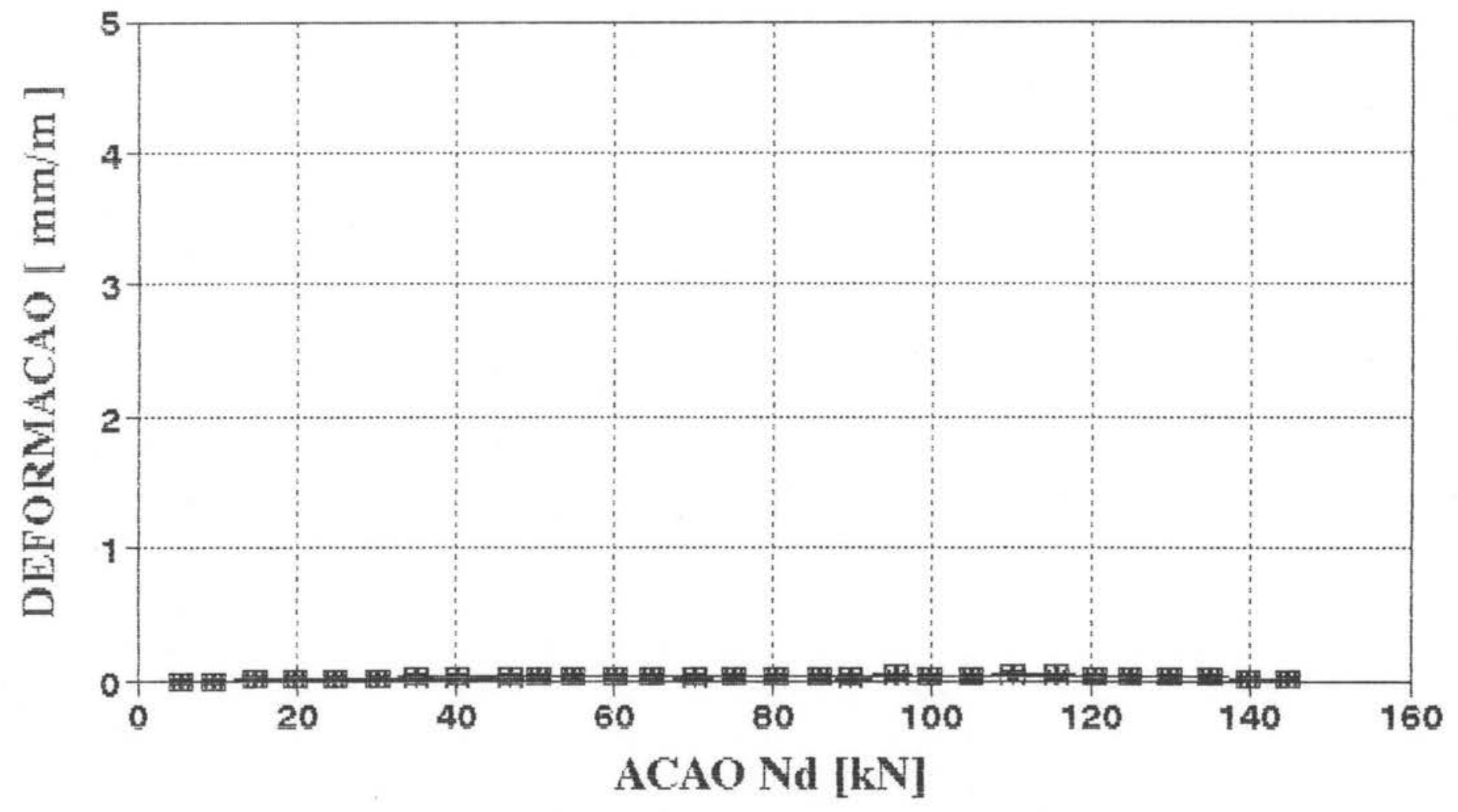

* B1HX1 (TOPO) $\square$ B1HX2 (MEIO) —- B1HX3 (BASE) 


\section{BLOCO 1 - ESTRIBOS HORIZONTAIS (SUL)}

EXTENSOMETROS 4, 5 E 6

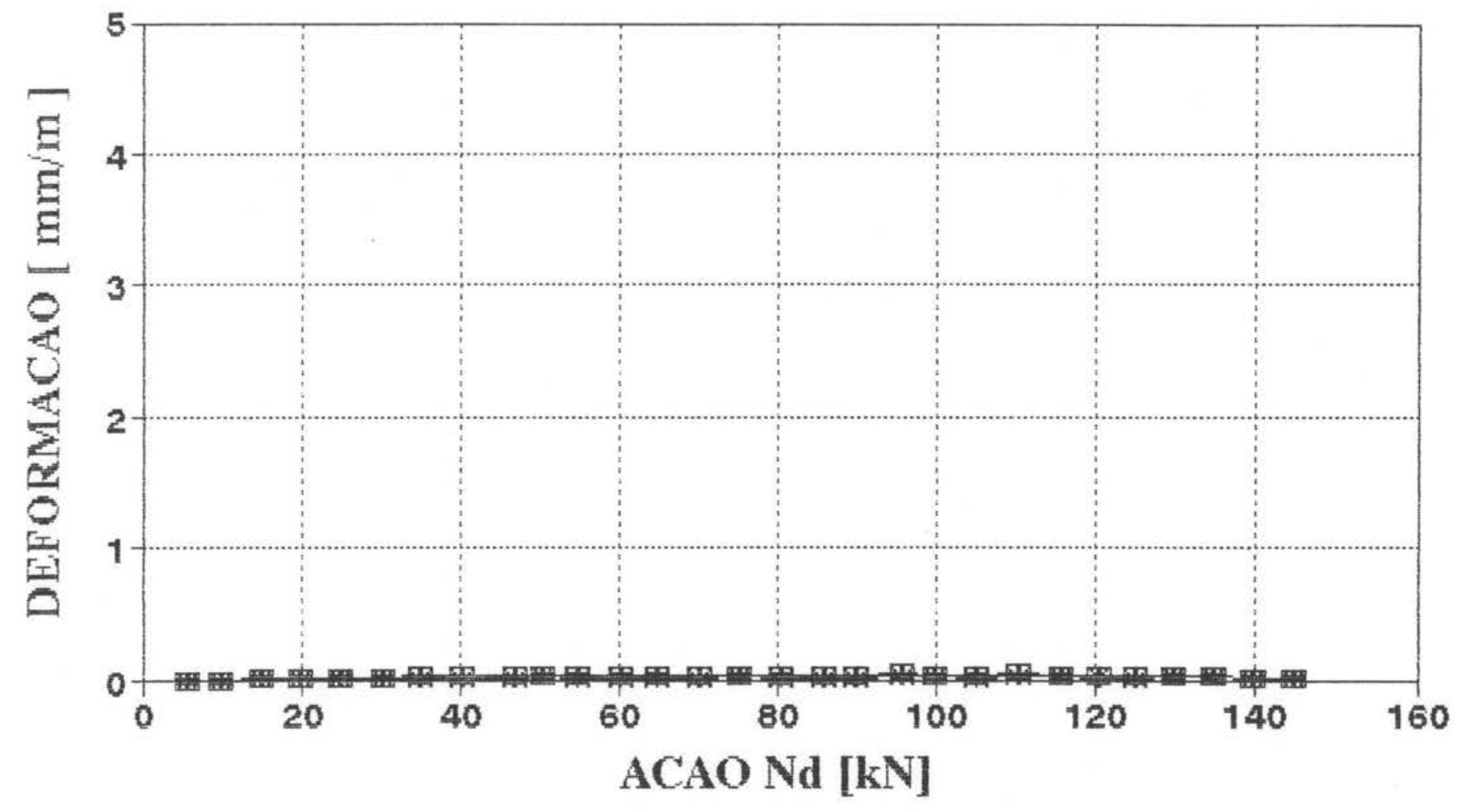

$$
\rightarrow \text { B BHY1 (TOPO) } \square-\text { B1HY2 (MEIO) —- B1HY3 (BASE) }
$$




\section{BLOCO 1 - ESTRIBOS VERTICAIS (TOPO)}

EXTENSOMETROS 7, 8 E 9

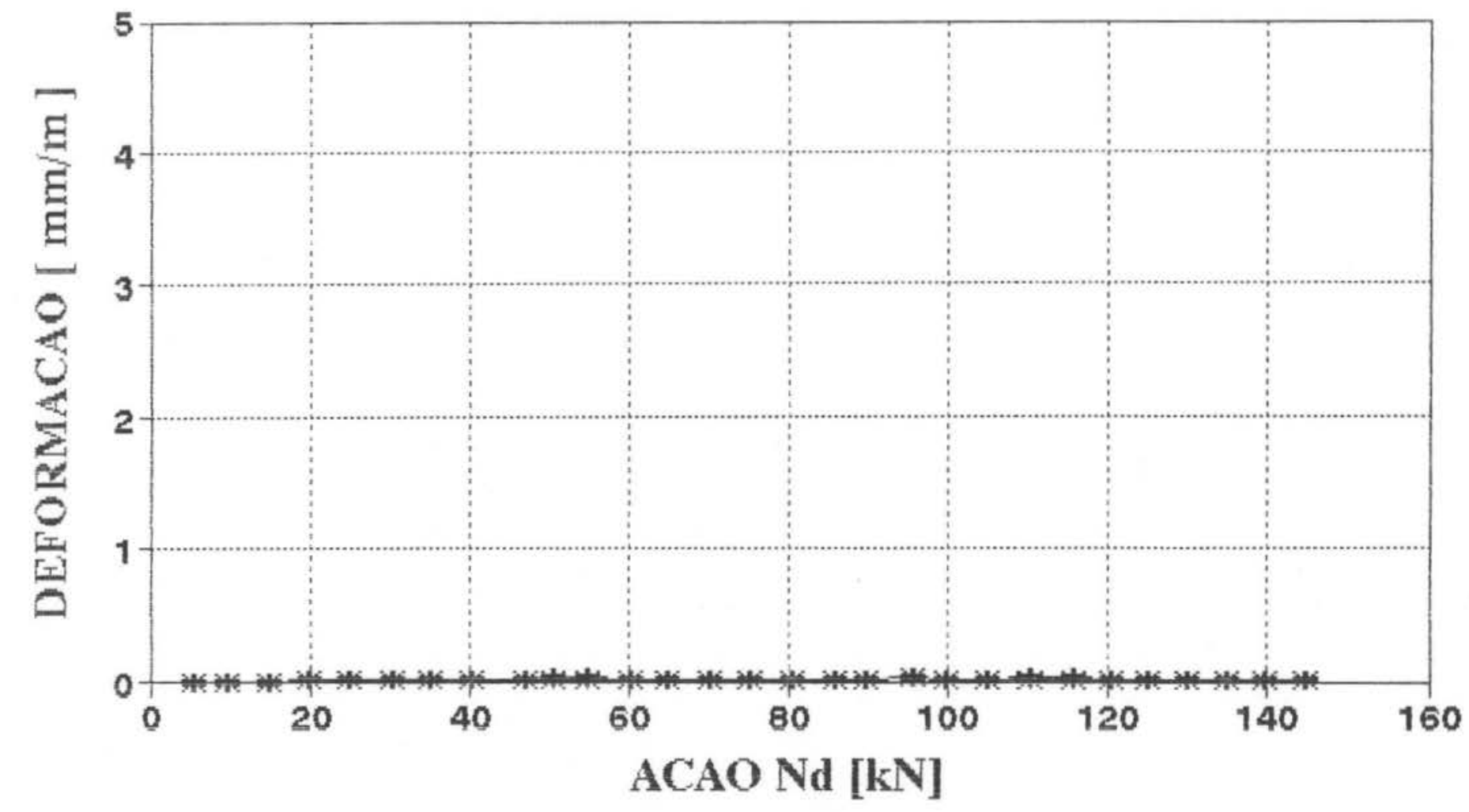

* B1VX1T (LESTE) $\quad \square-$ BIVX2T - PERDIDO - B1VX3T (OESTE) 


\section{BLOCO 1 - ESTRIBOS VERTICAIS (BASE)}

EXTENSOMETROS 10, $11 \mathrm{E} 12$

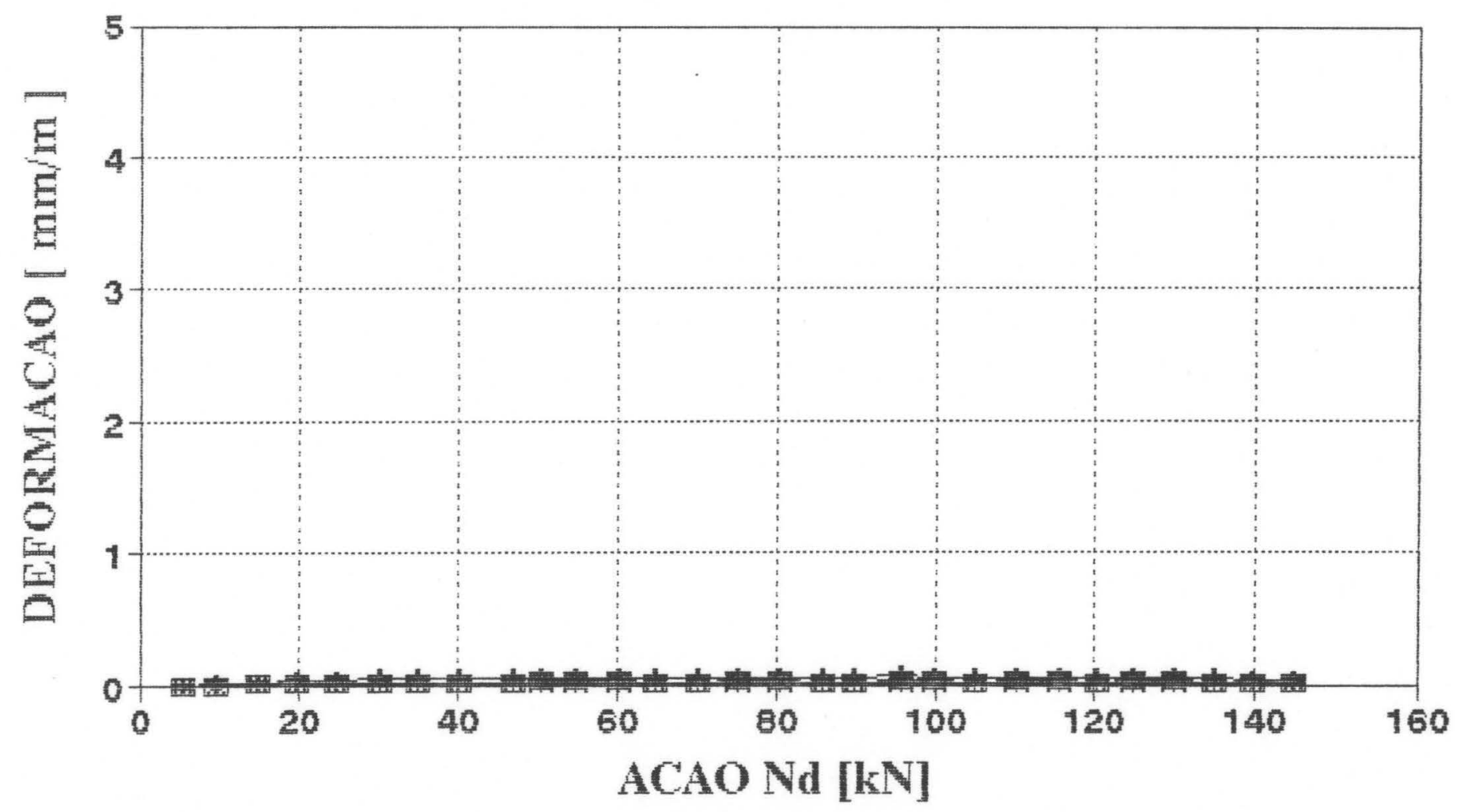

* BIVX1B (LESTE) $\square$ SIVX2B (CPC-18) - - BIVX3B (OESTE) 


\section{BLOCO 1 - BIELA}

EXTENSOMETRO 13

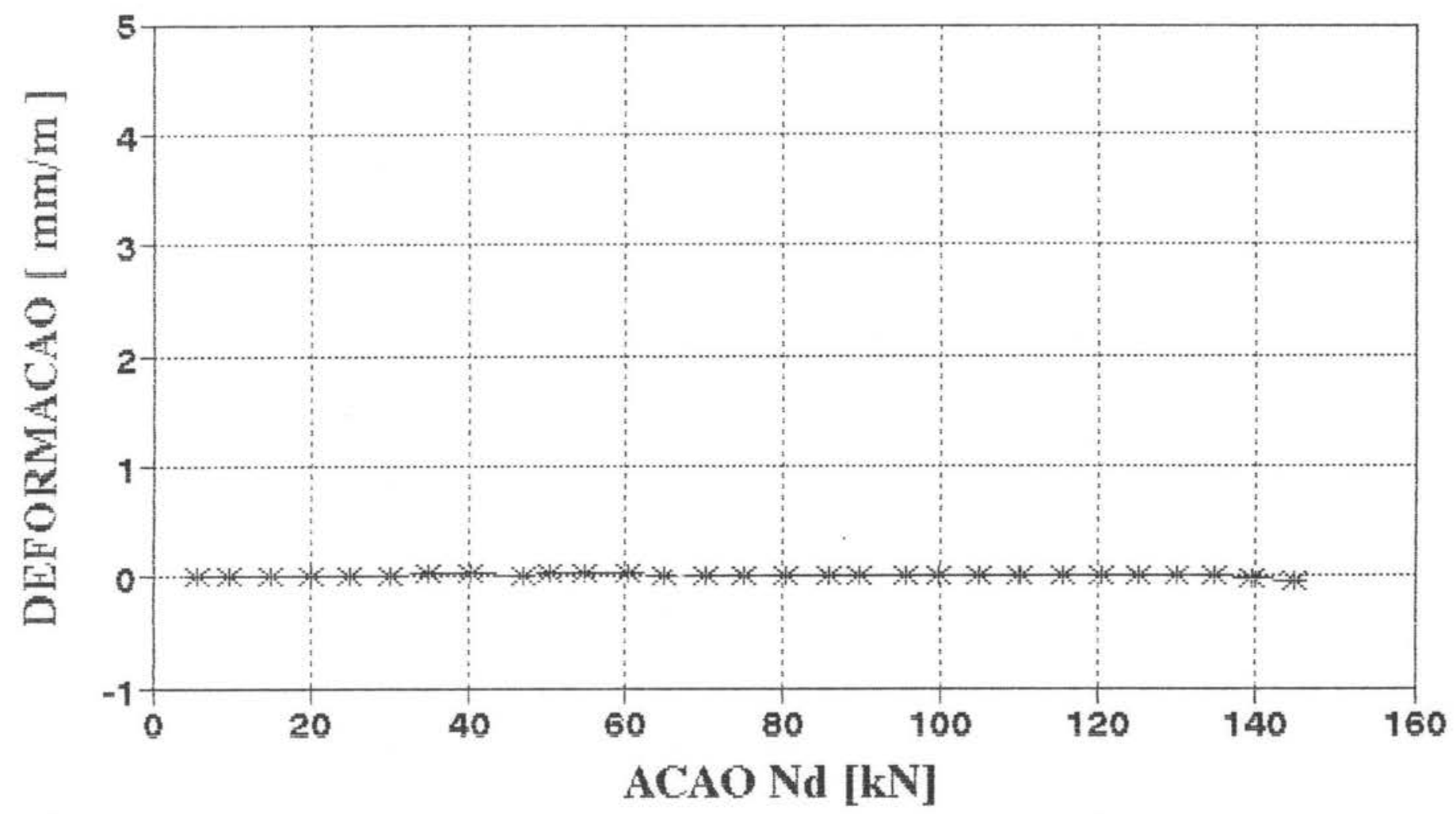

$\rightarrow$ B1B 


\section{BLOCO 2 - REACOES ESTACAS E SOLO}

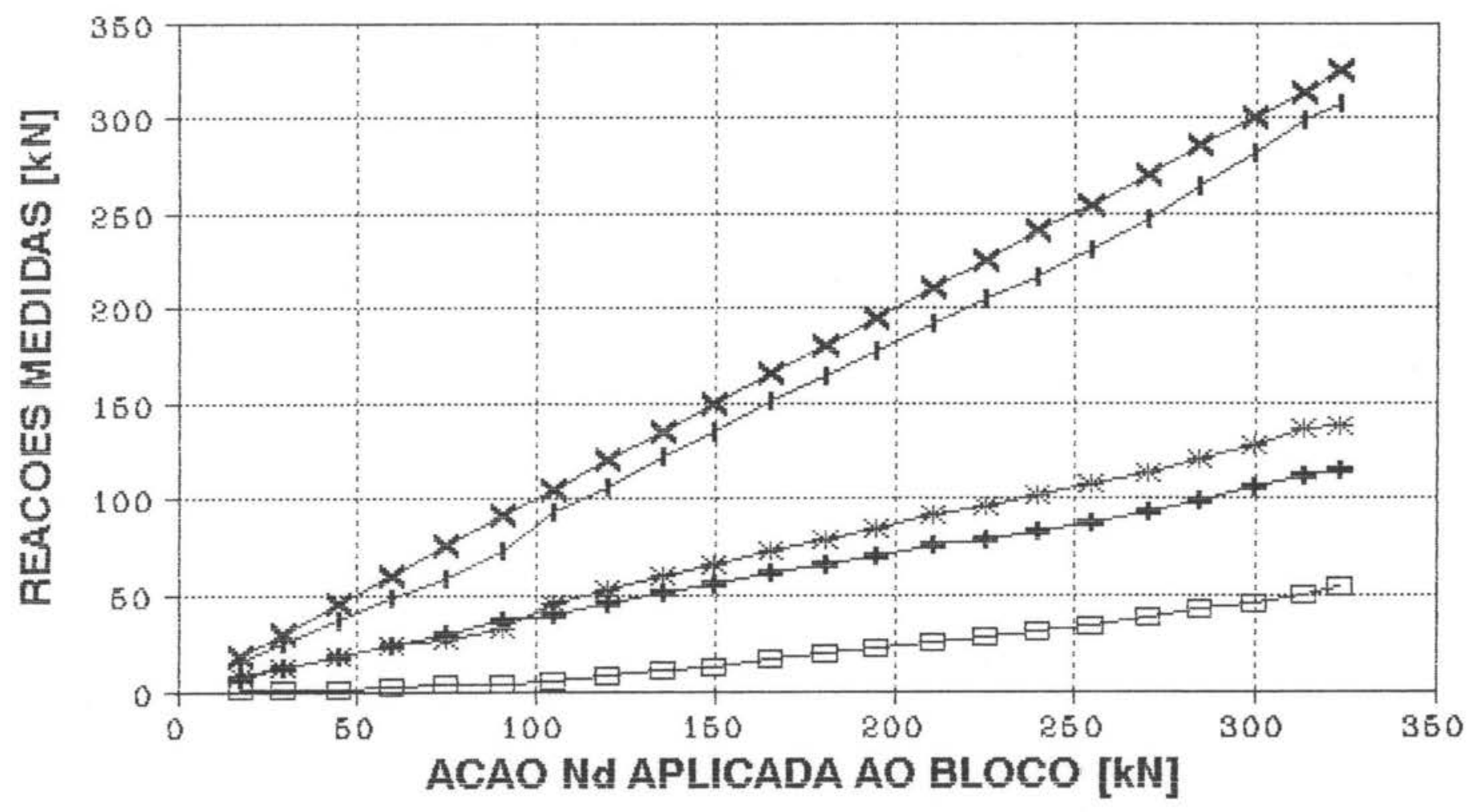

$$
\begin{array}{lll}
\rightarrow-C-05 & + \text { C-11 } \\
1-\text { REACAO TOTAL CP-SOLO } & \text { - ACAO AFLICADA }
\end{array}
$$




\section{BLOCO 2 - ESTRIBOS HORIZONTAIS (OESTE) ESTENSOMETROS 1, 2 E 3}

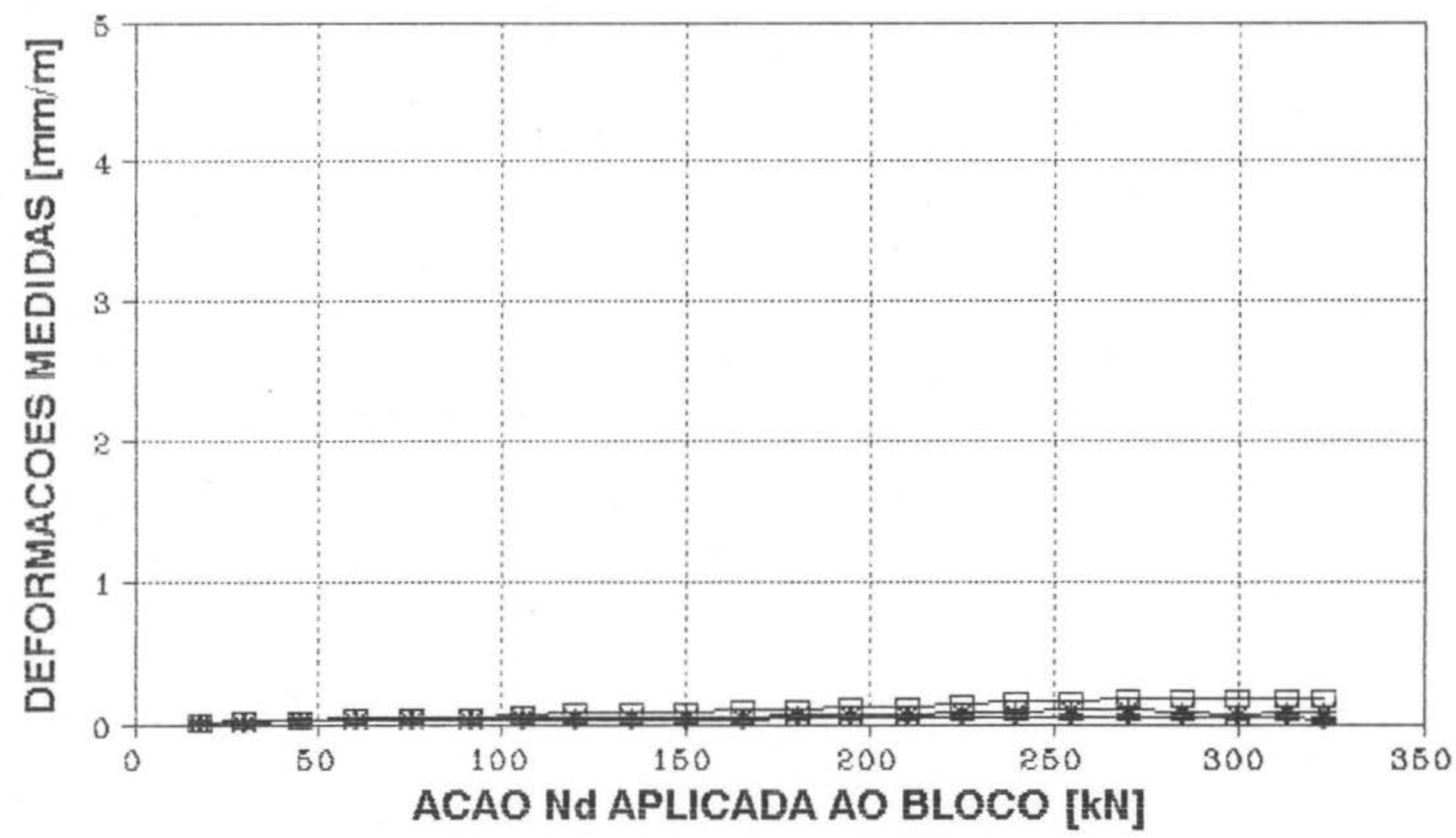

$$
\text { * B2HXI (TOPO) —- B2HX2 (MEIO) — B2HX3 (EASE) }
$$




\section{BLOCO 2 - ESTRIBOS HORIZONTAIS (NORTE) ESTENSOMETROS 4, 5 E 6}

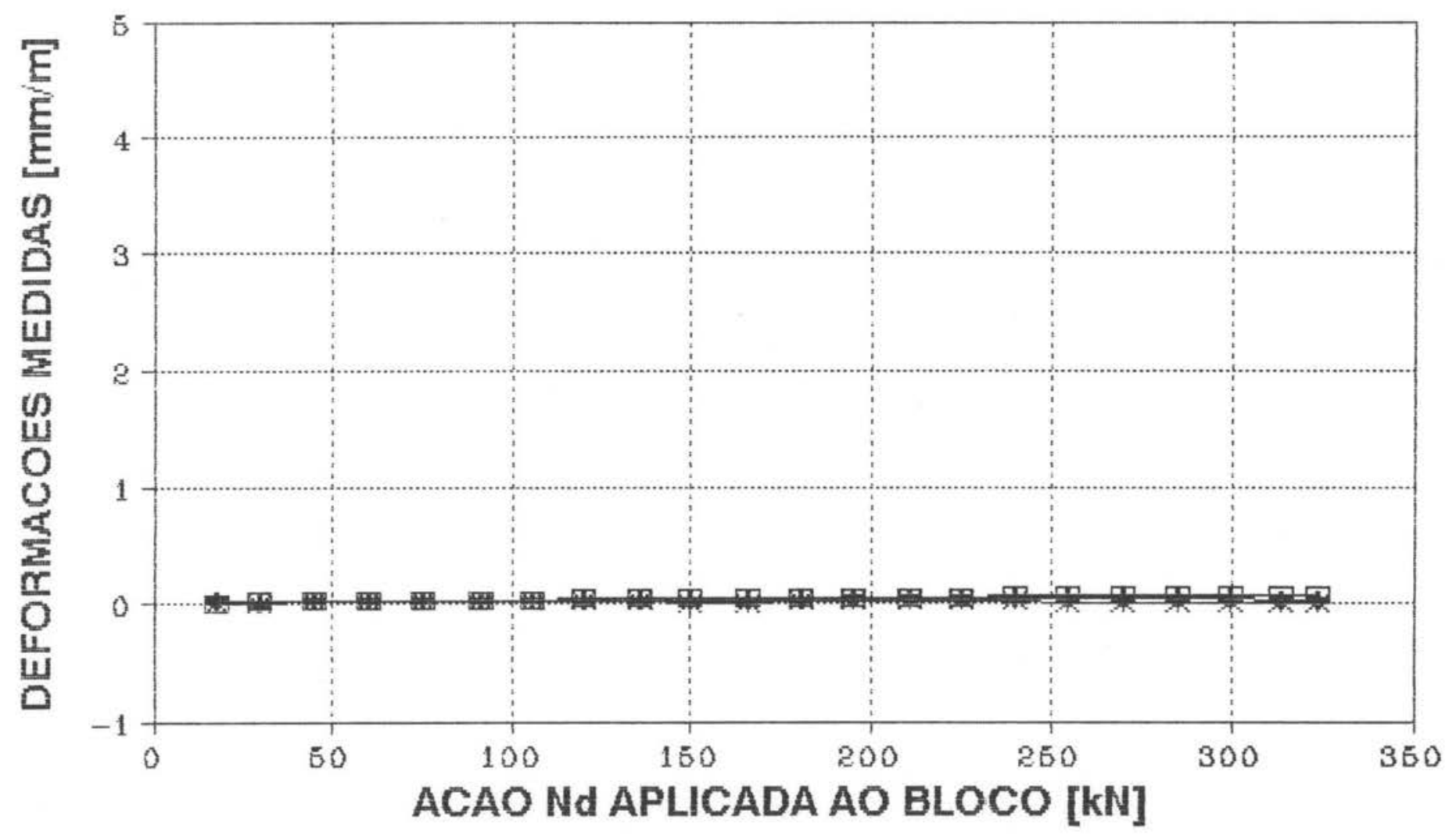




\section{BLOCO 2 - ESTRIBOS VERTICAIS (BASE) ESTENSOMETROS 7, 8 E 9}

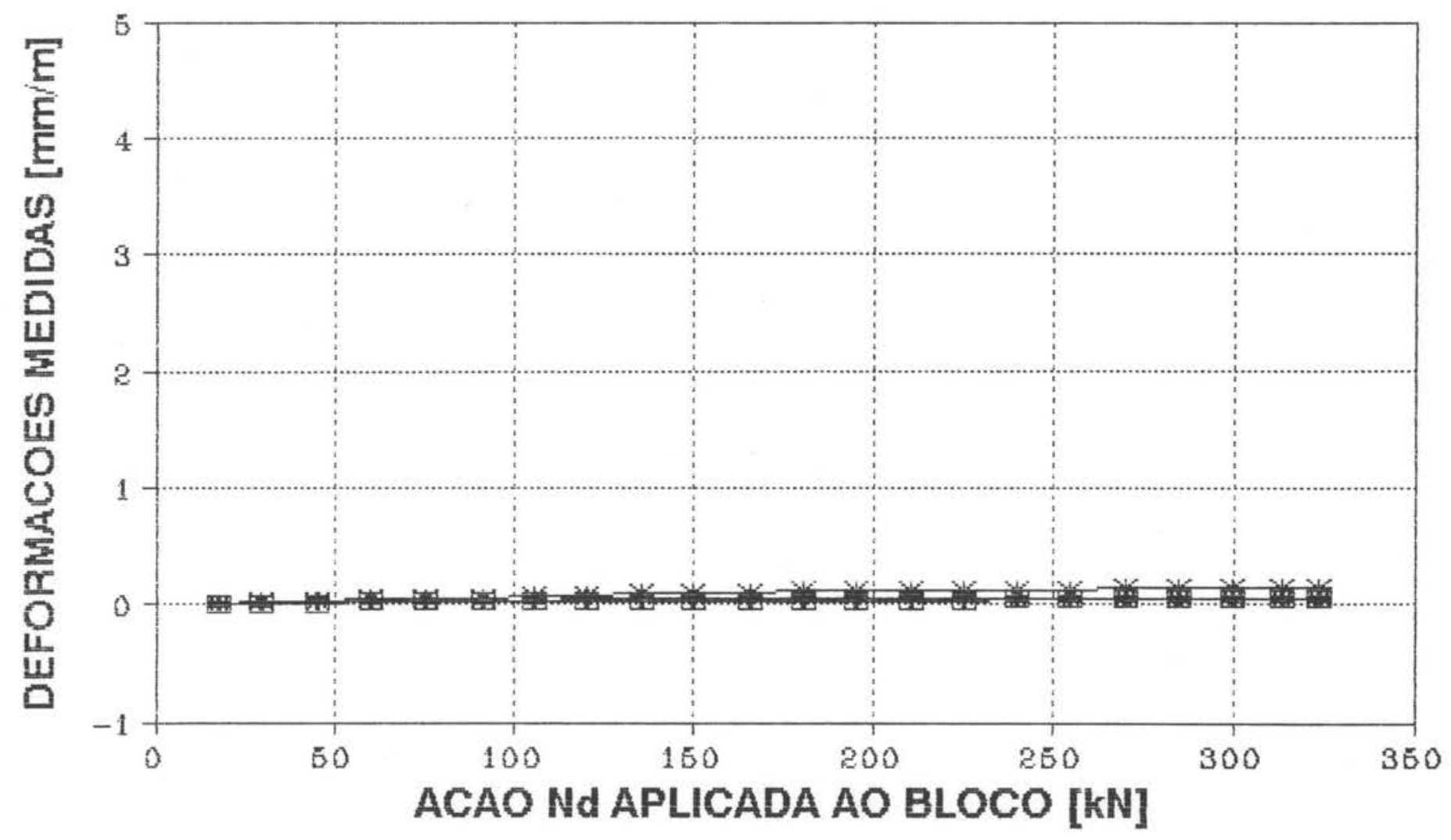

$$
\rightarrow \text { B B2VX1B (OESTE) } \rightarrow \text { B2VX2B (MEIO) E B2VX3E (LESTE) }
$$




\section{BLOCO 2 - ESTRIBOS VERTICAIS - LADO SUL ESTENSOMETROS 10, $11 \mathrm{E} 12$}

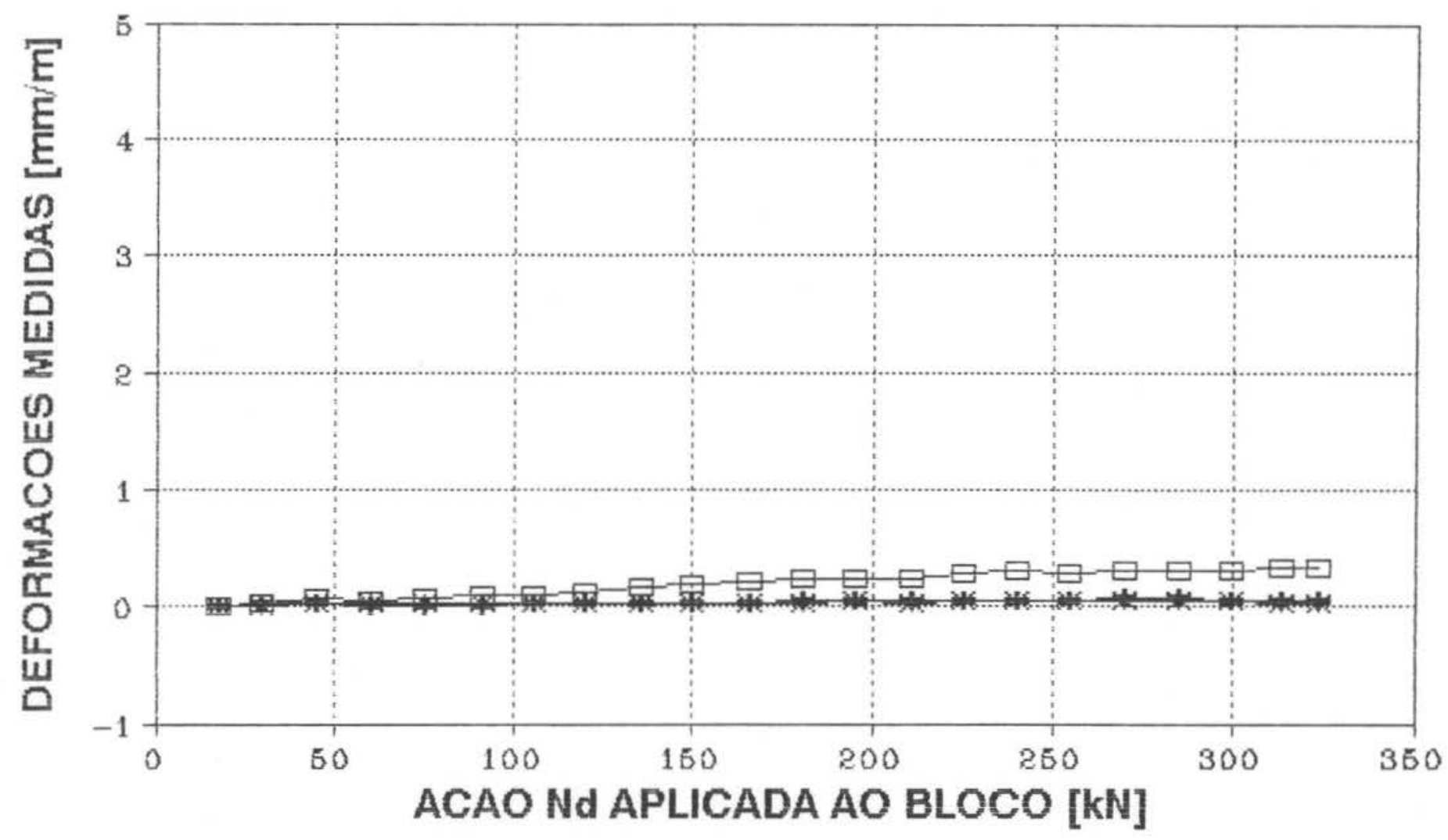

$$
\text { * B } 2 \text { VZI }\langle\text { OESTE) — B2VZ2 (MEIO) } \square \text { B2VZ3 (LESTE) }
$$




\section{BLOCO 2 - ARMADURA INFERIOR ESTENSOMETROS 13, 14 E 15}

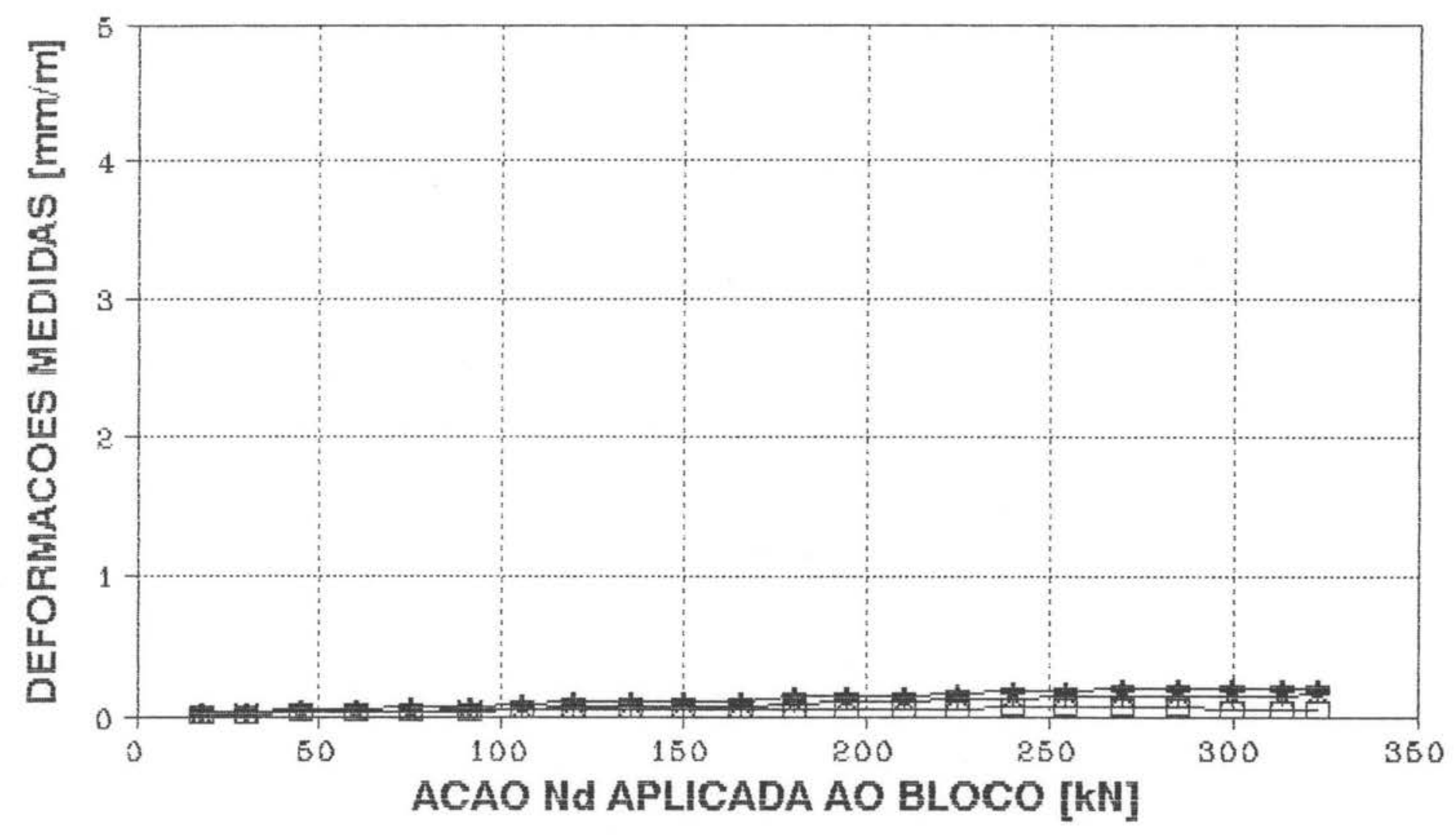




\section{BLOCO 2 - ARMADURA INFERIOR ESTENSOMETROS 16, 17, 18 E 19}

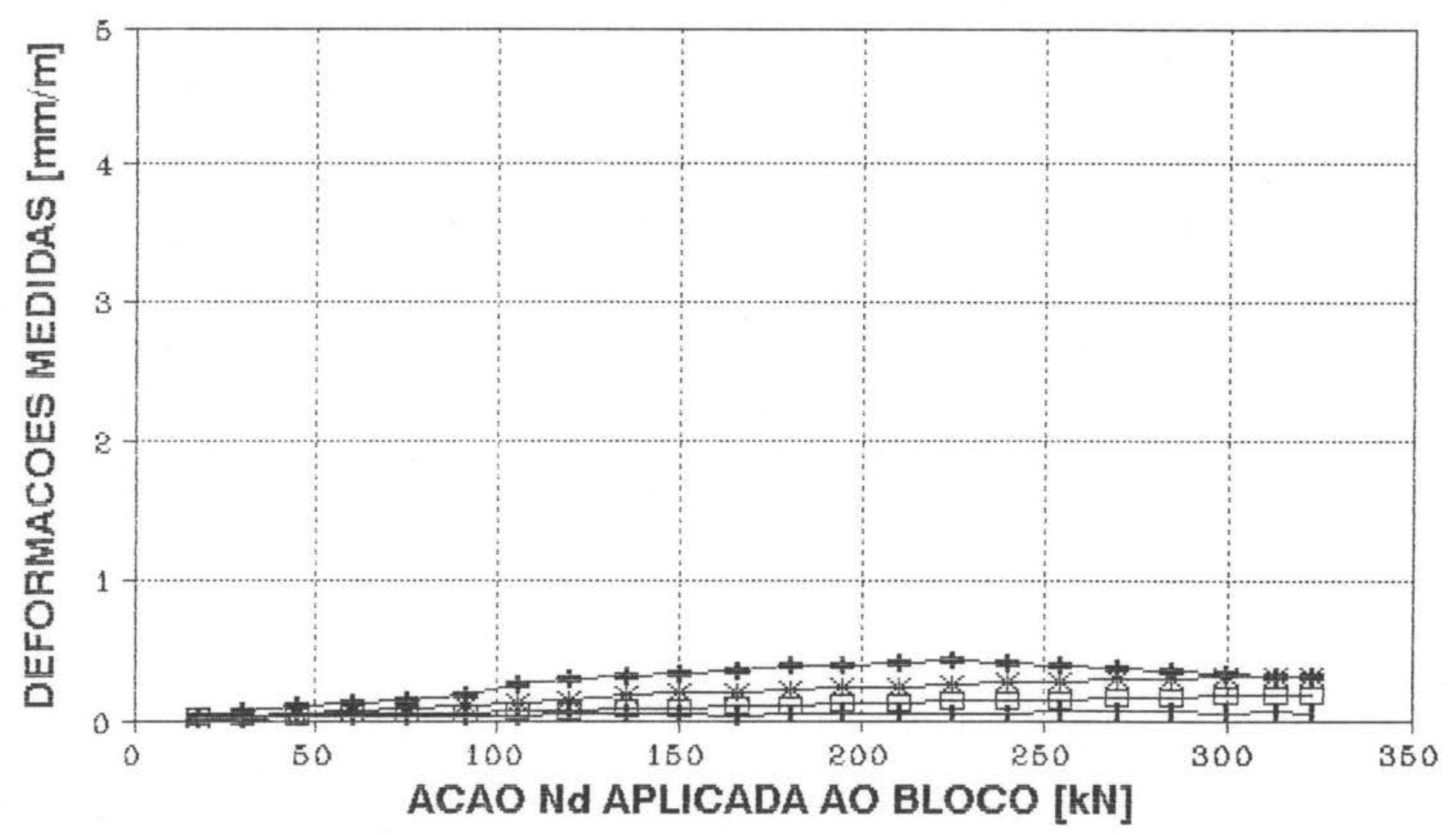

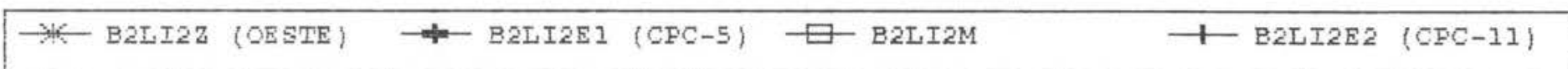




\section{BLOCO 2 - ARMADURA INFERIOR}

ESTENSOMETROS 20, $21 \mathrm{E} 22$

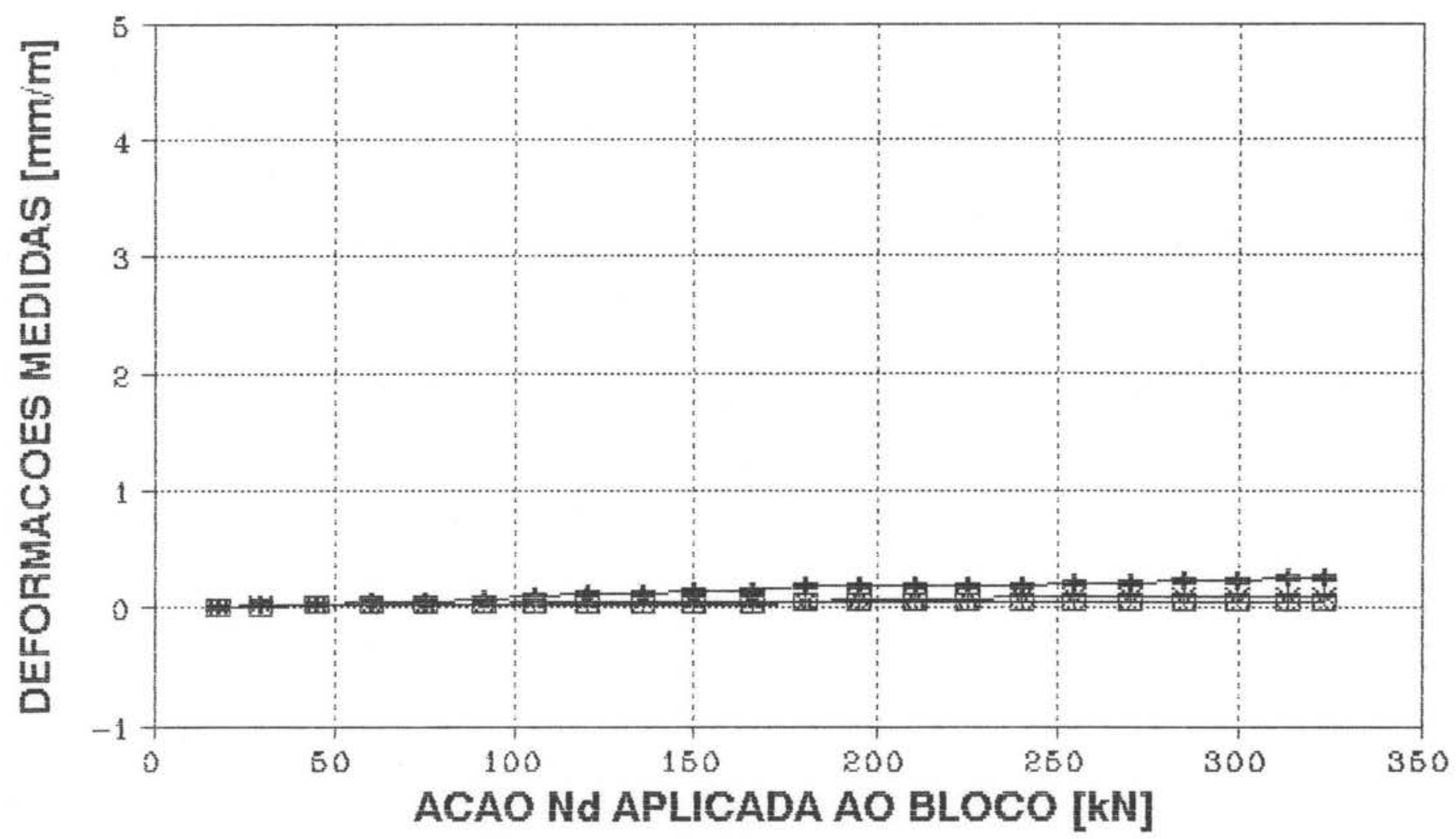

\#- B2LI3EI (CFC-5) क B2LI3M -




\section{BLOCO 2 - ARMADURA SUPERIOR ESTENSOMETROS 23 E 24}

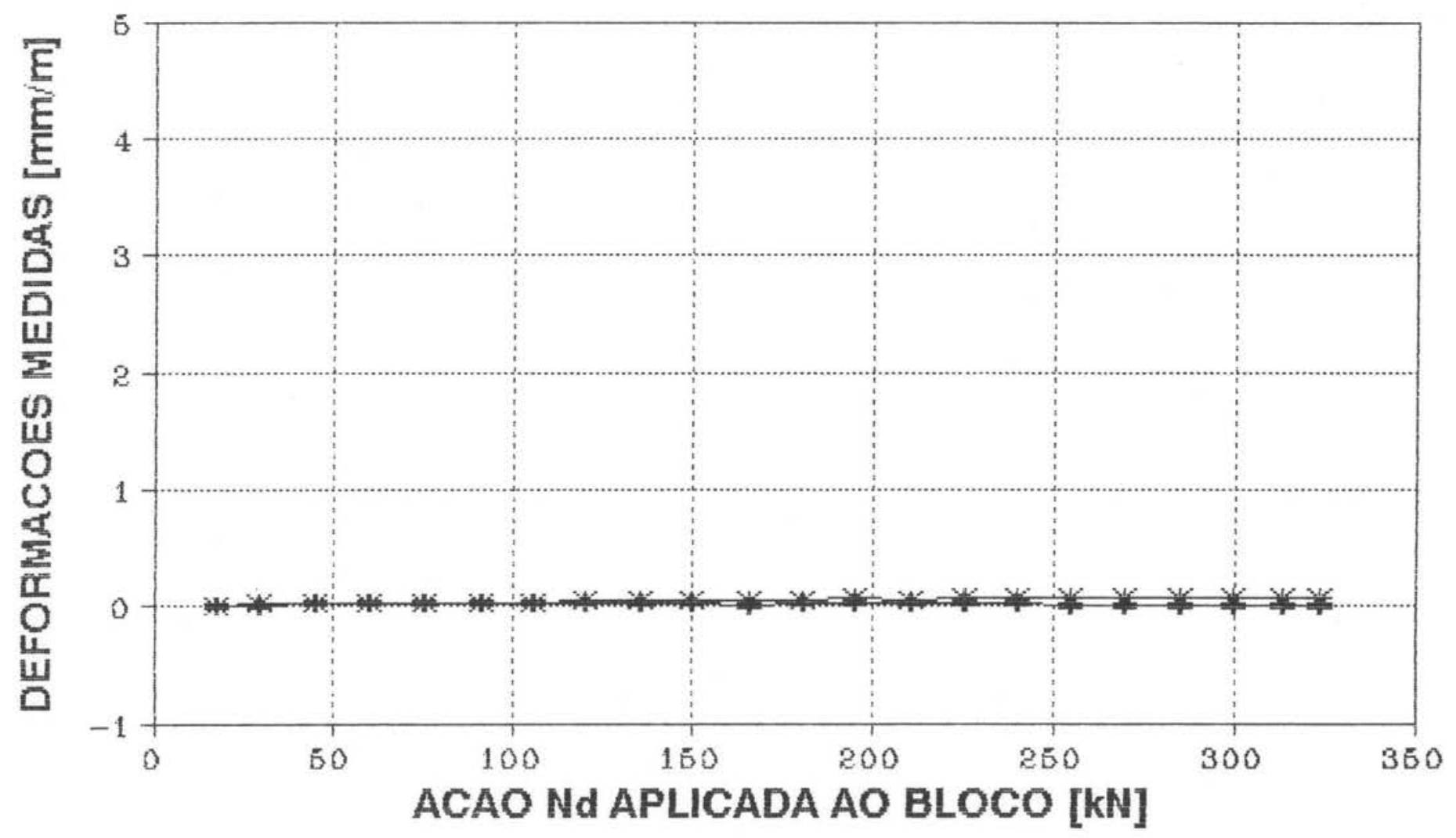




\section{BLOCO 2 - BIELAS \\ ESTENSOMETROS 25, 26 E 27}

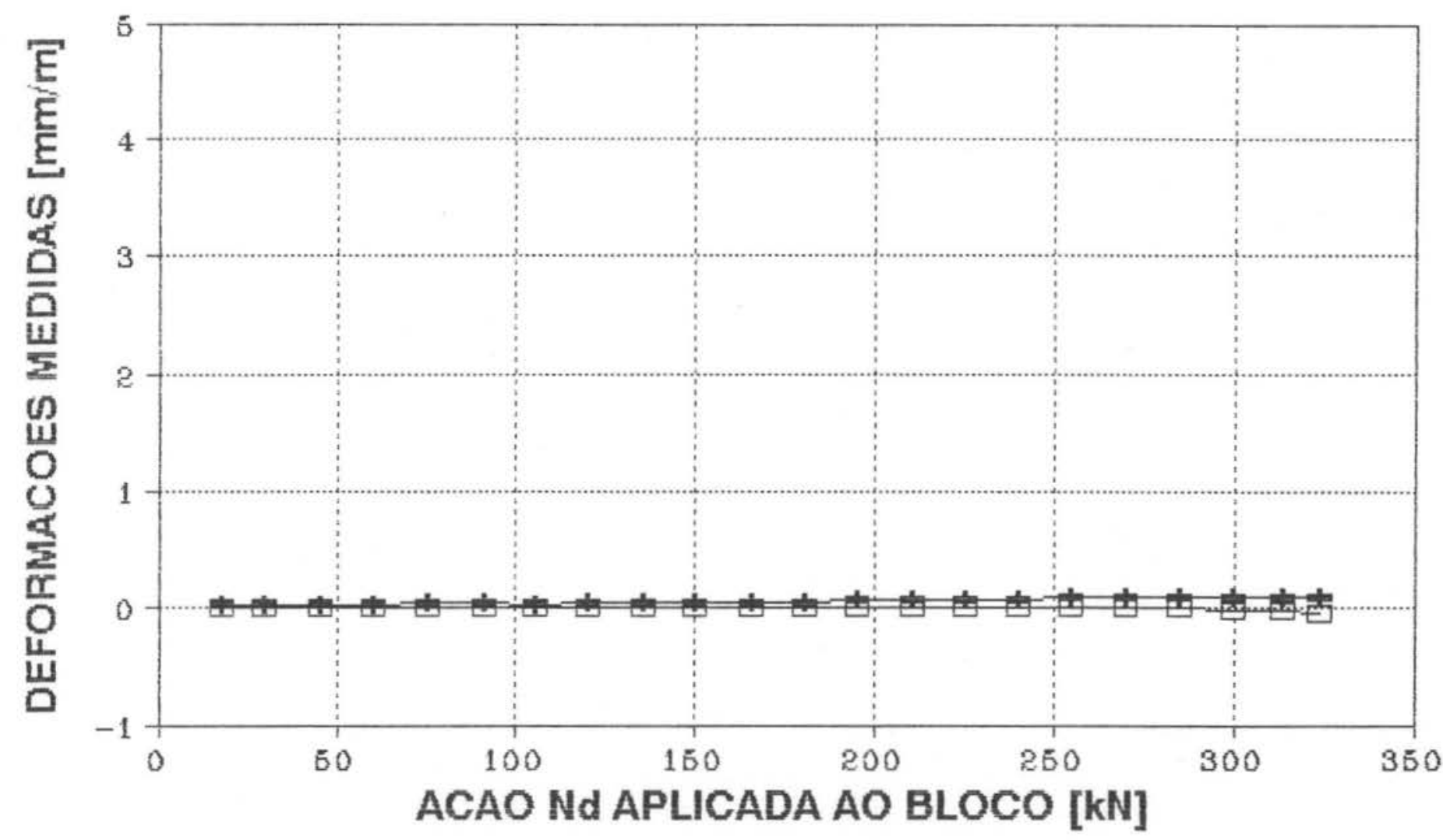

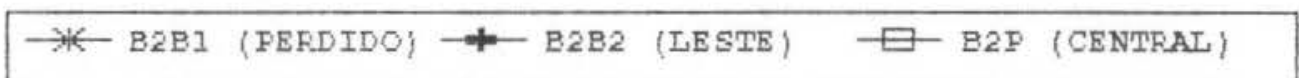




\section{BLOCO 3L - REACOES ESTACAS E SOLO}

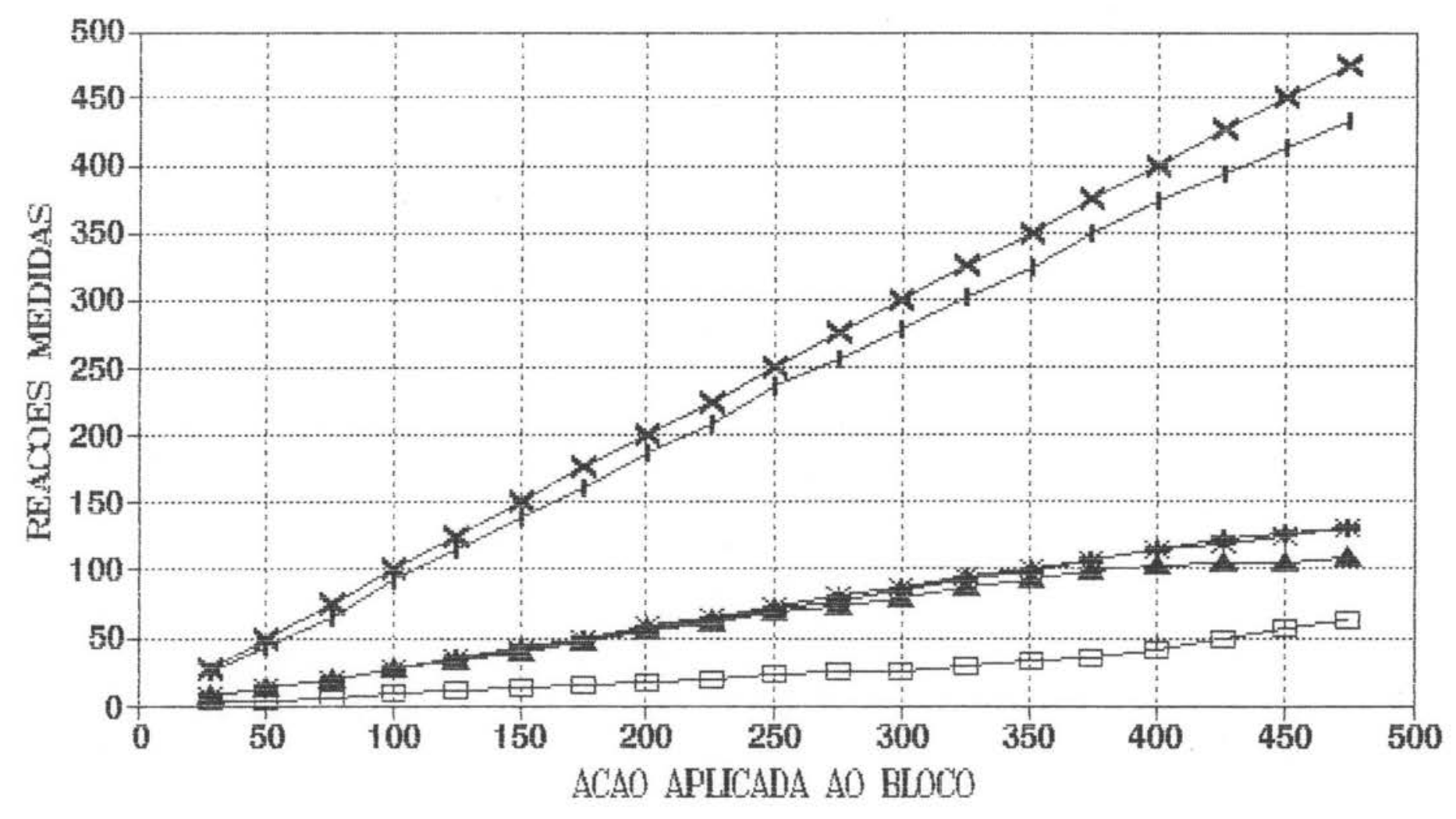

\begin{tabular}{|c|c|}
\hline$\div 0-15$ & $\triangle \mathrm{C}-09$ \\
\hline$\Xi$ CP-SOL (MENA) I REACAO TOTAL & * acao apucana \\
\hline
\end{tabular}




\section{ESTRIBOS HORIZONTAIS (OESTE) \\ ESTENSOMETROS 1 E 2}

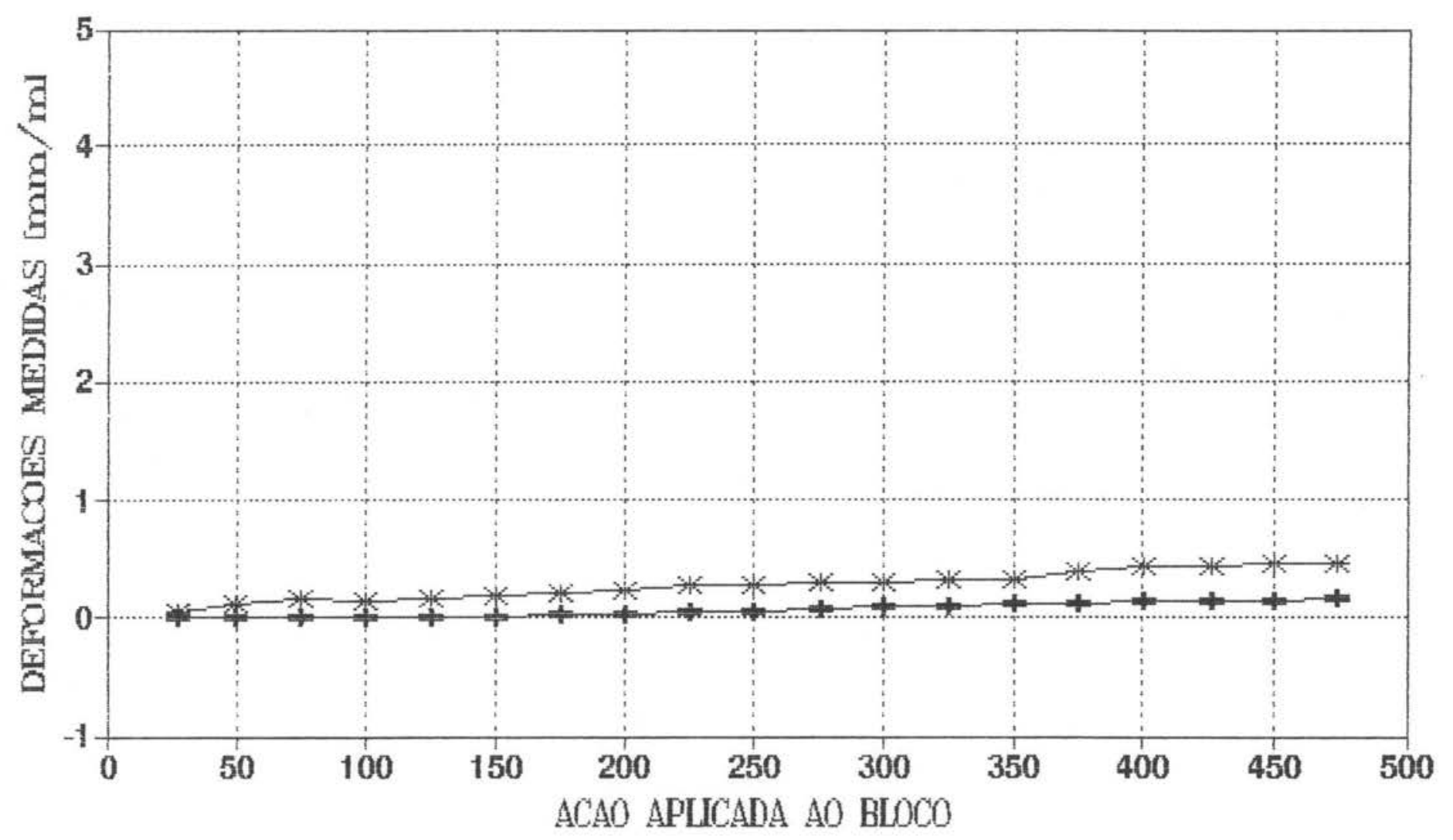

$$
\text { *ै- } \mathrm{BSHX1}+\mathrm{B} 3 \mathrm{HX2}
$$




\section{ESTRIBOS HORIZONTAIS (SUL) \\ ESTENSOMETROS 3, 4 E 5}

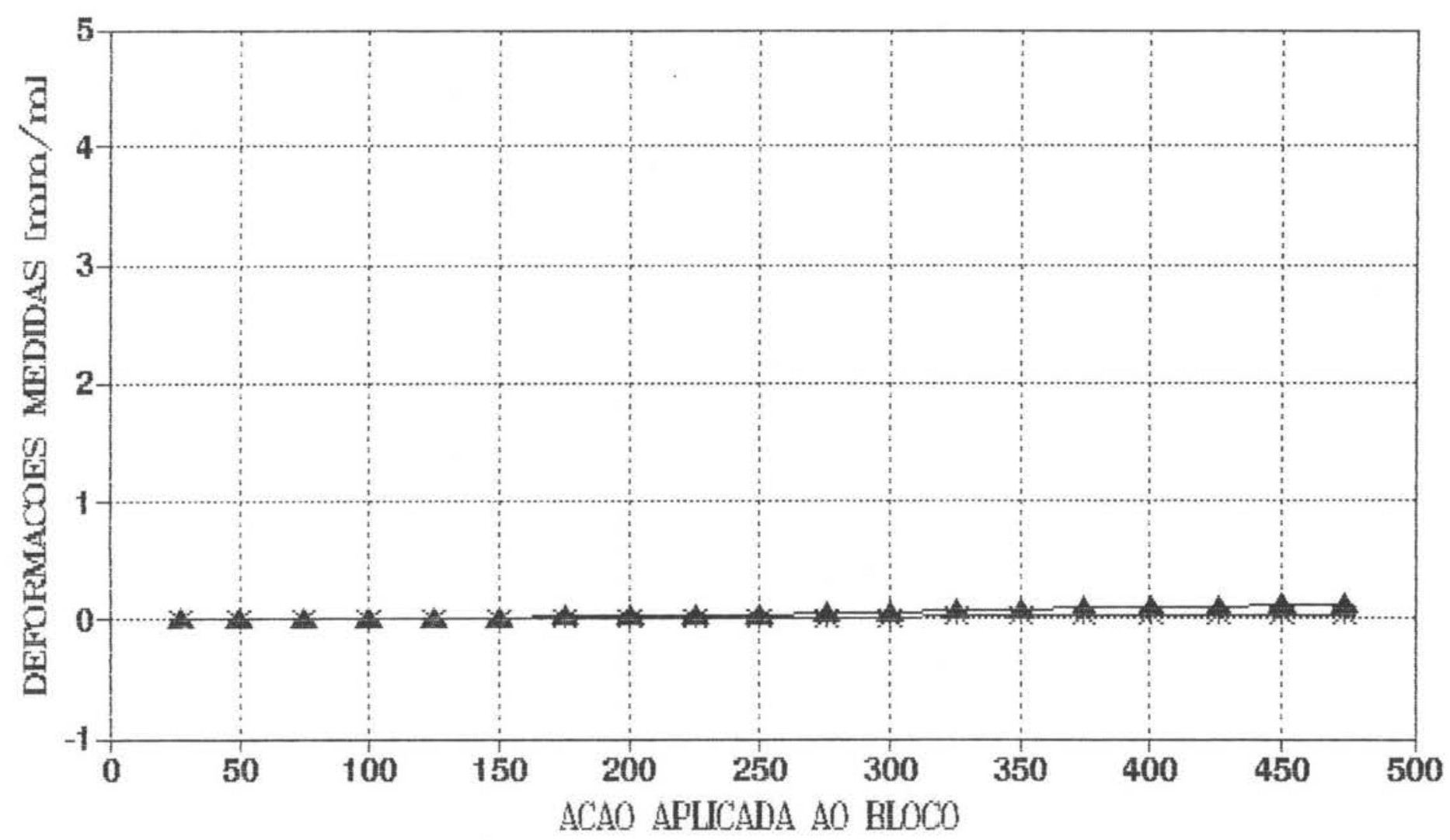




\section{ESTRIBOS VERTICAIS (BASE) ESTENSOMETROS 6, 7 E 8}

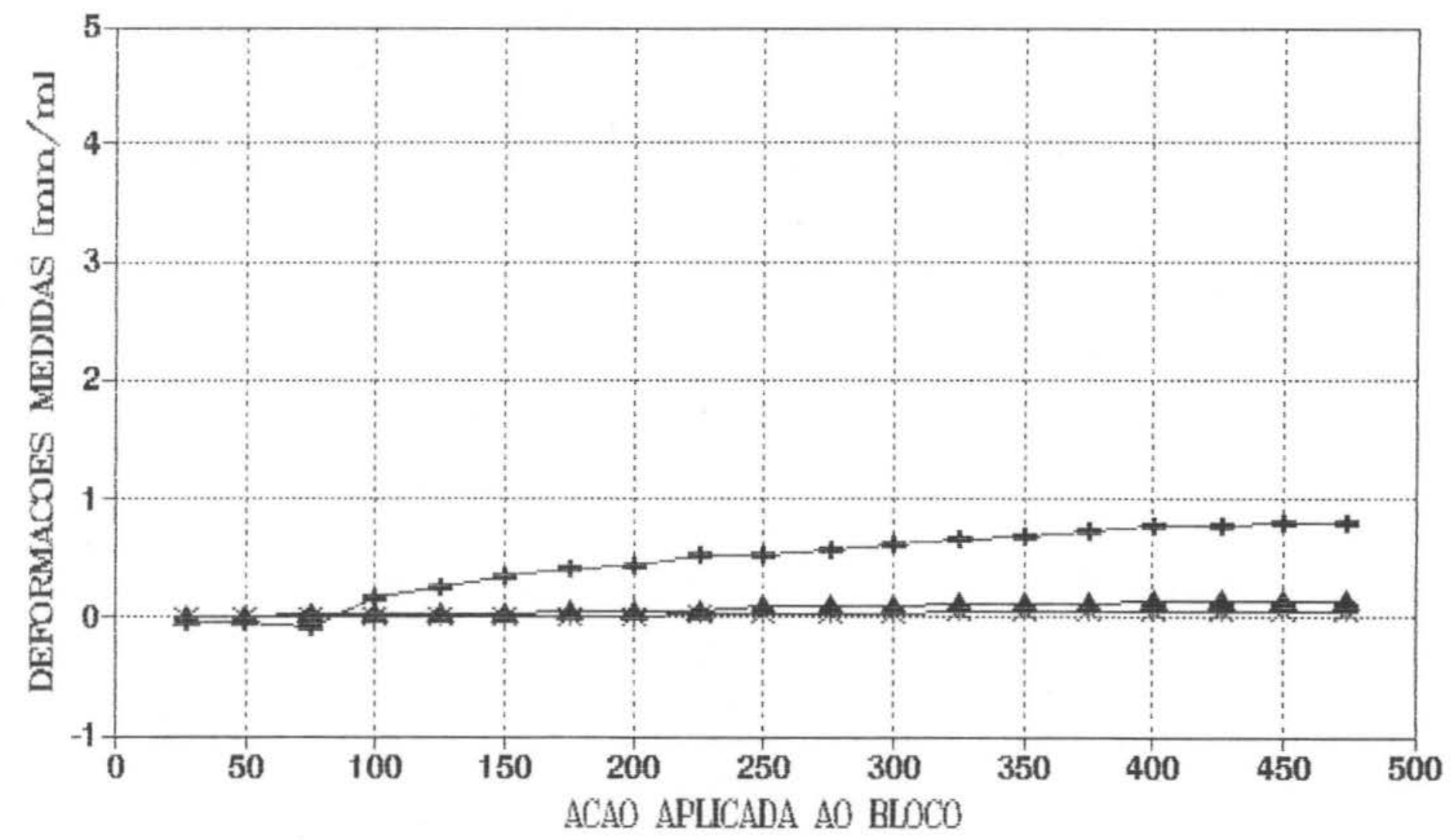

$$
\text { * } \mathrm{BSTMIB} \text { (OESIE) - B }
$$




\section{ESTRIBOS VERTICAIS (FACE SUL)}

ESTENSOMETROS 9, 10 E 11

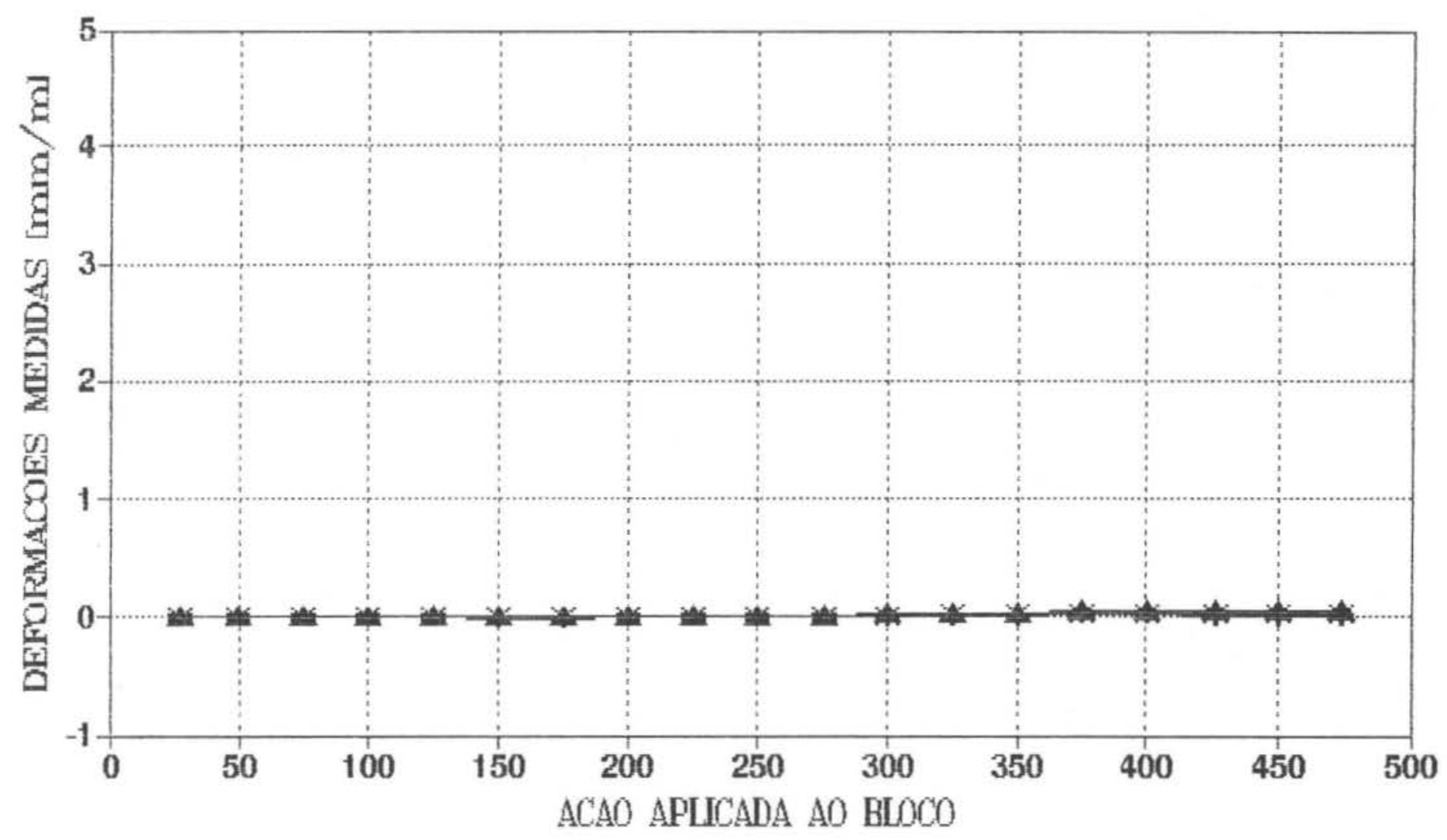

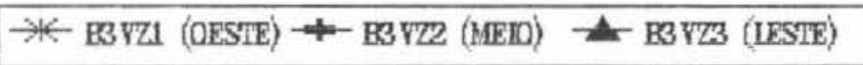




\section{ARMADURA INFERIOR (BARRA EXTERNA)}

\section{ESTENSOMETROS 12, 13, 14, 15 E 16}

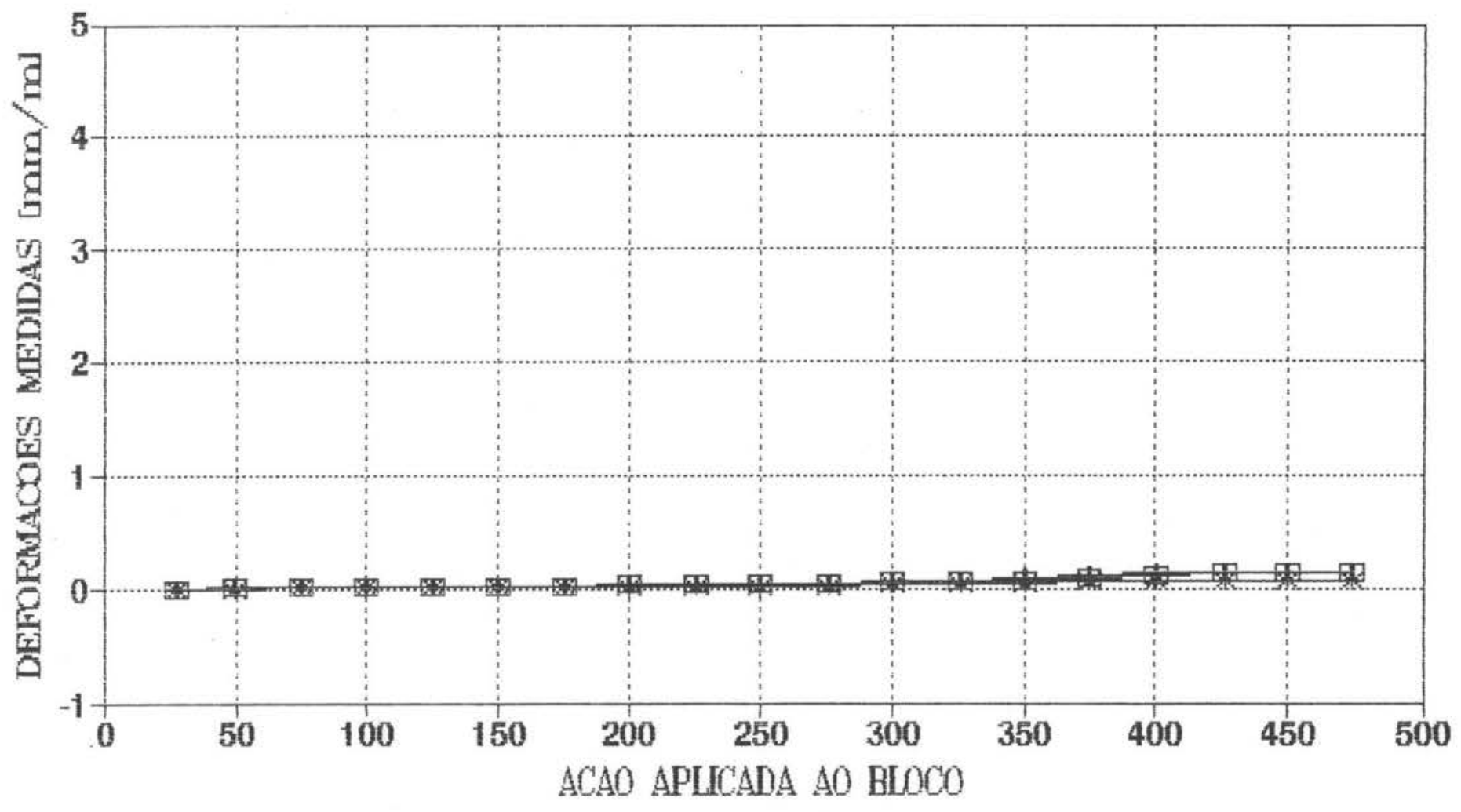

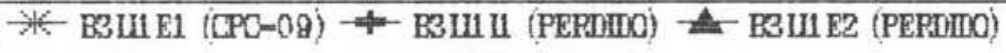

$$
\begin{aligned}
& \text { 曰 BOUE I RBWEB (CPC-12) }
\end{aligned}
$$


ARMADURA INFERIOR (BARRA CENTRAL)

ESTENSOMETROS 17, 18, 19, 20, 21 E 22

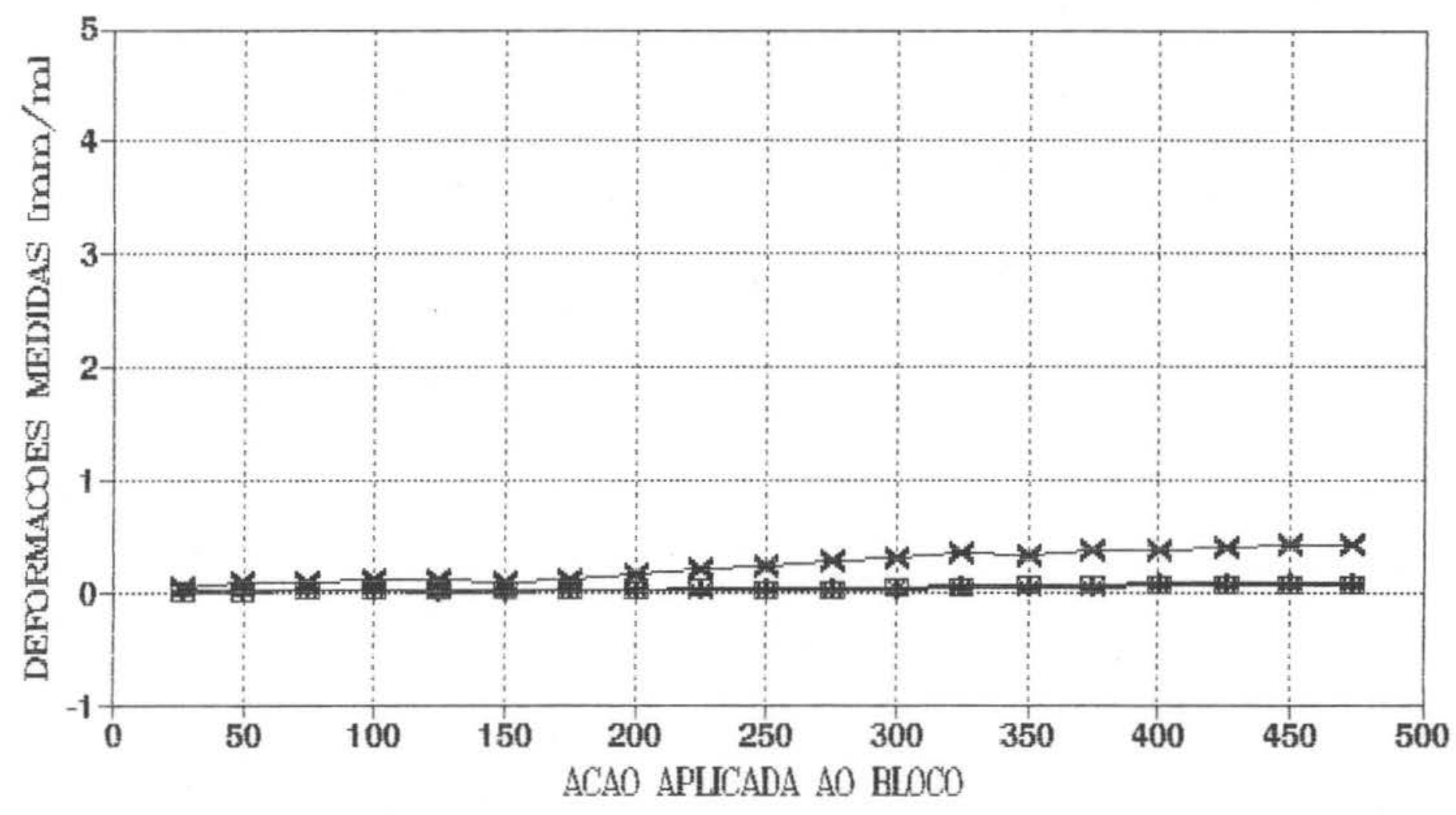

\begin{tabular}{|c|c|}
\hline * BSWZZ (OESTE) - BSUEEI (CPC-9) & $\triangle$ ВВLLL (PERWMO) \\
\hline 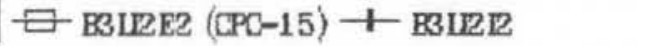 & ×- BSUEE3 (CPL-12) \\
\hline
\end{tabular}




\section{ARMADURA SUPERIOR}

ESTENSOMETROS 23 E 24

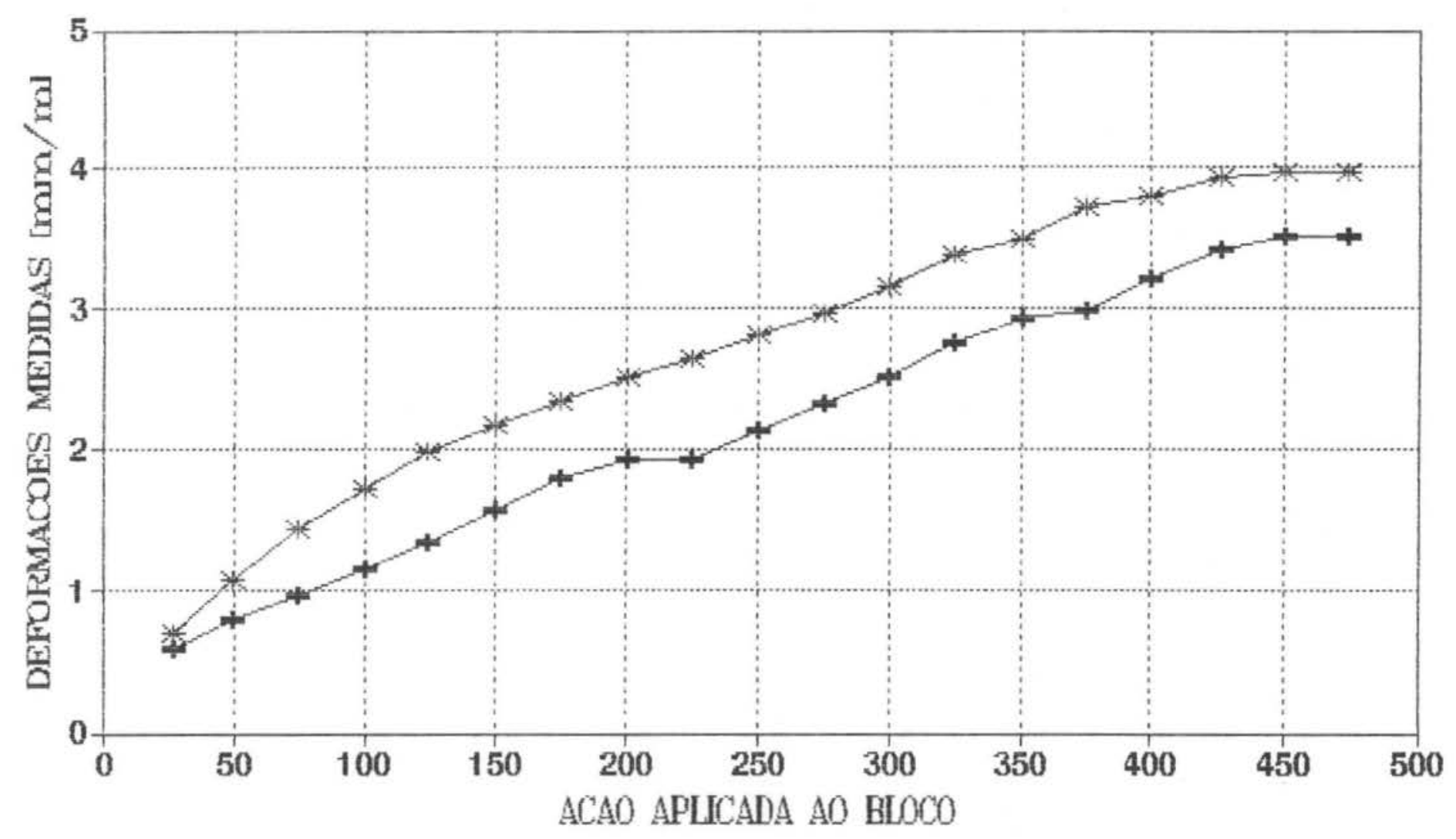

\% BSISI ED (MEID) - - BSISI II (OESIE) 


\section{BLOCO 3L - BIELAS}

ESTENSOMETROS 25, 26 E 27

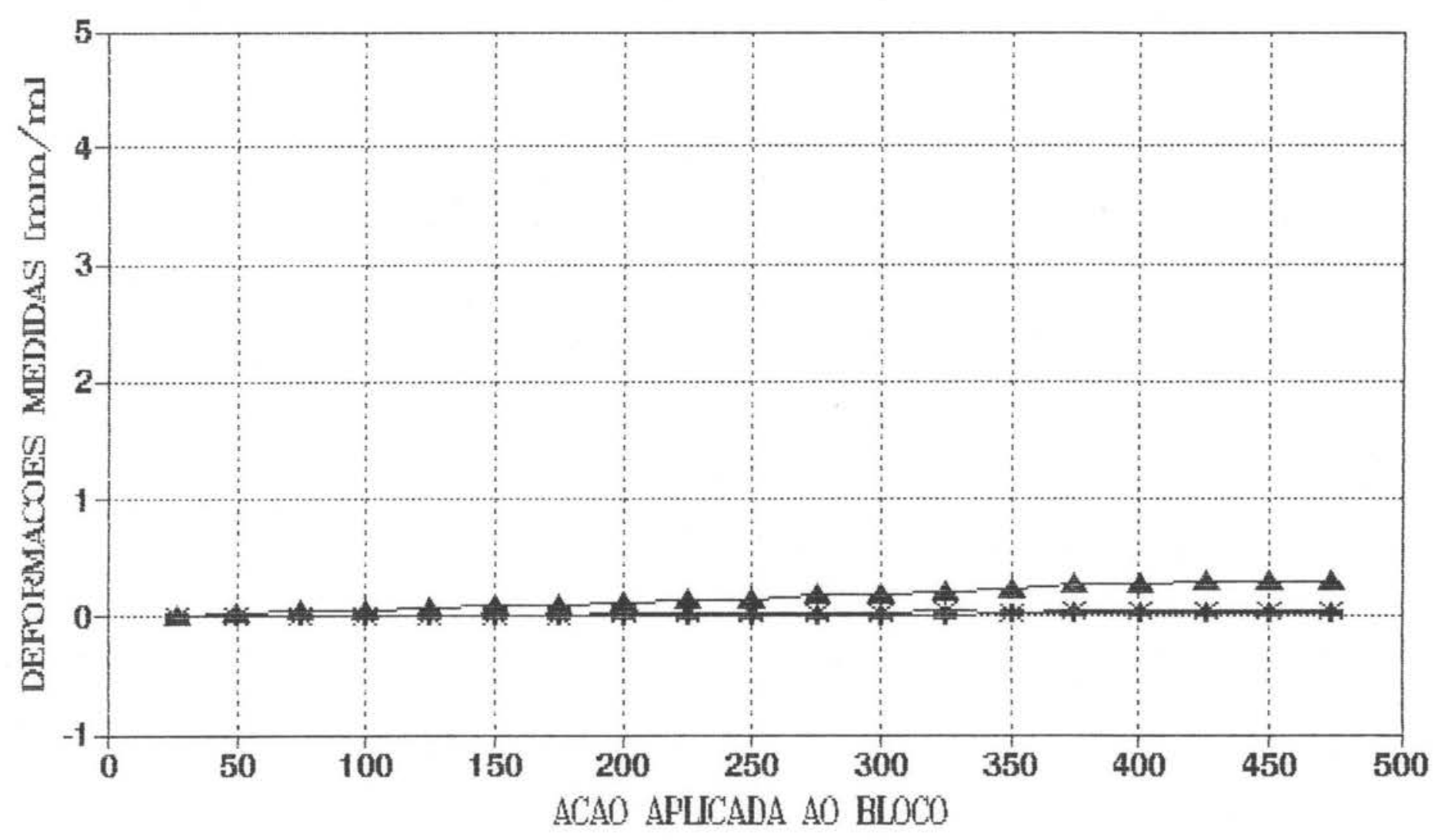

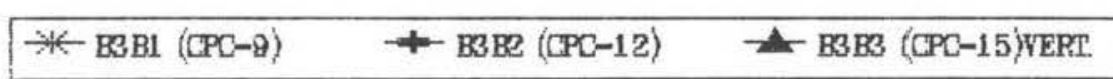




\section{BLOCO 3T - REACOES ESTACAS E SOLO}

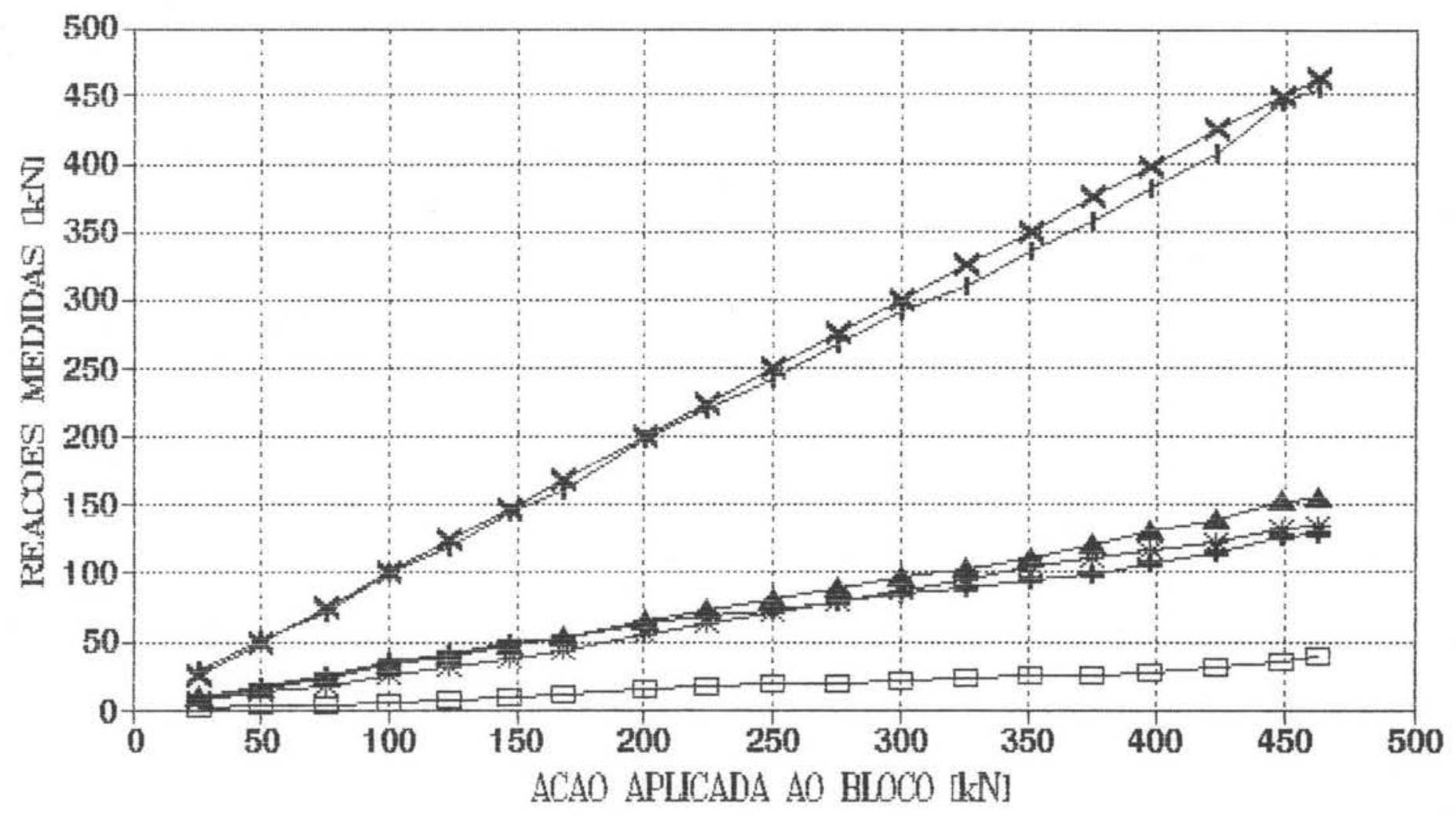

\begin{tabular}{|c|c|}
\hline \% -03 & $\div 0-16$ \\
\hline च CP-SXI0 & † PEACAD TOTAL T ACAD APUICADA \\
\hline
\end{tabular}




\section{B3T - ESTRIBOS HORIZONTAIS (FACE OESTE)}

EXTENSOMETROS 1, 4 E 7

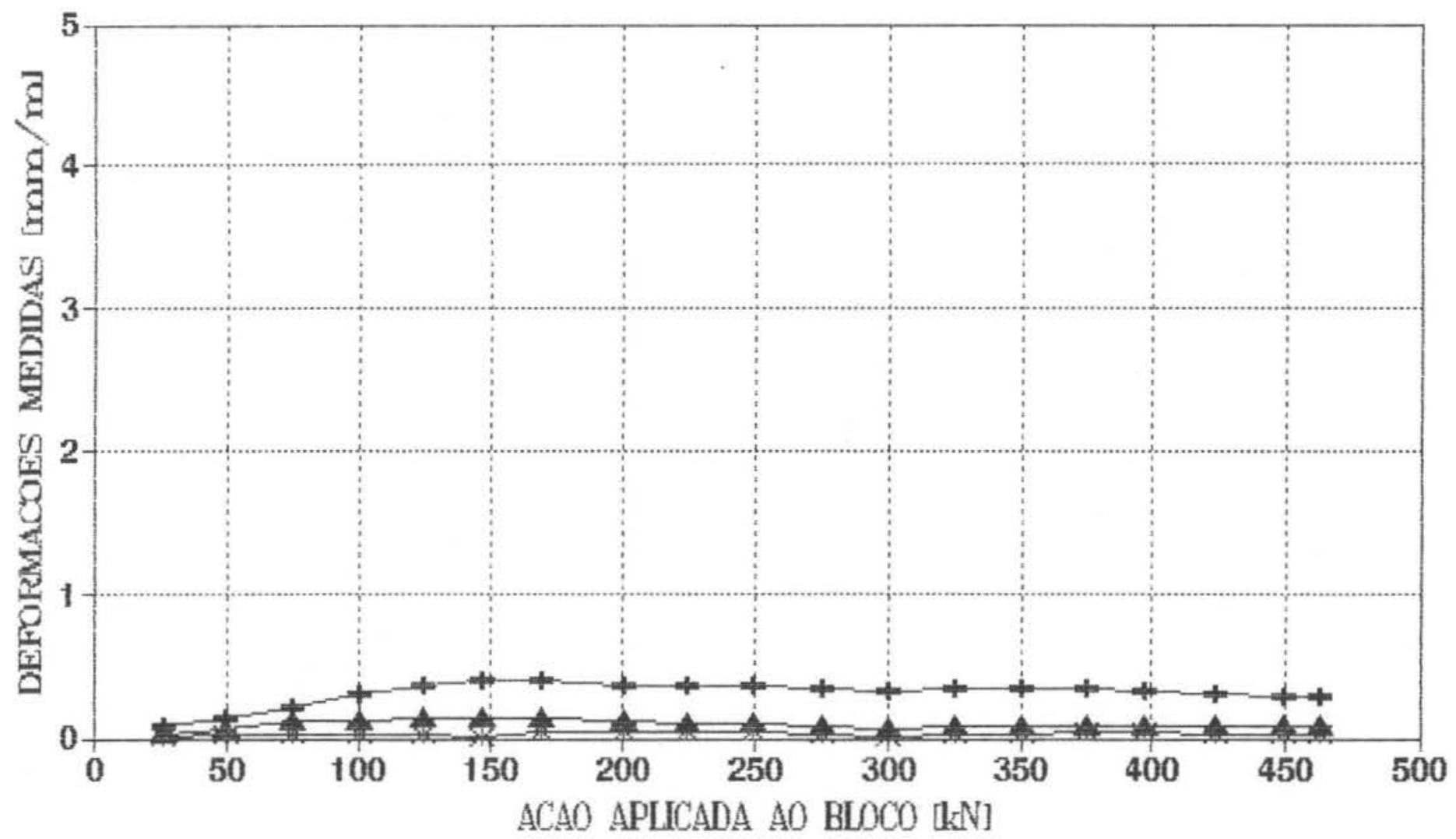




\section{B3T - ESTRIBOS HORIZONTAIS (FACE NORTE)}

EXTENSOMETROS 2, 5 E 8

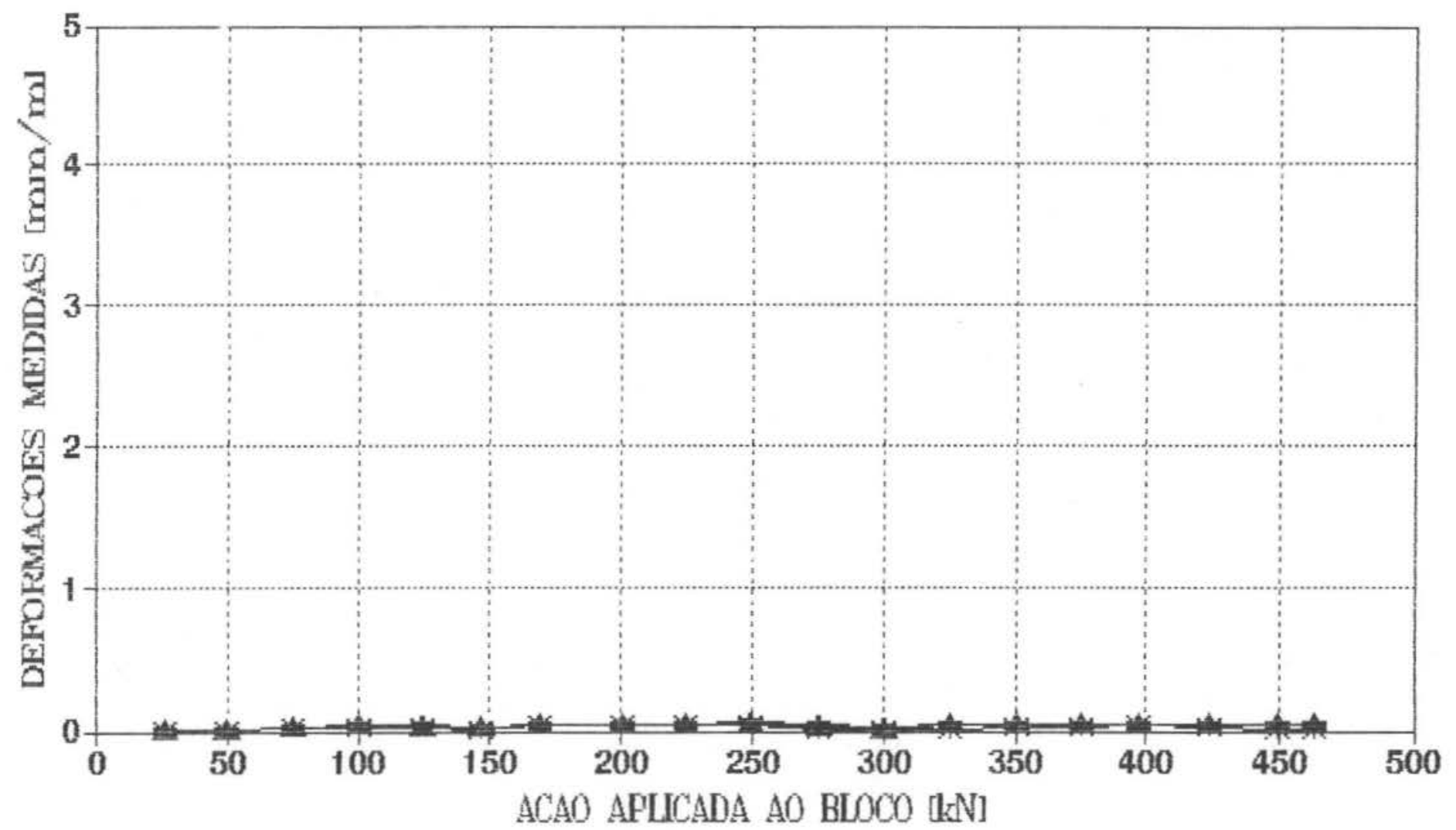




\section{B3T - ESTRIBOS HORIZONTAIS (FACE SUL) EXTENSOMETROS 3, 6 E 9}

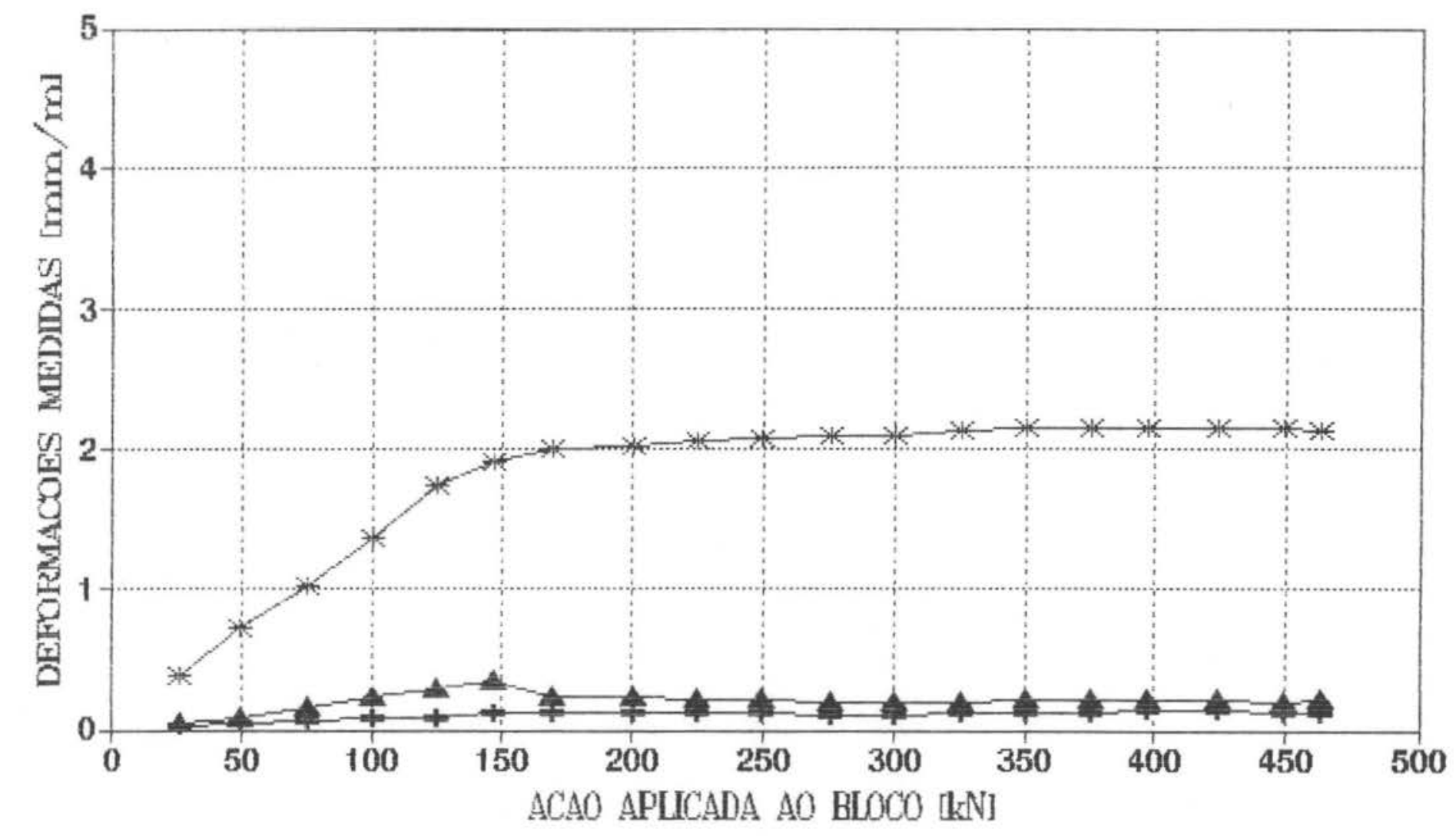




\section{B3T - ESTRIBOS VERTICAIS (FACE SUL) EXTENSOMETROS 10, 12 E 14}

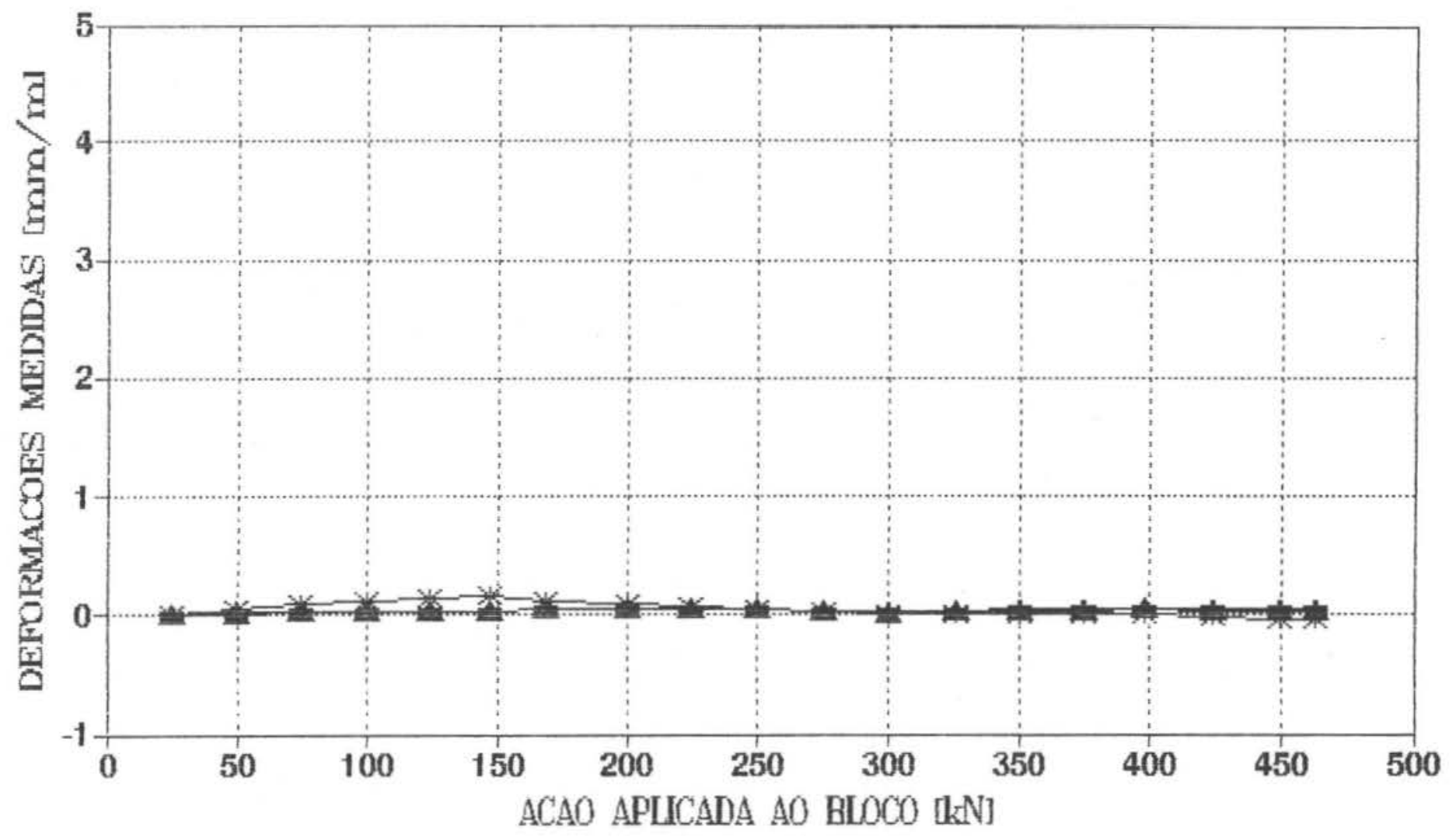

$$
\text { * BOTV1XZ (OESIE) - B3TV2XZ (MEIO) - B3 TY3XZ (LESIE) }
$$




\section{B3T - ESTRIBOS VERTICAIS (TOPO) \\ EXTENSOMETROS 11 E 13}

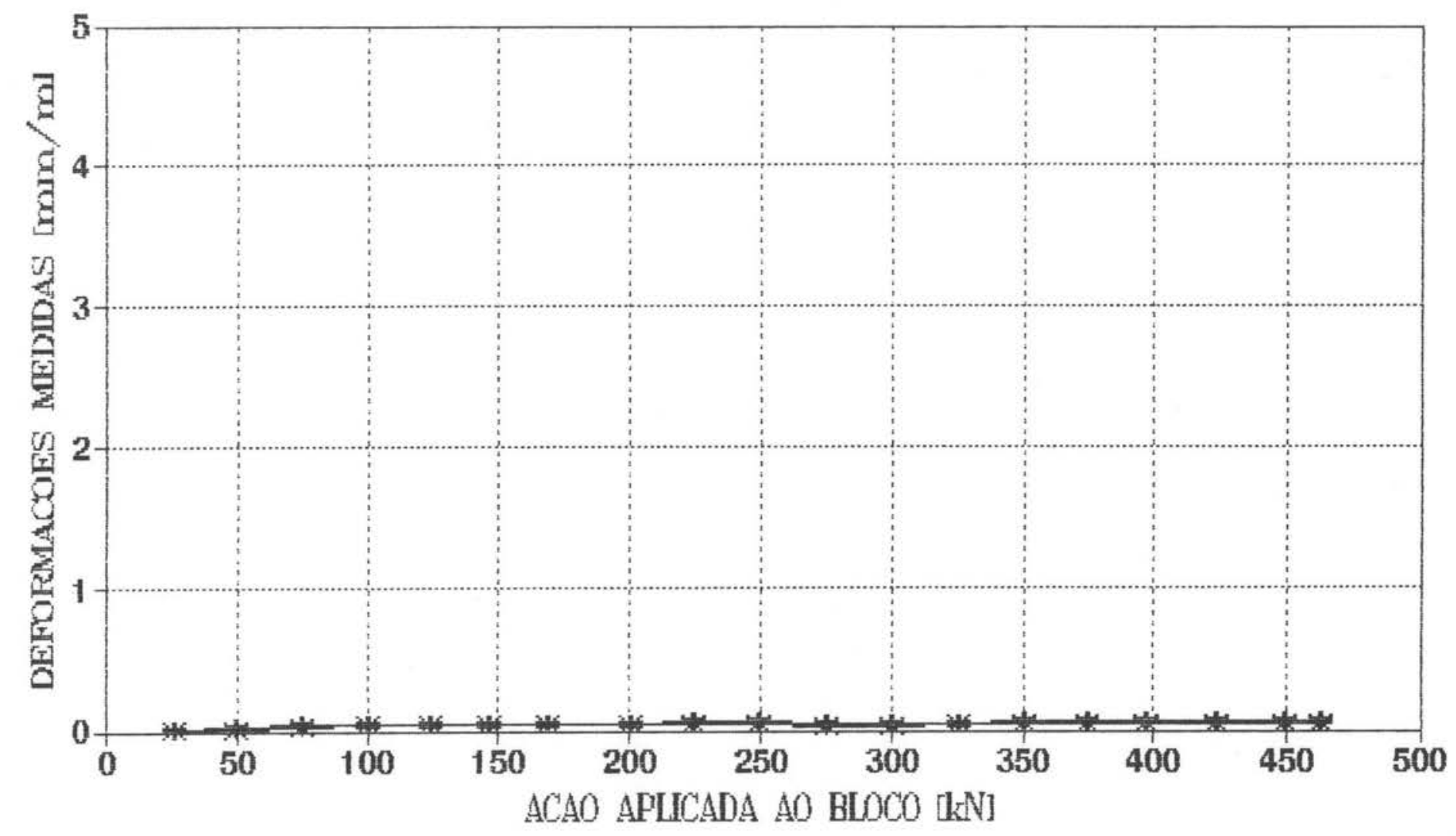

$$
\text { * } \mathrm{BSTVZX} \text { (MEID) - }+ \text { BSTVBX (UESTE) }
$$




\section{B3T - ESTRIBOS VERTICAIS (TOPO) EXTENSOMETROS 15, 17 E 19}

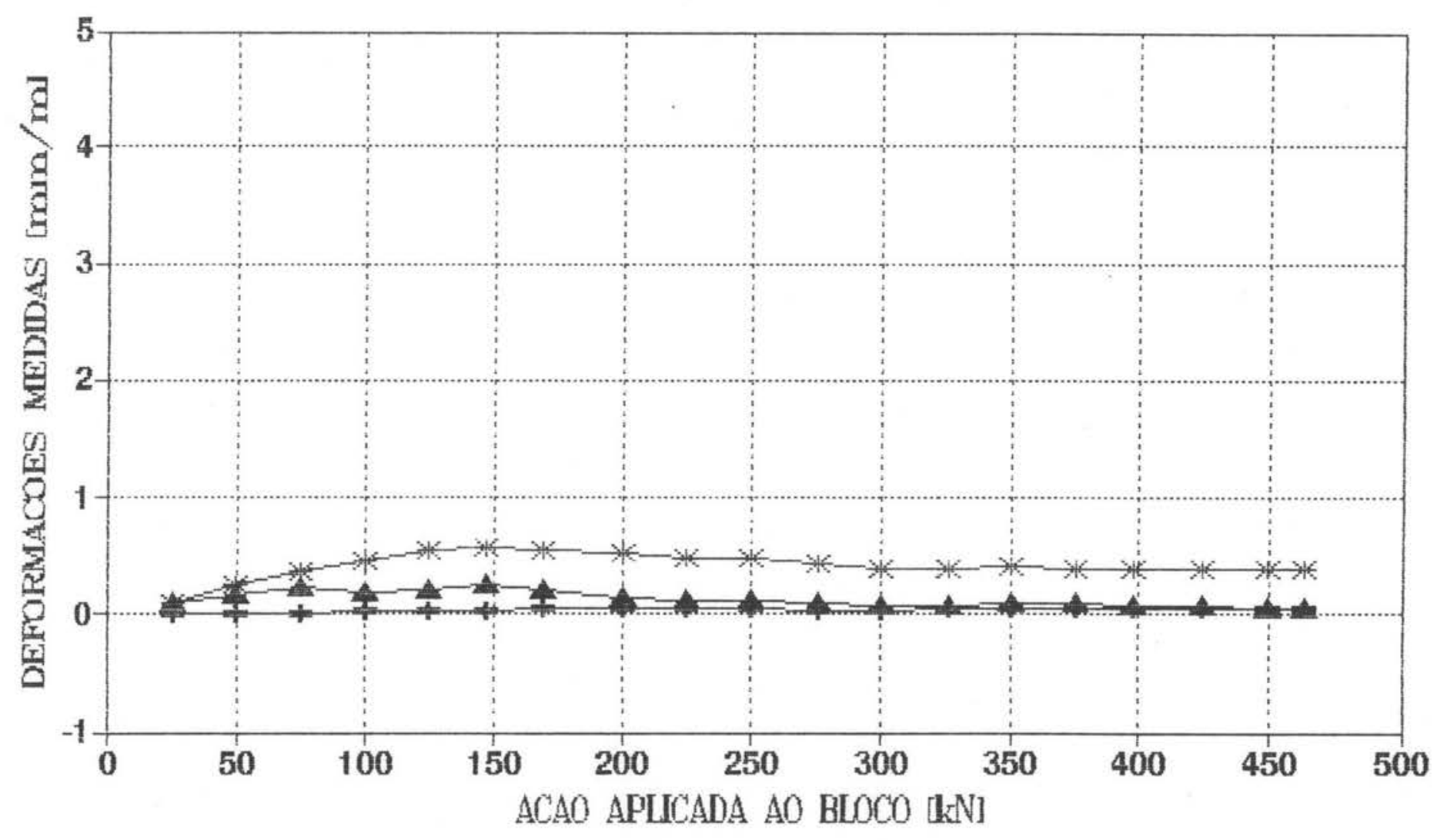

* $\mathrm{B} 3 \mathrm{TV} 1 \mathrm{Y}+\mathrm{B} 3 \mathrm{TV} 2 \mathrm{Y}-\mathrm{BSTVY}$ 


\section{B3T - ESTRIBOS VERTICAIS (FACE OESTE) \\ EXTENSOMETROS 16, 18 e 20}

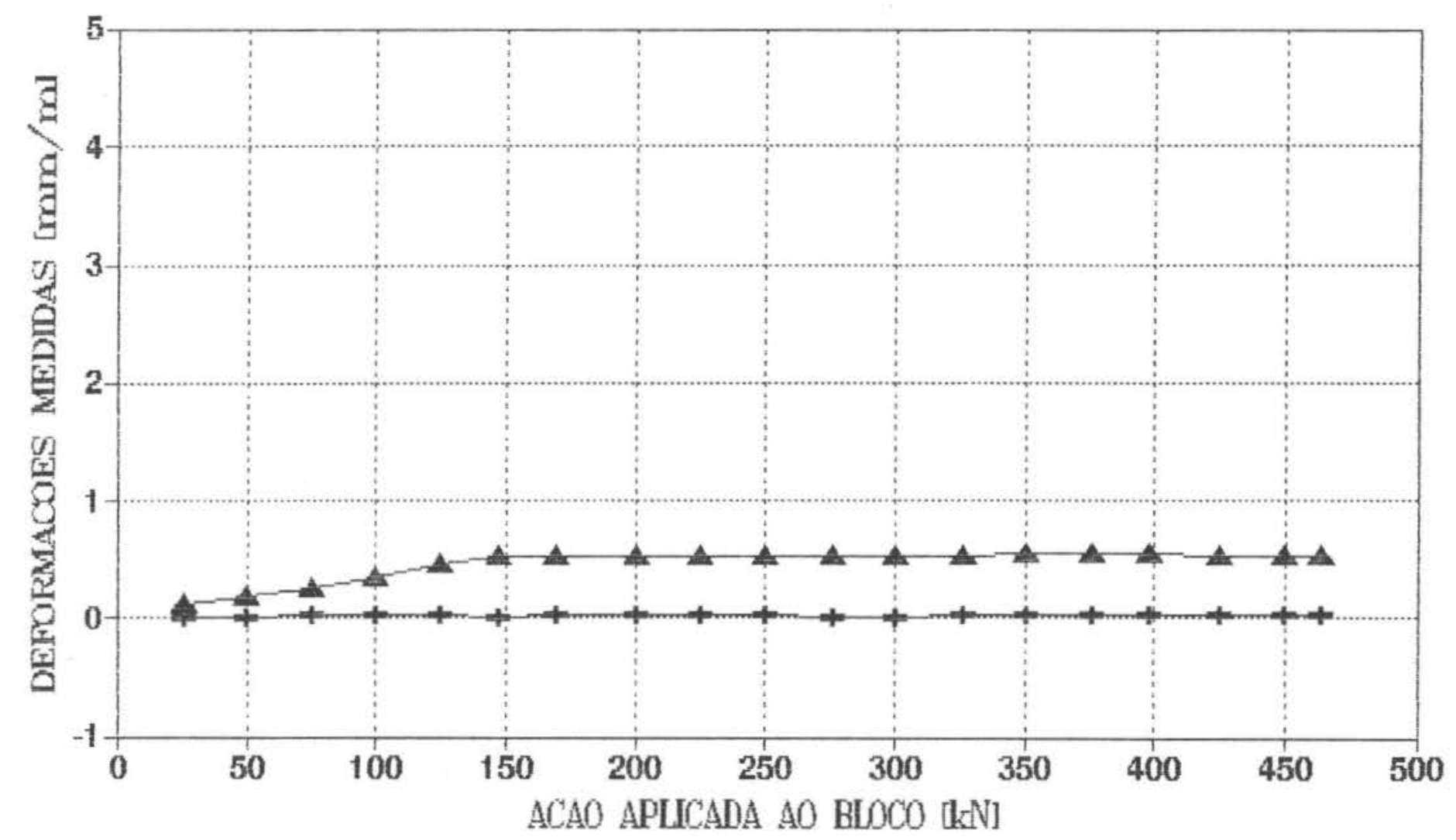

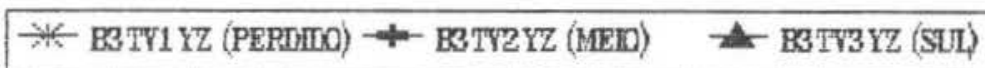




\section{B3T - ARMADURA INFERIOR (LADO OESTE) \\ EXTENSOMETROS 21, 22, 23 E 24}

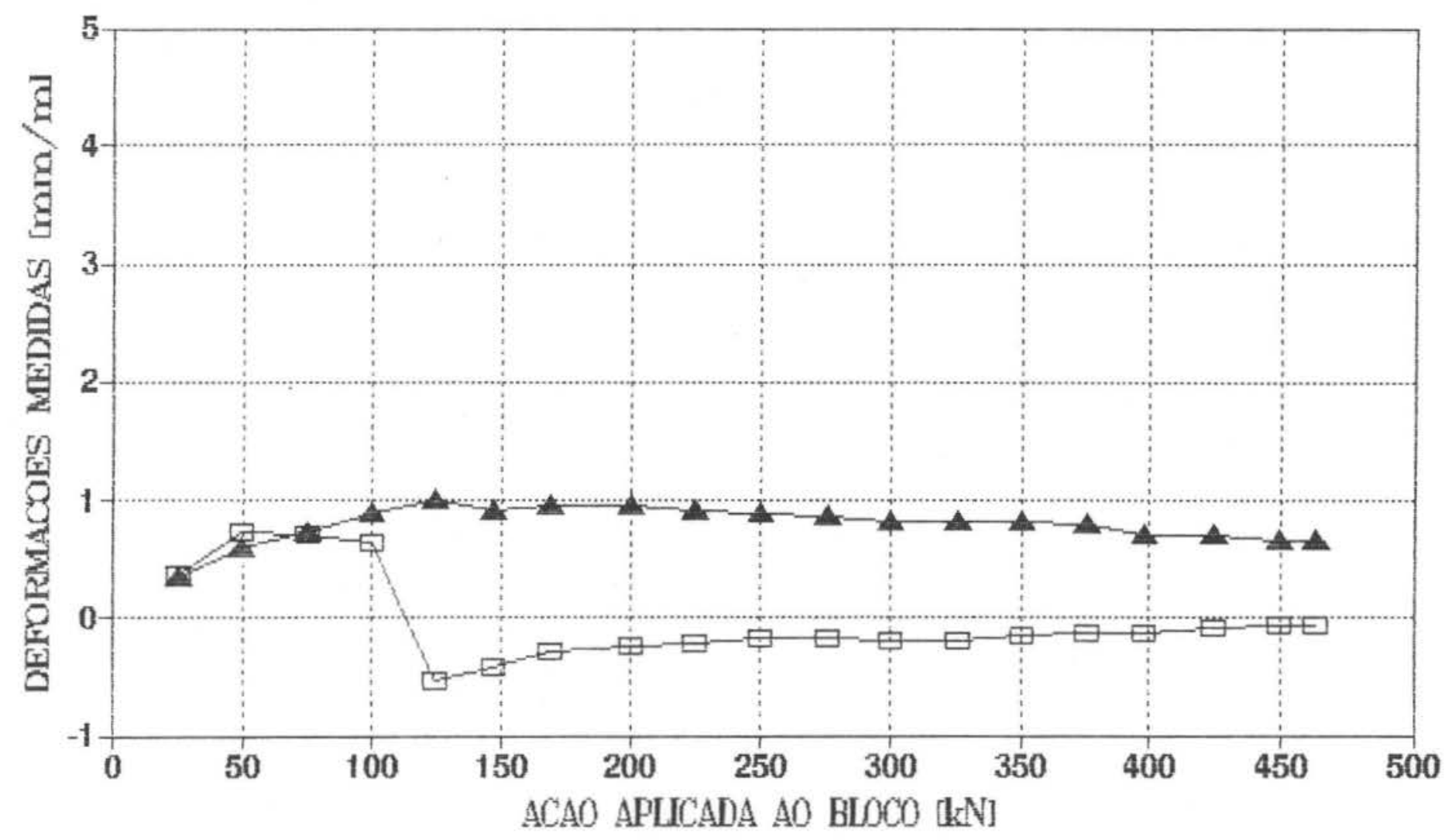

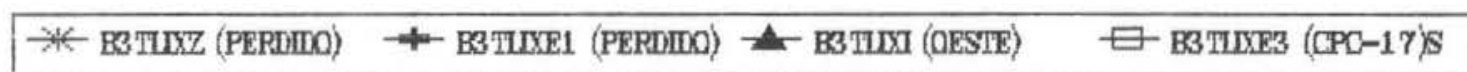




\section{B3T - ARMADURA INFERIOR (LADO NORTE) EXTENSOMETROS 25, 26, 27 E 28}

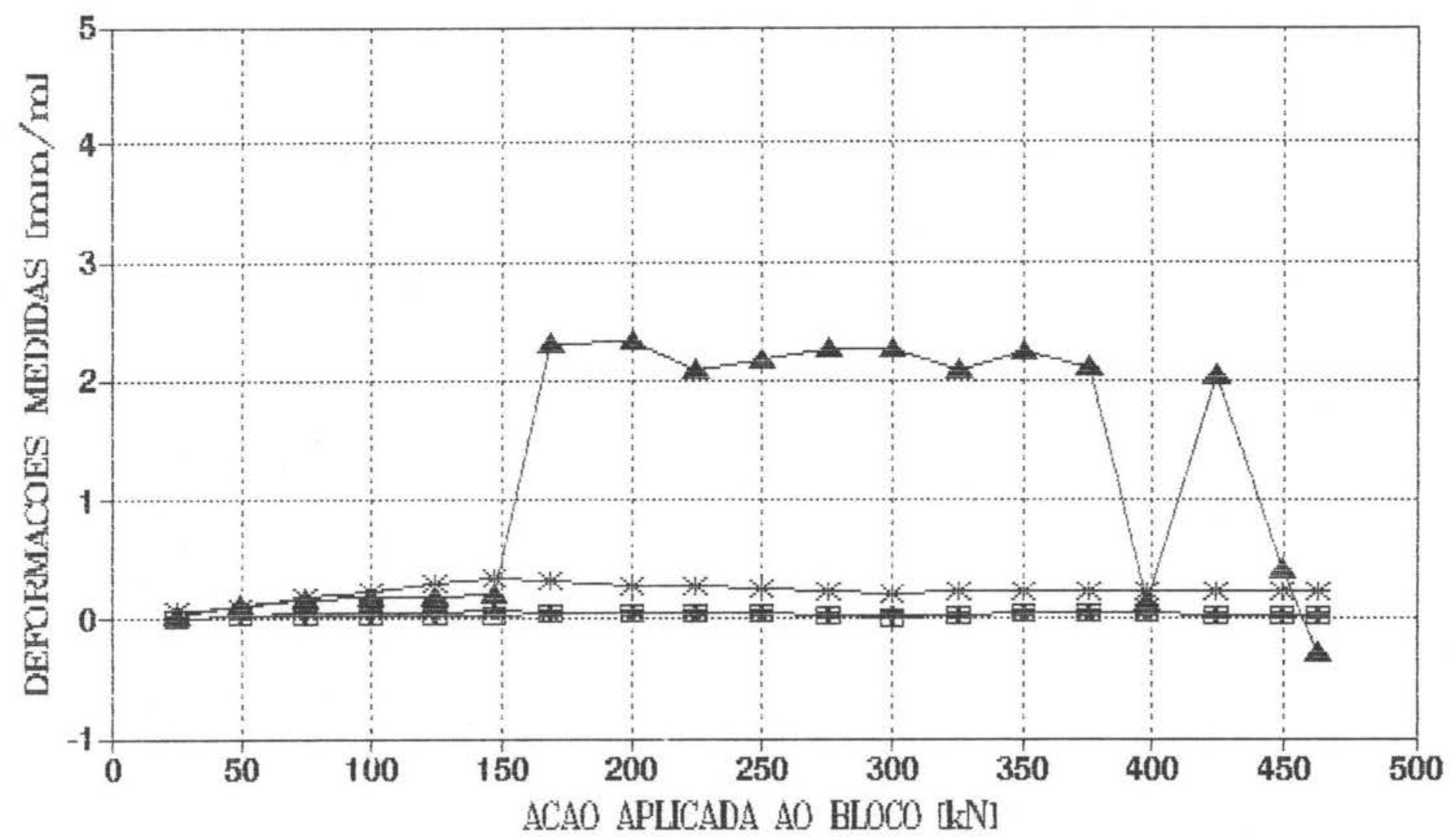




\section{B3T - ARMADURA INFERIOR (LADO SUL) EXTENSOMETROS 29, 30, 31 E 32}

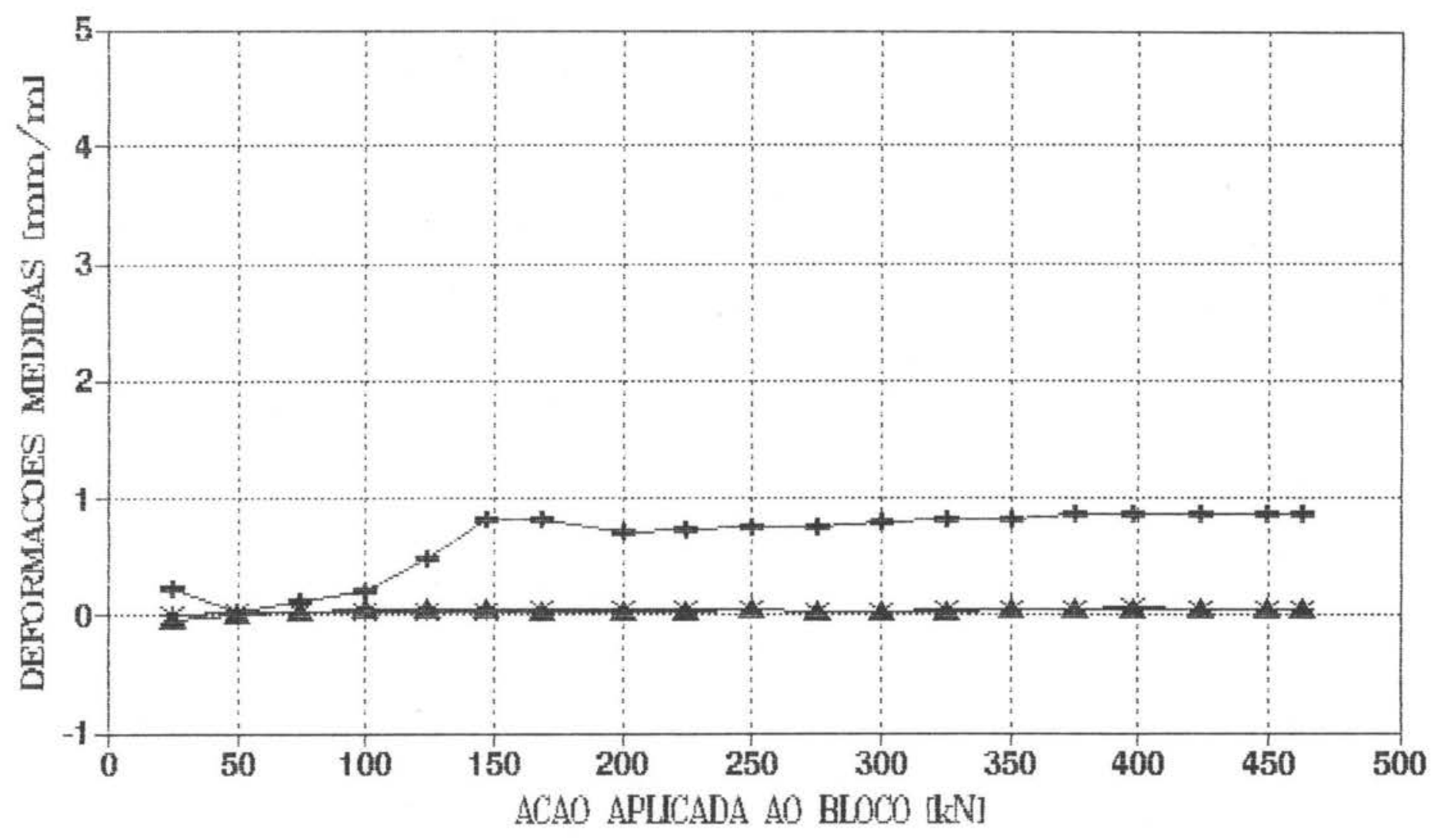

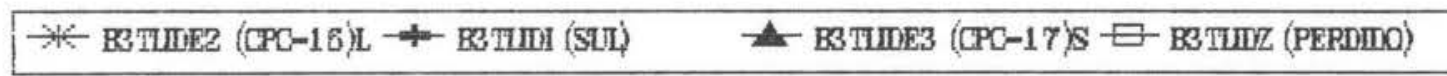




\section{B3T - ARMADURA SUPERIOR \\ EXTENSOMETROS 33, 34 E 35}

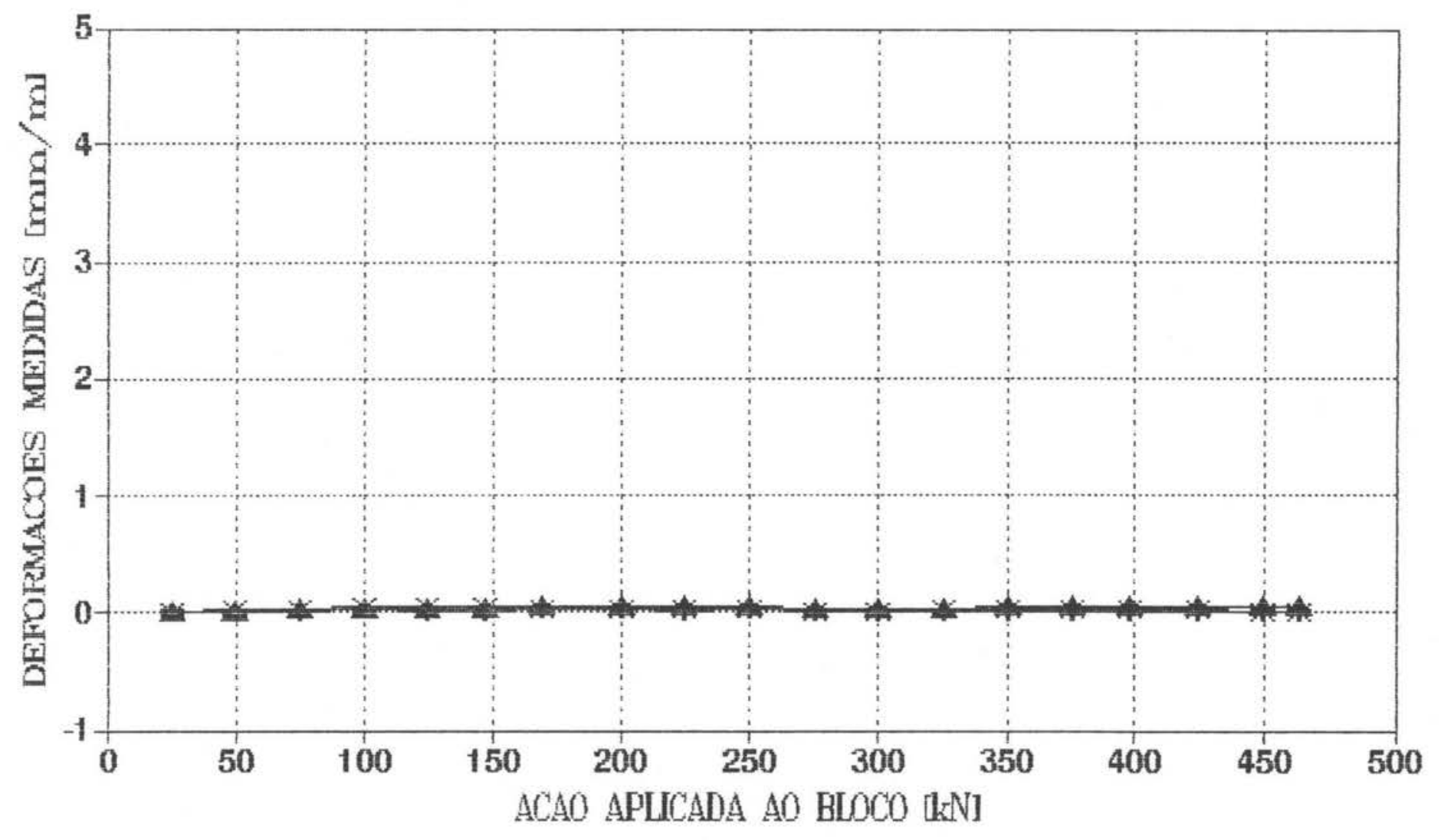

* BSTISX (OESIE) + B3TISE (NDPIE) - BSTISD (SUL) 


\section{BLOCO 3T - BIELAS \\ EXTENSOMETROS 36, 37, 38 E 39}

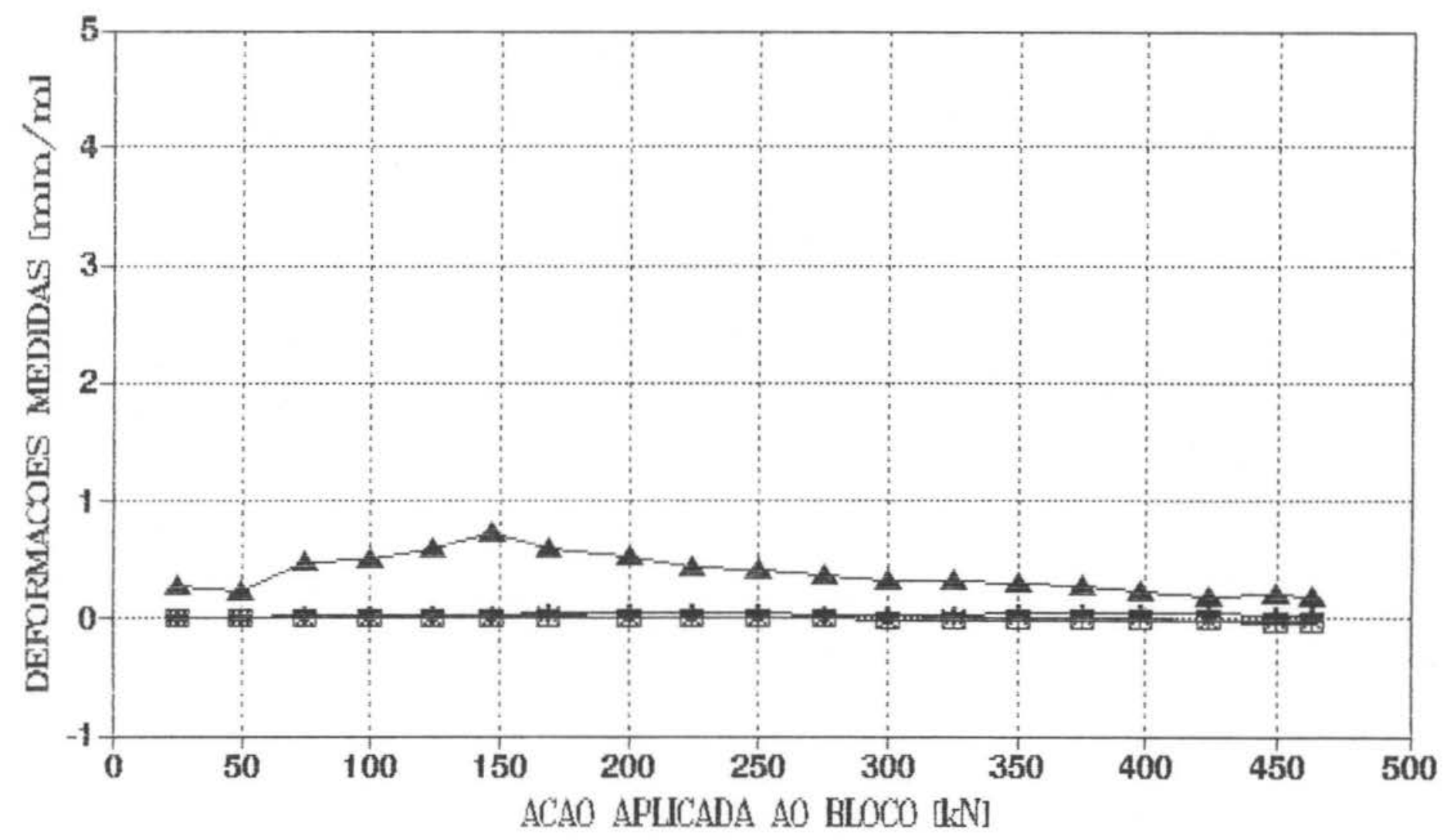

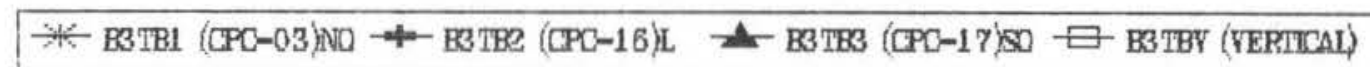




\section{BLOCO 4 - REACOES ESTACAS}

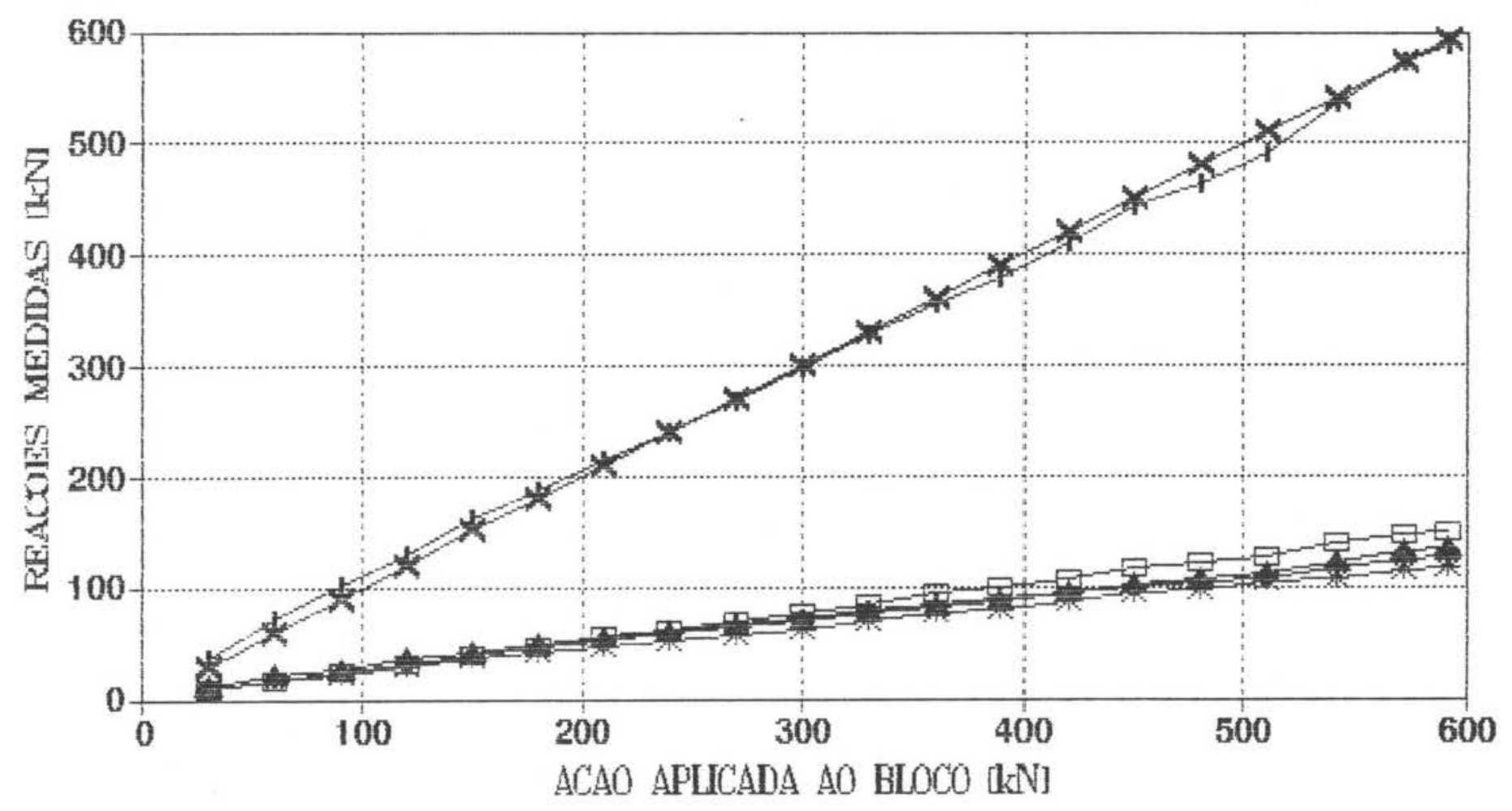

$\begin{array}{lll}* \text { CFC-06 } & \text { - CPC-02 } & \text { - CPC- } 10 \\ \text { E CPC-07 } & \text { 1 REACAO TOTAL } \rightarrow \text { ACAO APLICADA }\end{array}$




\section{B4 - ESTRIBOS HORIZONTAIS (FACE OESTE)}

EXTENSOMETROS 1 E 5

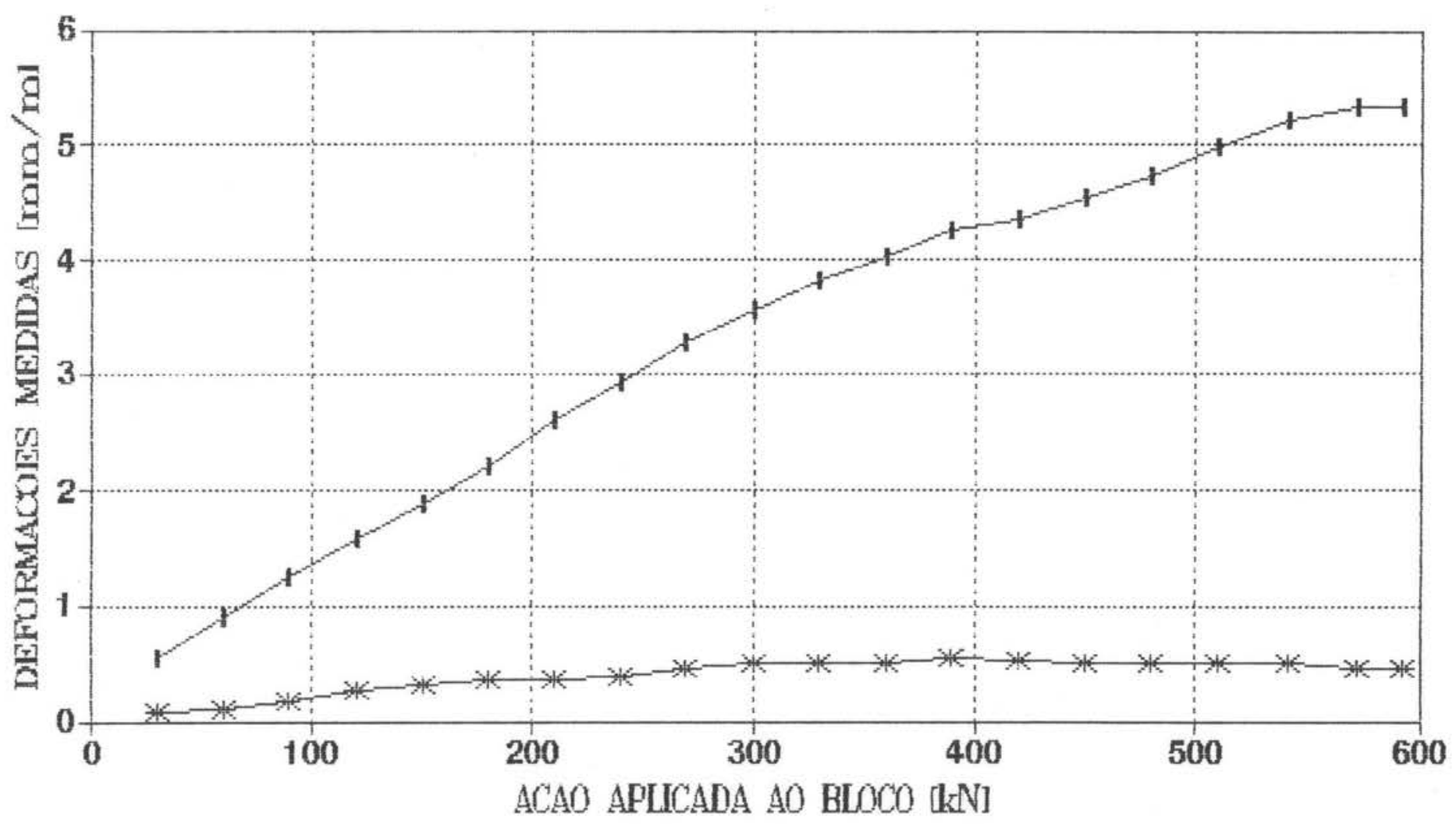

$\rightarrow$ B4H1X1 (TOPO) $+\mathrm{B} 4 \mathrm{H} 2 \times 1$ 


\section{BLOCO 4 - REACOES \\ SOLO}

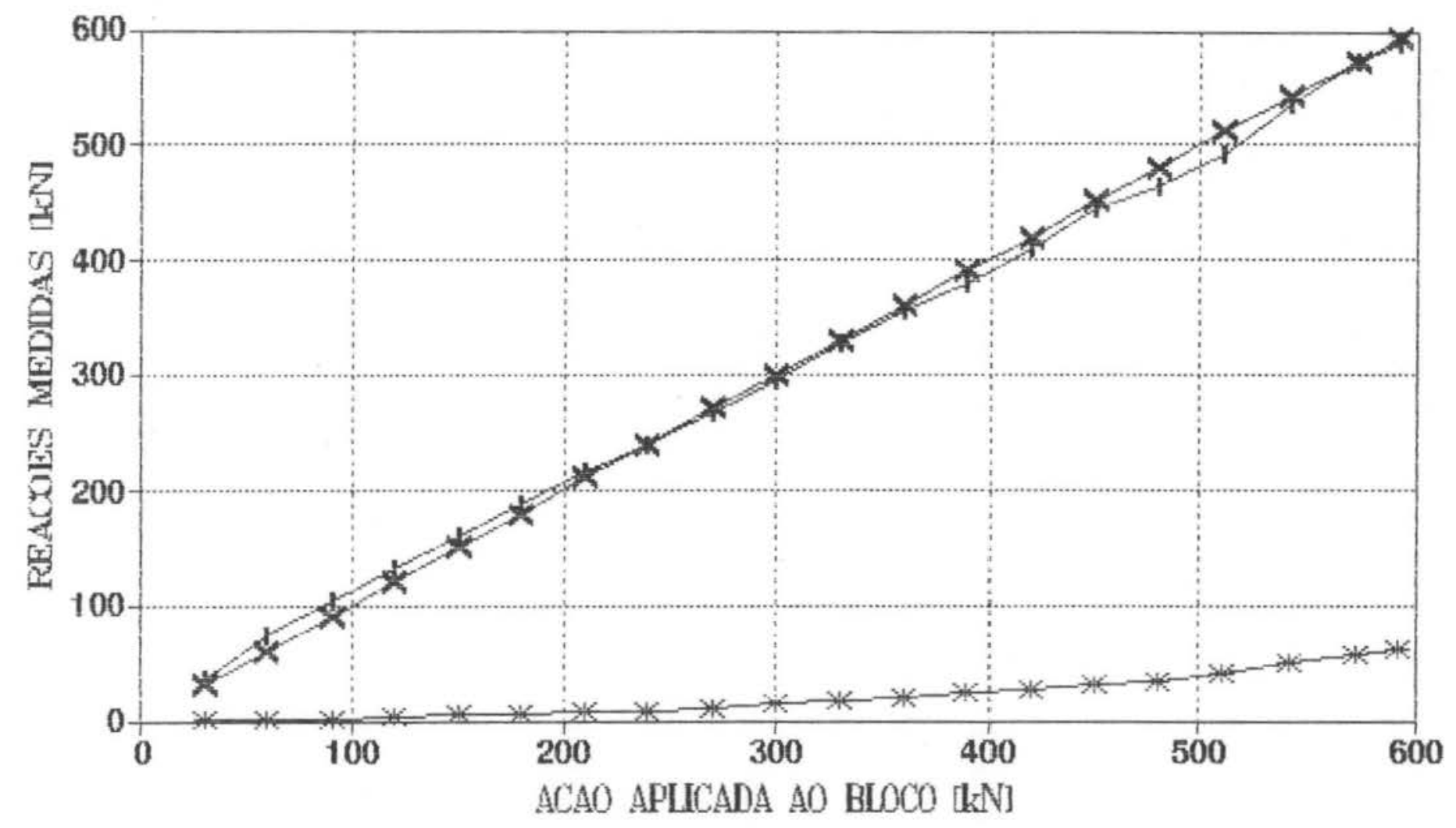

* CP-SOLO + REACAOTOTAL $*$ ACAOAPLICADA 


\section{B4 - ESTRIBOS HORIZONTAIS (FACE NORTE)}

EXTENSOMETROS 2 E 6

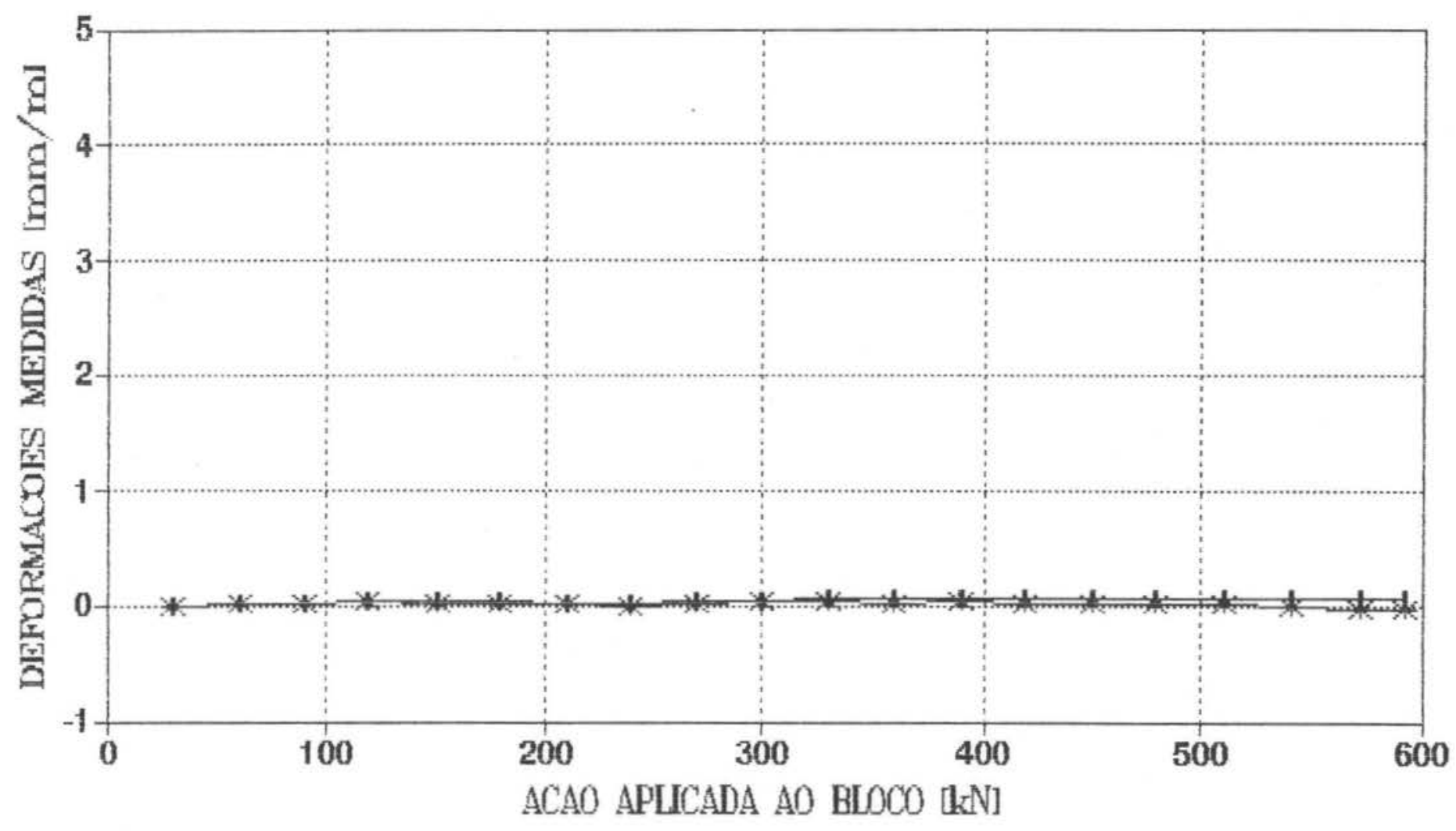




\section{B4 - ESTRIBOS HORIZONTAIS (FACE LESTE) EXTENSOMETROS 3 E 7}

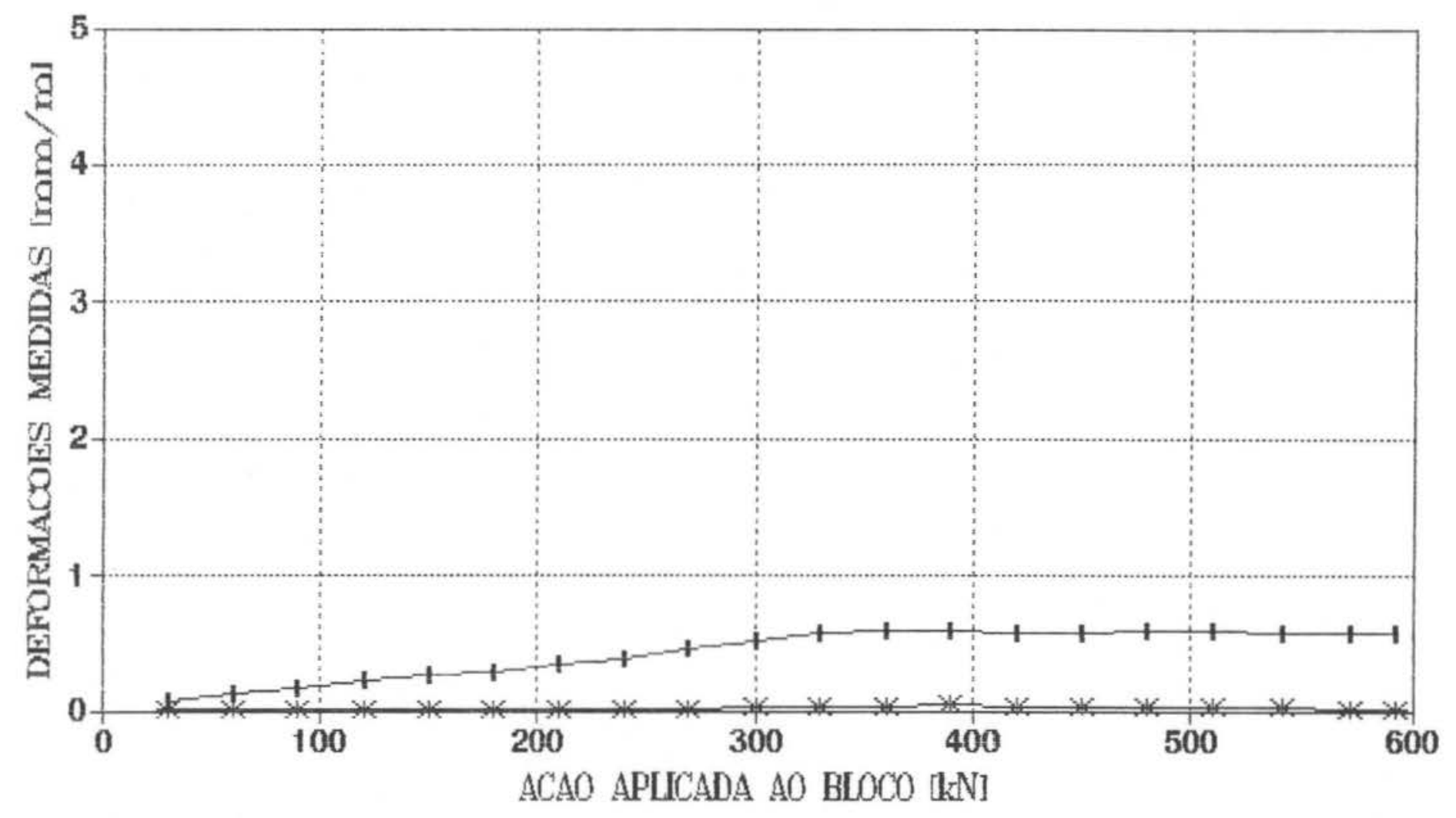

$\rightarrow \mathrm{k}_{6} \mathrm{~B} 4 \mathrm{H} 1 \times 2$ (TOPO) $1-\mathrm{B} 4 \mathrm{H} 2 \times 2$ 


\section{B4 - ESTRIBOS HORIZONTAIS (FACE SUL) EXTENSOMETROS 4 E 8}

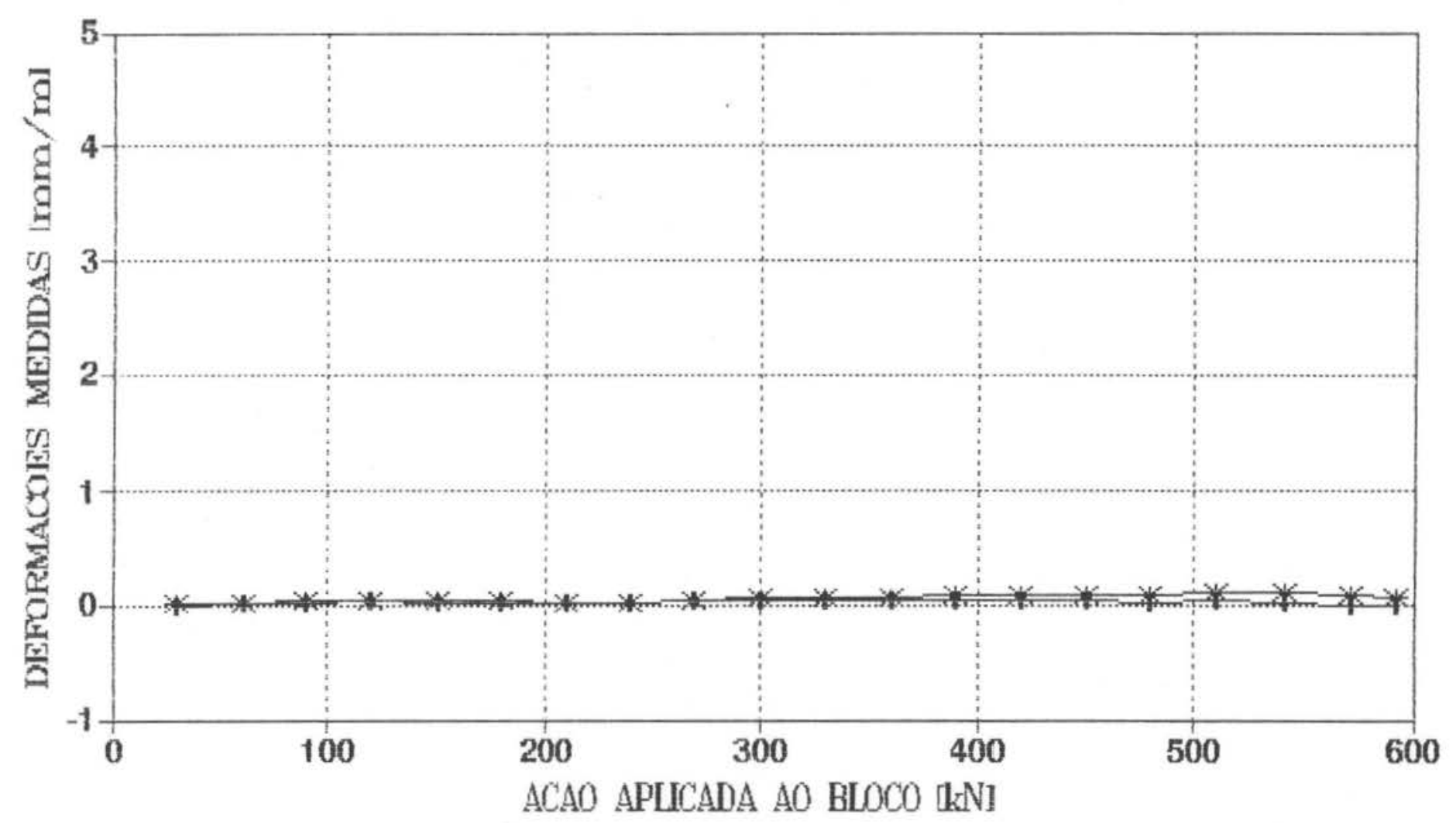

* B4H1Y2 (TOPO) - В4H2Y2 


\section{B4 - ESTRIBOS VERTICAIS (FACE NORTE) \\ EXTENSOMETROS 9, 10 E 12}

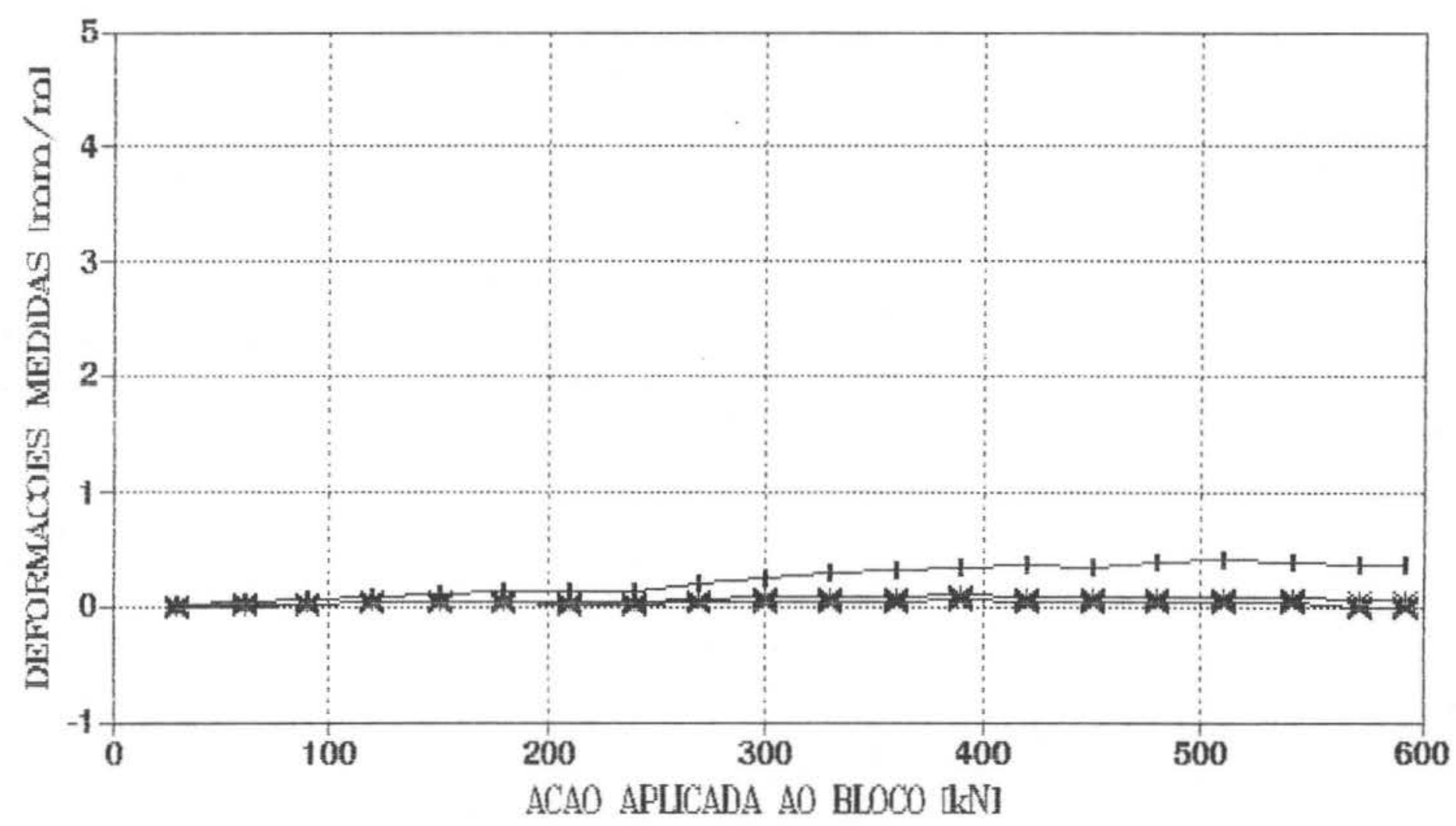

* B4V1XZ (LESTE) † B4V2XZ (MEIO) $\quad$ × B4V3XZ (OESTE) 


\section{B4 - ESTRIBOS VERTICAIS (FUNDO) \\ EXTENSOMETROS 11 E 15}

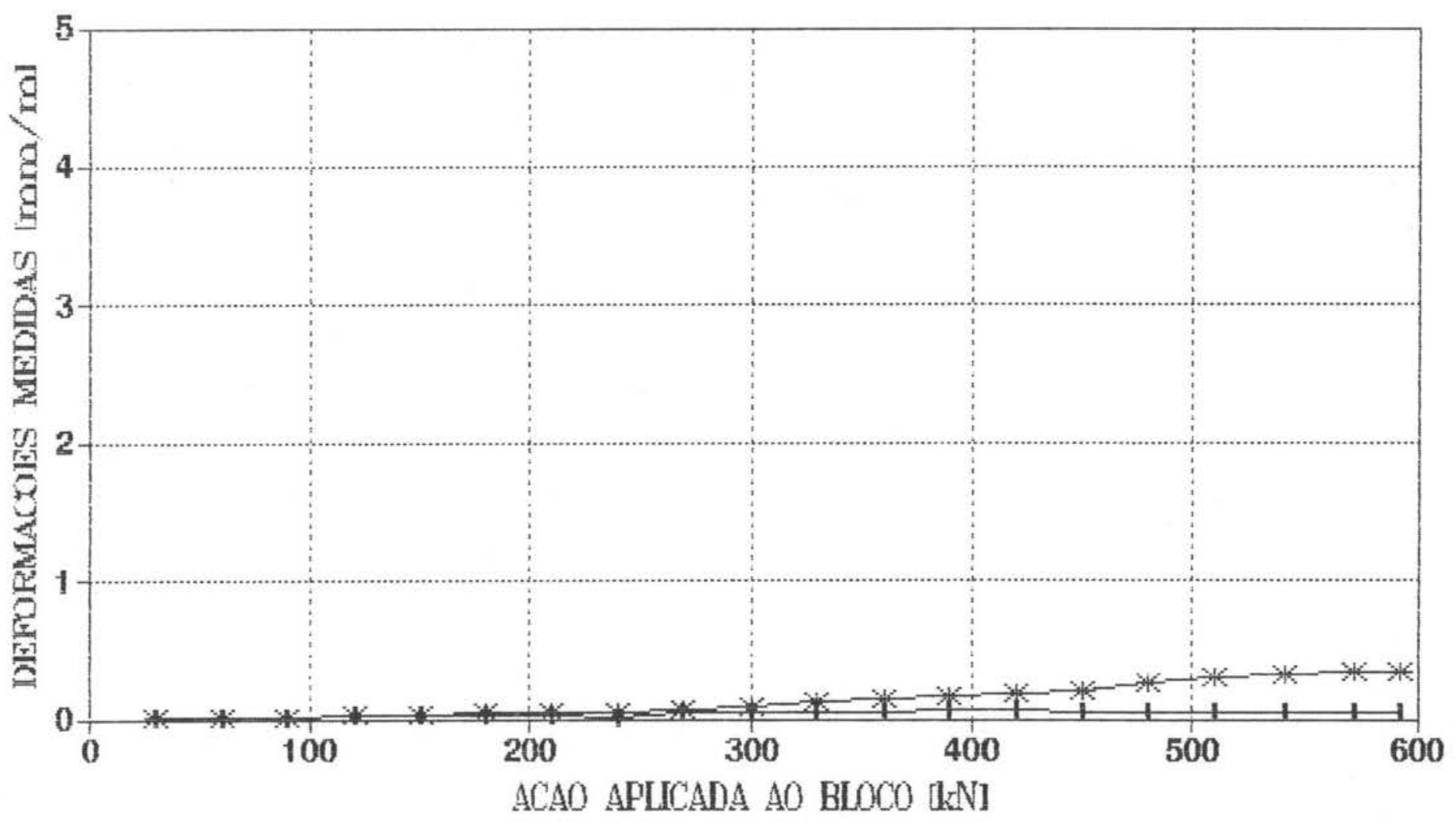

* $\mathrm{B} 4 \mathrm{~V} 2 \mathrm{XB} \rightarrow \mathrm{B} 4 \mathrm{~V} 2 \mathrm{YB}$ 


\section{B4 - ESTRIBOS VERTICAIS (FACE OESTE) EXTENSOMETROS 13, 14 e 16}

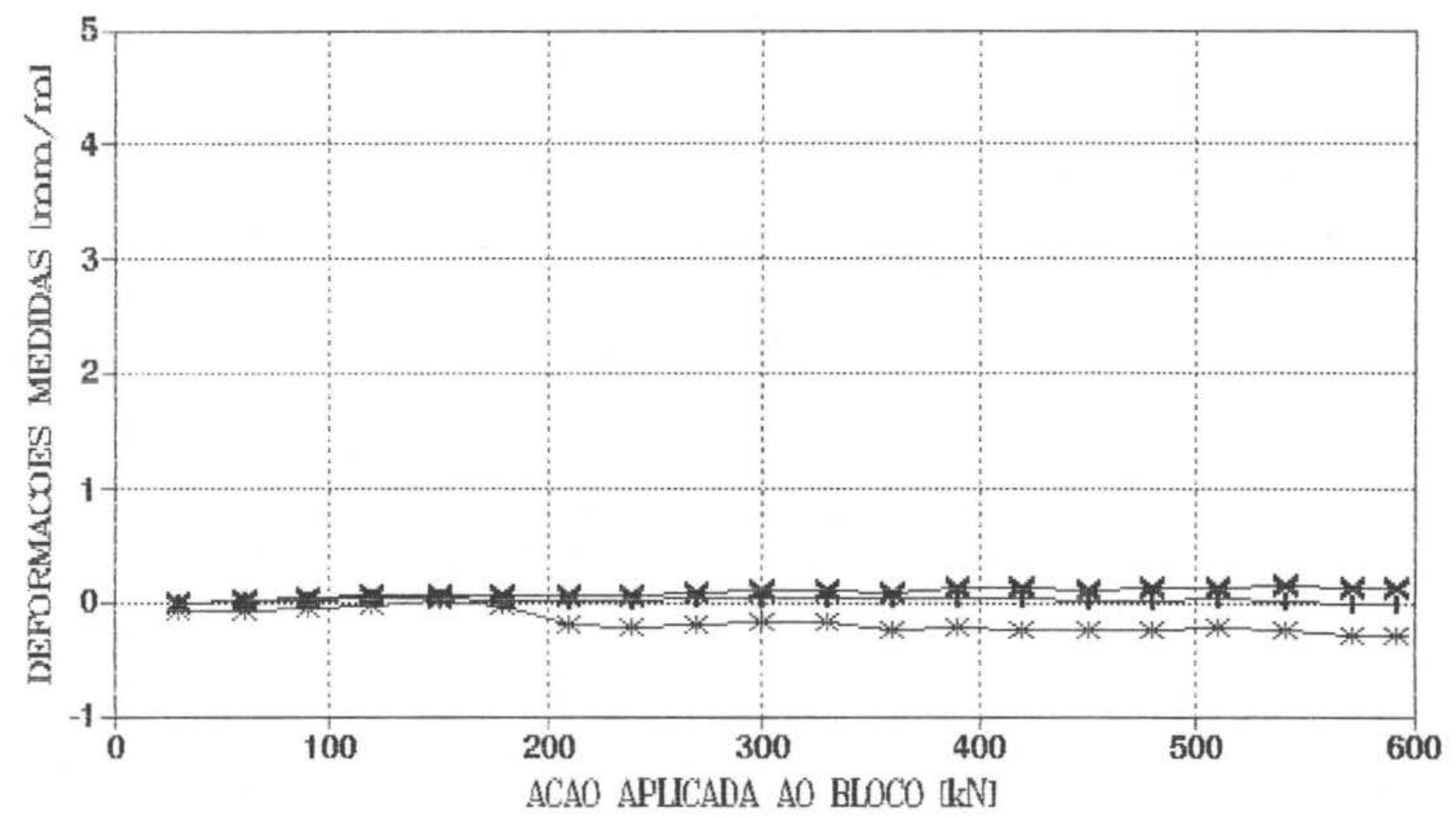

$\rightarrow$ B4V1YZ (NORTE) + B4V2YZ (MEIO) $\rightarrow$ B4V3YZ (SUL) 


\section{B4 - ARMADURA INFERIOR (LADO OESTE)}

EXTENS. 17, 18 E 19 (BARRA EXTERNA)

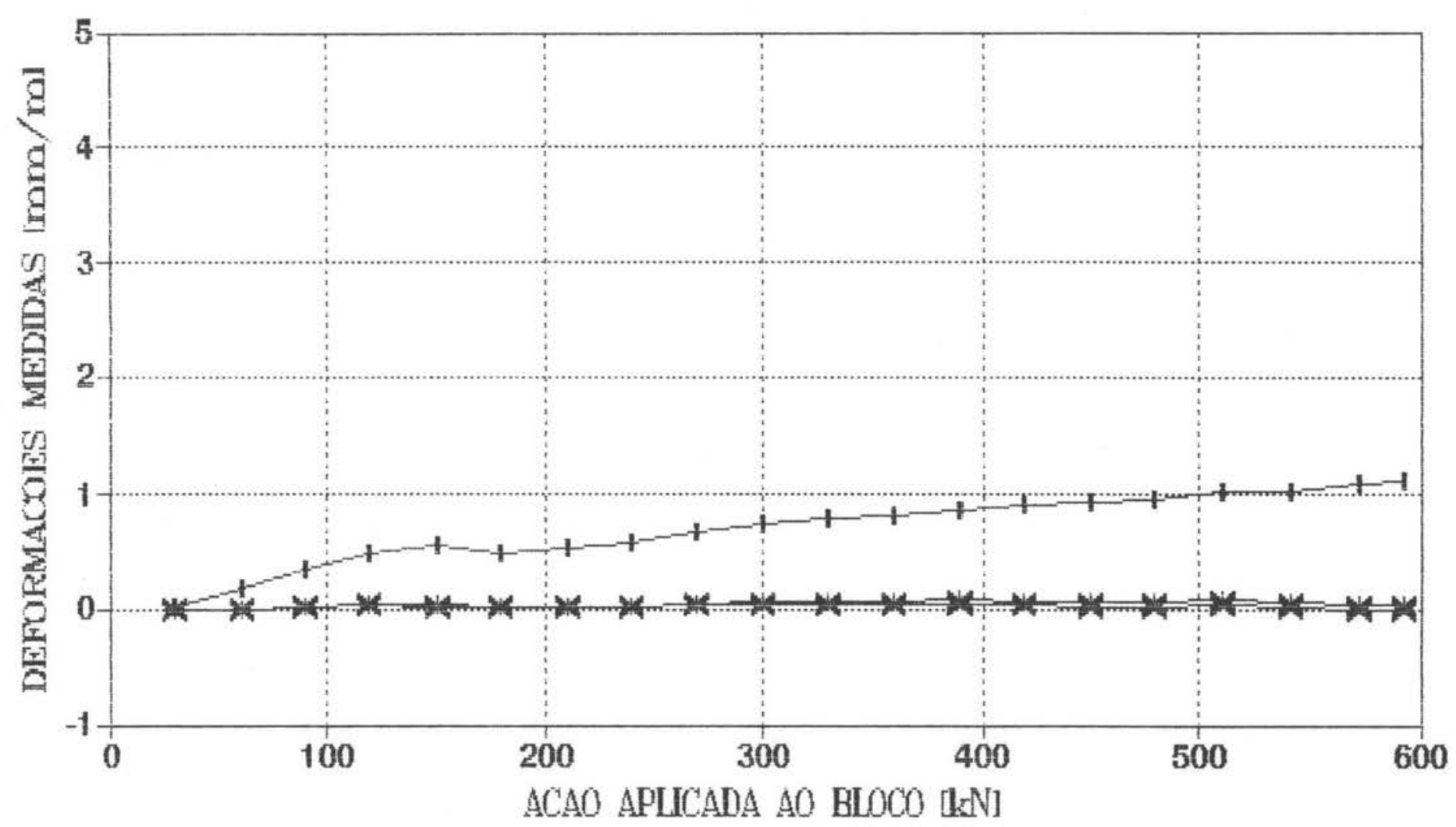

$\rightarrow$ B4LI1X1E1 (CPC-06) N — B4LI1X1I (MEIO)

$\rightarrow$ B4LI1X1E4 (CPC-07)S 


\section{B4 - ARMADURA INFERIOR (LADO OESTE) \\ EXTENS. 20, 21, 22 E 23 (INTERIOR)}

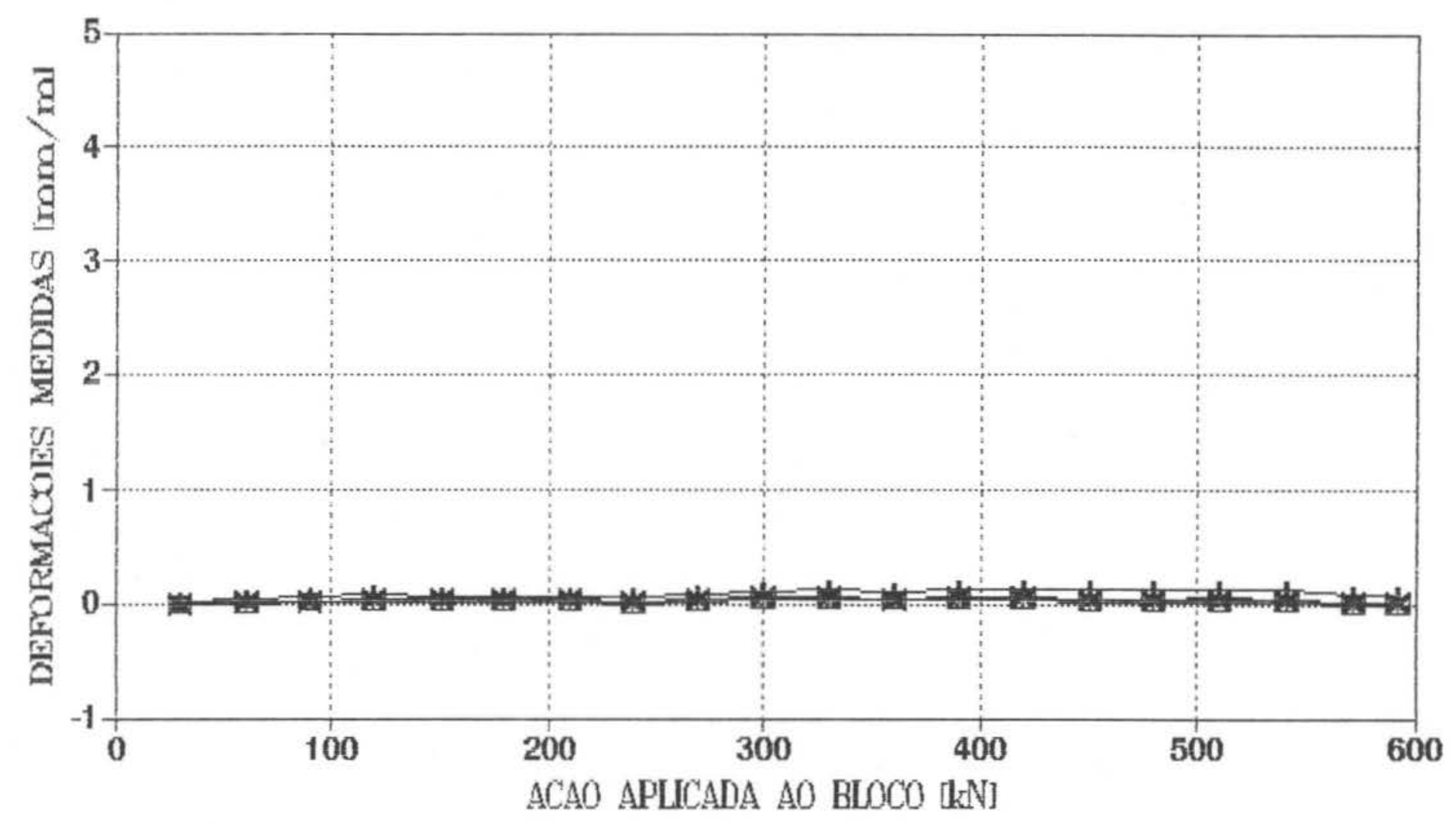




\section{B4 - ARMADURA INFERIOR (LADO OESTE) EXTENS. 24, 25 E 26 (BARRA EXTERNA)}

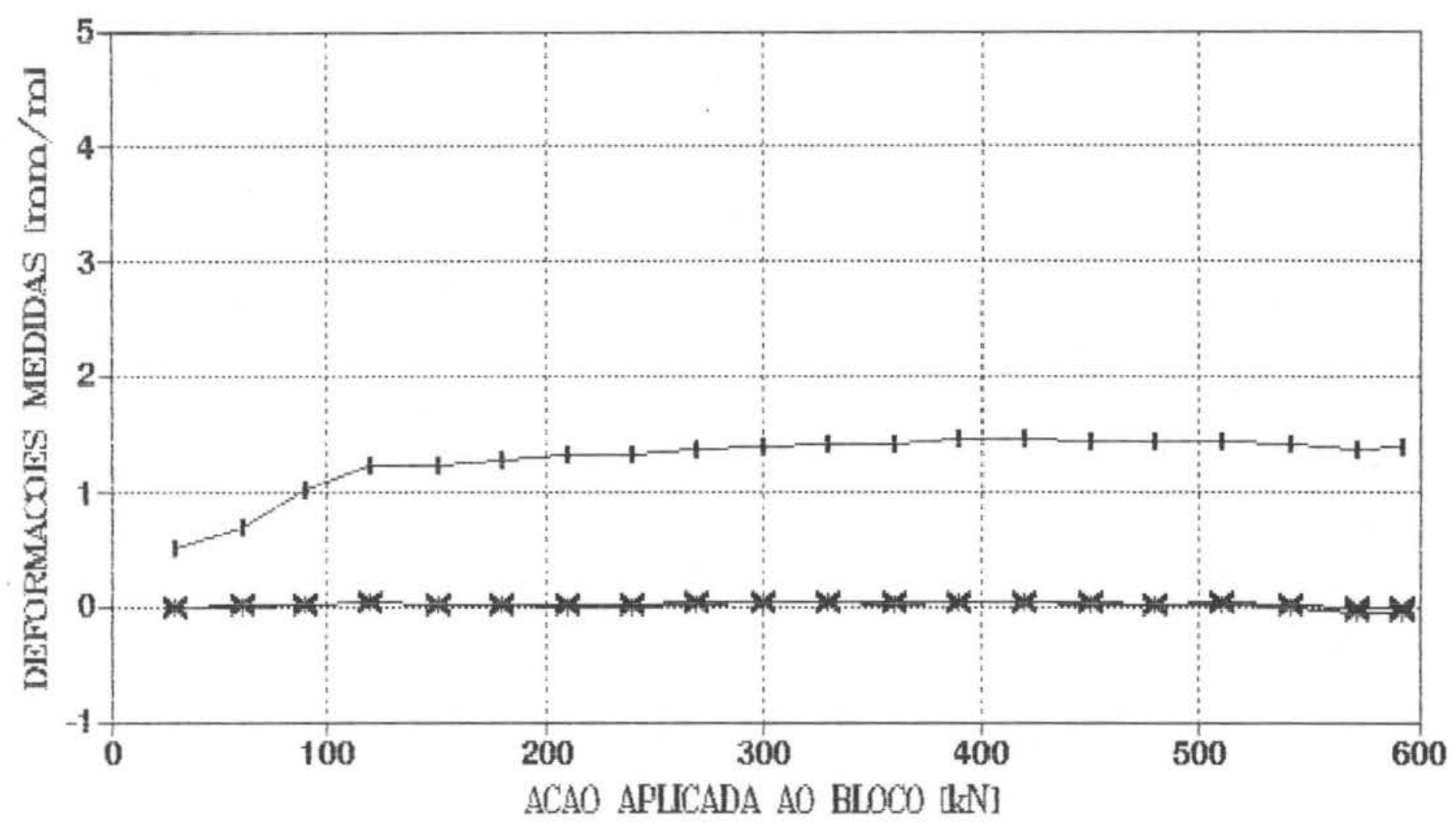

$\rightarrow$ * B4LI3X1E1 (CPC-06)N + B4LI3X1I (MEIO)

$x$ B4LI3X1E4 (CPC-07)s 


\section{B4 - ARMADURA INFERIOR (LADO LESTE) EXTENS. 27, 28 E 29 (BARRA EXTERNA)}

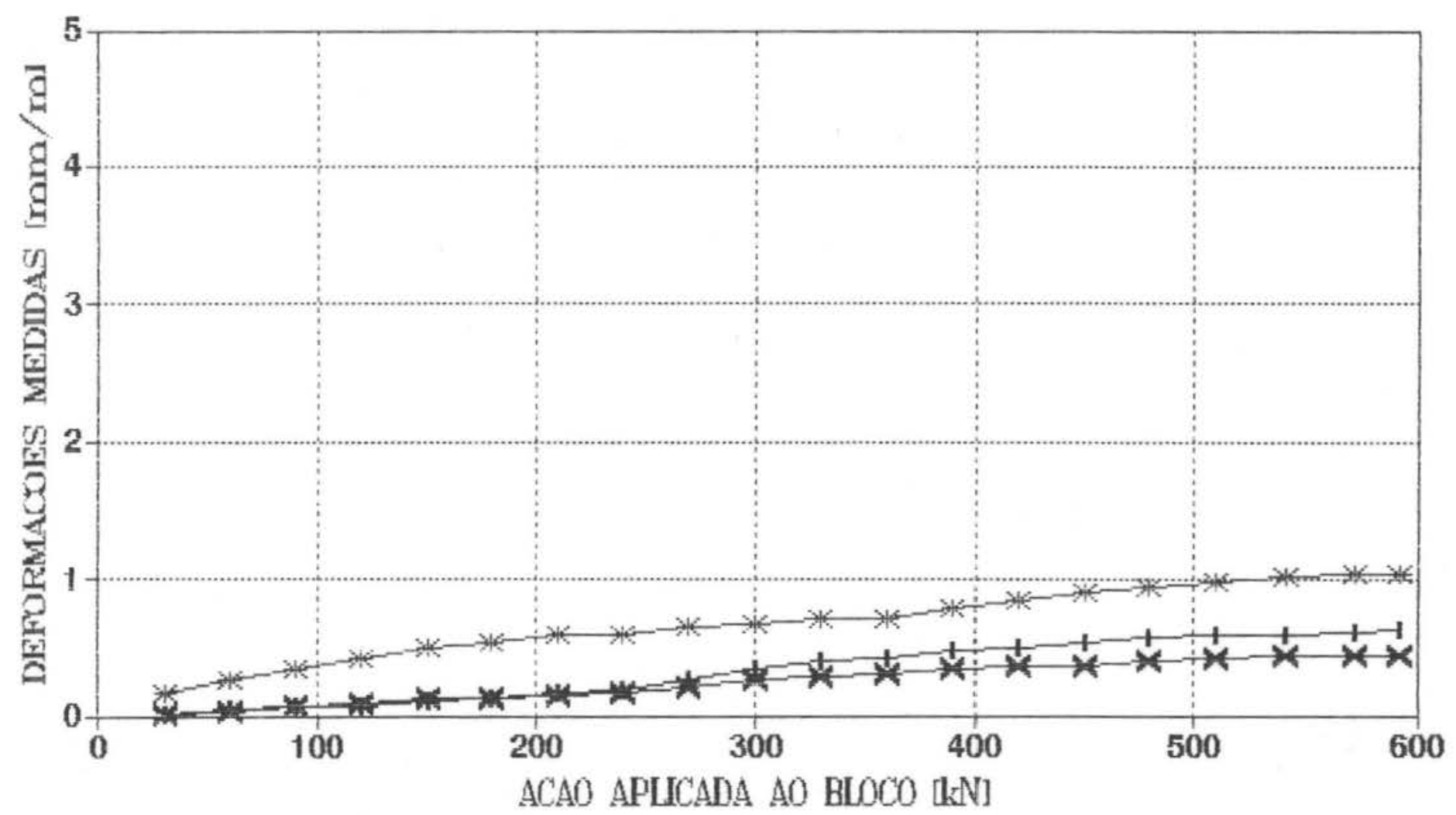

* B4LI1X2E2 (CPC-02) N + B4LI1X21 (MEIO) 


\section{B4 - ARMADURA INFERIOR (LADO LESTE) EXTENS. 30, 31, 32 E 33 (INTERIOR)}

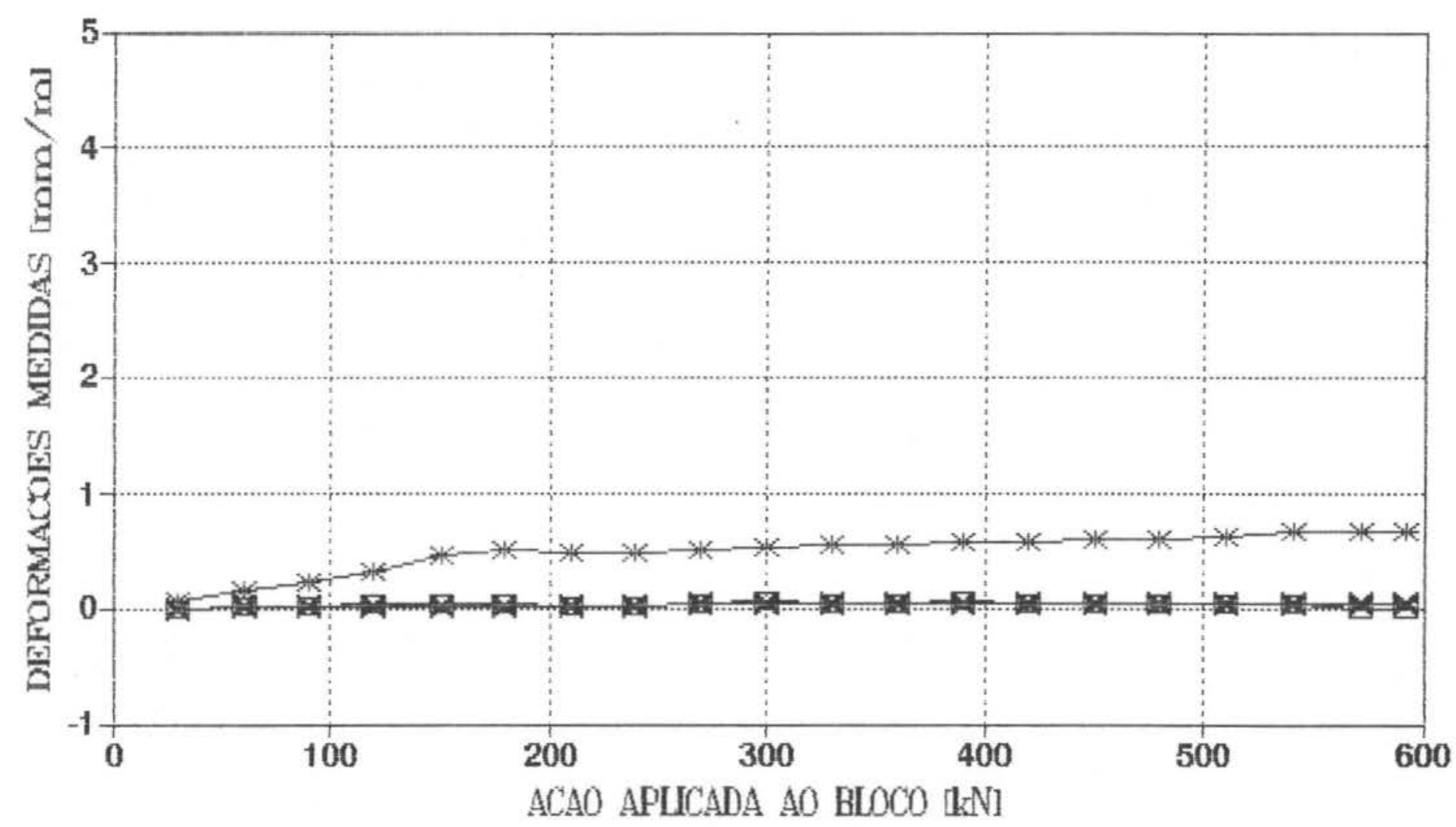




\section{B4 - ARMADURA INFERIOR (LADO LESTE)}

EXTENS. 34, 35 E 36

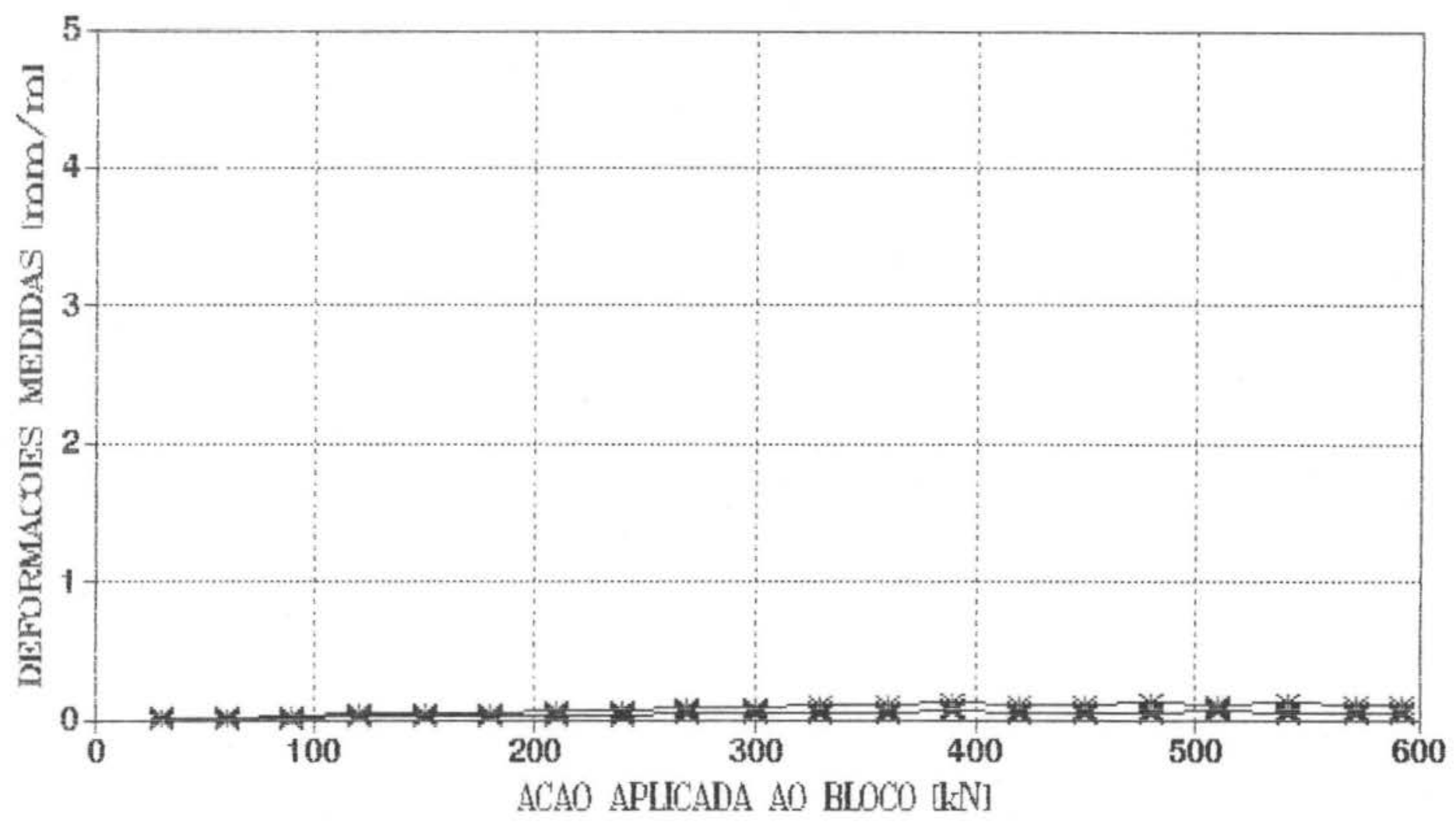




\section{B4 - ARMADURA INFERIOR (LADO NORTE) EXTENS. 37, 38 E 39 (BARRA EXTERNA)}

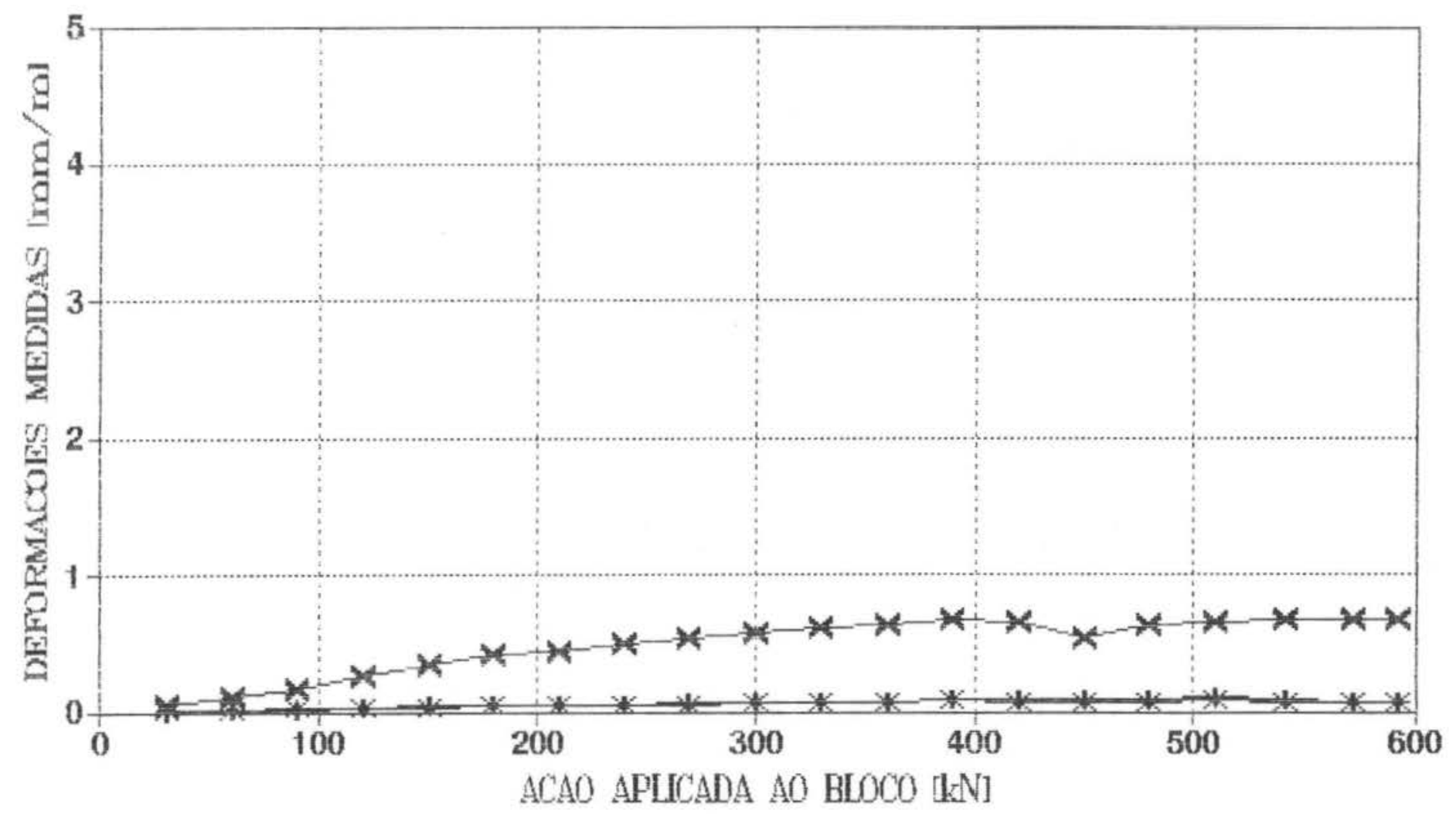

$\rightarrow$ B4LI1Y1E2 (CPC-02)L I B4LITY1I (MEIO) $\rightarrow$ B4LI1Y1E1 (CPC-06)O 


\section{B4 - ARMADURA INFERIOR (LADO NORTE) EXTENS. 40, 41, 42 E 43}

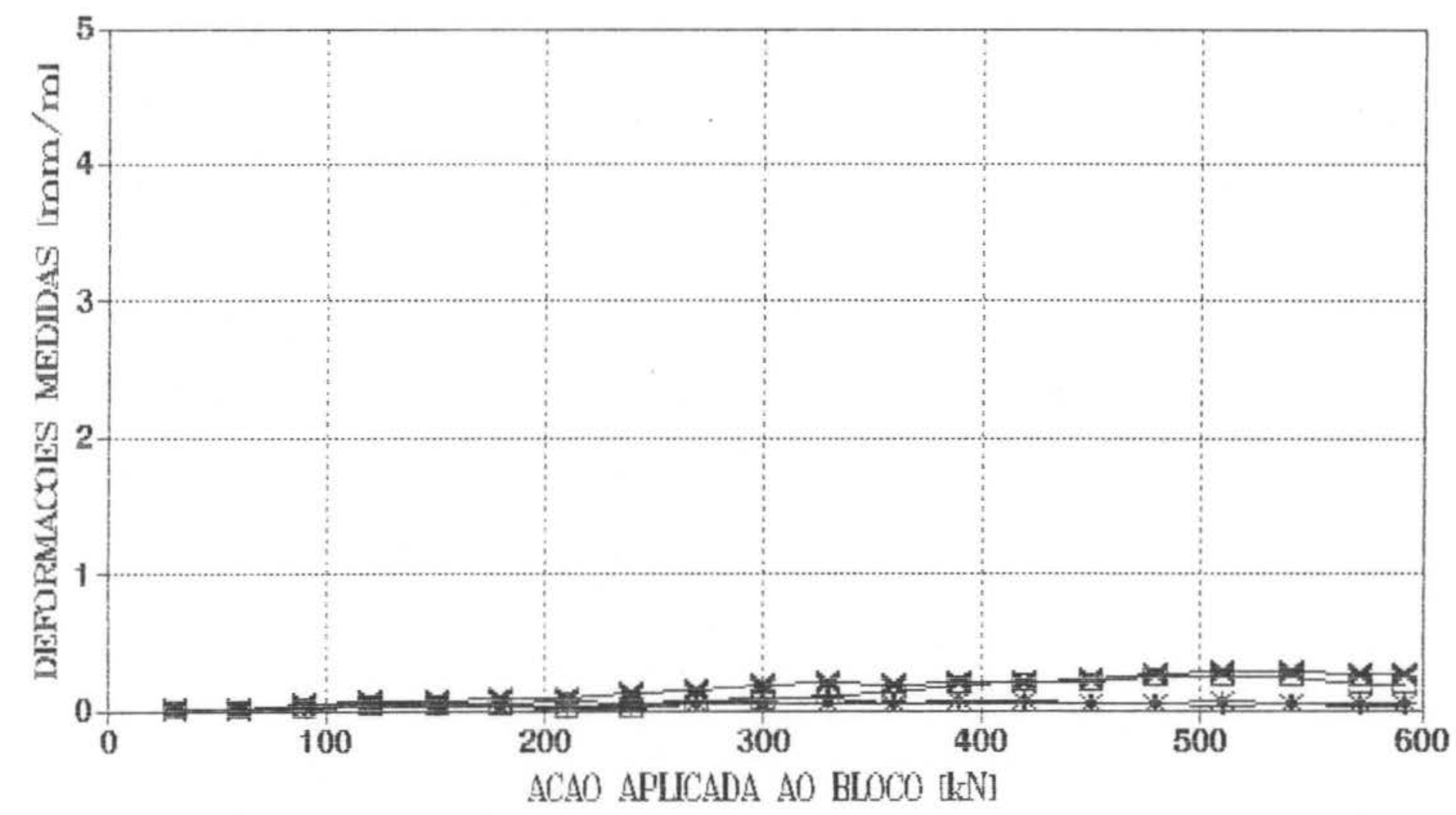

\#- B4LI2Y1E2 (CPC-02)L † B4LI2Y1I (MEIO)

$\rightarrow$ B4LI2Y1E1 (CPC-06)O $\square$ B4LI2Y1Z (OESTE) 


\section{B4 - ARMADURA INFERIOR (LADO NORTE) \\ EXTENS. 44, 45 E 46 (BARRA EXTERNA)}

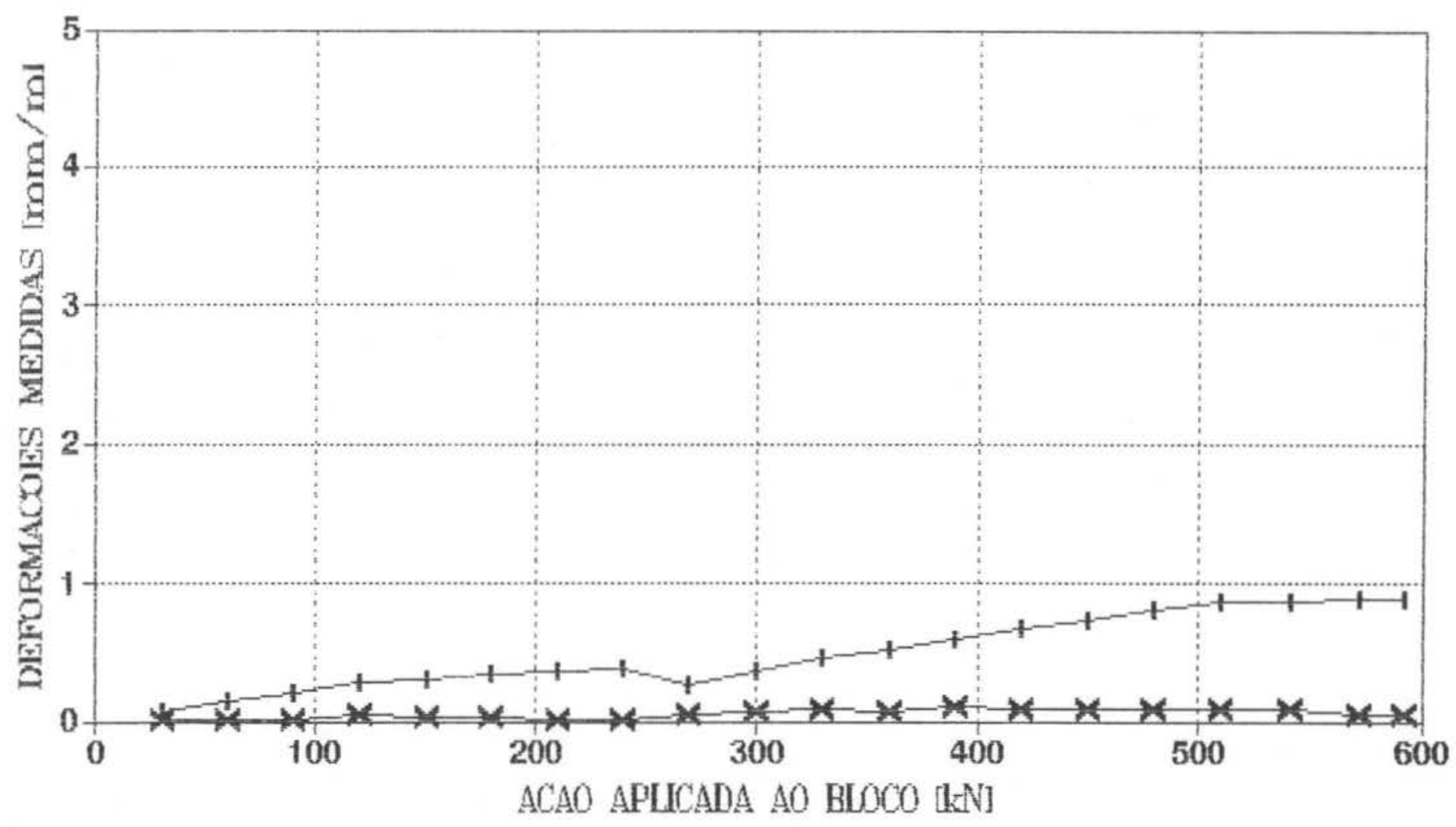

$$
\text { * B4LI3Y1E2 (PERDIDO) + B4LI3Y1I (MEIO) } \rightarrow \text { B4LI3Y1E1 (CPC-06)O }
$$




\section{B4 - ARMADURA INFERIOR (LADO SUL) EXTENS. 47, 48 E 49 (BARRA EXTERNA)}

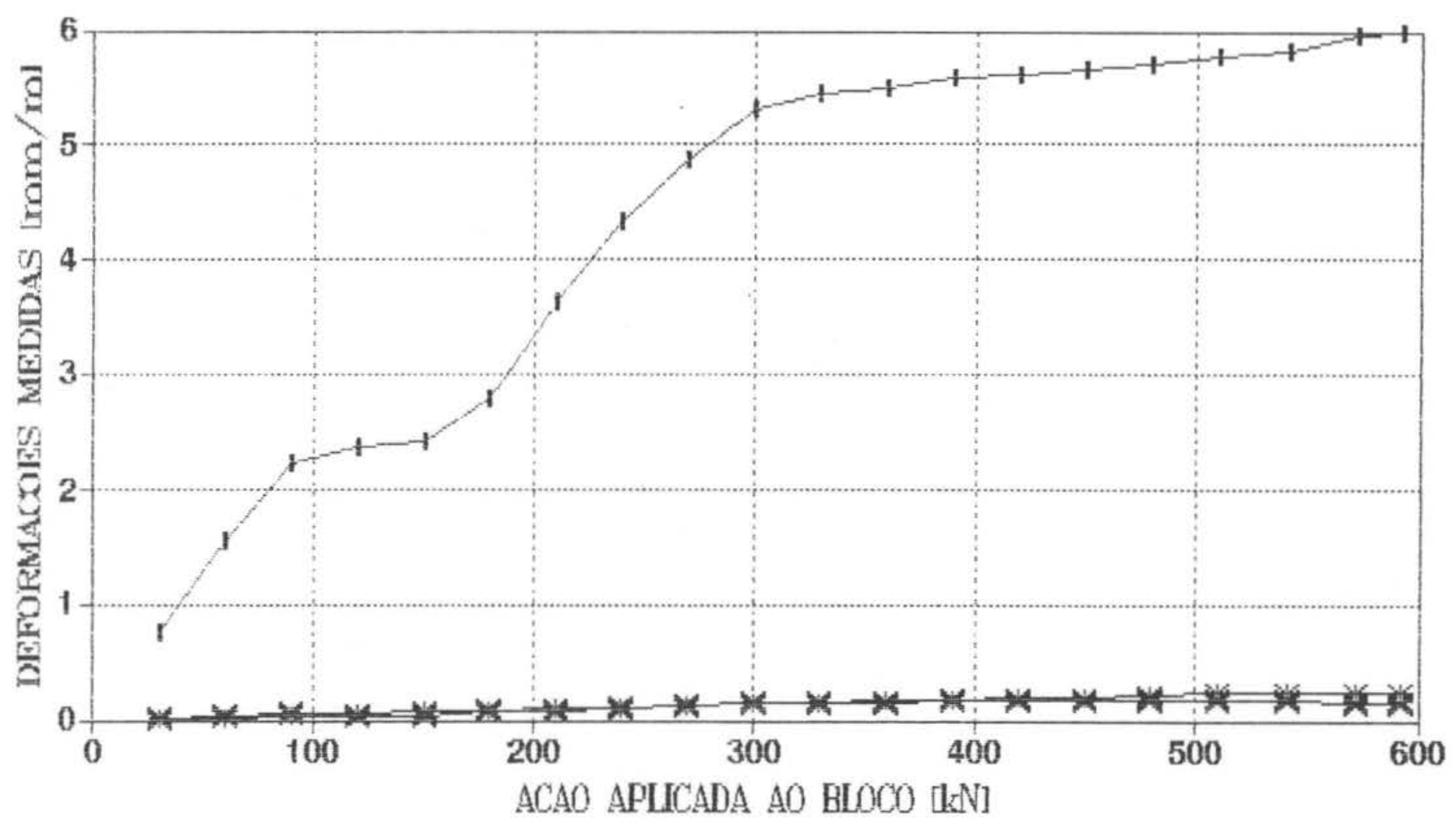

$$
\text { * B4LITY2E3 (CPC-10)L } \rightarrow \text { B4LI1Y2I (MEIO) } \rightarrow \text { B4LI1Y2E4 (CPC-07)O }
$$




\section{B4 - ARMADURA INFERIOR (LADO SUL) EXTENS. 50, 51, 52 E 53 (INTERIOR)}

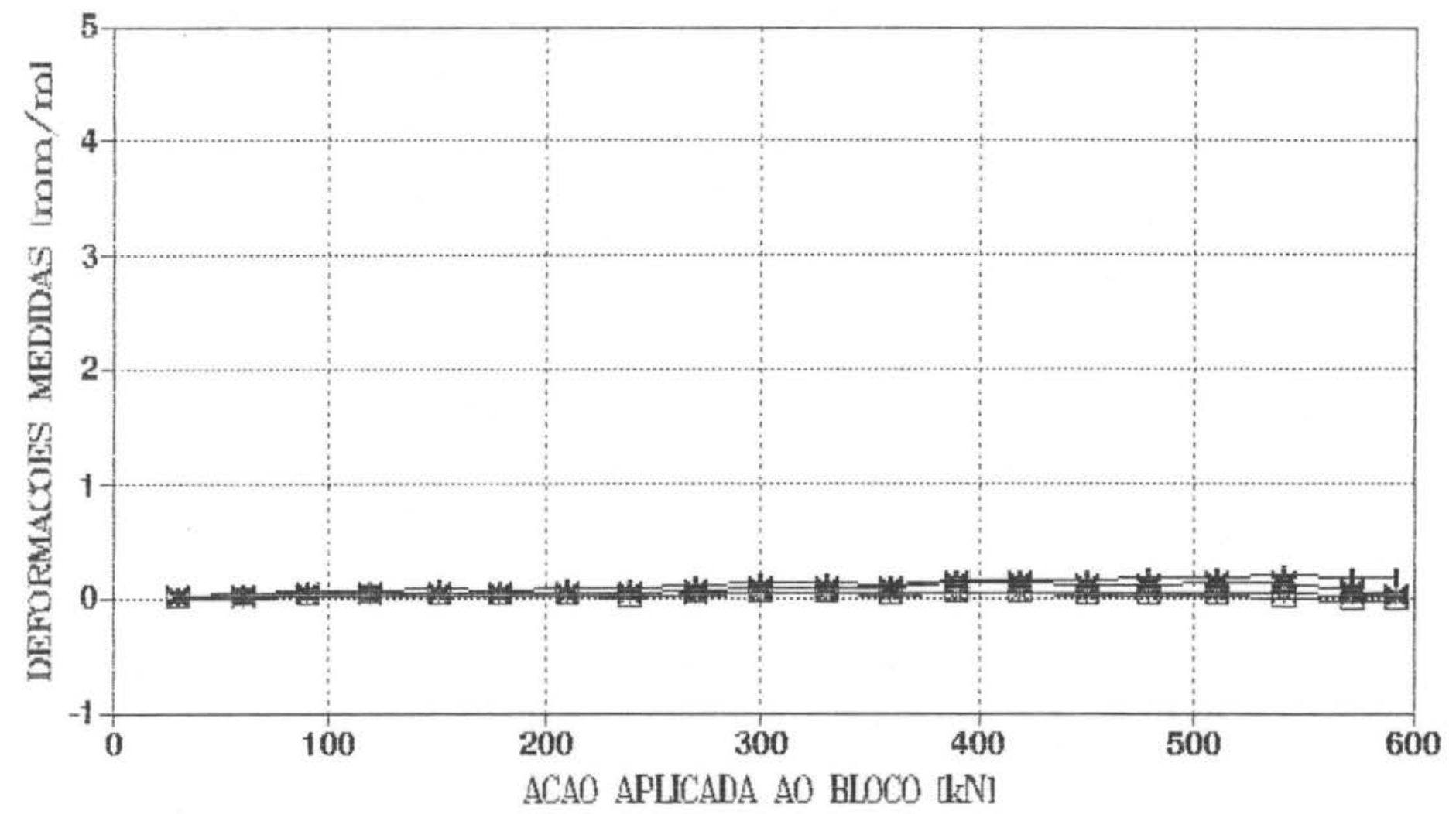

$\rightarrow$ B4LI2Y2E3 (CPC-10)L + B4LI2Y2I (MEIO) 


\section{B4 - ARMADURA INFERIOR (LADO SUL) EXTENS. 54, 55 E 56 (BARRA EXTERNA)}

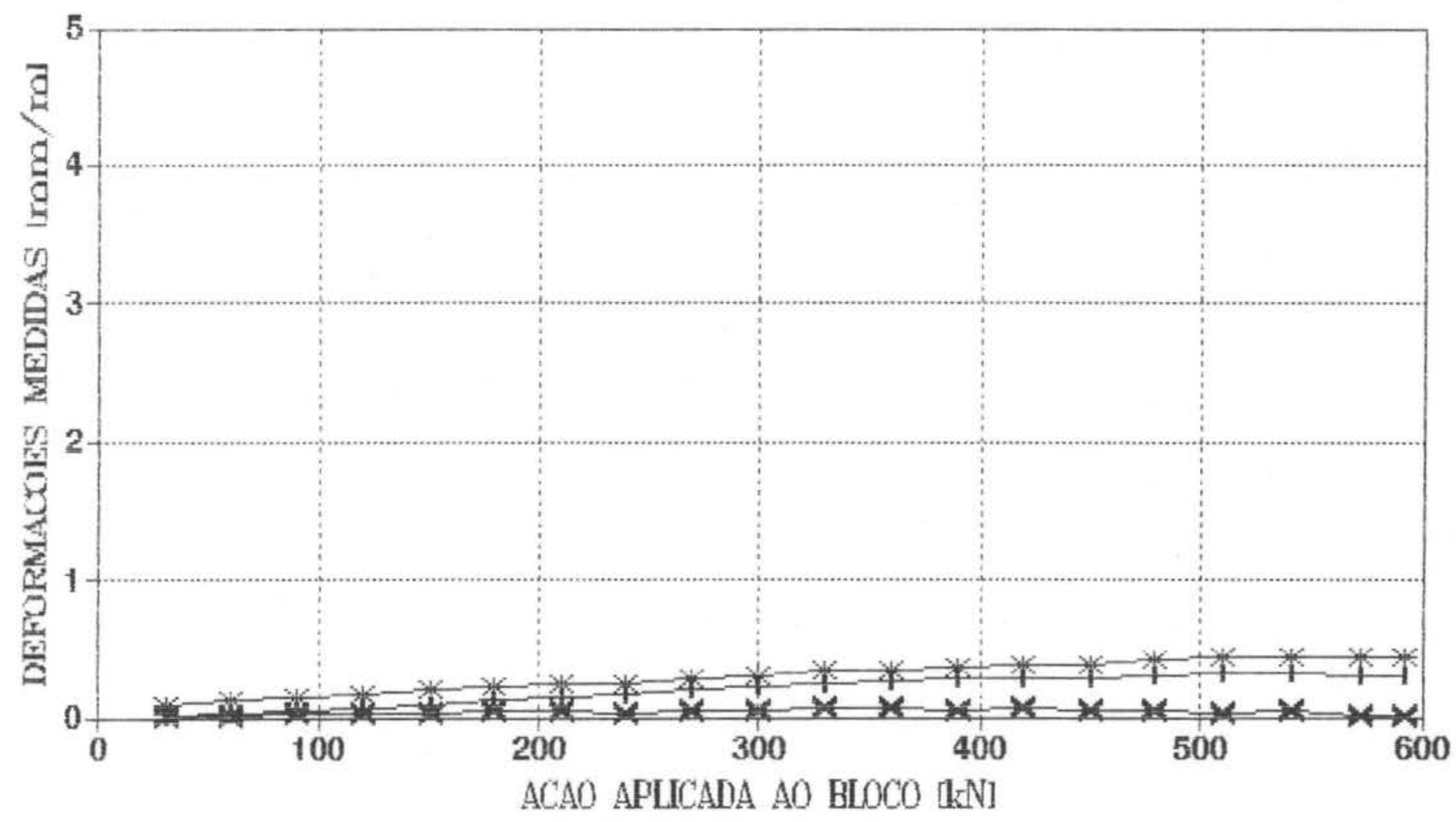

$\rightarrow$ B B4LI3Y2E3 (CPC-10)L † B4LI3Y2I (MEIO) $\rightarrow$ B4LI3Y2E4 (CPC-07)O 


\section{B4 - ARMADURA SUPERIOR}

EXTENSOMETROS 57, 58, $59 \mathrm{E} 60$

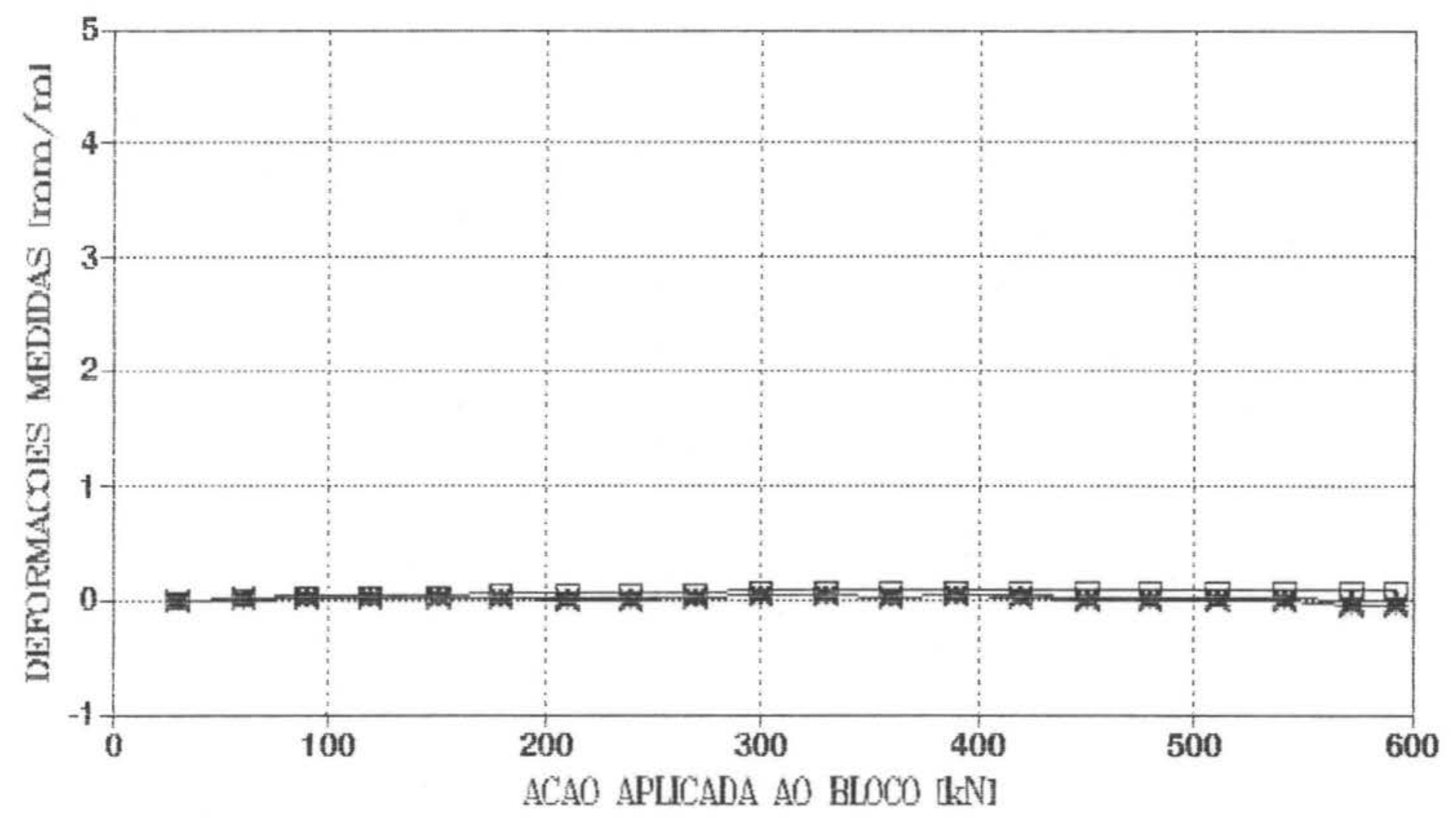

$\rightarrow$ B4LS1X (OESTE) $\rightarrow$ B4LS2X (LESTE) $\rightarrow$ B4LS1Y (NORTE) $\square-$ B4LS2Y (SUL) 
BLOCO 4 - BIELAS

EXTENSOMETROS 61, 62, 63, 64 E 65

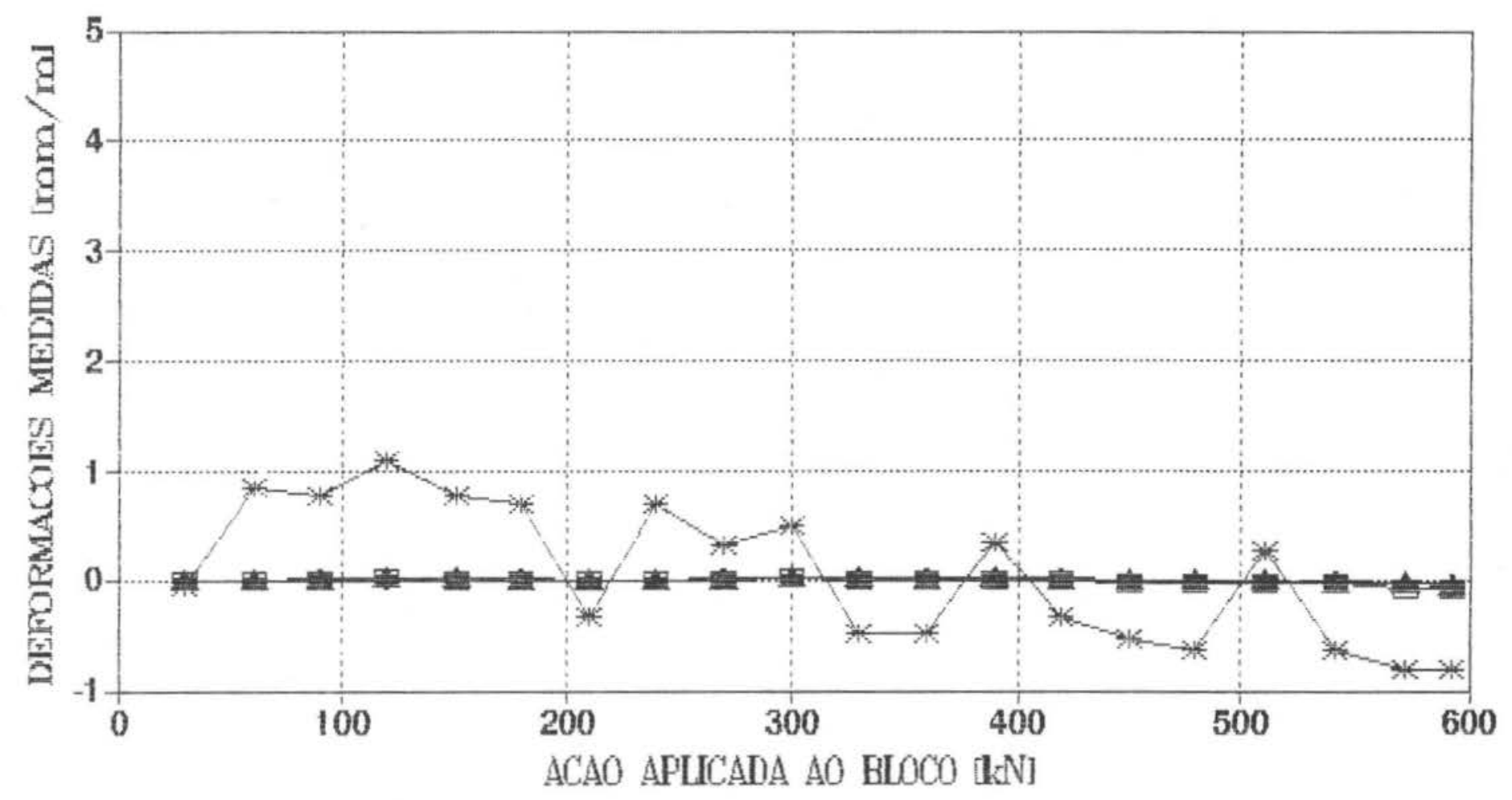

* $\mathrm{B} 4 \mathrm{~B} 1(\mathrm{CPC}-06)+\mathrm{B} 4 \mathrm{~B} 2(\mathrm{CPC}-02) \neq \mathrm{B} 4 \mathrm{~B} 3(\mathrm{CPC}-10)$
$\square \mathrm{B} 4 \mathrm{~B} 4(\mathrm{CPC}-07)+\mathrm{B} 4 \mathrm{BV}$ (VERTICAL)

